SANDRA UEMURA

\title{
INSTRUMENTOS DE AVALIAÇÃO E GESTÃO DE IMPACTOS GERADOS POR RUPTURAS DE BARRAGENS
}

Dissertação apresentada à Escola Politécnica da Universidade de São Paulo para obtenção do título de Mestre em Engenharia

Área de Concentração:

Engenharia Hidráulica

São Paulo 
SANDRA UEMURA

\section{INSTRUMENTOS DE AVALIAÇÃO E GESTÃO DE IMPACTOS GERADOS POR RUPTURAS DE BARRAGENS}

Dissertação apresentada à Escola Politécnica da Universidade de São Paulo para obtenção do título de Mestre em Engenharia

Área de Concentração:

Engenharia Hidráulica

Orientador:

Prof. Dr. José Rodolfo Scarati Martins

São Paulo 
Este exemplar foi revisado e alterado em relação à versão original, sob responsabilidade única do autor e com a anuência de seu orientador.

São Paulo, 22 de junho de 2009.

Assinatura do autor

Assinatura do orientador

FICHA CATALOGRÁFICA

Uemura, Sandra

Instrumentos de avaliação e gestão de impactos gerados por ruptura de barragens / S. Uemura. - Ed. Ver. - São Paulo, 2009

Dissertação (Mestrado) - Escola Politécnica da Universidade de São Paulo. Departamento de Engenharia Hidráulica e Sanitária.

1. Barragens 2. Simulação I. Universidade de São Paulo. Escola Politécnica. Departamento de Engenharia Hidráulica e Sanitária II.t. 


\section{DEDICATÓRIA}

Aos Meus Pais, Paulo Roberto e Noriko 


\section{AGRADECIMENTOS}

Ao Professor Doutor José Rodolfo Scarati Martins por sua paciência, dedicação e orientação.

À Professora Maria de Fátima Souza Curi pela amizade, apoio e incentivo desde os tempos da faculdade.

Ao Professor Paulo Takashi Nakayama por acreditar no meu profissionalismo e na minha capacidade.

A minha família: meu pai e amigo Paulo, minha mãe Noriko e meu irmão Sérgio, por estarem sempre ao meu lado. A todos os meus tios e tias, primos e primas, e demais familiares, em especial aos meus avós (in memoriam) que torceram pelo meu sucesso e são especiais na minha vida.

Os meus agradecimentos a todos os engenheiros, colegas e amigos da Fundação Centro Tecnológico de Hidráulica e do Centro Tecnológico de Hidráulica.

As minhas amigas e amigos Tatiana, Cristiane, Liliane, Mari, Nara, Gislaine, Flavio, Tiago, Rodolfo, pela ajuda com as palavras, pelo ombro amigo, pelo incentivo e pela sua amizade eterna.

Aos Professores e funcionários do Departamento de Engenharia Hidráulica e Sanitária da Escola Politécnica da Universidade de São Paulo.

Ao Eng. Hélio Luiz Castro Superintendente da Unidade de Negócios de Produção de Água - Metropolitana da SABESP e ao Eng. Antonio Bolognesi, Diretor de Geração da EMAE, pelo auxilio e fornecimento dos dados utilizados neste trabalho.

A Deus por sua bondade infinita e a todos aqueles que contribuíram direta ou indiretamente para a realização desta dissertação.

Muito Obrigada! 


\section{RESUMO}

Barragens são estruturas geralmente construídas transversalmente a um rio, tendo como objetivos, a geração de energia elétrica, a captação de água para abastecimento público, o controle de cheias e a navegação. Para atender a estes objetivos, as barragens elevam o nível d'água à montante de seu eixo e, em algumas obras, acumulam um significativo volume hídrico para garantir a regularização do corpo d'água afetado. Devido às grandes dimensões envolvidas, dos impactos provocados e dos investimentos necessários, as barragens devem ser sempre seguras, pois acidentes a ela relacionados, geralmente ligados a liberação dos volumes de água acumulados, afetam fortemente o meio ambiente e a sociedade em geral, incluindo vidas humanas. Desta forma, ferramentas que permitam a previsão destes impactos, e a subseqüente organização de planos de ações preventivas e emergenciais, fazem parte das rotinas de projeto, construção e operação destes empreendimentos. Neste trabalho apresenta-se um estudo metodológico, aplicado à Barragem Guarapiranga, voltado para a gestão de emergências ocasionadas por rupturas de barragens, visando o estabelecimento de rotinas para a avaliação dos impactos, através de ferramentas capazes de simular o efluente de um acidente hidrológico ou estrutural, seu desenvolvimento na forma de uma onda de cheia que se

propaga pelo vale a jusante e finalmente, a proposição de uma seqüência de atividades relacionadas a interpretação dos resultados das simulações, que permitam a formação dos planos de ações preventivas e emergenciais.

Palavras Chave: Barragens. Simulação. 


\begin{abstract}
Dams are structures usually built across a river with goals of, generation of electricity, public water supply, flood control and navigation. In order to achieve these goals, dams promote the raise of water level upstream of its axis and, in some cases, it accumulates a significant volume of water to ensure the regularization of the affected water mass. Due to their large dimensions, in associated impacts and the necessary investments, dams must be safe because accidents usually release big amount reserved water and strongly affect the environment and the society, including human lives. Thus, tools that are able to predict such impacts and then, construct plans for the preventive and emergency actions, must be part of the routine of design, built and operation of those dams. This work presents a methodological study, applied in Guarapiranga Dam, for management of emergencies caused by dam-breaks, with the purpose of establishing routines to evaluate the impacts, by using tools that are able to simulate the discharges related to a hydrologic or structural failure, and its wave propagation through the downstream. Finally this work proposes a sequence of activities related to the interpretation of the simulation results that allow the construction of plans for preventive and emergency plans.
\end{abstract}

Key Words: Dams. Simulation 


\section{LISTA DE ILUSTRAÇÕES}

Figura 1.1: Barragem de Malpasset antes e depois do rompimento ..........................4

Figura 1.2: Barragem de Orós (CE), durante o acidente e reconstruída (acervo

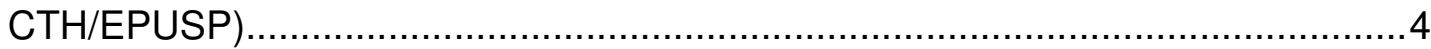

Figura 1.3: Barragem de Vajont antes e depois do overtopping (http://www.vajont.net/)

5

Figura 1.4: Vila de Longarone antes e depois do overtopping. (http://www.vajont.net/) 5

Figura 1.5: Rompimento da Barragem de Teton - EUA. (http://www.tetondam.org/) .....6

Figura 1.6: Barragem Euclides da Cunha durante o acidente e reconstruída ..............6

Figura 1.7: Barragem Armando Sales de Oliveira (http://www.aestiete.com.br/) ..........7

Figura 1.8: Barragem de Camará (PB) e danos a estrutura principal de concreto

(acervo Erton Carvalho) ........................................................................

Figura 1.9: Rompimento da Barragem de Apertadinho.

(http://www.diariodaamazonia.com.br/)

Figura 3.1: Formação da brecha por piping - a) Surgimento do poro; b) Aumento por erosão; c) Colapso da porção superior e erosão. (adaptado de Johnson e Illes, 1976 apud Collischonn 1997).

Figura 3.2: Brechas resultantes de falhas nas fundações - a) Barragens de terra ou concreto; b) Barragens de concreto em arco. (adaptado de Johnson e Illes, 1976 apud Collischonn 1997)

Figura 3.3: Rompimento da Barragem de Teton - EUA. (http://www.tetondam.org/) ...14

Figura 3.4: Formação da brecha por overtopping - a) início no ponto mais fraco; b)

brecha em forma "V"; c) aprofundamento da brecha; d) aumento lateral por erosão (adaptado de Johnson e Illes, 1976 apud Collischonn 1997). .14

Figura 3.5: Barragem de Vajont - Itália. (http://www.vajont.net/) 15

Figura 3.6: Características do Escoamento x Tamanho da Brecha. Adaptado de

(MACDONALD \& LANGRIDGE-MONOPOLIS, 1984).

Figura 3.7: Tamanho da brecha x Tempo de desenvolvimento da Brecha. Adaptado

(MACDONALD \& LANGRIDGE-MONOPOLIS, 1984) 19

Figura 3.8: Vista Frontal da Formação da Brecha na Barragem. (FREAD \& LEWIS, 1998)

Figura 3.9: Subdivisão da seção transversal em lamelas verticais. 
Figura 3.10: Interpolação de superfícies topográficas pelo método dos oito vizinhos mais próximos tomados dois a dois em cada quadrante....................................38

Figura 3.11: Complexo Cerros Colorados - Mapa Geral - Argentina ...........................49

Figura 3.12: Complexo Cerros Colorados - Barragens e Reservatórios (GOOGLE, 2009)

Figura 3.13: Diagrama de Fluxo de Comunicação para alerta Vermelho na barragem Portezuelo Grande.

Figura 3.14: Quadro de responsabilidades das comunicações em caso de ocorrência de alerta Vermelho em Portezuelo Grande - Argentina 52

Figura 3.15: Localização da UHE Dona Francisca - RS - Brasil. Adaptado de Google (2009) .53

Figura 3.16: UHE Dona Francisca (http://www.camaraagudo.rs.gov.br/) .53

Figura 3.17: Quadro de Situações e suas Emergências no PAE UHE Dona Francisca

Figura 3.18: Diagrama de Situações de Emergência e Alerta do PAE UHE Dona Francisca. .55

Figura 3.19: Vista da Barragem de Peti - MG (BALBI, 2008) ……........................56

Figura 4.1: Região Metropolitana do Estado de São Paulo ......................................58

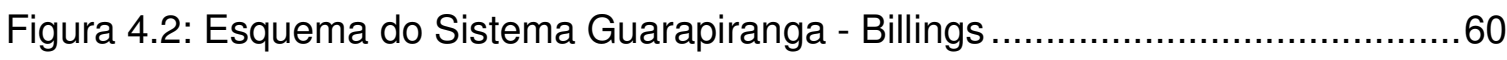

Figura 4.3: Hidrograma da Cheia de Janeiro de 1976 . Adaptado de LIGHT (1978)...61

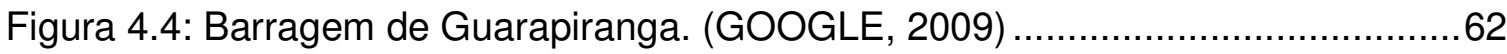

Figura 4.5: Curva Cota-Descarga das Comportas da Barragem Guarapiranga (EMAE, 2001) 63

Figura 4.6: Curva Cota-Descarga do Canal de Fuga da Barragem Guarapiranga (EMAE, 2001) 64

Figura 4.7: Vertedores da Barragem Guarapiranga (EMAE, 2001) .........................64

Figura 4.8: Planta geral do Vertedor da Barragem Guarapiranga. (LIGHT, 1978) ......65

Figura 4.9: Corte do Vertedor da Barragem Guarapiranga. (LIGHT, 1978)................66

Figura 4.10: Planta da Barragem Guarapiranga - parte 1-2 (LIGHT, 1978)...............67

Figura 4.11: Planta da Barragem Guarapiranga - parte 2-2 (LIGHT, 1978)...............67

Figura 4.12: Seção Transversal A - estaca 7+0,00 (LIGHT, 1978) ............................68

Figura 4.13: Seção Transversal B - estaca 10 + 0,00( (LIGHT, 1978) .......................68

Figura 4.14: Seção Transversal C - estaca 17 + 0,00( (LIGHT, 1978) .......................69 
Figura 4.15: Seção Transversal D - estaca 27 + 0,00 (LIGHT, 1978) .......................69

Figura 4.16: Seção Transversal E - estaca 42 + 0,00 (LIGHT, 1978) .......................70

Figura 4.17: Seção Transversal F - estaca 52 + 0,00 (LIGHT, 1978) .......................70

Figura 4.18: Seção Transversal G - estaca 57 + 0,00 (LIGHT, 1978) ......................71

Figura 4.19: Seção Transversal H - estaca 72 + 0,00 (LIGHT, 1978) .......................71

Figura 4.20: Curva Cota-Área-Volume do Reservatório Guarapiranga ......................72

Figura 4.21: Resultados da Simulação do Cenário 1 .............................................77

Figura 4.22: Resultados da Simulação do Cenário 2 ..........................................78

Figura 4.23: Resultados da Simulação do Cenário 3 .............................................79

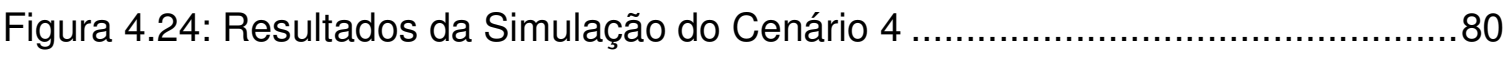

Figura 4.25: Resultados da Simulação do Cenário 5 .......................................... 82

Figura 4.26: Resultados da Simulação do Cenário 6 ............................................ 83

Figura 4.27: Resultados da Simulação do Cenário 7 .............................................. 83

Figura 4.28: Resultados da Simulação do Cenário 8 ............................................... 84

Figura 4.29: Vazões máximas efluentes obtidas nas simulações dos cenários 1 a 8.85

Figura 4.30: Resultados da Simulação do Cenário 9 ............................................ 87

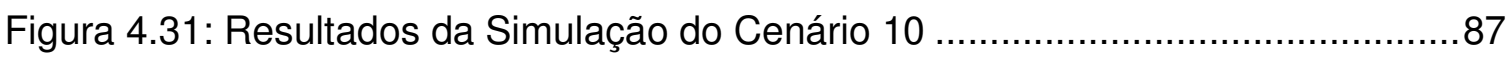

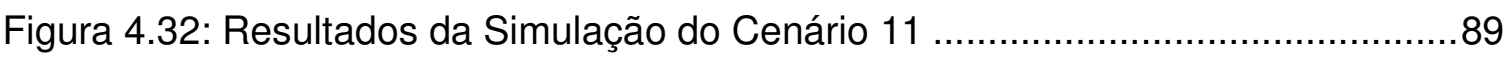

Figura 4.33: Resultados da Simulação do Cenário 12 ......................................... 89

Figura 4.34: Resultados da Simulação do Cenário 13 ............................................91

Figura 4.35: Resultados da Simulação do Cenário 14 ..........................................91

Figura 4.36: Vazões máximas efluentes obtidas nas simulações dos cenários 9 a 14.

Figura 4.37: Resultados da Simulação do Cenário 15 ..........................................93

Figura 4.38: Resultados da Simulação do Cenário 16 ...........................................94

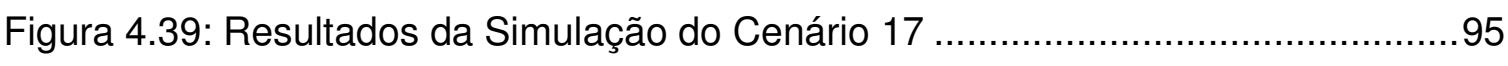

Figura 4.40: Resultados da Simulação do Cenário 18 ...........................................96

Figura 4.41: Resultados da Simulação do Cenário 19 ..........................................97

Figura 4.42: Resultados da Simulação do Cenário 20 ..........................................98

Figura 4.43: Vazões máximas efluentes obtidas nas simulações dos cenários 15 a 20.

Figura 4.44: Resultados da Simulação do Cenário 21 ........................................101

Figura 4.45: Resultados da Simulação do Cenário 22 ........................................102 
Figura 4.46: Resultados da Simulação do Cenário 23 ...........................................102

Figura 4.47: Resolução do MDT gerado pela FUNCATE (2003).............................106

Figura 4.48: MDT da Bacia do Alto Tietê gerado pela FUNCATE (2003)..................106

Figura 4.49: Porção do MDT gerado pela FUNCATE (2003) na região do estudo, observando-se nas zonas escuras os vales do Canal Guarapiranga,Rio Pinheiros e Rio Tietê. 107

Figura 4.50: Rede de simulação da onda de enchente Efluente resultante do rompimento da Barragem Guarapiranga. 109

Figura 4.51: Curva-Chave da Estação Elevatória de Traição...................................110

Figura 4.52: Curva-Chave da Estrutura de Retiro ...............................................110

Figura 4.53: Curva-Chave da Barragem Edgard de Souza ....................................111

Figura 4.54: Envoltória de N.A. no canal Guarapiranga, Rio Pinheiros e Rio Tietê...114 Figura 4.55: Envoltória de Q no canal Guarapiranga, Rio Pinheiros e Rio Tietê........115 Figura 4.56: Área Inundada para o Rompimento da Barragem Guarapiranga no Cenário 7. Adaptado de Google Earth (2009) 116

Figura 4.57: Área Inundada para o Rompimento da Barragem Guarapiranga no

Cenário 12. Adaptado de Google Earth (2009) 117

Figura 4.58: Área Inundada para o Rompimento da Barragem Guarapiranga no

Cenário 18. Adaptado de Google Earth (2009)

Figura 4.59: Área Inundada para o Rompimento da Barragem Guarapiranga no

Cenário 21. Adaptado de Google Earth (2009) 119

Figura 4.60: Área Inundada para o Rompimento da Barragem Guarapiranga no

Cenário 22. Adaptado de Google Earth (2009) 120

Figura 4.61: Área Inundada para o Rompimento da Barragem Guarapiranga no

Cenário 23. Adaptado de Google Earth (2009) 121

Figura 4.62: Pontos Notáveis no Canal Pinheiros ...............................................123

Figura 4.63: Hidrograma da Barragem Guarapiranga .........................................125

Figura 4.64: Limnigrama da Barragem Guarapiranga ............................................125

Figura 4.65: Hidrograma da Confluência do Canal Guarapiranga com o Rio Pinheiros

- Trecho: Montante do Canal Guarapiranga 126

Figura 4.66: Limnigrama da Confluência do Canal Guarapiranga com o Rio Pinheiros

- Trecho: Montante do Canal Guarapiranga 126 
Figura 4.67: Hidrograma da Confluência do Canal Guarapiranga com o Rio Pinheiros - Trecho: Montante do Rio Pinheiros 127

Figura 4.68: Limnigrama da Confluência do Canal Guarapiranga com o Rio Pinheiros

- Trecho: Montante do Rio Pinheiros 127

Figura 4.69: Hidrograma da Confluência do Canal Guarapiranga com o Rio Pinheiros

- Trecho: Jusante do Rio Pinheiros 128

Figura 4.70: Hidrograma da Confluência do Canal Guarapiranga com o Rio Pinheiros

- Trecho: Jusante do Rio Pinheiros 128

Figura 4.71: Hidrograma na Ponte João Dias ..................................................129

Figura 4.72: Limnigrama na Ponte João Dias 129

Figura 4.73: Hidrograma na Ponte Estaiada - Av. Jorn. Roberto Marinho/Água

Espraiada 130

Figura 4.74: Limnigrama na Ponte Estaiada - Av. Jorn. Roberto Marinho/Água

Espraiada 130

Figura 4.75: Curva de Permanência de N.A. na Ponte Estaiada - Av. Jorn. Roberto Marinho/Água Espraiada.

Figura 4.76: Hidrograma a Usina Elevatória de Traição - Trecho: Montante do Rio

Pinheiros

Figura 4.77: Limnigrama a Usina Elevatória de Traição - Trecho: Montante do Rio

Pinheiros 132

Figura 4.78: Hidrograma a Usina Elevatória de Traição - Trecho: Jusante do Rio Pinheiros 132

Figura 4.79: Hidrograma a Usina Elevatória de Traição - Trecho: Jusante do Rio Pinheiros 133

Figura 4.80: Hidrograma na Ponte da Av. Eusébio Matoso....................................133

Figura 4.81: Limnigrama na Ponte da Av. Eusébio Matoso....................................134

Figura 4.82: Hidrograma na Ponte da Av. Jaguaré ...........................................134

Figura 4.83: Limnigrama na Ponte da Av. Jaguaré ............................................ 135

Figura 4.84: Hidrograma na Estrutura de Retiro. Trecho: Montante do Rio Pinheiros 135

Figura 4.85: Limnigrama na Estrutura de Retiro. Trecho: Montante do Rio Pinheiros

Figura 4.86: Hidrograma na Estrutura de Retiro. Trecho: Jusante do Rio Pinheiros.136 
Figura 4.87: Limnigrama na Estrutura de Retiro. Trecho: Jusante do Rio Pinheiros. 137 Figura 4.88: Hidrograma no Cebolão (confluência dos Rios Pinheiros e Tietê). Trecho:

Rio Pinheiros

Figura 4.89: Limnigrama no Cebolão (confluência dos Rios Pinheiros e Tietê). Trecho:

Rio Pinheiros. 138

Figura 4.90: Hidrograma no Cebolão (confluência dos Rios Pinheiros e Tietê). Trecho:

Rio Tietê Montante 138

Figura 4.92: Hidrograma no Cebolão (confluência dos Rios Pinheiros e Tietê). Trecho:

Rio Tietê Jusante ................................................................................ 139

Figura 4.93: Fluxograma de Notificações ..................................................... 144

Figura 4.94: Mapa de Acesso a Barragem Guarapiranga (DER, 2008) ....................145

Figura 4.95: Av. Luiz Carlos Berrini - Área Potencialmente Inundada causada pelo

Rompimento da Barragem Guarapiranga no cenário 19

Figura 4.96: Av. Luiz Carlos Berrini - Área Potencialmente Inundada causada pelo

Rompimento da Barragem Guarapiranga no cenário 22 148

Figura 4.97: CEASA - Área Potencialmente Inundada causada pelo Rompimento da

Barragem Guarapiranga no cenário 19 149

Figura 4.98: CEASA - Área Potencialmente Inundada causada pelo Rompimento da

Barragem Guarapiranga no cenário 22 150

Figura 4.99: Ponte da Av. Eusébio Matoso - Área Potencialmente Inundada causada pelo Rompimento da Barragem Guarapiranga no cenário 19 151

Figura 4.100: Ponte da Av. Eusébio Matoso - Área Potencialmente Inundada causada pelo Rompimento da Barragem Guarapiranga no cenário 22 152 


\section{LISTA DE TABELAS}

Tabela 3.1 Lista de modelos de rupturas. Adaptado de Collischonn (1997) ...............26

Tabela 3.2: Classificação dos critérios e conseqüências da ELETROBRÁS

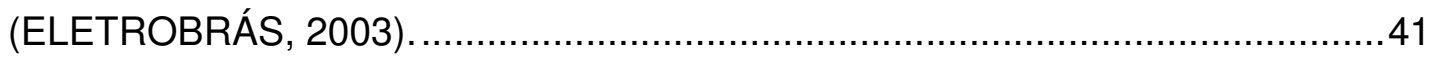

Tabela 4.1: Características da Barragem Guarapiranga .........................................62

Tabela 4.2: Dados gerais da barragem Guarapiranga. ............................................74

Tabela 4.3: Parâmetros utilizados no Cenário 1.....................................................76

Tabela 4.4: Resultados da Simulação do Cenário 1...............................................76

Tabela 4.5: Parâmetros utilizados no Cenário 2 …………………………….........76

Tabela 4.6: Resultados da Simulação do Cenário 2..............................................76

Tabela 4.7: Parâmetros utilizados no Cenário 3 .......................................................78

Tabela 4.8: Resultados da Simulação do Cenário 3 …………………………......78

Tabela 4.9: Parâmetros utilizados no Cenário 4....................................................79

Tabela 4.10: Resultados da Simulação do Cenário 4 ...............................................79

Tabela 4.11: Parâmetros utilizados no Cenário 5................................................... 80

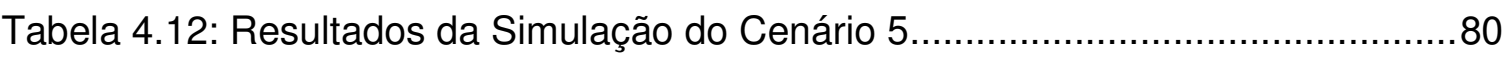

Tabela 4.13: Parâmetros utilizados no Cenário 6................................................... 81

Tabela 4.14: Resultados da Simulação do Cenário 6 .............................................. 81

Tabela 4.15: Parâmetros utilizados no Cenário 7 .......................................................... 81

Tabela 4.16: Resultados da Simulação do Cenário 7 .................................................. 82

Tabela 4.17: Parâmetros utilizados no Cenário 8 ……………………………....... 84

Tabela 4.18: Resultados da Simulação do Cenário 8…………………………....... 84

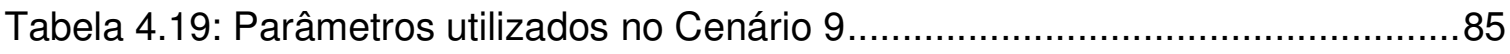

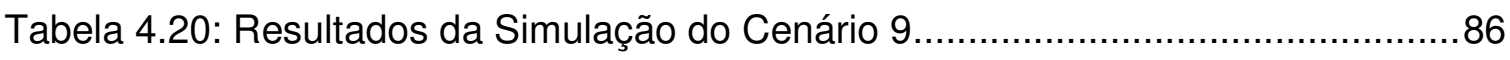

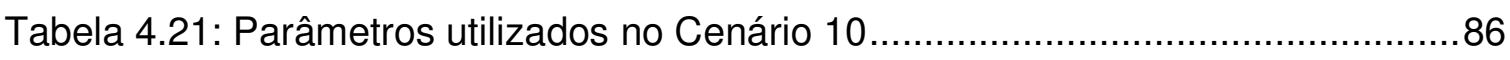

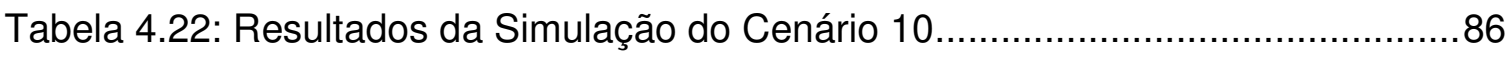

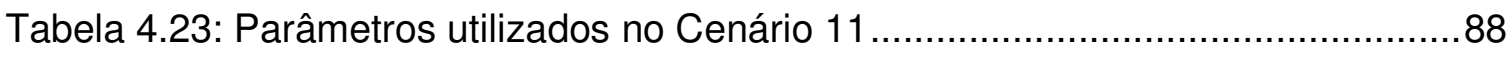

Tabela 4.24: Resultados da Simulação do Cenário 11 ................................................. 88

Tabela 4.25: Parâmetros utilizados no Cenário 12............................................... 88

Tabela 4.26: Resultados da Simulação do Cenário 12 ...........................................8

Tabela 4.27: Parâmetros utilizados no Cenário 13.................................................90 
Tabela 4.28: Resultados da Simulação do Cenário 13.............................................90

Tabela 4.29: Parâmetros utilizados no Cenário 14 …………………………........90

Tabela 4.30: Resultados da Simulação do Cenário 14...........................................90

Tabela 4.31: Parâmetros utilizados no Cenário 15.................................................92

Tabela 4.32: Resultados da Simulação do Cenário 15............................................93

Tabela 4.33: Parâmetros utilizados no Cenário 16 .................................................93

Tabela 4.34: Resultados da Simulação do Cenário 16 ...........................................94

Tabela 4.35: Parâmetros utilizados no Cenário 17..............................................94

Tabela 4.36: Resultados da Simulação do Cenário 17............................................95

Tabela 4.37: Parâmetros utilizados no Cenário 18 ....................................................95

Tabela 4.38: Resultados da Simulação do Cenário 18...........................................96

Tabela 4.39: Parâmetros utilizados no Cenário 19...................................................96

Tabela 4.40: Resultados da Simulação do Cenário 19...........................................97

Tabela 4.41: Parâmetros utilizados no Cenário 20 ................................................97

Tabela 4.42: Resultados da Simulação do Cenário 20...........................................98

Tabela 4.43: Parâmetros utilizados no Cenário 21 ....................................................99

Tabela 4.44: Resultados da Simulação do Cenário 21 ……………......................100

Tabela 4.45: Parâmetros utilizados no Cenário 22 ..................................................100

Tabela 4.46: Resultados da Simulação do Cenário 22..........................................100

Tabela 4.47: Parâmetros utilizados no Cenário 23..............................................101

Tabela 4.48: Resultados da Simulação do Cenário 23...........................................101

Tabela 4.49: Valores Máximos Obtidos das Simulações de Rompimento da Barragem

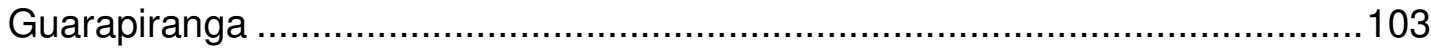

Tabela 4.50: Resultados das Simulações da Onda de Enchente..............................140

Tabela 4.51: Resultados das Simulações da Onda de Enchente (cont.)....................141

Tabela 4.52: Resultados das Simulações da Onda de Enchente (cont.)...................142 


\section{LISTA DE ABREVIATURAS E SIGLAS}

a.C. - antes de Cristo

CBDB - Comitê Brasileiro de Barragens

CTH - Centro Tecnológico de Hidráulica da Universidade de São Paulo

DAMBREAK - Rompimento de Barragem

DAMBRK - Dam Break

DNOCS - Departamento Nacional de Obras Contra as Secas

ELETROBRÁS - Centrais Elétricas Brasileiras S.A.

EPUSP - Escola Politécnica da Universidade de São Paulo

Eq. - Equação

EUA - Estados Unidos da América

FCTH - Fundação Centro Tecnológico de Hidráulica

FLDWAV - Flood Wave Routing Model

ICOLD - International Comission on Large Dams

LTDA. - Limitada

N.A. - Nível de Água

NWS - National Weather Service

PAE - Plano de Ações Emergenciais

RS - Rio Grande do Sul

SABESP - Companhia de Saneamento Básico do Estado de São Paulo

U. S. Bureau of Reclamation - United States Bureau of Reclamation

USA - United States of America

USBR - United States Bureau of Reclamation 


\section{LISTA DE SIMBOLOS}

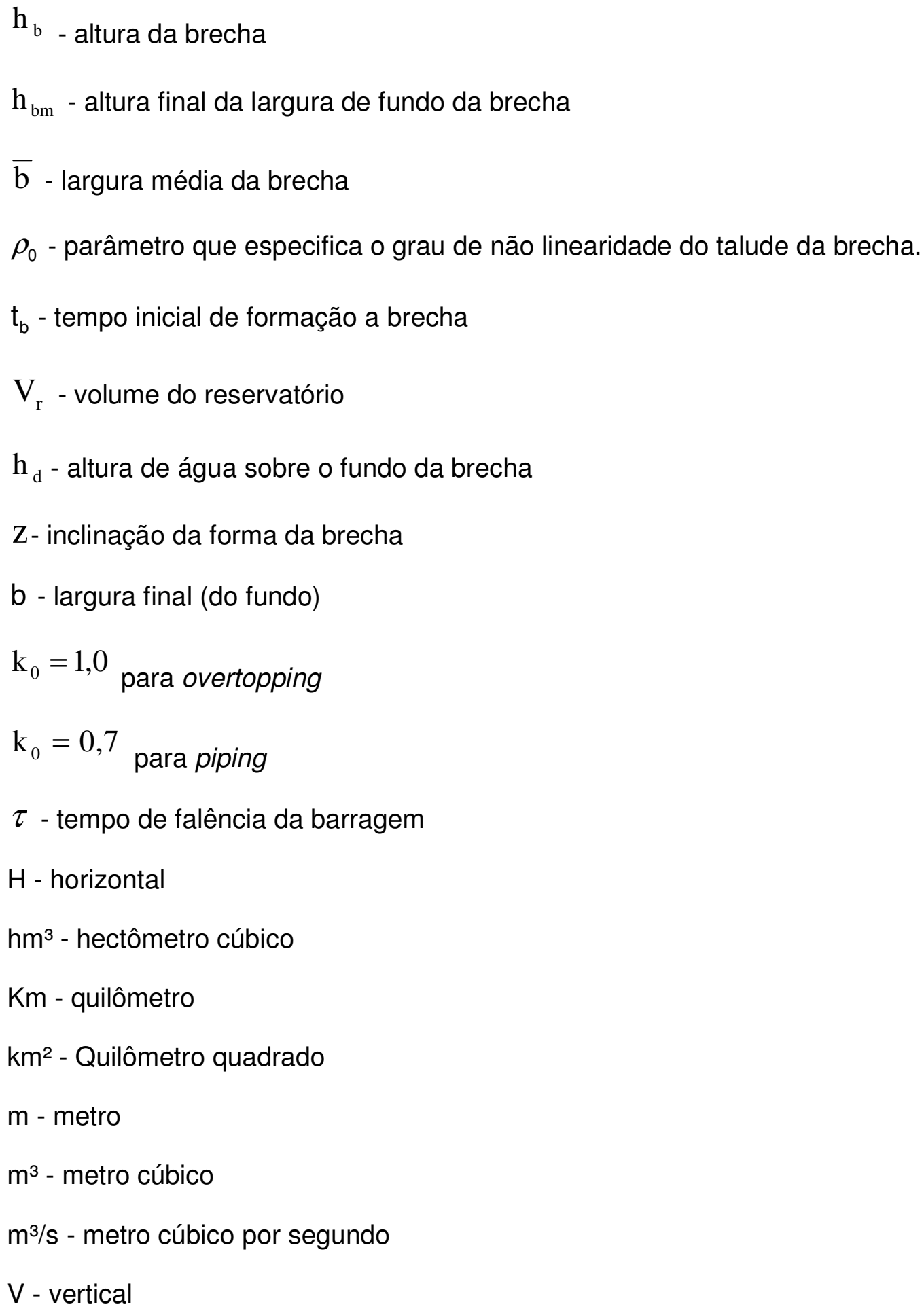




\section{SUMÁRIO}

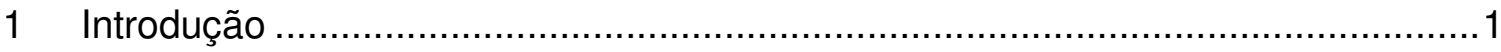

1.1 Casos Históricos .......................................................................................

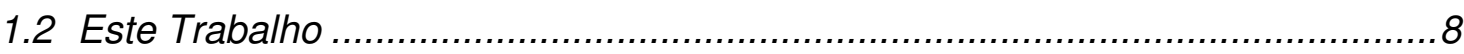

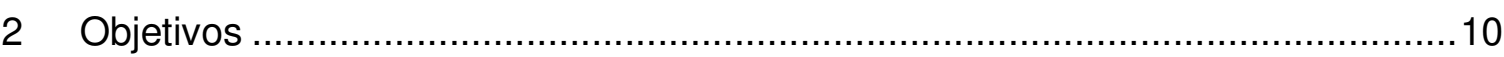

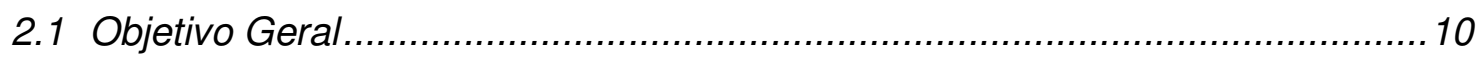

2.2 Objetivo Específico ................................................................. 10

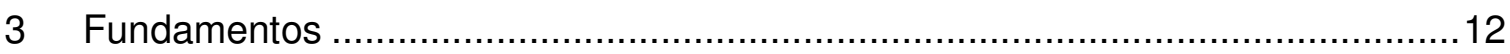

3.1 Mecanismos de Ruptura de Barragens ................................................ 12

3.1.1 Falência Estrutural ou Ruptura por Piping ......................................... 12

3.1.2 Falência Hidráulica ou Ruptura por Overtopping ..................................14

3.1.3 Modelos de Formação de Brechas ................................................. 15

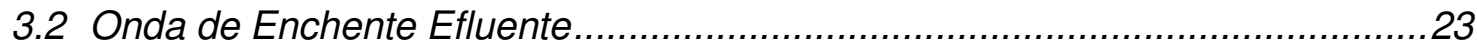

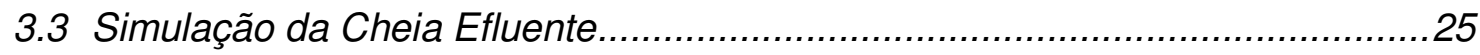

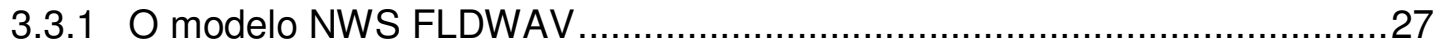

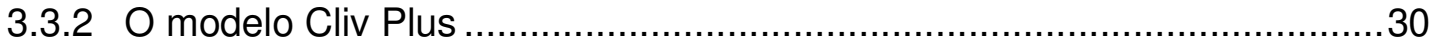

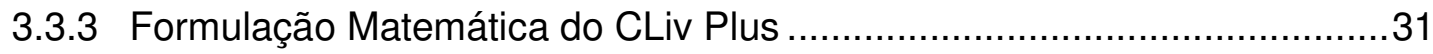

3.3.3.1 Algoritmo de Solução do CLiv Plus .......................................... 32

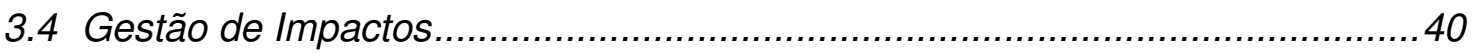

3.5 Planos de Ações Emergenciais - PAE ............................................ 42

3.5.1 Plano de Ação durante Emergências - P.A.D.E. Cerros Colorados S.A...48

3.5.2 Plano de Ações para Emergências Devido à Hipotética Ruptura de Dona

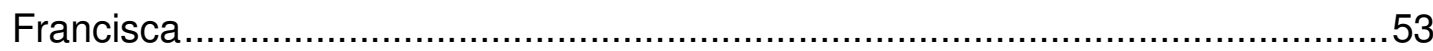

3.5.3 Plano de Emergência da Barragem de Peti........................................55

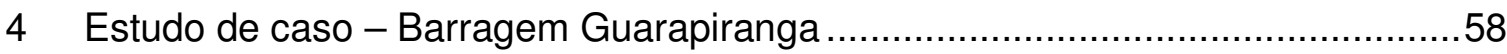

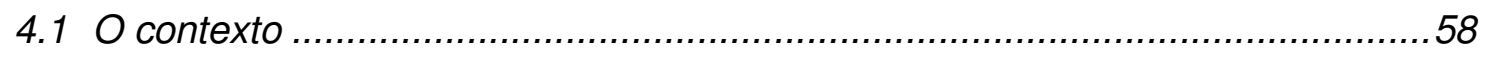

4.2 Características da Barragem e do Reservatório Guarapiranga .......................62 


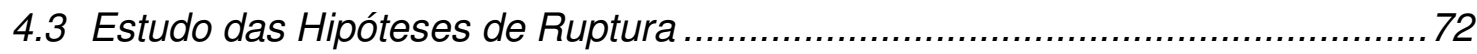

4.3.1 Fatores que Condicionam a Formação de Brechas …………………......73

4.3.2 Simulações de Ruptura por Overtopping .................................................75

4.3.3 Simulações de Ruptura por Piping ……………………………............99

4.4 Simulação da Onda de Enchente Efluente ...................................................104

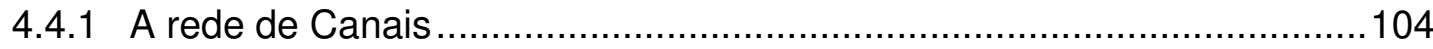

4.4.2 Simulações de Cálculo da Linha d'água...............................................111

4.4.3 Interpretação dos Resultados ...........................................................122

4.5 Diretrizes para Elaboração do Plano de Ações Emergenciais para a Barragem

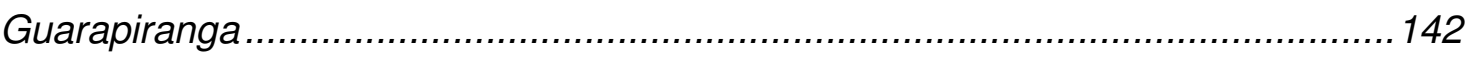

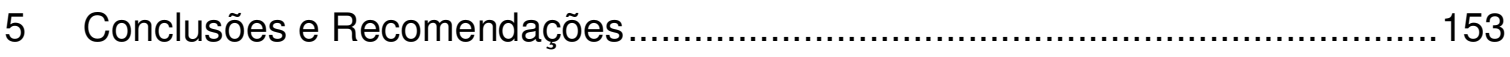

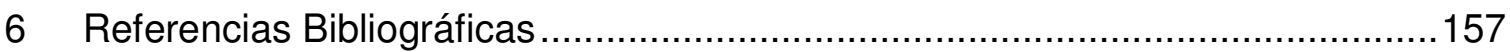
APÊNDICES 


\section{INTRODUÇÃO}

As questões ligadas à água vêm ocupando, com o passar do tempo, cada vez mais espaço no dia a dia das pessoas, empresas e governos. A consciência da limitação, a distribuição desigual deste recurso natural e o crescimento populacional confirmam as tendências previstas em passado recente, de que apenas a gestão eficiente e o uso racional farão com que este não seja um recurso limitante ao desenvolvimento humano.

Países desenvolvidos, que possuem recursos financeiros e infra-estrutura com tecnologias mais avançadas, já empregam técnicas de conservação, reutilização e "reciclagem" capazes de conservar a quantidade necessária para o consumo de acordo com a procura do recurso. Em muitas outras regiões onde a disponibilidade hídrica é desuniforme, crítica, principalmente no que diz respeito ao abastecimento humano, o homem não pode renunciar ao auxílio das barragens para formação de reservatórios. Durante milhares de anos as barragens têm servido para garantir, em determinadas estações do ano, quantidades suficientes de água para o abastecimento público e geração de energia, armazenando água nos períodos de cheia para posterior utilização nos períodos de seca.

O conceito de risco é tipicamente uma percepção de cada ser humano e sua avaliação pode ser feita de diferentes formas, destacando-se entre elas a economicista, a psicológica e a social (SCHINTTER, 1994). Em função das dimensões envolvidas, dos impactos provocados e dos investimentos necessários, estas estruturas devem ser sempre seguras, porém apesar da engenharia de barragens ter progredido muito, acidentes e rupturas podem prejudicar não só a economia, como também o meio ambiente e a sociedade, incluindo vidas humanas. No que diz respeito à segurança de obras complexas, tais como a construção de barragens, não se pode admitir o risco zero, ou seja, a segurança absoluta.

A segurança de uma barragem está associada a muitos fatores interligados, como seu partido hidráulico e estrutural, condicionantes geológicos, geotécnicos, hidrológicos e meteorológicos, bem como à própria falha humana na concepção, implantação, operação e manutenção da mesma. Um dos conceitos aceitáveis em diferentes partes do mundo é o da previsão e gestão dos impactos, através do planejamento. Este pode ser feito a partir de diferentes ferramentas de modelação, 
dentre as quais se destacam os modelos estatísticos e os determinísticos ou de simulação. Nos primeiros, a avaliação dos impactos é reduzida essencialmente a fatores econômico-financeiros, e procura criar uma estratégia de decisão que associa quaisquer danos a valores de risco previamente definidos com base no histórico de eventos similares. Na segunda procura-se simular processos físicos típicos dos acidentes de barragens, delimitando-se a área dos danos e então quantificando-se seus prejuízos.

As vantagens do segundo em relação aos primeiros é claramente visível, pois algumas peculiaridades relacionadas aos acidentes com barragens podem ser aventadas:

- $\quad$ Embora acidentes com barragens impliquem na liberação de grandes volumes de água para jusante, raramente o comportamento dos mesmos leva a uma correlação entre causas e efeitos consistente e que possa ser generalizada. São inúmeros os casos de rompimentos em que, embora os danos sejam pequenos, os custos são muito altos em função do valor social envolvido. É o caso de alguns rompimentos de barragens registrados no Brasil nos últimos anos, como Camará e Apertadinho.

- Enquanto os prejuízos materiais podem ser satisfatoriamente quantificados, os danos ambientais e as perdas de vidas humanas são suficientemente polêmicos, resultando num grau elevado de incerteza na transposição de conclusões de um caso para outro. Observou-se claramente este aspecto quando da ruptura das barragens de mineração no Rio Paraíba do Sul, manancial situado entre os estados do Rio de Janeiro e São Paulo, e que concentra 25\% do PIB do Brasil (IBGE, 2000).

- A gestão da crise ou emergência é um aspecto que altera totalmente a interpretação real dos motivos geradores do fato. Este aspecto foi observado nas repercussões do acidente com os diques da cidade norte-americana de Nova Orleans, durante o evento do Furacão Catrina.

Desta forma, o desenvolvimento e a sofisticação das sociedades exige que o planejamento e a implantação de empreendimentos passe a englobar também a análise de seus impactos em caso de acidentes, independentemente de suas causas, 
como fator inerente ao risco. Isto significa que, na concepção destes empreendimentos, afetarão o risco final do mesmo a existência do conhecimento prévio dos impactos decorrente de falhas diversas e da forma de tratá-las.

\section{$1.1 \quad$ Casos Históricos}

A construção de barragens pelo homem, para diversos usos, data de mais de 5.000 anos, com o registro da construção da barragem Saad El-Kafara, na atual Jordânia por volta de 2600 a.C (SCHINTTER, 1994), barragem esta que teve seu rompimento ocasionado por transbordamento durante a sua construção. A longo da história, inúmeros casos de sucesso, como as barragens romanas que chegaram até os dias atuais, como de insucesso, ilustram a literatura ligada ao tema.

Os diferentes e inúmeros acidentes com barragens documentados em todo o mundo fizeram com que o Internacional Comission on Large Dams (ICOLD), durante o Congresso Internacional de Grandes Barragens de 1979, em Nova Delhi, decidisse pela intensificação do desenvolvimento de segurança de barragens (CBDB, 2001). Desde então, em países como Estados Unidos, Portugal, Suécia, Canadá e França, a legislação estabeleceu rigorosos critérios de segurança para a construção e operação das barragens. A seguir, citam-se alguns casos de que tiveram destaque, entre tantos documentados pelo mundo.

Barragem Malpasset (Figura 1.1) - localizada no rio Reyran, a 15 quilômetros a montante de Fréjus, na Riviera Francesa, rompeu em 02 de dezembro de 1959 por falhas geológicas não detectadas na época da construção. A Figura 1.1 a seguir ilustra a barragem de Malpasset antes e depois do rompimento, que para Collischonn (1997), “... foi o mais famoso rompimento de barragem de concreto em arco". 

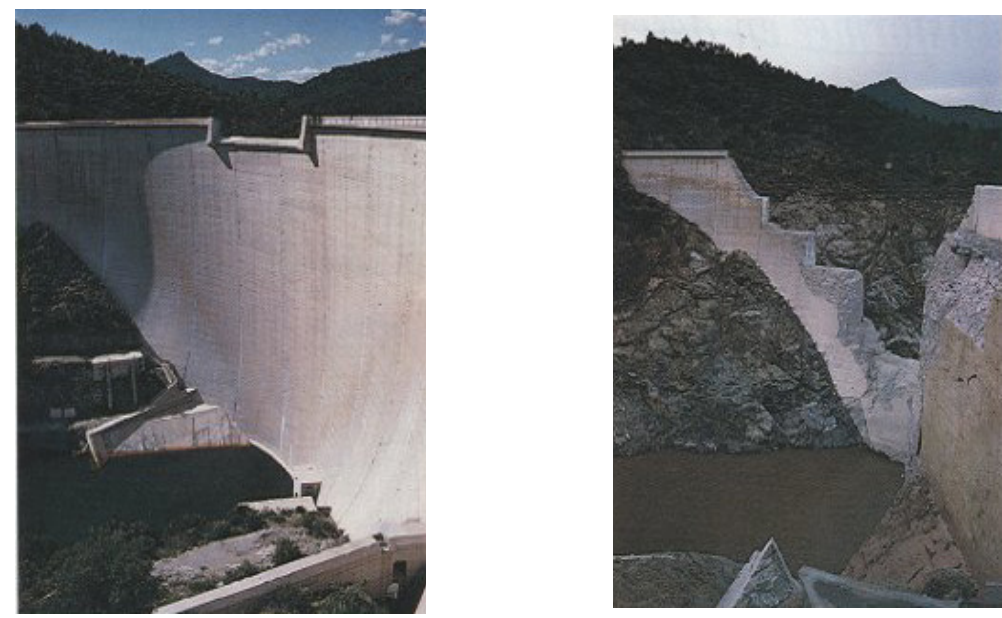

Figura 1.1: Barragem de Malpasset antes e depois do rompimento

Barragem de Orós (Barragem Juscelino Kubitschek de Oliveira - Figura 1.2), localizada no rio Jaguaribe no estado do Ceará, teve seu rompimento em março de 1960 devido a uma grande enchente, com uma brecha de 200 metros de comprimento e 35 metros de largura, provocando uma onda de cheia que se propagou até o Oceano Atlântico. (DNOCS).
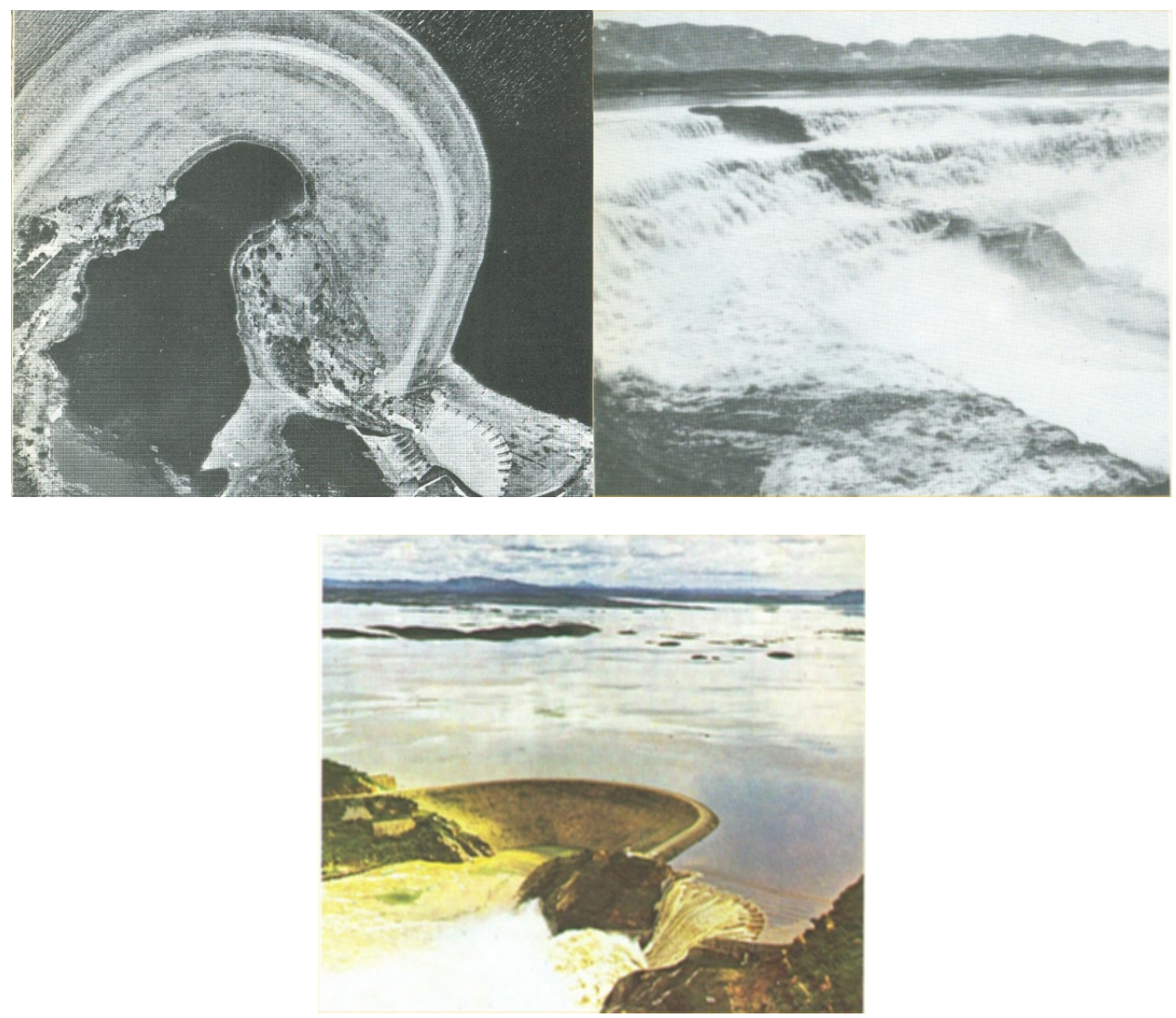

Figura 1.2: Barragem de Orós (CE), durante o acidente e reconstruída (acervo CTH/EPUSP) 
Barragem de Vajont (Figura 1.3) - localizada na região das Dolomites, Alpes Italianos, um grande deslizamento de terra proveniente do Monte Toc, com aproximadamente 30 milhões de metros cúbicos, em menos de 45 segundos adentrou ao reservatório. Todo este volume de terra "expulsou" uma grande quantidade de água, formando uma onda de aproximadamente $250 \mathrm{~m}$ de altura, provocando o overtopping da estrutura da barragem, sem rompê-la. Esta onda se propagou a uma velocidade de mais de 30 metros por segundo atingindo os vilarejos de Longarone (Figura 1.4), Pirago, Villanova, Rivalta e Fae, causando a morte de aproximadamente 2500 pessoas.
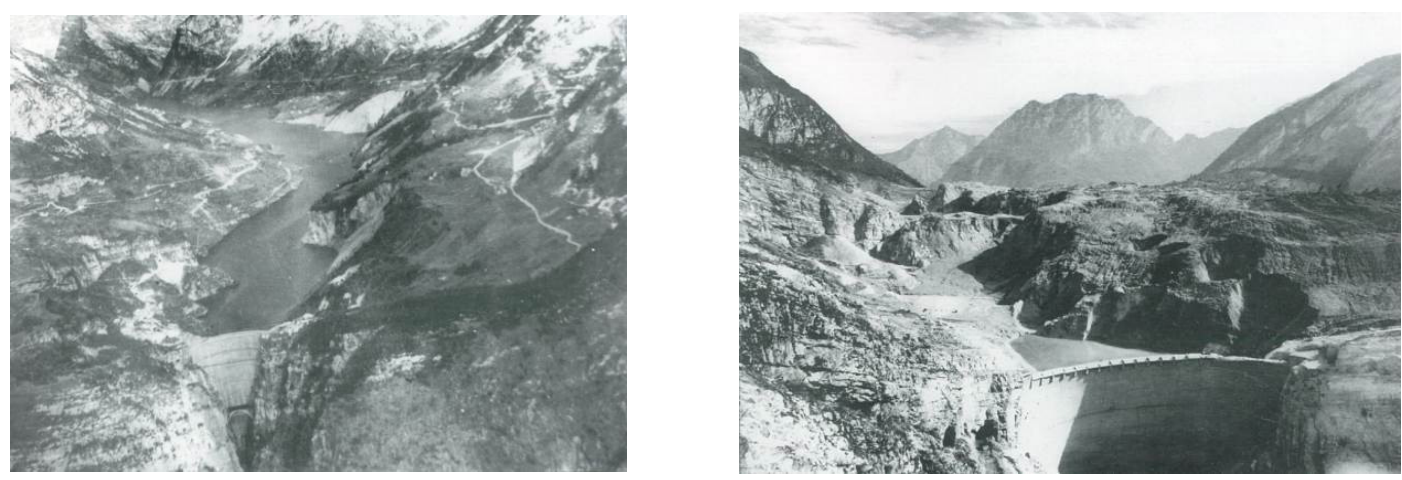

Figura 1.3: Barragem de Vajont antes e depois do overtopping (http://www.vajont.net/)
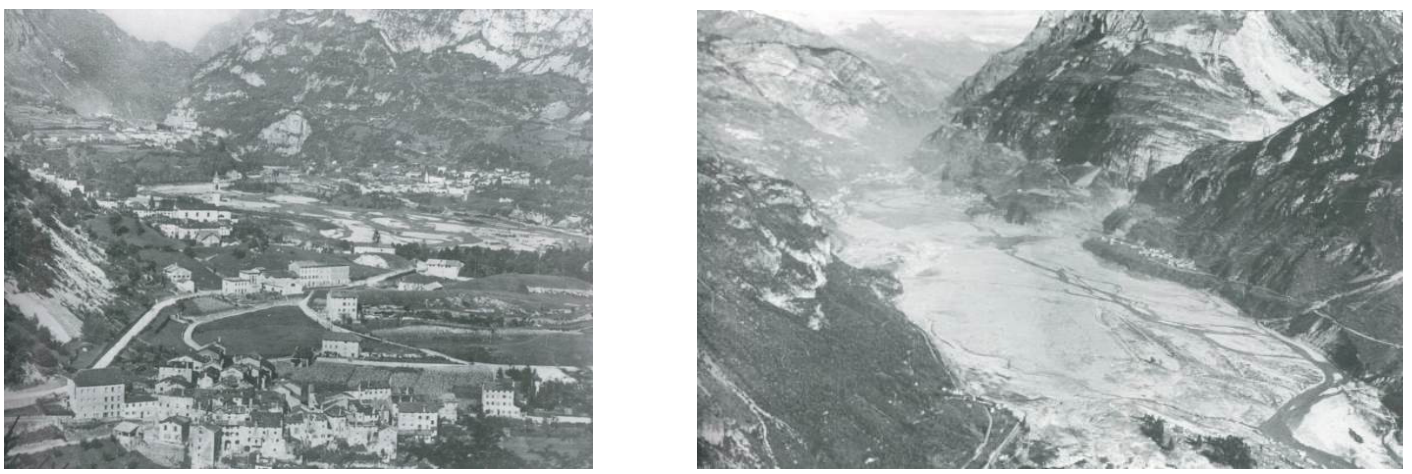

Figura 1.4: Vila de Longarone antes e depois do overtopping. (http://www.vajont.net/)

Barragem de Teton (Figura 1.5) teve seu rompimento em 5 de junho de 1976 no primeiro enchimento do reservatório, com uma brecha de dimensões 190 por 79 metros de largura e altura respectivamente. A barragem está localizada na cidade de Rexburg, Idaho EUA. 

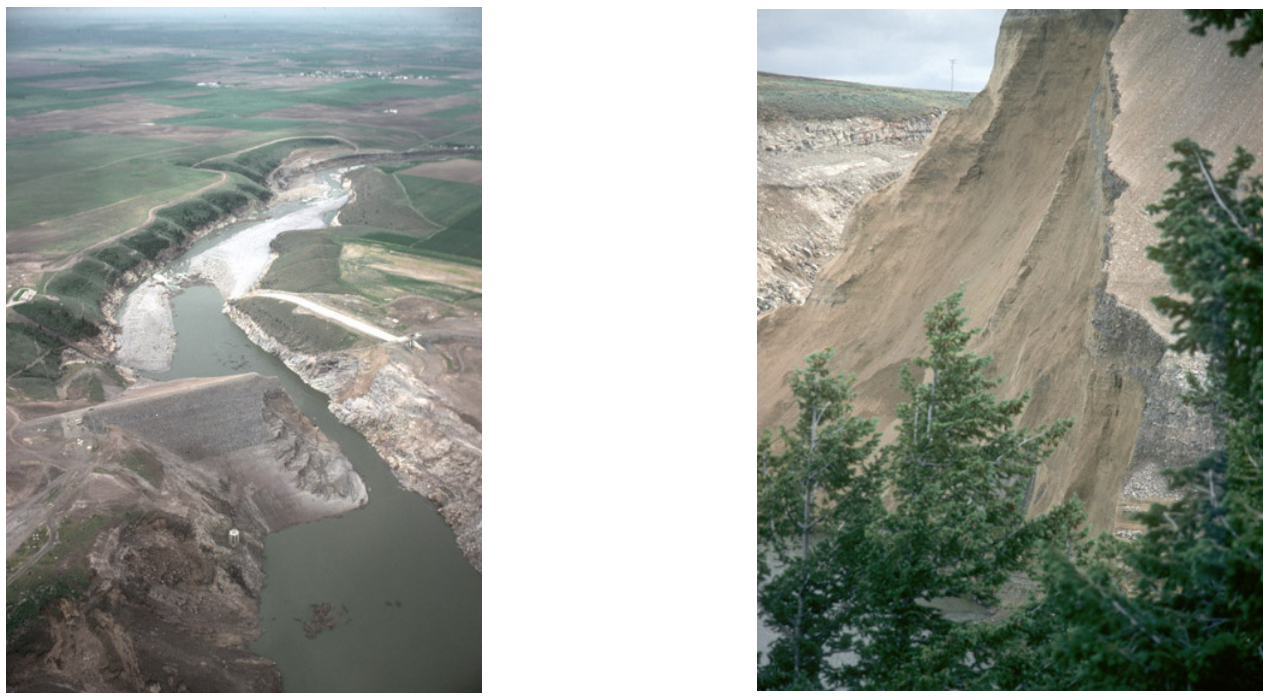

Figura 1.5: Rompimento da Barragem de Teton - EUA. (http://www.tetondam.org/)

Barragens Euclides da Cunha (Figura 1.6) e Armando Sales de Oliveira (Limoeiro Figura 1.7), concluídas na década de 1960 no rio Pardo, região de Mogi-Guaçu, Estado de São Paulo, sofreram transbordamento em janeiro de 1977, devido a uma enchente de grande magnitude (aproximadamente $2.200 \mathrm{~m} / \mathrm{s}$ ), provocando $\mathrm{o}$ galgamento, inundações na casa de força, rompimento do maciço e destruição total das estruturas a jusante (fonte: AES, 2005)
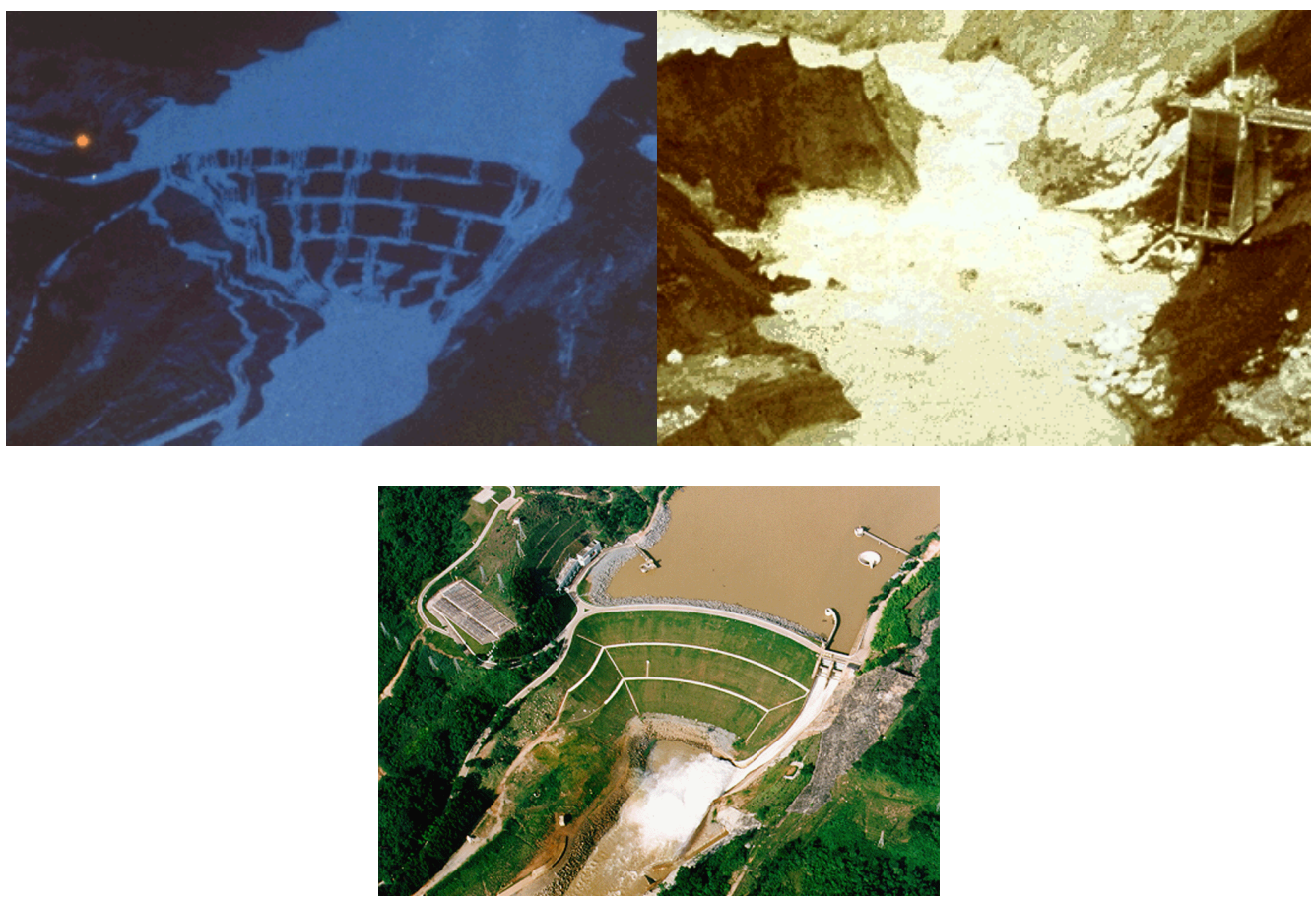

Figura 1.6: Barragem Euclides da Cunha durante o acidente e reconstruída (fonte: acervo CTH/EPUSP) 


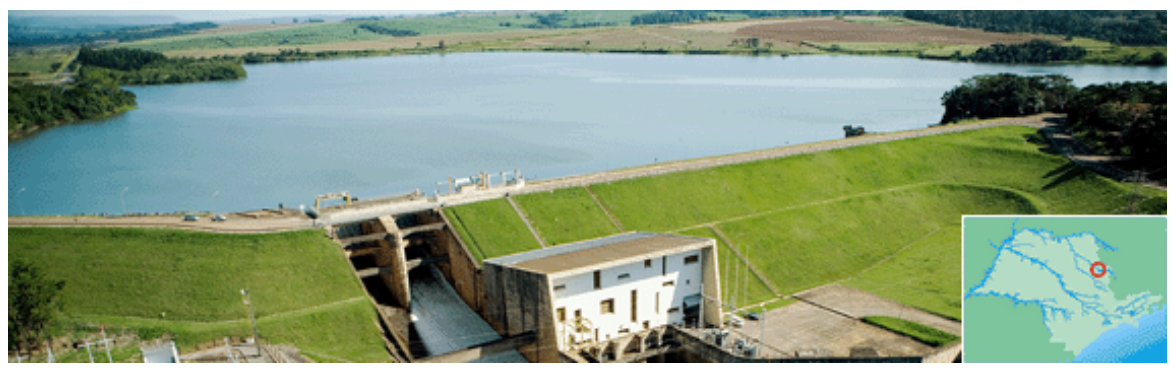

Figura 1.7: Barragem Armando Sales de Oliveira (http://www.aestiete.com.br/)

Barragem Camará (Figura 1.8), construída em concreto compactado a rolo no leito do rio Riachão - afluente do rio Mamanguape, localizada entre os municípios de Alagoa Nova e Areia, Estado da Paraíba, rompeu devido a uma falha geotécnica em 17 de junho de 2004 atingindo os municípios de Alagoa Nova, Areia, Alagoa Grande e Mulungu.
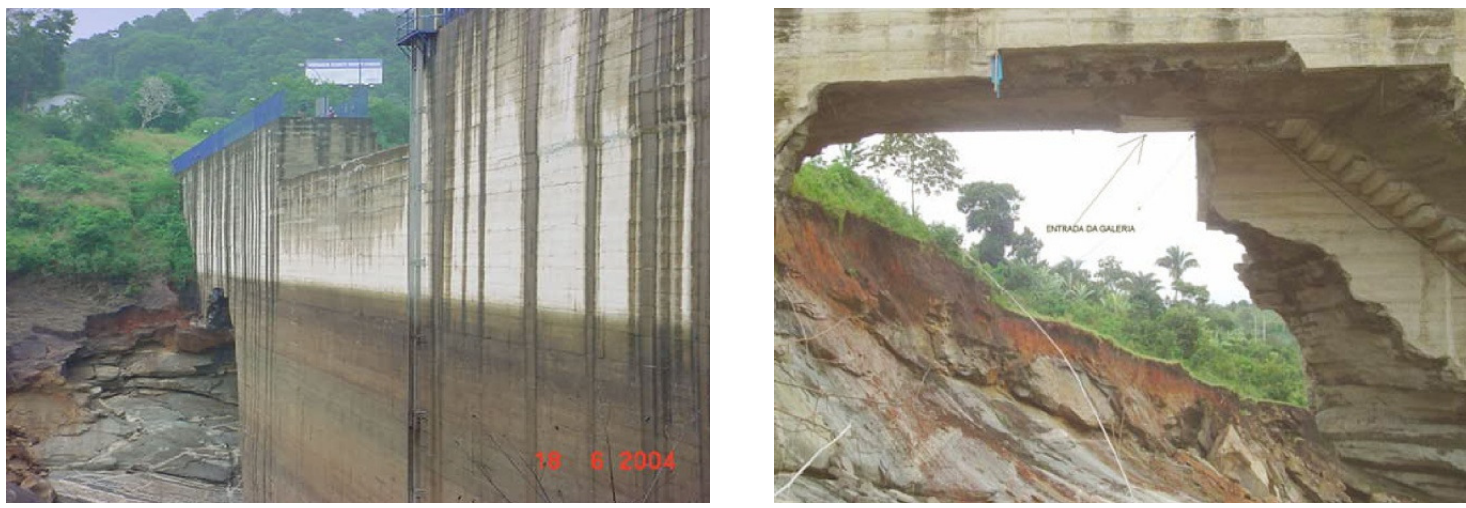

Figura 1.8: Barragem de Camará (PB) e danos a estrutura principal de concreto (acervo Erton Carvalho)

Barragem Campos Novos construída no rio Canoas, divisa dos municípios de Celso Ramos, Anita Garibaldi e Campos Novos, Estado de Santa Catarina, teve o rompimento nas comportas de fechamento dos túneis de desvio em 19 de junho de 2006.

Barragem de Apertadinho (Figura 1.9), um dos casos de mais recentes rompimentos noticiados no Brasil. Localizada no município de Vilhena, no estado de Rondônia, sobre o rio Comemoração, rompeu no dia 09 de janeiro de 2008, antes de sua inauguração em fevereiro de 2008. 


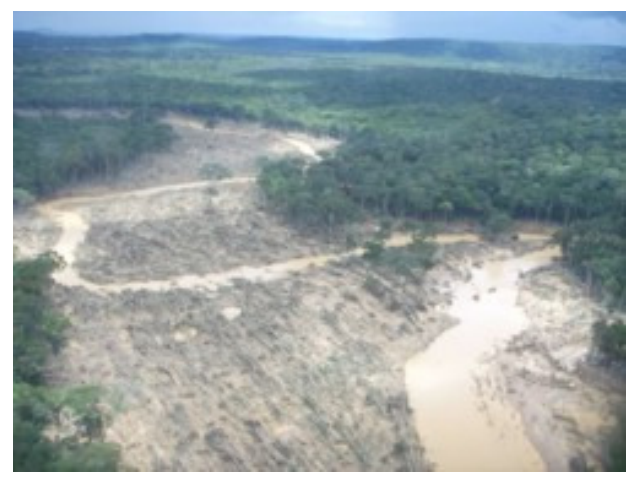

Figura 1.9: Rompimento da Barragem de Apertadinho. (http://www.diariodaamazonia.com.br/)

Barragem de rejeitos de bauxita da Mineração Rio Pomba Cataguases (Rio Fubá $M G$ ), teve seu rompimento em 10 de janeiro de 2007, despejando mais de 2 milhões de metros cúbicos de lama na zona da mata mineira. Em março de 2006, a barragem também sofreu o vazamento de mais de 400 milhões de litros de rejeitos de lavagem de bauxita.

Como se observa no Quadro 1 do APÊNDICE deste trabalho, diversos fatores podem e levam barragens ao colapso e, embora a engenharia moderna conte com ferramentas de análise e previsão que permitem reduzir ou minimizar os riscos ainda na fase de projeto, é importante considerar os eventuais impactos associados ao eventual processo de ruptura de uma estrutura de barramento na fase operacional.

A antecipação de conseqüências de uma ruptura que leva a liberação dos volumes reservados, do esvaziamento rápido de um reservatório e da perda dos volumes reservados permite a planificação e o gerenciamento da situação, minimizando os efeitos extremamente negativos sobre a população a jusante, sobre a economia ligada à água e sobre a conservação deste recurso.

\section{$1.2 \quad$ Este Trabalho}

Neste trabalho é apresentada uma revisão bibliográfica dos mecanismos de ruptura de barragens, dos modelos de formação de brechas e da formação da onde de cheia efluente de um acidente que causa a liberação do volume acumulado em um reservatório de barragem. Em seguida, são avaliados os processos de simulação da propagação da cheia resultante pelos rios e canais situados a jusante, destacando-se os dados e informações necessárias para diferentes ferramentas disponíveis no cenário técnico atual. Em seguida são analisados exemplos documentados de planos 
de ação preventiva e emergencial, objetivando-se a composição de diretrizes para a concepção e o desenvolvimento de tais instrumentos de gestão de emergências. A etapa final deste trabalho comporta a aplicação dos estudos realizados na elaboração de uma proposta de plano de gestão para um hipotético acidente com a Barragem Guarapiranga, estrutura componente do sistema de abastecimento urbano da cidade de São Paulo.

Este trabalho é composto por 5 capítulos. O presente capítulo, refere-se à Introdução, onde há uma descrição do conteúdo da pesquisa, casos históricos de acidentes com barragens no mundo, bem como a forma como está organizado o texto.

No capítulo 2, são descritos os objetivos geral e específico que levaram a realização dessa pesquisa.

No capítulo 3: Fundamentos são descritos os mecanismos de ruptura de barragens, onde são definidos os tipos de rompimentos adotados neste trabalho, os modelos de formação das brechas e os modelos de calculo da propagação da onda de enchente efluente desenvolvidos e utilizados. Esse capítulo, trata ainda de aspectos referentes à gestão de emergências quando da ocorrência de um rompimento de uma barragem, apresenta ainda alguns exemplos de Plano de Ações Emergenciais elaborados por diversos autores.

O capítulo 4, Estudo de Caso, refere-se ao estudo de caso utilizado para a aplicação metodologia proposta. Neste capítulo é apresentada uma breve caracterização do Sistema Guarapiranga, bem como os parâmetros referentes à elaboração, escolha e simulação de cenários para ruptura da Barragem Guarapiranga. É apresentada, ainda, a discussão e avaliação dos resultados obtidos e suas aplicações na elaboração de Planos de Ações Emergenciais.

Por fim, no capítulo 6, Conclusões e Recomendações, são apresentadas as conclusões deste trabalho e algumas recomendações para estudos futuros. 


\section{OBJETIVOS}

\section{$2.1 \quad$ Objetivo Geral}

Neste trabalho objetiva-se analisar e discutir o processo de gestão dos impactos gerados pela ruptura de barragens em cursos d'água, englobando as técnicas de previsão e simulação da falência estrutural destas obras, a propagação das ondas de cheia efluentes e a formação de planícies de inundação. Como resultado deste processo, pretende-se discutir a metodologia para elaboração dos planos de contingência e gerenciamento destas emergências.

Dentro deste escopo, são discutidos os mecanismos de rupturas de barragens em função de seu partido estrutural e construtivo, como as barragens em aterro compactado e as barragens em concreto. Os critérios apresentados na literatura para formação de brechas e liberação dos volumes reservados serão enfocados de forma a se consolidar a metodologia para geração dos hidrogramas efluentes dos eventos de falência estrutural.

$\mathrm{Na}$ seqüência, serão avaliados os métodos de cálculo da propagação das cheias efluentes, através de modelos matemáticos de translação de ondas de cheia. Desta forma o trabalho abordará os principais modelos de simulação da ruptura de barramentos, considerando seus critérios e faixa de aplicabilidade. Em seguida, serão discutidos os principais modelos de propagação de cheias efluentes, destacando suas limitações.

Finalmente, é apresentado um estudo metodológico da elaboração dos planos de ações emergenciais para gestão de acidentes com barragens, a partir da analise de exemplos existentes.

\section{$2.2 \quad$ Objetivo Específico}

Os modelos e técnicas de previsão e gestão de impactos causados pela ruptura apresentados neste trabalho serão aplicados à Barragem Guarapiranga, localizada na cidade de São Paulo sobre o Canal Guarapiranga, afluente da margem esquerda do Rio Pinheiros, por sua vez afluente do Rio Tietê, que dá nome à bacia mais importante do Estado de São Paulo e foi berço de sua formação e desenvolvimento. 
A barragem foi escolhida como exemplo por situar-se em área densamente ocupada por habitação e face a diversos elementos componentes da infra-estrutura local, estadual e nacional. Para tal, desenvolve-se uma análise aplicada dos mecanismos de ruptura, através da avaliação da sensibilidade dos parâmetros envolvidos, bem como a simulação da propagação da cheia efluente através das calhas do Canal Guarapiranga, Rio Pinheiros e Rio Tietê, com o emprego de um modelo hidrodinâmico unidimensional, denominado CLiv Plus. (FCTH, 2006) (UEMURA \& MARTINS, 2007) A simulação da cheia efluente permite, com o emprego de ferramentas baseadas em SIG, a interpretação dos impactos potenciais, como o zoneamento das áreas atingidas, a estimativa do tempo até o impacto, sua duração e extensão (profundidade ou área) bem como a planificação de ações preventivas e de gestão durante a emergência. Desta forma, por meio de exemplos típicos, objetiva-se finalmente, formular um roteiro para a elaboração destes planos de ação. 


\section{FUNDAMENTOS}

\subsection{Mecanismos de Ruptura de Barragens}

As barragens podem romper por diferentes causas, entre as quais as listadas a seguir (ELETROBRÁS, 2003):

- $\quad$ Rompimento de uma das faces da barragem (montante ou jusante);

- Ruptura da fundação (fratura da rocha, deslizamento de camadas, etc.);

- $\quad$ Galgamento, normalmente por um evento hidrológico extremo;

- Ruptura por entubamento, em função de falhas no corpo da barragem;

- $\quad$ Ações de guerra ou terroristas.

Neste capítulo são abordados os aspectos relativos às falhas que causam a liberação brusca dos volumes reservados, que podem ser estruturais (rompimento da barragem, contraforte, pilar, fundação, etc.) e por deficiências construtivas e hidrológicas, causadas geralmente por galgamento da crista e escoamento sobre o paramento. Há ainda que se considerar as falhas mecânicas de componentes, como as comportas e válvulas.

Nos estudos realizados para o estabelecimento de ruptura de barragens de terra, enrocamento ou concreto, buscou-se contemplar a avaliação de todos os principais condicionantes hidráulicos e geotécnicos que interferem nos possíveis mecanismos de rompimento, ou seja, falência estrutural e falência hidráulica das barragens.

\subsection{1 $\quad$ Falência Estrutural ou Ruptura por Piping}

O piping, que no jargão geotécnico significa 'retro-erosão', corresponde ao fenômeno de erosão interna que progride de jusante para montante na forma de um tubo, em função do fluxo no interior de uma massa de solo, iniciado sob condições de gradiente hidráulico elevado e capaz de carrear materiais do aterro formando canais dentro da massa de solo em sentido contrário ao do fluxo de água. Este fenômeno é mais freqüente no início dos chamados 'períodos secos' ou fim da época de cheia da bacia, pois nesta situação os reservatórios encontram-se totalmente cheios tendo em vista a 
necessidade do atendimento às demandas de água durante a seca a dispensa da alocação de volumes de espera para controle de cheias.

A água que se movimenta através do maciço ou das fundações de uma estrutura de terra pode resultar na formação de uma brecha quando os volumes de água e material sólido superam determinados limites de segurança (COLLISCHONN W. , 1997). A brecha inicia-se em um ponto como um poro (Figura 3.1) em um ponto qualquer da barragem, desenvolvendo-se para todos os lados, até ocorrer o colapso.

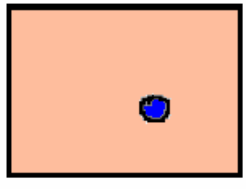

a

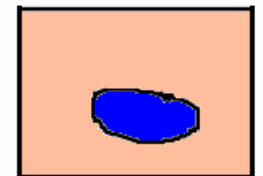

b

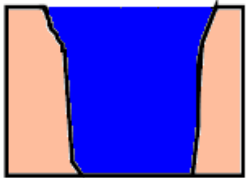

C

Figura 3.1: Formação da brecha por piping - a) Surgimento do poro; b) Aumento por erosão; c) Colapso da porção superior e erosão. (adaptado de Johnson e llles, 1976 apud Collischonn 1997).

Também podem ser consideradas como falhas estruturais aquelas ocorridas nas fundações das barragens (Figura 3.2) oriundas das acomodações geológicas quando da saturação do material da fundação por infiltração (COLLISCHONN \& TUCCI, 1997) e as imperfeições construtivas no contato entre o maciço estrutural e o solo existente nas margens, usualmente chamadas de 'ombreiras'.

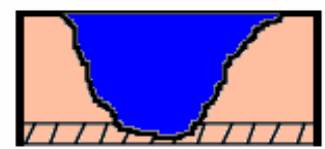

a

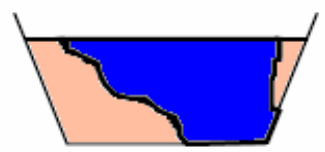

$\mathrm{b}$

Figura 3.2: Brechas resultantes de falhas nas fundações - a) Barragens de terra ou concreto; b) Barragens de concreto em arco. (adaptado de Johnson e Illes, 1976 apud Collischonn 1997).

O fenômeno de piping pôde ser observado no caso da ruptura da barragem de Teton, Idaho, Estados Unidos, em 05 de junho de 1976. A barragem, com cerca de 90 metros de altura, teve seu rompimento após o primeiro dia de enchimento do reservatório $\left(356 \mathrm{hm}^{3}\right)$. A brecha formada nesse rompimento teve dimensões de 190 metros de largura por 79 metros de altura. 

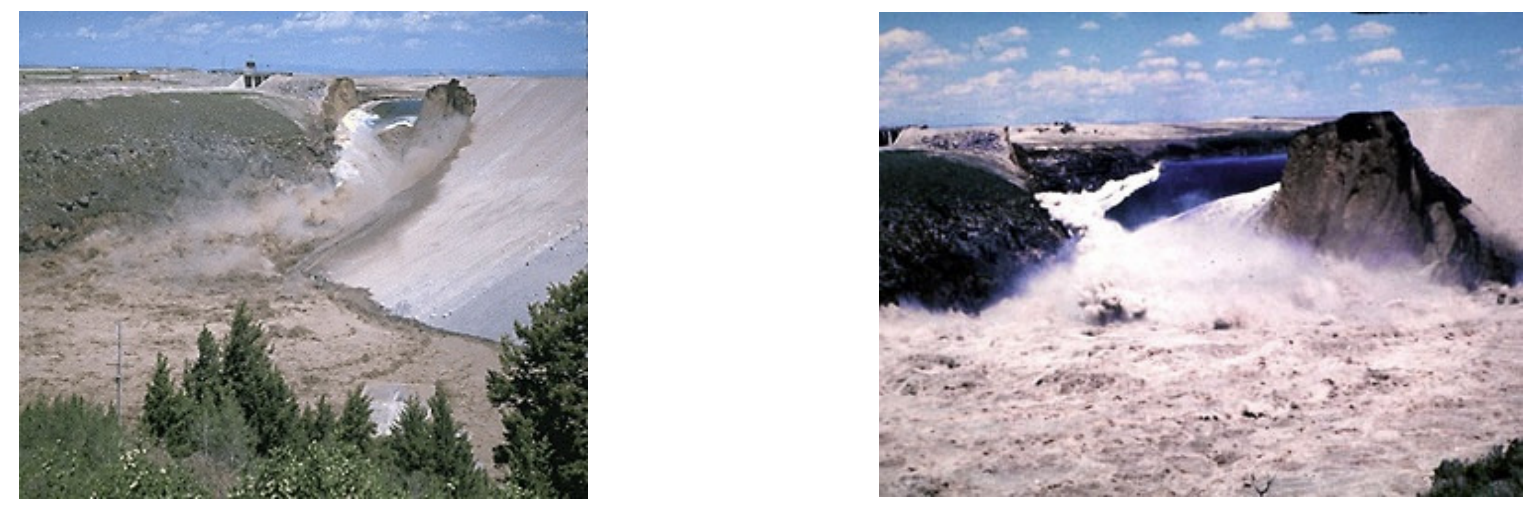

Figura 3.3: Rompimento da Barragem de Teton - EUA. (http://www.tetondam.org/)

\subsubsection{Falência Hidráulica ou Ruptura por Overtopping}

O overtopping corresponde ao fenômeno de galgamento ou transbordamento da barragem, ou seja, a passagem das águas sobre a estrutura da mesma, resultado da chegada de uma onda de cheia excepcional ou de uma falha operacional do reservatório Figura 3.4). Este fenômeno está normalmente associado a um evento hidrológico extremo, onde o volume do reservatório e as estruturas de descarga da barragem não são suficientes para armazenar e extravasar a quantidade de água.

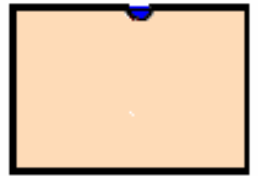

a

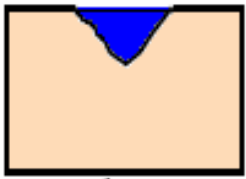

$\mathrm{b}$

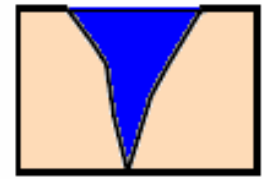

c

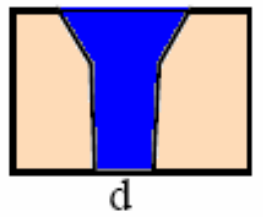

Figura 3.4: Formação da brecha por overtopping - a) início no ponto mais fraco; b) brecha em forma "V"; c) aprofundamento da brecha; d) aumento lateral por erosão (adaptado de Johnson e Illes, 1976 apud Collischonn 1997).

Pode-se citar ainda como situações que levem ao galgamento de uma estrutura de barramento, problemas operacionais oriundos do mau funcionamento de comportas e válvulas de descarga, obstrução das mesmas por material de assoreamento e até mesmo embarcações desgovernadas, problemas operacionais gerados por falta de comunicação e informações, despreparo de operadores e outros fatores que podem acidentalmente comprometer a capacidade de descarga dos órgãos extravasores e causar a elevação do nível d'água. 


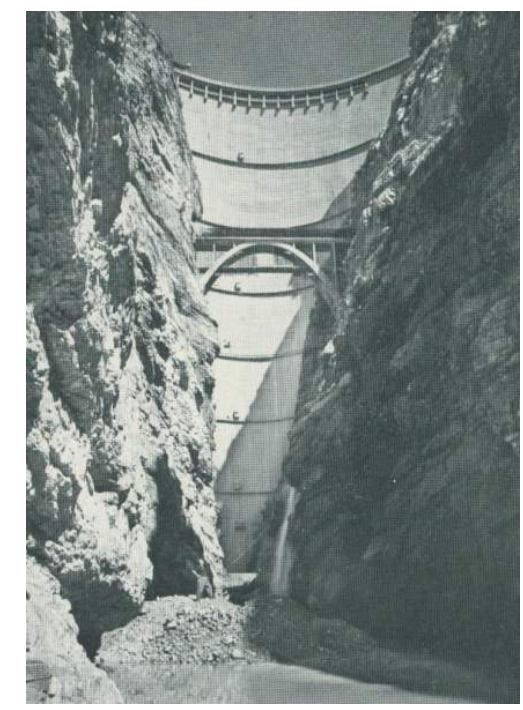

Figura 3.5: Barragem de Vajont - Itália. (http://www.vajont.net/)

\subsubsection{Modelos de Formação de Brechas}

A brecha é uma abertura formada na barragem pela qual a água do reservatório escoa, alterando progressivamente sua forma (FREAD D. , 1977). A modelação da evolução da brecha na barragem é de fundamental importância no processo de simulação de rompimento, quando da simulação de cenários como acidentes provocados por eventos de cheia. Entende-se que a evolução da brecha depende das características do material a ser erodido e da energia associada ao escoamento através dela. As variáveis envolvidas são a vazão, o nível d'água no reservatório, a velocidade a montante da brecha, a forma da soleira formada na brecha e o tempo do fenômeno.

Nas últimas décadas, muitos avanços têm sido alcançados no campo da modelação dos processos de ruptura de barragens (MARTINS, 2003). Nos estudos mais antigos, quando os conhecimentos e pesquisas sobre o assunto eram ainda bastante incipientes, admitia-se a hipótese que o rompimento das barragens se dava de forma completa e instantânea. Esta hipótese pode ser considerada razoável nos casos de estruturas de concreto em forma de arco ou ainda de barragens em painéis de concreto sustentados por contrafortes. Entretanto, ela se torna inadequada quando a análise envolve o colapso de barragens de concreto tipo gravidade, (concreto massa ou compactado de diversas formas) ou ainda nas barragens de terra, enrocamento com face impermeável a montante ou mistas terra-enrrocamento. 
Atualmente, reconhece-se a necessidade de se avaliar, sobretudo nos casos onde a ruptura é gradual, os efeitos gerados pela liberação dos volumes retidos de forma mais lenta, e que resultam em inundações a jusante com elevado tempo de permanência, causando danos tão importantes quanto os causados nas situações hipotéticas de ruptura instantânea.

A necessidade de se simular a ruptura gradual foi destacada inicialmente por Cristofano, em 1965 (PONCE \& TSIVOGLOU, 1981). Usando os princípios da engenharia geotécnica, estabeleceu-se uma relação entre a quantidade de material erodido do corpo da barragem e a vazão efluente da mesma. Para isso, foi assumido que a seção de ruptura mantém a forma trapezoidal ao longo de todo o processo e que os taludes desta seção apresentam inclinação igual ao ângulo de atrito interno do material da barragem.

No final da década de 1950, o USACE - Corpo de Engenheiros do Exército dos Estados Unidos da América (apud MacDonald, 1984) construiu um modelo físico através do qual se desenvolveram intensivas investigações sobre rompimentos de barragens. Para rupturas instantâneas, pôde-se estabelecer uma relação entre o pico da vazão efluente e um fator de forma relacionado à geometria da seção de ruptura da barragem. Entretanto, este resultado não pode ser estendido para casos de ruptura gradual, uma vez que as características hidráulicas envolvidas nos dois processos são significativamente diferentes.

Brown \& Rogers (1977) apresentaram conclusões interessantes sobre os mecanismos de rupturas de barragens de terra, observando a necessidade de se incorporar os efeitos da erosão lateral nos modelos de simulação da seção de ruptura. Além disso, apresentaram uma análise dos mecanismos de ruptura típicos que ocorrem em barragens de solo compactado em função da altura das mesmas.

Singh e Scarlatos (1988) estudaram cinco modelos analíticos de ruptura de barragens de terra, discutindo suas vantagens e desvantagens e seus limites de aplicabilidade. Os modelos são baseados em princípios hidráulicos e geotécnicos, e abrangem a ruptura em formato triangular, retangular e trapezoidal. A taxa de erosão da seção de ruptura que se desenvolve no corpo da barragem é admitida como sendo uma função linear ou quadrática da velocidade média do escoamento nesta seção. Os principais parâmetros envolvidos nos modelos são determinados através de uma análise de sensibilidade baseada em dados históricos de ocorrências em ruptura de barragens. 
Fread (1977) apresentou contribuições substanciais à modelação do fenômeno em questão, avaliando diversas formas de geometria da seção de ruptura da barragem (triangular, retangular e trapezoidal) e assumindo que o crescimento desta seção é uma função do tempo. Entretanto, admitiu em seus estudos que a hipótese de que a taxa de erosão vertical da seção de ruptura é constante no tempo, o que pode não ser verificado em muitas situações. Além disso, o autor não destaca o fato de que o hidrograma efluente gerado pelo colapso é extremamente sensível à escolha desta taxa de erosão vertical.

MACDONALD \& LANGRIDGE-MONOPOLIS (1984) analisaram as características da formação da brecha em quarenta e duas barragens rompidas, sendo 30 barragens de solo compactado e 12 outros tipos de barragens. Segundo os autores, foram analisadas para a formação das brechas as seguintes categorias: variáveis associadas às características do maciço, variáveis associadas ao fluxo de água que passa pela brecha e características com que as brechas foram formadas.

As variáveis associadas às características do maciço levam em consideração o tamanho e a forma geométrica do mesmo, o tamanho e o fator de coesão do material do aterro e o tipo e local de formação da brecha. De acordo com esses parâmetros, as barragens estudadas foram então agregadas como 'barragens de terra' e 'demais barragens'. Para as barragens de terra, o fator fundamental de análise foi à taxa de material removido durante a evolução, considerado o fator predominante para a previsão da formação da mesma. Para as barragens cujo material do maciço não é de terra, o material removido pode ser considerado formado não só pela erosão, mas também pelo tipo de material do maciço.

As variáveis associadas às características do escoamento consideram o volume do escoamento, a diferença de altura entre a base da brecha e a altura máxima da barragem e a vazão máxima que passará pela brecha. Para casos de overtopping, além do volume do reservatório, foi considerada também a água proveniente de um evento pluviométrico.

Além das variáveis associadas às características do maciço e do escoamento, foram analisadas as geometrias das brechas resultantes. Essas características consideram a forma e o tamanho da brecha, os taludes laterais, o volume do material removido durante a formação da brecha e o tempo máximo de evolução da brecha. Neste estudo, os autores constataram que para a maioria dos rompimentos analisados, a 
brecha tinha o formato trapezoidal com inclinação dos taludes $2 \mathrm{~V}: 1 \mathrm{H}$. As barragens que romperam por overtopping, tiveram sua brecha iniciada no ponto mais fraco da barragem e para os casos de piping, o processo de formação da brecha inicia em um ponto a jusante do maciço até o ponto onde ocorre o piping propriamente dito. Ao analisarem o tamanho da brecha, os autores consideraram que o tamanho máximo que a brecha pode atingir depende da geometria do maciço e do volume de material a ser erodido durante a formação da brecha. Essa relação pode ser observada no gráfico apresentado na Figura 3.6. Em relação ao tempo de formação da brecha, os autores afirmam que o tempo máximo de formação da brecha para as barragens de terra está associado ao volume de material removido durante a formação da brecha. Esta relação pode ser observada no gráfico apresentado na Figura 3.7

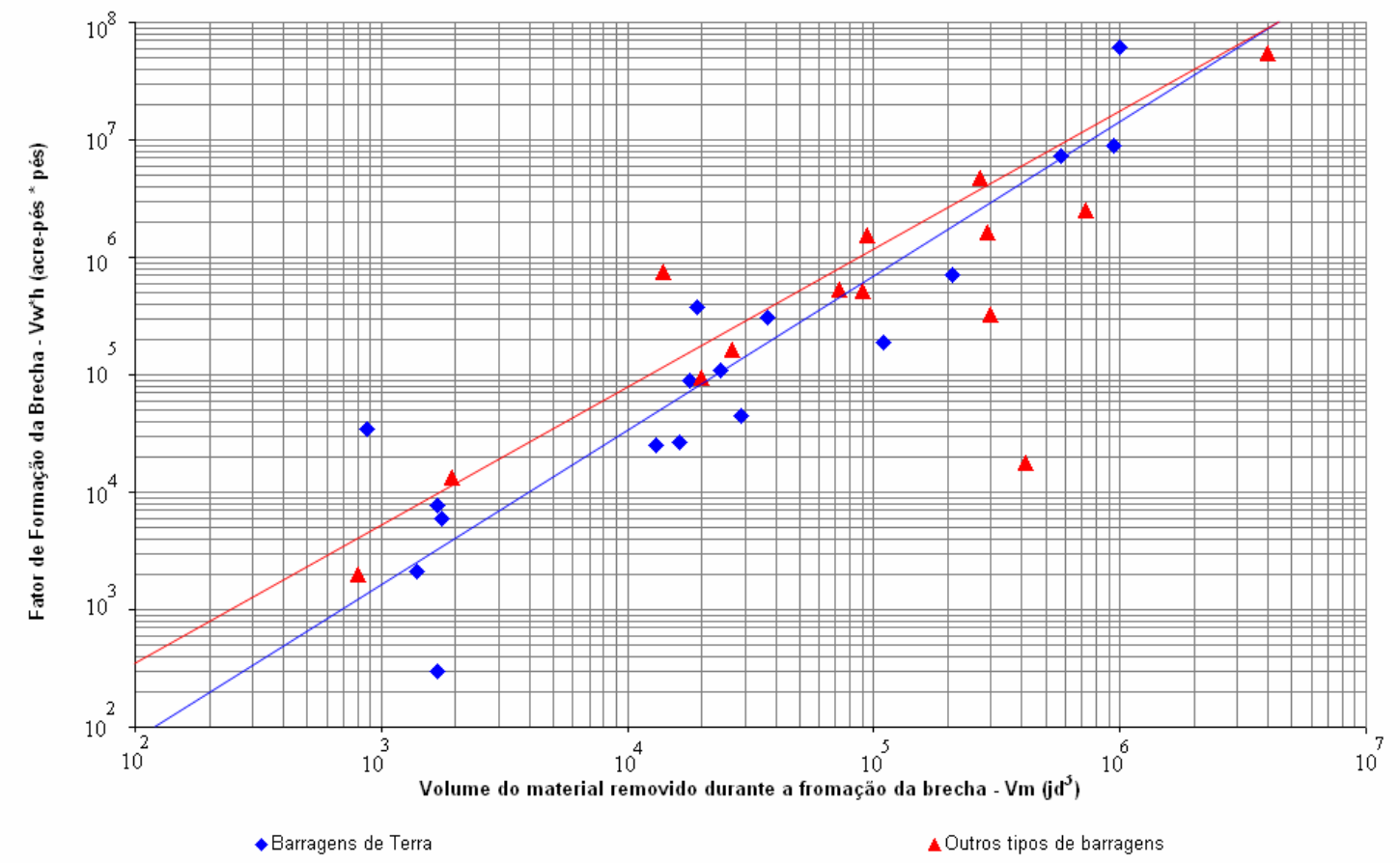

Figura 3.6: Características do Escoamento x Tamanho da Brecha. Adaptado de (MACDONALD \& LANGRIDGE-MONOPOLIS, 1984). 


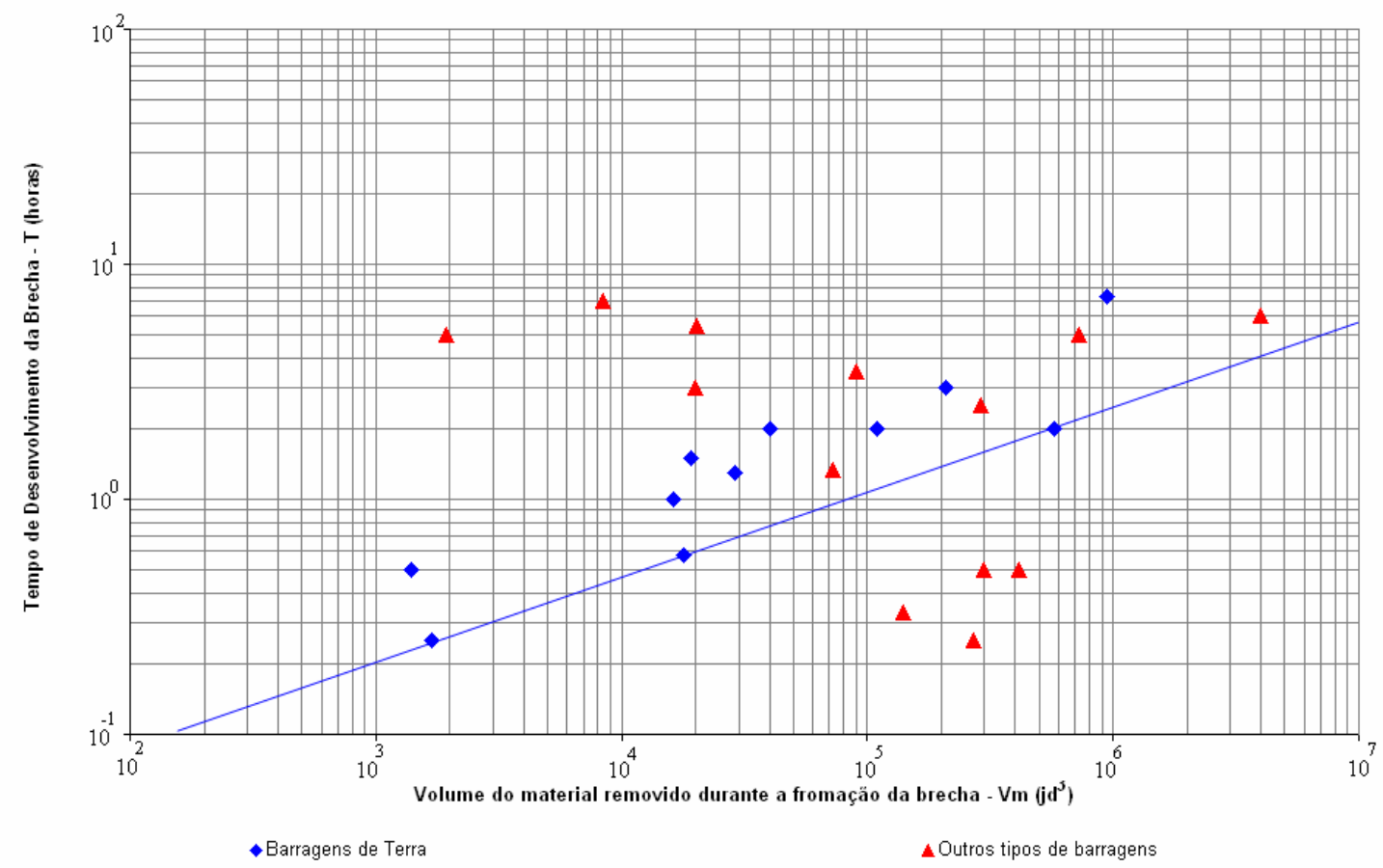

Figura 3.7: Tamanho da brecha $x$ Tempo de desenvolvimento da Brecha. Adaptado (MACDONALD \& LANGRIDGE-MONOPOLIS, 1984)

Após essas análises, os autores concluíram que para as estimativas dos fatores que influenciam na formação de brechas, tanto para barragens de terra como para os outros tipos de barragens, as brechas assumem a forma trapezoidal com taludes $2 \mathrm{~V}: 1 \mathrm{H}$, o volume removido do maciço durante o rompimento da barragem pode ser estimado de acordo com o fator de formação da brecha como apresentado na Figura 3.6, e que somente para as barragens de terra, o tempo de formação das brechas pode ser estimado usando a relação apresentada na Figura 3.7.

Em agosto de 1997, Wahl em parceria com o U. S. Bureau of Reclamation, estudaram a possibilidade de propor um modelo baseado em observações de rompimento em barragens de terra, onde consideram o tempo em que a brecha se inicia, as condições de formação, a geometria, o tempo total de desenvolvimento e a forma final da brecha. $O$ autor observou que apesar do fenômeno piping ser mais comum, também deveriam ser considerados estudos para rompimentos causados por overtopping. Assim, o USBR juntamente com outras instituições tem estudado a possibilidade de melhorar a avaliação da estabilidade do "riprap", da superfície coberta por grama dos taludes das barragens, bem como o escoamento e a 
capacidade do transporte dos materiais soltos, fornecendo base para 0 desenvolvimento do modelo a ser proposto.

FREAD e LEWIS (1998), ao desenvolverem o modelo FLDWAV para a National Weather Service - NWS, especificaram alguns parâmetros para formação de brechas no caso do rompimento de barragens de concreto e terra. Os parâmetros da brecha, também estudados por outros pesquisadores de rompimento de barragens, dependem do tipo de material da barragem. Para as barragens de concreto em arco, a brecha tem formação rápida e instantânea, o que não ocorre com barragens de terra e barragens de concreto por gravidade. Para o modelo desenvolvido, a brecha se forma em um intervalo de tempo determinado, e assume um tamanho final com geometria trapezoidal, determinado pelo parâmetro b (largura de fundo). A forma do trapézio depende do parâmetro z, como ilustrado na Figura 3.8.

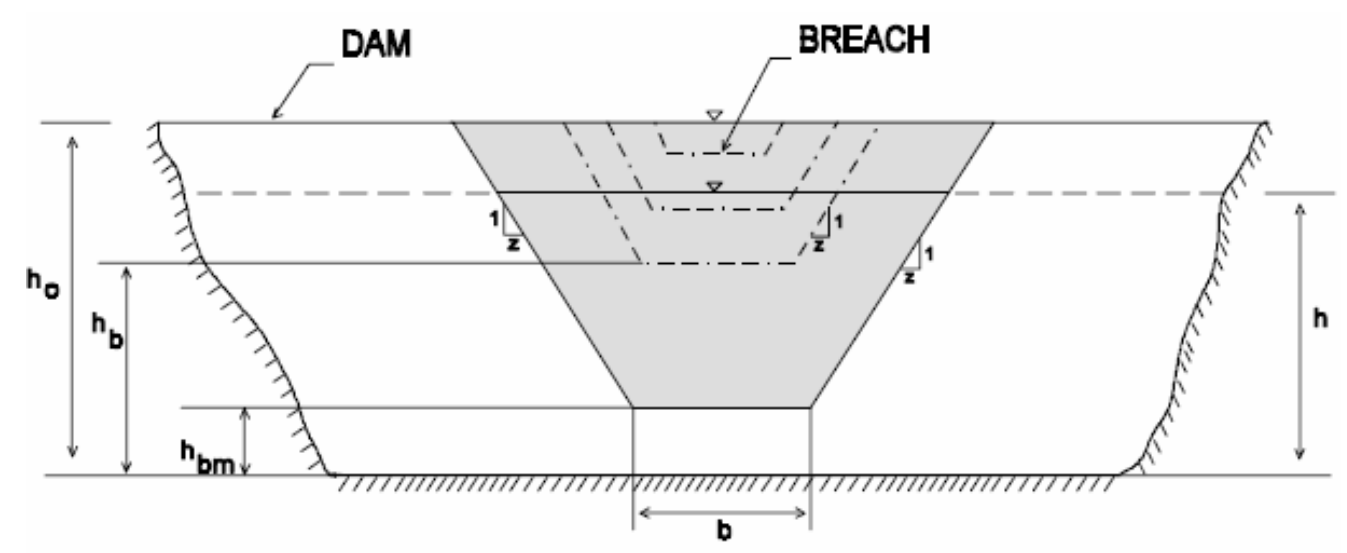

Figura 3.8: Vista Frontal da Formação da Brecha na Barragem. (FREAD \& LEWIS, 1998)

O autor assume que a brecha pode possuir formatos que dependem do parâmetro $z$ que está relacionado à inclinação da forma da brecha. A largura final da brecha está relacionada com a largura média da brecha segundo a Equação 3.1.

$\mathrm{b}=\overline{\mathrm{b}}-\mathrm{z} * \mathrm{~h}_{\mathrm{d}}$

Equação 3.1

Onde: 
b é a largura final (do fundo);

$\overline{\mathrm{b}}$ é a largura média da brecha;

Zé a inclinação da forma da brecha;

$\mathrm{h}_{\mathrm{d}}$ é a altura de água sobre o fundo da brecha.

O modelo desenvolvido por Fread assume que a largura final da brecha começa de acordo com a Figura 3.8 e cresce linearmente ou não linearmente em função do tempo de falência até a largura final ser atingida e o fundo da brecha estar totalmente erodido (parâmetro $h_{b m}$ ). A altura de fundo da brecha $h_{b}$ é determinada em função do tempo $\tau$, segundo a Equação 3.2:

$\mathrm{h}_{\mathrm{b}}=\mathrm{h}_{\mathrm{d}}-\left(\mathrm{h}_{\mathrm{d}}-\mathrm{h}_{\mathrm{bm}}\right) *\left(\frac{\mathrm{t}_{\mathrm{b}}}{\tau}\right)^{\rho_{0}} \quad$ se $0<\mathrm{t}_{\mathrm{b}} \leq \tau \quad$ Equação 3.2

onde:

$\mathrm{h}_{\mathrm{bm}}$ é a altura final da largura de fundo da brecha;

$t_{b}$ é o tempo inicial de formação a brecha;

$\rho_{0}$ é o parâmetro que especifica o grau de não linearidade do talude da brecha.

Para barragens de concreto por gravidade, o autor salienta que estas apresentam uma pequena ou parcial brecha formada durante a sua formação, permitindo o escoamento de água excedente. $O$ tempo de formação dessas brechas é de apenas alguns minutos. Devido a esse fato, é de grande dificuldade estimar a quantidade de monolitos que podem se deslocar ou até mesmo ruir. As barragens de concreto em arco tendem a romper por completo com a formação da brecha em apenas alguns minutos. Para ambos os casos, o parâmetro de forma $z$ (inclinação da forma da brecha) é considerado zero. 
Já para as barragens de terra que, diferentemente das barragens de concreto, não se rompem por completo nem instantaneamente, a brecha formada possui normalmente uma largura média entre $0,5 h_{d}<\bar{b} \leq 8 h_{d}$ onde $\mathrm{h}_{\mathrm{d}}$ é a altura da barragem. O tempo de formação das brechas em barragens de terra, considerado por Fread, é o tempo entre o início da formação da brecha na face à montante da barragem até a sua completa formação. $O$ tempo de ruptura para o caso de rompimento por overtopping depende da altura, do tipo de material usado na construção, da medida de compactação dos grãos, da magnitude e duração do fenômeno de escoamento da água.

A ruptura por piping ocorre quando um ponto da estrutura da barragem é afetado por uma erosão interna deixando a água do reservatório escapar por entre a brecha. O tempo de formação da brecha neste caso é normalmente considerado mais longo em relação às rupturas por overtopping.

Os parâmetros $\bar{b}$ e $\tau$ podem ser determinados através das Equação3.3 e Equação3.4 resultantes de estudos realizados por FROELICH (1995) para 43 brechas formadas em barragens com alturas de 5 (cinco) a 90 (noventa) metros.

$\overline{\mathrm{b}}=9,5 * \mathrm{k}_{0}\left(\mathrm{~V}_{\mathrm{r}} * \mathrm{~h}_{\mathrm{d}}\right)^{0,25}$

Equação3.3

$\tau=0,59 * \frac{\mathrm{V}_{\mathrm{r}}^{0,47}}{\mathrm{~h}_{\mathrm{d}}^{0,9}}$

Equação3.4

onde

$\overline{\mathrm{b}}$ é a largura média da brecha;

$\tau$ é o tempo de falência da barragem;

$\mathrm{k}_{0}=0,7$ para piping e $\mathrm{k}_{0}=1,0$ para overtopping;

$\mathrm{V}_{\mathrm{r}}$ é o volume do reservatório; 
$\mathrm{h}_{\mathrm{d}}$ é a altura de água sobre o fundo da brecha.

\subsection{Onda de Enchente Efluente}

A onda efluente dos fenômenos de ruptura de barragens é caracterizada por elevados gradientes de descarga, sendo sua propagação para jusante influenciada pelas condições da calha, planícies laterais de inundação e resistência ao escoamento. Quando os efeitos hidrodinâmicos resultam em superfícies livres com pequena inclinação, o fenômeno de propagação pode ser considerado semelhante ao das ondas de cheias naturais. De outro lado, quando os mesmos apresentam superfícies fortemente inclinadas, devem ser tratados como ondas de choque.

É de se observar que, embora não se possa descartar a ocorrência de ondas de choque, o escoamento nos vales a jusante das barragens tende a ocupar rapidamente as seções principais dos cursos d'água, extravasando para o leito maior, o que causa o abatimento da inclinação da superfície livre ao mesmo tempo em que grandes volumes são armazenados. Desta forma, é usual o tratamento das ondas efluentes de rompimento através do equacionamento hidrodinâmico unidimensional, considerando-se, entretanto a existência de um caminho preferencial de escoamento no vale, na região de maior profundidade, com velocidades maiores do que nas regiões sobre as várzeas.

MARTINS e FADIGA JR (1989) avaliaram o amortecimento da onda efluente de rompimentos de barragens a partir de um modelo hidrodinâmico unidimensional, correlacionando o fator de abatimento com a geometria do canal principal (largura B), a declividade da linha de energia $S_{f}$ e 0 fator de resistência ao escoamento, representado pelo coeficiente de Manning.

Em 1997, COLLISCHONN \& TUCCI estudaram a aplicação do modelo denominado DAMBREAK para a simulação do rompimento hipotético da barragem de Ernestina, localizada no rio Jacuí (RS-Brasil). Os autores analisam a sensibilidade dos parâmetros de entrada do modelo, bem como a formação da brecha (Fread, 1991) e a propagação do hidrograma resultante do rompimento no canal a jusante do reservatório. 
Mais recentemente, BEGNUDELLI e SANDERS (2007) aplicaram um modelo bidimensional baseado nos esquemas de volumes finitos "Gudonov-type" para simulação de rompimento da Barragem St. Francis no Sul da Califórnia. Para a simulação do escoamento no canal a jusante da barragem, os autores utilizaram as equações básicas do escoamento superficial (quantidade de movimento e conservação de massa). Também consideraram a hipótese estudada por Katopodes e Strelkoff (1978) de que a distribuição de pressões verticais é hidrostática.

WU e WANG (2007) desenvolveram um modelo unidimensional para simular o rompimento de barragens associado ao transporte de sedimentos no canal a jusante da barragem. O modelo adota as equações do escoamento superficial, que considera os efeitos do transporte de sedimento e mudanças no leito do canal. O modelo de transporte de sedimentos calcula a variação do transporte dos sedimentos em suspensão e de fundo, associado a um fator de correção que adapta as equações de Van Rijin.

O coeficiente de Manning, é um dos parâmetros que influenciam nas simulações. Este modelo foi testado em dois casos experimentais (Taipei e Bélgica) apresentando boa aderência.LEAL et al. (2006), estudaram a velocidade da propagação (celeridade) da onda de cheia efluente proveniente de um rompimento de barragem, através de um modelo numérico que considera diferentes condições iniciais de contorno do canal a jusante de uma barragem: canal cheio ou seco, fundo fixo ou móvel do canal (para cinco tipos de materiais) e canal com ou sem degraus no fundo. O modelo é baseado na aproximação das equações básicas do escoamento superficial juntamente com as equações do transporte de sedimento. Os resultados numéricos e analíticos obtidos através do modelo foram comparados com dados experimentais e mostraram que a celeridade da onda depende do coeficiente de atrito, da inércia do sedimento, da profundidade inicial a jusante e da altura inicial do degrau no fundo do canal. Para os canais onde o leito a jusante encontrava-se "seco", o coeficiente de atrito é o fator que indica a amplitude da celeridade da onda, já para os canais onde o leito encontravase "úmido", a celeridade da onda é drasticamente reduzida com o aumento da relação entre a profundidade inicial a montante e a jusante da barragem. A celeridade nos casos onde o fundo é fixo apresentou similaridade nos casos onde o fundo do leito é móvel. 
MOHAPATRA e CHAUNDHRY (2004) apresentaram um esquema numérico que estuda o efeito da pressão não hidrostática nos escoamentos de rompimentos de barragem. Os autores simularam esses efeitos por meio de soluções numéricas unidimensionais das equações de Boussinesq usando o esquema explícito das diferenças finitas de quarta ordem. Os autores compararam os resultados obtidos das equações de Saint Venant para determinar a contribuição individual dos termos das equações de Boussinesq nas simulações de rompimento de barragens e somente 0 primeiro termo da equação de Boussinesq afeta os resultados computacionais.

Em 2003, (ZOPPOU \& ROBERTS) apresentaram um trabalho que testou 20 esquemas numéricos explícitos para resolver equações em escoamento superficial. Os resultados para a maioria dos esquemas numéricos apresentaram-se razoáveis para escoamentos subcríticos. Onde há a transição entre o escoamento subcrítico e supercrítico, os modelos apresentaram performances mistas. Para esquemas numéricos de escoamento unidimensional, foram estudados esquemas das diferenças finitas, esquemas de primeira ordem, esquemas de segunda ordem acoplados a limites de fluxo, esquemas Gudunov-type, esquemas de quarta ordem adaptado das soluções de Riemann. Os autores concluem que com exceção dos esquemas de segunda ordem, para escoamentos subcríticos os esquemas de primeira ordem são os mais adequados, porém resultando em oscilações nos resultados. Desta forma, o esquema mais adequado a se empregar nos casos de simulações de rompimento de barragens seriam os de segunda ordem.

\subsection{Simulação da Cheia Efluente}

Dentro da engenharia hidráulica, a modelação matemática já comprovou ser indispensável nos campos específicos da hidráulica fluvial e drenagem urbana, principalmente quando o estudo das situações transitórias do escoamento é necessário. $O$ emprego dos modelos matemáticos associados a suportes informáticos, que facilitam a "entrada" e manipulação de extensas quantidades de dados, bem como a organização dos resultados de forma clara e concisa, sido feito em todo o mundo com o objetivo de verificação, projeto e manutenção de obras hidráulicas (Fadiga \& Martins, 1990). 
É possível representar-se o processo físico através de um modelo matemático, admitindo-se parâmetros que permitem a determinação numérica de uma grandeza representativa do fenômeno. As consagradas equações da hidráulica clássica, como as de Darcy ou Chèzy são exemplos característicos de ferramentas matemáticas utilizadas para simular um dado fenômeno.

Para simulação de rompimento de barragens podem-se citar inúmeros modelos clássicos de referência, como por exemplo, o modelo desenvolvido por FREAD (1998) e para a NWS, dentre outros. A Tabela 3.1 apresenta os modelos de simulação de rompimento existentes.

Tabela 3.1 Lista de modelos de rupturas. Adaptado de Collischonn (1997)

\begin{tabular}{ll}
\hline \multicolumn{1}{c}{ AGÊNCIA } & NOME DO MODELO \\
\hline USA/NATIONAL WEATHER SERVICE & \\
USA/NATIONAL WEATHER SERVICE & FLDWAV \\
USA/NATIONAL WEATHER SERVICE & DAMBREAK \\
BOSS & SMPBRK \\
HAESTED METHODS & BOSS DAMBRK \\
BINNIE \& PARTNERS & HAESTED DAMBRK \\
DEPARTAMENT OF WATER AFFAIRS AND FORESTY PRETORIA, & UKDAMBRK \\
SOUTH AFRICA & DWAF-DAMBRK \\
USA/COE HEC & MODELOS HEC \\
TAMS & LATIS \\
IPRHEH - CHINA & DKB1 \\
IPRHEH - CHINA & DKB2 \\
INSTITUTO DE TECNOLOGIA DE ESTOCOLMO & TVDDAM \\
CEMAGREF & RUBAR3 \\
CEMAGREF & RUBAR2O \\
CEMAGREF & CASTOR \\
DELFT HYDRALICS & WENDY \\
DELFT HYDRALICS & DELFLO/DELQUA \\
CONSULTING ENGENNERS REITER LTD. & DYX1O \\
ANU-REITER LTD. & DYNET-ANUFLOOD \\
ENEL CENTRO DI RICERCA IDRAULICA & RECAS \\
ENEL CENTRO DI RICERCA IDRAULICA & FLOOD2D \\
ENEL CENTRO DI RICERCA IDRAULICA & STREAM \\
INTITUTO DE HIDRAULICA DA DINAMARCA & MIKE11 \\
ETH ZURIQUE & FLORIS \\
INTITUTO DE HIDRAULICA DA DINAMARCA & MIKE21 \\
EDF - LABORATORIO NACIONAL DE HIDRAULICA - FRANÇA & RUPTURE \\
EDF - LABORATORIO NACIONAL DE HIDRAULICA - FRANÇA & TELEMAC \\
FUNDAÇÃO CENTRO TECNOLÓGICO DE HIDRÁULICA & CLIV PLUS \\
\hline
\end{tabular}


Dentre os modelos matemáticos disponíveis, podem ser citados, em nível internacional, o modelo FLDWAV, do NWS, o modelo DAMBRK, implementado pela Boss International com o titulo de Boss Dambrk e o modelo HEC-RAS, desenvolvido pelo Hydrological Engineering Center (HEC). No âmbito nacional aponta-se o modelo CLiv Plus (FCTH, 2001), desenvolvido pela Fundação Centro Tecnológico de Hidráulica (FCTH). Apresenta-se a seguir a descrição suscinta do primeiro e do último mencionados.

\subsubsection{O modelo NWS FLDWAV}

O modelo FLDWAV - Flood Wave Routing Model - foi desenvolvido pelo National Weather Service (NWS, 1977) para simulação do escoamento não permanente unidimensional. Corresponde a uma agregação dos modelos DWOPER - Dynamic Wave Operational Model, e DAMBRK - Dam-Break Flood Forecasting Model, ambos também desenvolvidos pelo NWS. O modelo FLDWAV tem sido desenvolvido e testado desde meados dos anos 80 . O modelo combina as ferramentas disponíveis nos modelos DWOPER e DAMBRK e fornece recursos adicionais que aumentam sua robustez. O escoamento pode englobar um único curso d'água ou um sistema de cursos d'água intercomunicados, e pode variar ao longo do tempo e do espaço de subcrítico para supercrítico e de livre para forçado, ou vice versa. O fluido pode obedecer aos princípios de fluidos Newtonianos (água) ou não-Newtonianos (barro, por exemplo). É possível simular a ruptura de barragens e a operação de estruturas de controle (vertedores e comportas) sob condições de contorno internas particulares como a existência de pontes e reservatórios.

O FLDWAV emprega um esquema implícito de diferenças finitas de quatro pontos para a solução das equações de Saint-Venant. Neste esquema, os termos diferenciais das equações da continuidade e da quantidade de movimento são transformados em diferenças finitas, e o problema se resume à solução de um sistema de equações algébricas, sob as condições iniciais e de contorno previamente conhecidas.

Embora este esquema apresente resultados satisfatórios na maior parte das aplicações, ele se mostra pouco adequado à modelação de escoamentos mistos, muito freqüentes em problemas de dam-break (ou seja, escoamentos em que há a variação do regime subcrítico para o supercrítico, ou vice versa, ao longo do tempo 
e/ou do espaço), apresentando baixa estabilidade numérica durante as transições de regime. Desta forma, foram incorporadas ao modelo três técnicas de solução das equações de Saint-Venant para as situações em que o regime misto deve ser modelado.

A primeira técnica, denominada LPI - Local Partial Inertial - baseia-se no Modelo de Analogia de Difusão, que simplifica as equações de Saint-Venant ao desprezar as parcelas inerciais na equação da quantidade de movimento. Esta técnica surgiu da observação de que, nas situações em que há mudança de regime (subcrítico/supercrítico), o esquema implícito de quatro pontos tende a ser numericamente mais estável quando se adota o modelo de analogia de difusão do que quando se adota o modelo completo de onda dinâmica. Desta forma, no método LPI, a equação da quantidade de movimento é modificada por um filtro numérico, de forma que as parcelas inerciais são parcialmente ou totalmente omitidas de acordo com as condições do regime existente. Nos trechos do canal em que o escoamento é subcrítico, o escoamento é modelado considerando-se os termos inerciais de forma completa (o que corresponde ao modelo de onda dinâmica); nas proximidades do regime crítico, os efeitos inerciais são apenas parcialmente considerados, e nos trechos de escoamento supercrítico nenhum efeito inercial é considerado (correspondendo ao modelo de analogia de difusão).

A segunda técnica consiste em um algoritmo que subdivide automaticamente o canal em sub-trechos onde o escoamento é subcrítico e onde o escoamento é supercrítico, com base no número de Froude. As seções transversais com número de Froude inferior a 0.95 são classificadas como subcríticas, e aquelas com número de Froude superior a 1.05 são classificadas como supercríticas. As seções em que o número de Froude varia entre 0.95 e 1.05 são consideradas seções críticas, e correspondem a pontos de transição entre os regimes subcrítico e supercrítico. Estes pontos são, então, tratados como condições de contorno do problema, o que evita a aplicação das equações de Saint-Venant nas vizinhanças do regime crítico. A utilização deste algoritmo aumenta o tempo de processamento computacional em cerca de $20 \%$.

A terceira e última técnica corresponde a um esquema de solução misto que associa o esquema implícito de diferenças finitas de quatro pontos com um esquema de solução explícito baseado no método das características. Este método envolve a identificação dos pontos ao longo do canal onde ocorre o regime crítico (pontos de 
controle). O escoamento supercrítico é solucionado no sentido de montante para jusante, enquanto que o escoamento subcrítico é solucionado em sentido duplo (primeiramente de montante para jusante, e em seguida de jusante para montante).

A estabilidade numérica dos métodos explícitos está condicionada à utilização de intervalos de tempo de cálculo suficientemente pequenos que garantam a obediência às condições de Courant-Friedrichs-Lewys. Isto exige, muitas vezes, um tempo de processamento computacional elevado quando comparado ao tempo exigido pelos métodos implícitos, em que a estabilidade numérica é mais facilmente atingida. Desta forma, no algoritmo misto, o esquema explícito é empregado somente nos trechos em que o escoamento se aproxima da condição crítica, garantindo uma boa estabilidade numérica; nos demais trechos, é utilizado o método implícito (que suporta intervalos de tempo de cálculo maiores), visando à minimização do tempo de processamento.

Em algumas aplicações, o modelo FLDWAV está sujeito a limitações que podem se originar tanto das próprias equações que regem o fenômeno do escoamento não permanente como de incertezas associadas a alguns parâmetros utilizados pelo modelo.

O equacionamento matemático utilizado no FLDWAV é baseado na solução das equações de Saint-Venant para escoamentos unidimensionais em fundo fixo, não considerando os efeitos do transporte de sedimentos e a dinâmica de conformação do leito em fundos móveis, o que significa ignorar os efeitos da movimentação do leito sobre as características hidro-geométricas do escoamento, como a resistência ao escoamento e a geometria das seções transversais.

A rugosidade de Manning é um parâmetro a ser considerado nas resoluções de problemas de rompimento de barragens, uma vez que a grande magnitude da onda cheia tende a causar inundações em áreas geralmente secas, exigindo a adoção de um Coeficiente de Manning impossível de ser calibrado e sem relação direta com a realidade. Quando a faixa de variação do coeficiente de Manning é consideravelmente larga, deve-se tratar o canal de forma a separar o trecho de escoamento principal da planície de inundação, levando-se em conta a velocidade do escoamento. De acordo com este conceito (CERMINARO, MARTINS, RAMOS, \& PINTO, 2008), o canal principal transporta uma parcela elevada da descarga (acima de 95\%), ficando o restante a cargo dos efeitos da planície de inundação. Tal artifício permite a calibração do modelo dentro de valores aceitáveis para o coeficiente de rugosidade. 
Há também incertezas associadas a outros parâmetros do modelo, como aqueles que representam à forma de ruptura das barragens ou o volume armazenado nas planícies laterais de inundação, que também devem ser muito bem avaliadas, sempre que possível via análises de sensibilidade.

\subsubsection{O modelo Cliv Plus}

O modelo CLiv Plus, desenvolvido no Laboratório de Hidráulica da Escola Politécnica - CTH (FCTH, 2001) deriva do aperfeiçoamento da tecnologia de simulação e análise de propagação de ondas de enchentes em canais já consagrada desde os anos 1990 com o Modelo CLiv. Para incorporar os efeitos provocados por rompimento de barragens, foram introduzidas as equações desenvolvidas por Fread \& Lewis (1998) e o acoplamento de condições de contorno tipo 'reservatório' para as extremidades de montante e jusante, de forma a permitir também a simulação de cadeias de barragens.

No modelo Cliv Plus, o tratamento genérico do escoamento em canais é baseado na utilização das equações básicas de Saint-Venant, as quais se derivam da aplicação das equações de Navier-Stokes reduzidas a uma dimensão, combinando os princípios da conservação da massa e da quantidade de movimento. O esquema numérico de solução deriva do proposto por Preissmann (apud Tucci, 1981), com fator de ponderação espacial igual a 0,5 e fator temporal variável entre 0,5 e 1,0.

De forma similar ao descrito no modelo FLDWAV, as equações são linearizadas através por meio de um esquema de diferenças finitas de quatro pontos, resultando num sistema de equações algébricas resolvidos através em etapas denominadas 'varreduras'. As condições de contorno disponíveis permitem a consideração de elementos nas extremidades de montante e jusante dos canais, como barragens e estruturas de controle, entradas e saídas de vazões além de situações nas seções intermediárias, como estruturas de controle de nível e comportas.

O modelo apresenta ainda a possibilidade de geração de uma representação digital de terreno, em função de um MDT (Digital Terrain Modeling - DTM), que consiste na geração de uma grade ou malha de pontos igualmente espaçados a partir das coordenadas $(x, y, z)$ de pontos conhecidos, adquiridos segundo uma distribuição irregular no plano xy - por exemplo, pontos obtidos em levantamentos topográficos. 
Com relação à aplicação do modelo na simulação de cenários de ruptura, algumas observações são pertinentes. Inicialmente, observa-se que a acuracidade com que os cenários de dam-break podem ser modelados é consideravelmente menor que a obtida na modelação dos cenários tradicionais de escoamento em rios e canais. No primeiro caso, as condições do escoamento são muito mais complexas e os dados disponíveis para validação dos resultados são escassos. Há, ainda, incertezas relativas aos mecanismos de ruptura e formação de brechas e à modelação da propagação de ondas de grande magnitude - sobretudo em sua interação com a topografia do vale e com a infra-estrutura existente, como pontes, rodovias e áreas urbanas - que não devem ser desprezadas. Em função destas incertezas, destaca-se a necessidade de se dar maior atenção às características globais da topografia do vale, as quais realmente influenciam na propagação da onda de dam-break. Pequenos detalhes da topografia serão submersos imediatamente à passagem da onda, não apresentando influência sobre o resultado final e tornam-se irrelevantes enquanto as planícies de armazenamento lateral mostram ter grande efeito no amortecimento da onda e nos níveis d'água resultantes.

\subsubsection{Formulação Matemática do CLiv Plus}

O modelo CLiv Plus contempla uma série de características de modo a permitir a adequada manipulação dos dados de entrada, a simulação dos eventos de acordo com a formulação apresentada e a correta interpretação e análise dos resultados obtidos.

Nos trechos correspondentes aos reservatórios componentes do sistema, utiliza-se um modelo de balanço de massas (routing) de modo a considerar a variação do nível d’água no reservatório.

O escoamento nas soleiras vertentes, por sua vez, é simulado de acordo com uma lei de operação específica, ou mesmo uma lei que dependa do cenário de rompimento, onde as variações de vazão e nível decorrem da hipótese da ruptura.

Nos trechos intermediários onde o escoamento se dá através da calha principal, utiliza-se um modelo de propagação de ondas, podendo-se utilizar uma formulação hidrodinâmica ou ainda uma simplificação, como a pura translação do hidrograma, dependendo do objeto da simulação. 
O modelo, seguindo estes critérios permite que cada uma das metodologias a serem empregadas possa ser vinculada diretamente ao problema em questão. Seguindo este conceito de encapsulamento, pode-se modificar ou mesmo substituir uma determinada metodologia por outra, garantindo que seja possível contar com o melhor conjunto de ferramentas de acordo com o cenário a ser estudado.

O modelo considera como parâmetros de entrada no caso de uma simulação de uma onda de cheia no reservatório, dados relativos ao hidrograma de cheia, ao reservatório e às restrições de montante e jusante.

O hidrograma de cheia afluente ao reservatório poderá ser aquele definido a partir de estudos de cheias na bacia hidrográfica, ou ainda um hidrograma já observado (em análise pós-operação) ou um hidrograma previsto, no caso de operação em tempo real.

Os dados relativos ao reservatório resumem-se, basicamente, ao conhecimento da curva cota x volume, das equações de descarga dos órgãos extravasores da barragem, das leis de operação hidráulica estabelecidas e das condições iniciais de operação (nível e vazão defluente no instante de início da simulação).

A curva cota $x$ volume consiste na relação entre o nível d'água do reservatório e o volume a ele correspondente. A capacidade de um reservatório construído em terreno natural é determinada por integração da curva cota $x$ área, esta última obtida através de levantamentos topográficos, por planimetria das áreas entre as curvas de nível levantadas topograficamente.

As restrições externas à área da barragem são entendidas como a capacidade máxima do canal de jusante e o nível d'água máximo a montante, limitado pela cota da crista do barramento ou pela área inundável máxima desejada. Das restrições assim estabelecidas resultam as leis de operação hidráulica do reservatório, que definem a defluência necessária em um dado período de tempo, em função do nível d'água de montante e da vazão afluente, por exemplo.

\subsubsection{Algoritmo de Solução do CLiv Plus}

O problema do routing em reservatórios consiste na resolução da equação da continuidade. Reordenando-se os termos da Equação3.4, obtém-se: 


$$
Q_{E 1}+Q_{E 2}+\frac{V_{1}}{\Delta t / 2}-Q_{S 1}=Q_{S 2}+\frac{V_{2}}{\Delta t / 2}
$$

$\mathrm{Na}$ equação anterior, são conhecidos os termos $\Delta$ t (intervalo de tempo considerado para os cálculos), $Q_{E 1}, Q_{E 2}$ (vazões afluentes no início e no fim do intervalo considerado, respectivamente), $Q_{S 1}$ e $V_{1}$ (vazão efluente e volume armazenado no início do intervalo considerado, respectivamente).

As incógnitas $Q_{\mathrm{S} 2}$ e $V_{2}$ (vazão efluente e volume armazenado no fim do intervalo considerado, respectivamente) podem ser expressas em função do nível d'água final do reservatório $N A_{2}$. $O$ volume $V_{2}$ relaciona-se diretamente com o nível do reservatório $\mathrm{NA}_{2}$ através da curva cota $x$ volume conhecida. A vazão efluente $Q_{\mathrm{S} 2}$, por sua vez, resulta em geral de uma composição de parcelas (a vazão descarregada pelos descarregadores de fundo, a vazão vertida pelos extravasores de superfície, a vazão turbinada, e, nos casos de simulação de ruptura de barragens, a vazão efluente pela brecha formada na ruptura), sendo todas função do nível do reservatório.

Desta forma, a Equação 3.5 pode ser representada por:

$Q_{E 1}+Q_{E 2}+\frac{V_{1}}{\Delta t / 2}-Q_{S 1}=Q_{S 2}+\frac{V_{2}}{\Delta t / 2}=\phi\left(N A_{2}\right)$

Equação 3.6

Portanto, sendo construída previamente a curva $\left(\phi=Q_{S}+\frac{V}{\Delta t / 2}\right) \times(\mathrm{NA})$, a simples interpolação do primeiro termo da equação anterior nesta curva resulta no nível d'água final do reservatório $\mathrm{NA}_{2}$, a partir do qual são calculadas as incógnitas desejadas $Q_{\mathrm{S} 2}$ e $V_{2}$.

No modelo de simulação, o tratamento genérico do escoamento em canais baseia-se na utilização das Equações Básicas de Saint-Venant, as quais derivam-se da aplicação das equações de Navier-Stokes reduzidas à uma dimensão, combinando os princípios da conservação da massa e da quantidade de movimento.

Tais equações foram apresentadas no final do século XIX como insolúveis analiticamente e desde então inúmeros modelos matemáticos têm sido propostos para torná-las integráveis e, portanto, passíveis de serem aplicadas aos casos práticos. Estas equações, já comentadas anteriormente, são detalhadas a seguir: 
Conservação da Massa: $\frac{\partial Q}{\partial x}+B \frac{\partial y}{\partial t}=q_{L}$

Equação 3.7

Quantidade de Movimento:

Equação 3.8

Tais equações consideram o caso mais amplo onde todos os parâmetros hidráulicos variam no tempo.

A primeira equação representa simplesmente o balanço de massa sobre um volume de controle, e a segunda o balanço das forças externas sobre o volume de controle, por unidade de peso. As grandezas envolvidas representam:

$x \rightarrow$ Coordenada longitudinal

$\mathrm{t} \rightarrow$ Tempo

Q $\rightarrow$ Vazão líquida

y $\rightarrow$ Cota do nível d'água

$\mathrm{p} \rightarrow$ Perímetro molhado

A $\rightarrow$ Área molhada

$B \rightarrow$ Largura à superfície livre

$\beta \rightarrow$ Coeficiente de Quantidade de Movimento

$\mathrm{q}_{\mathrm{L}} \rightarrow$ Vazão líquida de contribuição lateral específica

$\mathrm{S}_{\mathrm{f}} \rightarrow$ Inclinação da linha de energia

$\checkmark \rightarrow$ Velocidade da contribuição lateral líquida

$\gamma \rightarrow$ Ângulo da contribuição lateral com o eixo do canal

O parâmetro $S_{f}$ representa as perdas de carga, usualmente calculadas pela equação de Chézy, da forma:

$$
S_{f}=Q|Q| K^{-2}
$$

onde 


$$
K=\mathrm{CA} \sqrt{\mathrm{R}_{\mathrm{h}}}
$$

A Equação 3.8 pode ser rescrita da forma:

$$
\begin{array}{r}
\frac{\partial Q}{\partial t}+\frac{Q^{2}}{A} \frac{\partial \beta}{\partial x}+2 \beta \frac{Q}{A} \frac{\partial Q}{\partial x}+g A\left(1-\beta F_{r}^{2}\right) \frac{\partial y}{\partial x}+ \\
-\beta \frac{Q^{2}}{A^{2}} \frac{\partial A}{\partial x}{ }_{\mid y=\text { const }}+g A S_{f}=q v \cos \gamma
\end{array}
$$

onde

$F_{r}{ }^{2}=Q^{2} B / g A^{3}$

Equação 3.12

é o quadrado do número de Froude do escoamento.

O escoamento permanente nos canais naturais tem como objetivo a análise do funcionamento dos mesmos nas condições onde as grandezas hidráulicas variam ao longo do espaço em função de um dado conjunto de dados de geometria e condições de extremidade.

Pode-se observar que a Equação 3.11 quando simplificada com as hipóteses de regime permanente e sem contribuições laterais com quantidade de movimento, permite o cálculo genérico do escoamento permanente:

$$
\begin{aligned}
& \frac{\partial Q}{\partial t}+\frac{Q^{2}}{A} \frac{\partial \beta}{\partial x}+2 \beta \frac{Q}{A} \frac{\partial Q}{\partial x}+g A\left(1-\beta F_{r}^{2}\right) \frac{\partial y}{\partial x}- \\
& \begin{array}{ccc}
\downarrow & \downarrow & \downarrow \\
0 & 0 & \downarrow \\
& & \downarrow
\end{array} \\
& -\beta \frac{Q^{2}}{A^{2}} \frac{\partial A}{\partial x}{ }_{\mid y=\text { const }}+g A \quad S_{f}=q v \quad \cos \gamma \\
& \begin{array}{ccc}
\downarrow & \downarrow & \downarrow \\
0 & j & 0
\end{array}
\end{aligned}
$$


da qual resulta:

$$
2 \beta \frac{Q}{A} q+g A\left(1-\beta F_{r}^{2}\right) \frac{\partial y}{\partial x}+g A S_{f}=0
$$

A discretização do rio ou canal para o cálculo do regime permanente ou variado é sempre feita através de seções transversais típicas. A escolha do número de seções deve atender ao critério de se representar o mais fielmente possível as variações do conduto, tanto em planta como em perfil. Uma maior acuracidade, para fins de estabilidade numérica pode ser obtida posteriormente com critérios de interpolação a cargo do próprio software de cálculo.

A escolha de um número pequeno de seções pode levar a erros físicos muito grandes e, por outro lado, um número muito elevado de seções provoca grande quantidade de cálculos, aumentando a propagação de erros numéricos. Vários autores têm citado que o espaçamento ideal de seções deve ser entre 10 e 20 vezes a largura da seção à superfície. Trechos sinuosos ou com grandes variações de fundo devem ser representados por seções menos espaçadas, que traduzam as influências dos alargamentos e estreitamentos bruscos, soleiras de fundo e outros controles.

As seções transversais dos canais naturais devem ter seus parâmetros bem avaliados, para cada cota assumida pelo nível d'água. Representando-se as seções através de pontos cartesianos, os parâmetros de interesse podem ser calculados através da subdivisão em lamelas verticais, como indica a figura a seguir:

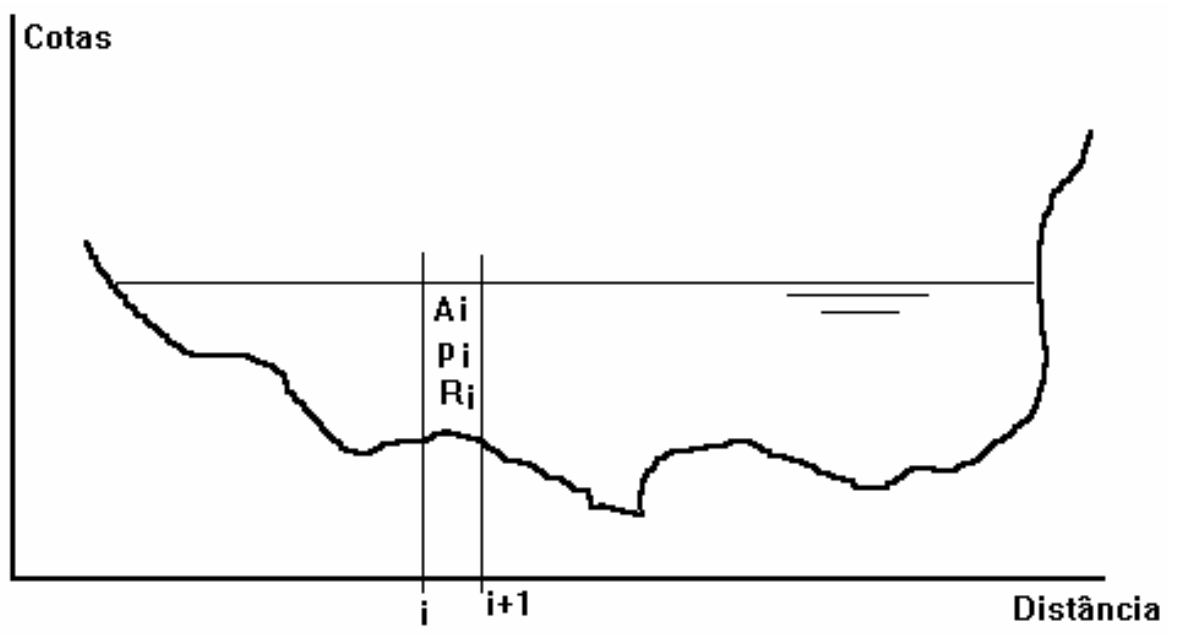


FIGURA 3.9: Subdivisão da seção transversal em lamelas verticais.

As características hidrogeométricas são obtidas pelas seguintes expressões:

a) Área Molhada

$A=\sum_{i+1}^{n} A_{i}$

Equação 3.14

b) Perímetro Molhado

$p=\sum_{i+1}^{n} p_{i}$

Equação 3.15

c) Raio Hidráulico Composto

$Q=\sum Q_{i}=\frac{1}{n} A R_{h}^{2 / 3} S_{f}^{1 / 2}=\frac{1}{n} \sum A_{i} R_{h_{i}}^{2 / 3} S_{f}^{1 / 2}$

Equação 3.16

$R_{h}=\left[\frac{\sum A_{i} R_{h_{i}}^{2 / 3}}{A}\right]^{3 / 2}$

d) Raio Hidráulico de Engelund

$Q=\sum Q_{i}=C_{i} A_{i} R_{h}^{1 / 2} S_{f}^{1 / 2}=C A R_{E}^{1 / 2} S_{f}^{1 / 2}$

Equação 3.17

$R_{E}=\left[\frac{\sum C_{i} A_{i} R_{h_{i}}^{1 / 2}}{C A}\right]^{2}$

No CLiv Plus, a modelagem digital de terrenos - MDT (Digital Terrain Modeling - DTM) consiste na geração de uma grade ou malha de pontos igualmente espaçados a partir das coordenadas $(x, y, z)$ de pontos conhecidos, adquiridos segundo uma distribuição irregular no plano xy - por exemplo, pontos obtidos em levantamentos topográficos.

Uma vez definido o espaçamento da malha nas direções $x$ e y, as técnicas de MDT permitem representar as características espaciais do terreno de maneira bastante fiel, modelando a cota $z$ de cada ponto pertencente à malha a partir de suas coordenadas $(x, y)$ e das coordenadas $(x, y, z)$ dos pontos amostrados. 
O espaçamento da grade, ou seja, a resolução da malha nas direções x e y, deve ser idealmente menor ou igual à menor distância entre duas amostras com cotas diferentes. Ao se gerar uma malha muito densa, ou seja, com espaçamentos muito pequenos, existirá um maior número de informações sobre a superfície modelada, porém será necessário maior tempo de processamento para sua geração. Por outro lado, considerando espaçamentos muito grandes, será criada uma malha grosseira, podendo acarretar perda de informações ou baixo nível de detalhamento da superfície obtida. Desta forma, para a resolução final da grade, deve haver uma compatibilidade entre a precisão dos dados e o tempo de geração necessário.

Os modelos digitais de terrenos podem se basear em uma série de métodos de interpolação para calcular o valor aproximado da cota dos pontos de interesse. Dentre eles, destaca-se o método dos oito vizinhos mais próximos com média ponderada por cota e por quadrante. Neste método, o valor da cota de um ponto qualquer da malha de coordenadas $(\mathrm{xc}, \mathrm{yc})$ é calculado a partir da média ponderada das cotas dos oito vizinhos mais próximos a este ponto, tomados dois a dois em cada um dos quatro quadrantes que circundam o ponto, conforme ilustrado a seguir.

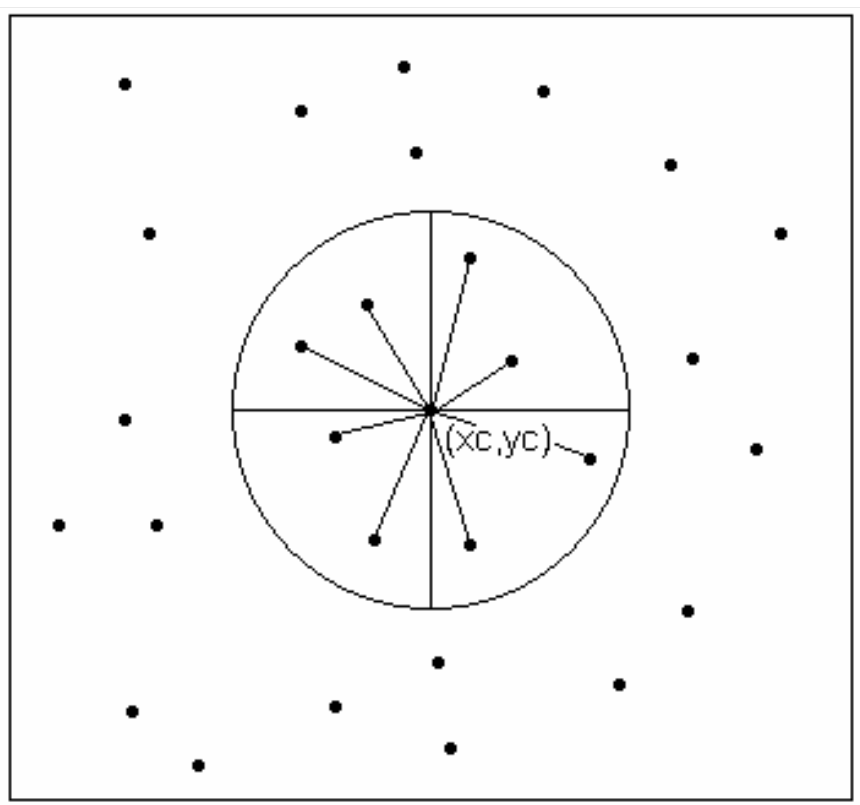

FIGURA 3.10: Interpolação de superfícies topográficas pelo método dos oito vizinhos mais próximos tomados dois a dois em cada quadrante. 
São atribuídos pesos variados para cada vizinho, através de uma função de ponderação que considera a distância entre o ponto cotado ("vizinho") e o ponto da grade. Desta forma, sendo:

- $\mathrm{z}_{\mathrm{i}}=$ cota do vizinho i de coordenadas $\left(\mathrm{x}_{\mathrm{i}}, \mathrm{y}_{\mathrm{i}}\right)$

- $\mathrm{d}_{\mathrm{i}}=\sqrt{\left(\mathrm{x}_{\mathrm{i}}-\mathrm{x}_{\mathrm{c}}\right)^{2}+\left(\mathrm{y}_{\mathrm{i}}-\mathrm{y}_{\mathrm{c}}\right)^{2}}=$ distância entre o ponto interpolado $\left(\mathrm{x}_{\mathrm{c}}, \mathrm{y}_{\mathrm{c}}\right)$ e o vizinho $\mathrm{i}$

- $\mathrm{f}_{\mathrm{i}}\left(\mathrm{x}_{\mathrm{i}}, \mathrm{y}_{\mathrm{i}}\right)=\left(\frac{1}{\mathrm{~d}_{\mathrm{i}}}\right)^{2}=$ função de ponderação atribuída ao vizinho $\mathrm{i}$

A cota do ponto interpolado $(\mathrm{xc}, \mathrm{yc})$ é dada por:

$$
z\left(x_{c}, y_{c}\right)=\frac{\sum_{i=1}^{8}\left(f_{i} \times z_{i}\right)}{\sum_{i=1}^{8}\left(f_{i}\right)}
$$

Em algumas aplicações, o modelo CLiv Plus está sujeito a limitações que podem se originar tanto das próprias equações que regem o fenômeno do escoamento não permanente como de incertezas associadas a alguns parâmetros utilizados pelo modelo.

O modelo matemático é baseado fundamentalmente na solução das equações de Saint-Venant para escoamentos unidimensionais em fundo fixo. Entretanto, há circunstâncias em que o escoamento aproxima-se mais da situação bidimensional, ou seja, em que a velocidade do fluxo e os níveis d'água variam não apenas na direção longitudinal, mas também na direção transversal ao curso d'água. Nestas situações, desprezar-se a natureza bidimensional do fluxo pode incorrer em erros de vulto significativo. Além disso, as equações de Saint-Venant não consideram os efeitos do transporte de sedimentos e a dinâmica de conformação do leito em fundos móveis, o que significa ignorar os efeitos da movimentação do leito sobre as características 
hidro-geométricas do escoamento, como a resistência ao escoamento e a geometria das seções transversais.

Tais limitações devem ser levadas em consideração quando da aplicação do modelo, que deve ser feita mantendo-se os parâmetros de cálculo dentro da faixa de validade de aplicação das equações.

Com relação à aplicação do modelo na simulação de cenários dam-break, algumas observações são pertinentes. Inicialmente, observa-se que a acuracidade com que os cenários de dam-break podem ser modelados é consideravelmente menor que a obtida na modelação dos cenários tradicionais de escoamento em rios e canais. No primeiro caso, as condições do escoamento são muito mais complexas e os dados disponíveis para validação dos resultados são escassos. Há, ainda, incertezas relativas aos mecanismos de ruptura e formação de brechas e à modelação da propagação de ondas de grande magnitude - sobretudo em sua interação com a topografia do vale e com a infra-estrutura existente, como pontes, rodovias e áreas urbanas - que não devem ser desprezadas.

Em função destas incertezas mencionadas, destaca-se a necessidade de se dar maior atenção às características globais da topografia do vale, as quais realmente influenciam na propagação da onda de dam-break. Pequenos detalhes da topografia serão submersos imediatamente à passagem da onda, não apresentando influência sobre o resultado final e tornando-se, assim, irrelevantes. Por outro lado, as planícies de armazenamento lateral mostram ter grande efeito no amortecimento da onda e nos níveis d’água resultantes.

Desta forma, as incertezas associadas aos parâmetros do modelo - como aqueles que representam a forma de ruptura das barragens ou o volume armazenado nas planícies laterais de inundação - devem ser sempre consideradas quando de sua aplicação em simulações de dam-break.

\subsection{Gestão de Impactos}

Os impactos causados pelo rompimento de estruturas hidráulicas de barramento podem ser classificados de acordo com diferentes critérios, destacando-se aqueles que consideram os efeitos da perda do barramento e das estruturas em si, os 
impactos causados pela cheia efluente e aqueles indiretos, causados pelos desdobramentos dos dois primeiros.

No primeiro caso, citam-se os danos gerados pela perda do volume reservado, a interrupção do atendimento proporcionado pela barragem, prejuízos com a falta de energia, desabastecimento de água e etc. No segundo caso, são computados os danos gerados pela cheia efluente, como a destruição de pontes e estradas, interrupções diversas, a inundação de áreas urbanas e rurais com a conseqüente destruição de propriedades e outros bens, perdas de vida diretamente e função das cheias, etc. Por fim, os impactos indiretos são aqueles originados pelos desdobramentos dos anteriores, como doenças de veiculação hídrica, desabastecimento de gêneros de primeira necessidade tais como alimentos e remédios na região atingida, perda do valor das propriedades e fazendas, interrupção de acessos como estradas, ferrovias e hidrovias e etc.

Assim, considerando a possibilidade de ocorrência de rupturas em barramentos, fazse necessário um planejamento antecipado, integrado à finalidade e características da estrutura e ao ambiente, com o objetivo de se minimizar as probabilidades de ocorrência e os danos provocados pelas falhas (ELETROBRÁS, 1999). Este planejamento insere-se portanto no que se denomina 'Gestão de Emergência'.

O CBDB (2001) prescreve que, caso a ruptura seja inevitável, torna-se fundamental a existência de um plano de emergência que tenha como objetivo principal preservar as pessoas residentes a jusante, sendo importante, para tanto, o conhecimento da conseqüência da ruptura. Esta pode ser classificada conforme critérios apresentados no quadro a seguir (ELETROBRÁS, 2003)

Tabela 3.2: Classificação dos critérios e conseqüências da ELETROBRÁS (ELETROBRÁS, 2003).

\begin{tabular}{ccc}
\hline $\begin{array}{c}\text { Conseqüência de } \\
\text { ruptura }\end{array}$ & Perda de vidas & Econômico, social e danos ambientais \\
\hline Muito alta & Significativa & Dano Excessivo \\
Alta & Alguma & Dano Substancial \\
Baixa & Nenhuma & Dano Moderado \\
Muito baixa & Nenhuma & Dano Mínimo \\
\hline
\end{tabular}

A gestão da emergência deve englobar aspectos que procurem antes de mais nada evitar ou reduzir o risco de ruptura de estruturas já implantadas, incluindo as 
chamadas medidas preventivas, como as inspeções das estruturas e dos equipamentos, a instrumentação da barragem, treinamento da operação e realização das manutenções preventivas e corretivas. São ações que visam eliminar ou reduzir a probabilidade de ocorrência de falhas e desastres.

Considerando fatores como o porte da barragem, sua idade e histórico de inspeções e manutenções, condições geológicas e hidrológicas locais e a evolução observada da bacia a montante e a jusante, a gestão de eventuais emergências exige a elaboração de planos de ações emergenciais, fundamentados antes de tudo, na avaliação preliminar dos impactos potenciais. Nos planos de ações emergenciais são organizadas as estruturas para comando, comunicações, salvamento, normalização e reparação de danos.

\subsection{Planos de Ações Emergenciais - PAE}

O Plano de Ação Emergencial - PAE tem como finalidade descrever procedimentos necessários à atuação em situações de emergência. As premissas para a elaboração dos planos de ações são: adaptado de (ELETROBRÁS, 2003) e (FEMA, 2004):

- Quantificação dos riscos naturais, tais como os hidrológicos, geotécnicos, sísmicos e etc.;

- $\quad$ Avaliação dos riscos extraordinários como guerra, atentados e etc.;

- Identificação e avaliação de impactos diretos e indiretos, estabelecimento dos mapas de inundações;

- $\quad$ Estabelecimento de ações preventivas como sistema de informações, monitoramento da bacia, dos agentes naturais, monitoramento estrutural, vigilância e segurança;

- $\quad$ Estabelecimento de modelos de previsão e identificação de eventos críticos;

- Rotinas de treinamento e simulação de ações emergenciais como evacuação, interrupção de estradas, paralisação no abastecimento de energia e água;

- Elaboração dos fluxogramas de notificações e do sistema de comunicações de emergência; 
- $\quad$ Dimensionamento de equipamentos e mão de obra necessários;

- $\quad$ Dimensionamento dos estoques de suprimentos, fontes de energia de emergência;

Em função das possíveis alterações, tanto sob o aspecto dos riscos como dos impactos potenciais, estes planos devem ser periodicamente atualizados e revisados.

O PAE, segundo o Projeto de Lei $n^{\circ} 1181$, de 2003, é um documento que deve estabelecer ações a serem tomadas pelo empreendedor da barragem em caso de situação de emergência, bem como identificar os agentes a serem notificados a uma ocorrência extrema. Um PAE deve conter pelo menos:

- $\quad$ Conjectura e análise das possíveis situações de emergência;

- Procedimentos para identificação e notificação de mau funcionamento ou ruptura da barragem;

- $\quad$ Procedimentos preventivos e corretivos a serem adotados, com indicação clara do responsável por cada ação, bem como obter materiais e recursos para as situações de emergências.

- $\quad$ Sistemas de alerta e mapas de inundação com indicação do alcance das ondas de cheia e respectivos tempos de chegada;

De acordo com MENESCAL e MIRANDA (1997), o desenvolvimento do modelo do Plano de Ação Emergencial baseou-se nas diretrizes estabelecidas pela Federal Emergency Managment Agency - FEMA (1987), Eletrobrás (1987), Gehring (1987) e USBR (1995), sendo dividido nas seções apresentadas a seguir:

- $\quad$ Atribuição de responsabilidades - uma lista que indica quem é o responsável pela tomada de ações especificas, para cada situação emergencial na barragem;

- Mapas de Inundação - indicando as áreas e construções que poderão ser afetadas por ondas de cheias causadas por um rompimento de uma barragem;

- $\quad$ Tipos de Ruptura - são definidos os tipos de ruptura a serem considerados na elaboração de um PAE (ruptura em progressão, ruptura iminente e ruptura em desenvolvimento lento);

- $\quad$ Situações de Emergência - para cada uma das situações de emergências estabelecidas pelo PAE proposto, deve-se seguir uma seqüência 
de etapas na tentativa de estabilizar a situação bem como os procedimentos a serem seguidos ao termino da situação emergencial. São considerados eventos que podem contribuir diretamente para a ruptura de uma barragem: abalos sísmicos, enchentes, erosão, abatimento, encharcamento e trincamento, infiltrações, deslizamentos a montante, entre outros.

Os autores ainda destacam que um PAE deve conter:

- Indicações de ações preventivas que podem ser tomadas a fim de prevenir ou retardar a ruptura de uma barragem;

- Recursos e suprimentos de emergência - uma relação de possíveis fornecedores de equipamentos e suprimentos (sacos de areia, equipamentos de terraplenagem, trabalhadores, etc.), com o nome da pessoa de contato e o número de telefone;

- $\quad$ Aprovação, distribuição e atualização do PAE;

- $\quad$ Lista de notificação - contendo os contatos dos órgãos responsáveis no caso de ocorrência de uma emergência.

A Federal Energy Regulatory Commission - FERC (1998) estabeleceu uma norma para elaboração de Planos de Ação Emergencial. Criada em 1979 e atualizada em 1988, esta norma estabelece que o PAE deve seguir sempre um mesmo formato para facilitar a elaboração, o manuseio e a revisão anual do documento.

Segundo esta norma, um PAE deve conter:

$\begin{array}{ll}\text { - } & \text { Fluxograma de notificação } \\ \text { - } & \text { Situação: ruptura iminente ou passada; } \\ \text { - } & \text { Situação: potencial ocorrência de situação de perigo. } \\ \text { - } & \text { Principais responsabilidades do PAE } \\ \text { - } & \text { Atividades de controle } \\ \text { - } & \text { Regras para a fiscalização dos empreendimentos; } \\ \text { - } & \text { Alertas de perigo; } \\ \text { - } & \text { Avisos quanto à mudança climática; } \\ \text { - } & \text { Disponibilidade no uso de sistema de comunicações; } \\ \text { - } & \text { Recursos e suprimentos de emergência; }\end{array}$




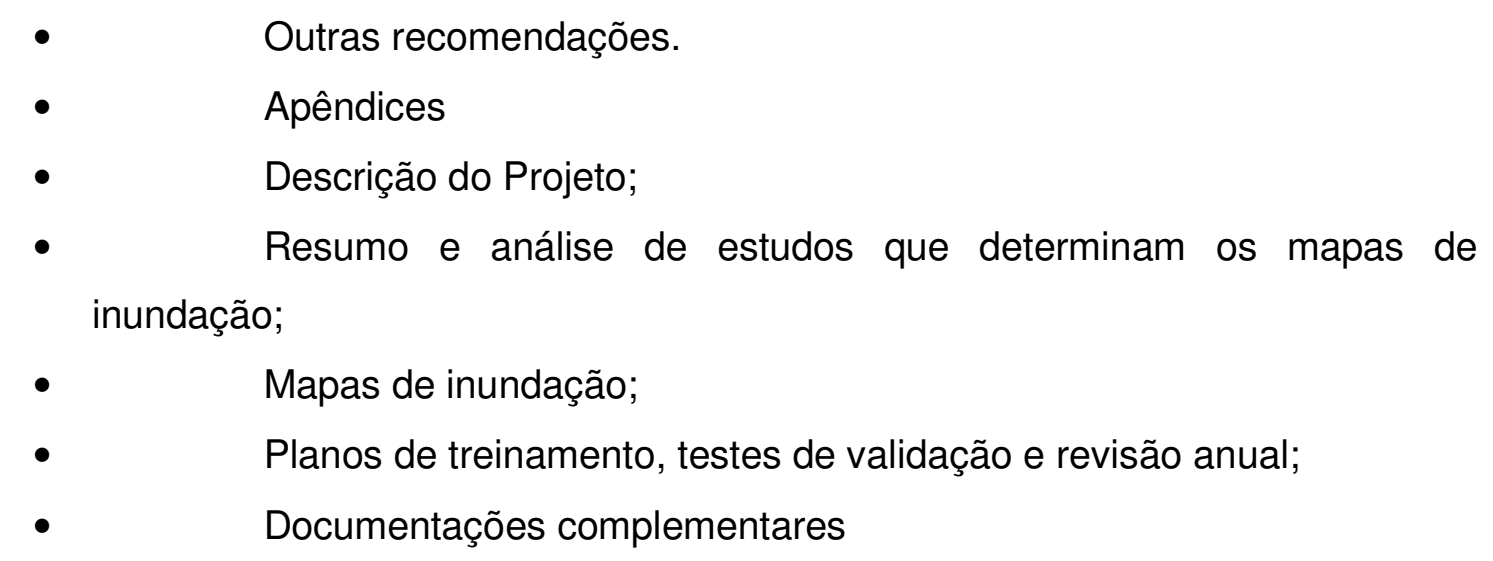

A necessidade de elaboração de um Plano de Ações Emergenciais deve ser específica para cada barragem, a partir de uma análise específica quanto às condições de risco a jusante (CBGB, 1999). Um PAE deve descrever as ações a serem tomadas pelo proprietário e operador da barragem, no caso de emergência. Deverá, ainda, delegar às pessoas ou órgãos competentes, as responsabilidades para cada ação a ser tomada, devendo ser remetido àqueles que estiverem envolvidos. Este deve ser publicado e distribuído àqueles a quem as responsabilidades foram delegadas, e ser constantemente atualizado.

Para o Ministério da Integração Nacional (2002), o PAE é um plano formalmente escrito que identifica os procedimentos e processos que serão seguidos pelos operadores das barragens na eventualidade de uma situação de emergência. Este deve ser preparado, verificado, divulgado e mantido para qualquer barragem, cuja ruptura possa ocasionar perda de vidas humanas, bem como para qualquer barragem para a qual um alerta antecipado possa reduzir danos a montante ou jusante. Um processo notificativo deve ser iniciado imediatamente, ao se encontrar uma condição insegura.

O Plano de Ação Emergencial deve ser preparado para cada barragem, a menos que as conseqüências da ruptura sejam baixas. Este documento deve descrever as ações a serem tomadas pelo proprietário e operador da barragem no caso de um evento ou uma situação de emergência. Sendo assim, deve conter:

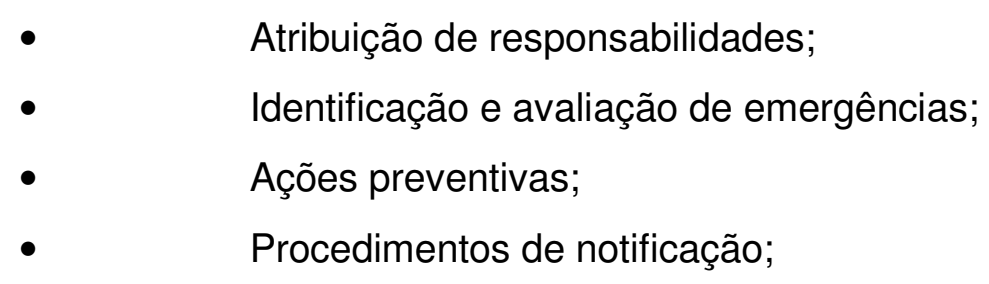




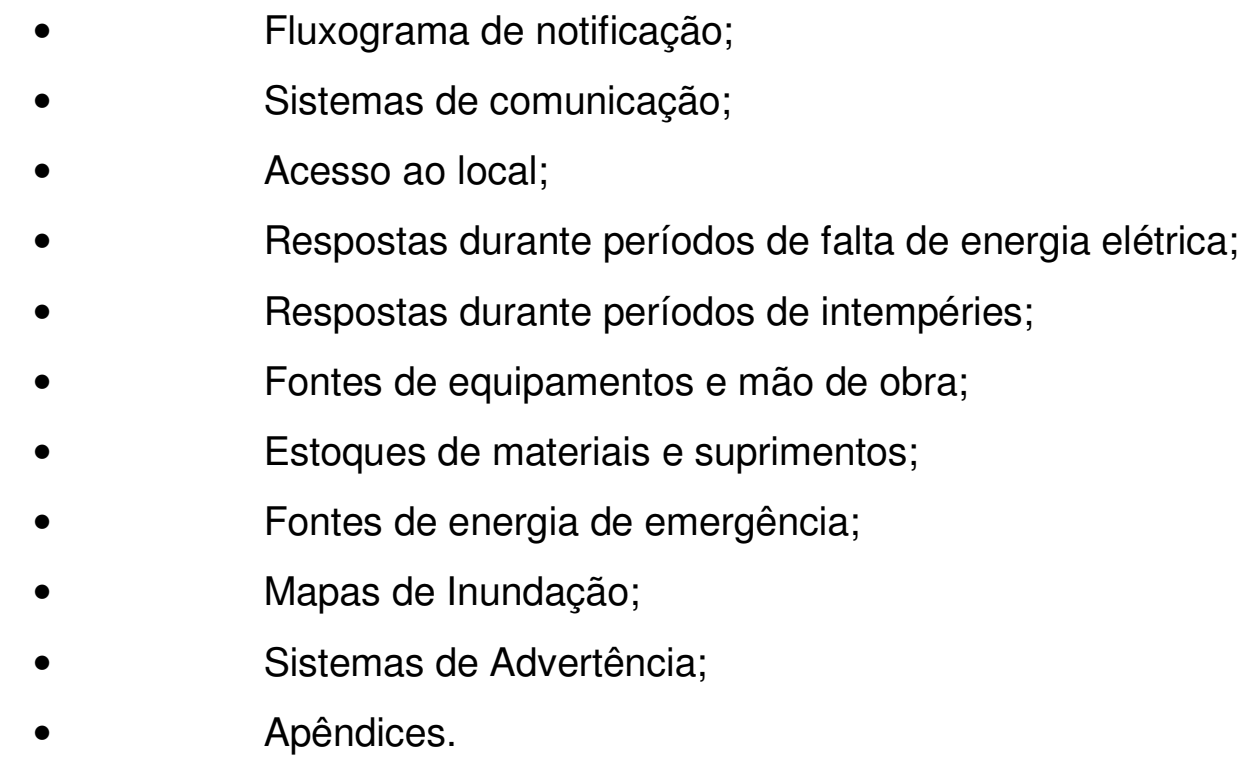

O ICOLD (2005), recomenda O "ICOLD EAP Guidelines for Dam Owners" (Orientações de Planos de Ações Emergenciais para proprietários das barragens) como um modelo consistente e "uniforme" das entidades mantenedoras de barragens. O formato do modelo pode ser considerado como um "checklist" a ser completado pelos proprietários das barragens (FEMA, Emergency Action Planning for Dam Owners - Federal Guidelines for Dam Safety, 2004). Neste formulário deve constar:

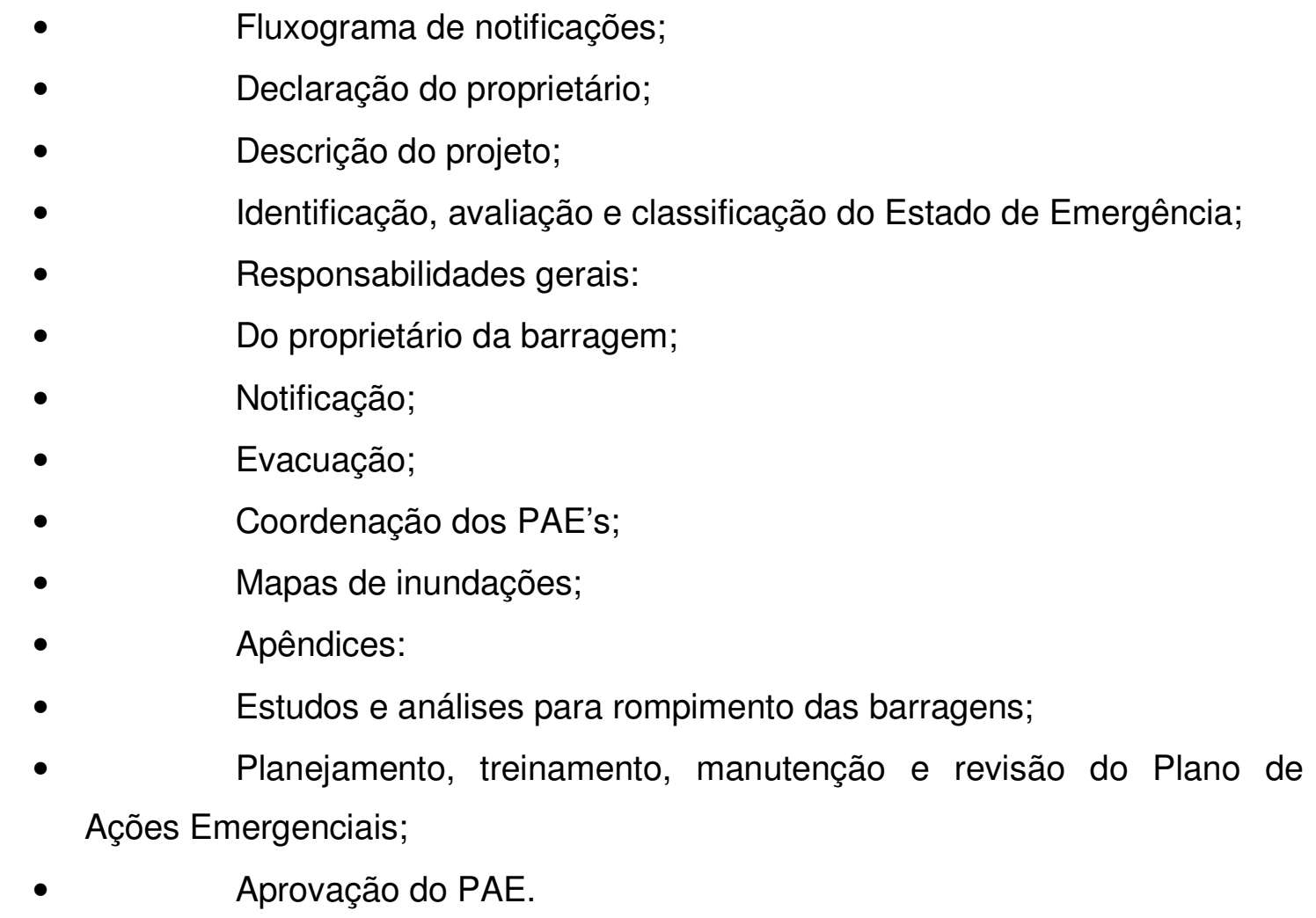


De maneira geral, a literatura e legislação correlata estabelece que a segurança de uma barragem, está diretamente associada ao risco e ao gerenciamento das ações a serem tomadas antes, durante e depois da detecção de uma possível situação de perigo para a obra. Um PAE neste caso deve ser mais uma ferramenta a ser utilizada na gestão de barragens.

Para FRANCO (2008), referindo-se à elaboração do plano de ação para a Barragem de Flores em Goiás, estes planos devem ser baseados nas diretrizes apontadas nos volumes da Diretoria Estadual da Defesa Civil de Goiás e no Manual de Segurança e Inspeção de Barragens (Ministério da Integração Nacional; Secretaria de InfraEstrutura Hídrica, 2002). Seguindo essas considerações, o PAE deve contar com:

Designação do Grupo de Trabalho;

Caracterização de Riscos;

Necessidades de Monitoramento;

Definição das Ações a Realizar;

Detalhamento do Planejamento;

Difusão e Aperfeiçoamento do Planejamento.

A elaboração e a implantação de um Plano de Ação Emergencial em uma barragem se faz fundamental, principalmente porque estabelece quais são os responsáveis e quais atitudes a serem tomadas em caso de ocorrência de acidentes envolvendo barragens. O PAE é uma documentação formal que identifica os riscos associados a uma barragem; este, especifica as responsabilidades e estabelece ações a serem tomadas de maneira organizada e uniforme com o intuito de agilizar o processo durante um evento de emergência. “... embora não seja necessário seguir o formato proposto, é determinante que todos os PAE's tenham uma linguagem comum para minimizar a possibilidade de informações confusas por ocasião do acionamento do Plano." (FEMA, 2004).

Em países como a França e Estados Unidos é obrigatória a formulação de um Plano de Emergência para todas as barragens com mais de $20 \mathrm{~m}$ de altura, ou reservatórios com capacidade superior a $15 \mathrm{hm}^{3}$ (COLLISCHONN W. , Análise do Rompimento da Barragem de Enerstina, 1997).

Em resumo, um PAE deve conter os procedimentos para atuação em situações de emergências, uma relação contendo as pessoas e/ou os órgãos envolvidos (lista de 
notificações), os mapas de inundação com os tempos de chegada da onda de enchente.

A existência de uma legislação sobre Planos de Ações Emergenciais, em alguns países vigora desde a década de 1970 (BALBI, 2008). Em países como Suíça, Portugal, Espanha Reino Unido, Estados Unidos e Argentina, a maioria das barragens já possuem Planos de Ação Emergenciais atualizados ou em fase de atualização.

Descreve-se a seguir alguns produtos típicos de planos de ações preventivas e emergenciais de barragens.

\subsubsection{Plano de Ação durante Emergências - P.A.D.E. Cerros}

\section{Colorados S.A.}

Pode-se citar como exemplo o "Plan de Acción Durante Emergencia" (DUKE-Energy, 2008) elaborado para a Hidroelétrica Cerros Colorados S.A. na Argentina Figura 3.11, onde seu principal propósito é salvar a vida da população e reduzir os danos das propriedades localizadas nos vales dos rios Neuquén e Negro, em conseqüência do rompimento de uma das barragens do Complexo Cerros Colorados. O P.A.D.E. Cerros Colorados é um documento que prescreve os procedimentos a serem tomados diante a uma anormalidade no complexo, que coordena as ações que devem ser tomadas de maneira adequada e eficaz.

O complexo Cerros Colorados está localizado na planície Banderita, 60 quilômetros a noroeste da cidade Neuquén e é composto por um conjunto de quatro obras (Figura 3.12):

- $\quad$ Portezuelo Grande - um açude de 7 metros de altura e 3 quilômetros de comprimento, onde termina o canal Neuquén e sua área inundável, com vertedor central composto por 6 comportas que permitem uma descarga de $3.600 \mathrm{~m}^{3} / \mathrm{s}$.

- Loma de La Lata - dois diques de terra, um de aproximadamente $1500 \mathrm{~m}$ e outro de aproximadamente $2300 \mathrm{~m}$ de comprimento. $\mathrm{Na}$ barragem Loma de La Lata, está construída uma estrutura que permite a passagem da água do reservatório Los Barreales para o reservatório Mari Menuco. 
- $\quad$ Planicie Banderita - compreende em um canal de adução de 2 quilômetros de comprimento e desde a bacia mari Menuco até a obra de Toma com uma profundidade de $20 \mathrm{~m}$.

- $\quad$ El Chañar - a barragem compreende em um dique frontal e um dique lateral e um vertedor com capacidade de descarga de 3.600 m³/s.

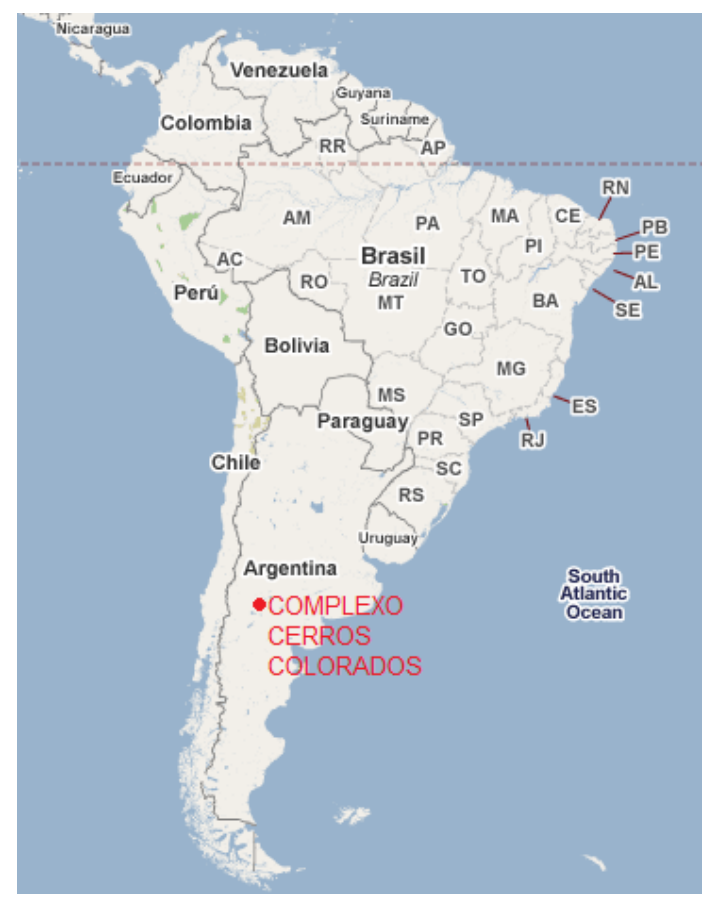

Figura 3.11: Complexo Cerros Colorados - Mapa Geral - Argentina

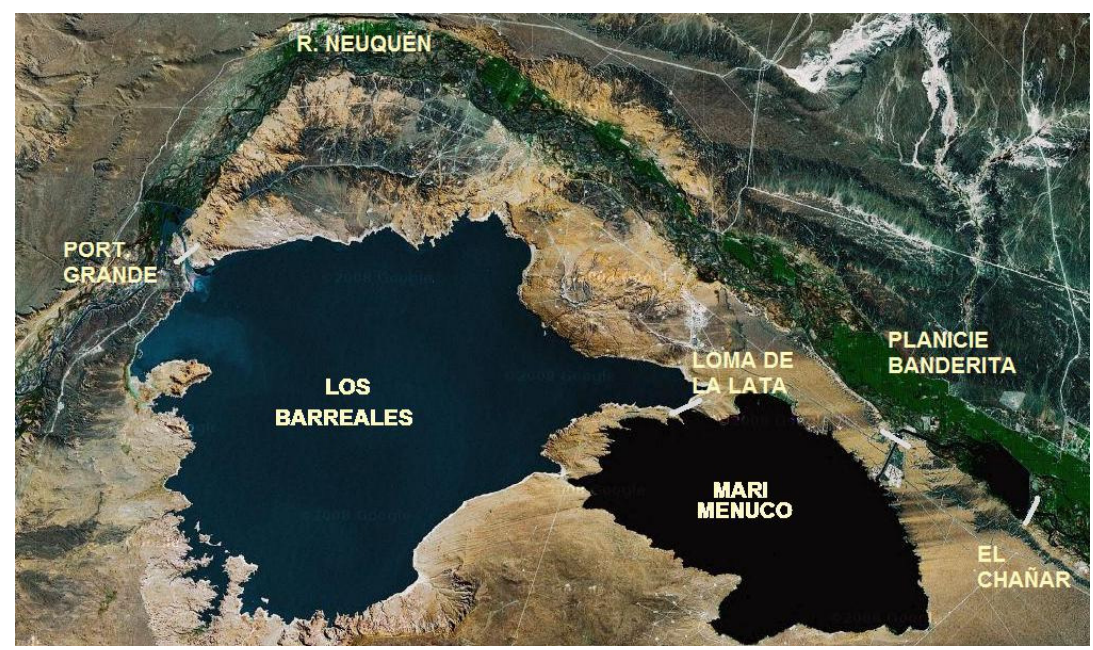

Figura 3.12: Complexo Cerros Colorados - Barragens e Reservatórios (GOOGLE, 2009) 
No P.A.D.E. estão estabelecidas duas categorias de emergências:

- $\quad$ Alerta Vermelho - A falha é iminente ou já ocorreu. Após essa categoria, a condição da barragem representa uma situação incontrolável conduzindo a falha, ou uma falha ocorrendo com perdas de água do reservatório e risco e catástrofe. Nesta situação, não se estima que haja tempo para controlar a situação.

- $\quad$ Alerta Amarelo - Uma situação potencialmente perigosa este em desenvolvimento. Após esta categoria, a barragem apresenta uma condição onde à falha pode se desenvolver, e ainda existem procedimentos que podem impedir ou retardar e evitar efeitos catastróficos. Geralmente se espera ter algum tempo disponível antes da formação da falha.

Como parte integrante do P.A.D.E. Cerros Colorados são apresentados diagramas de fluxo de comunicações onde são indicados os números de telefone e contatos dos serviços institucionais. A Figura 3.13 e a Figura 3.14 exemplificam respectivamente o diagrama de fluxo de comunicação da situação e o quadro de responsabilidades das comunicações quando a falha é iminente ou está a ocorrer em Portezuelo Grande. Assim como os diagramas, este documento contempla uma descrição das responsabilidades da Hidroeléctrica Cerros Colorados S.A. em comunicar a ORSEP Región Comahue (Organismo Regulador de Segurança de Barragens) de qualquer anormalidade que possa afetar a integridade e segurança das obras e que ponham em risco as áreas a jusante da barragem.

No P.A.D.E. também são apresentadas as condições de emergência para cada uma das obras hidráulicas que compõem o complexo Cerros Colorados, bem como os critérios que avaliam a mudança da categoria de emergência ou determinar o seu término, as ações que devem ser tomadas durante a emergência e as ações preventivas. 


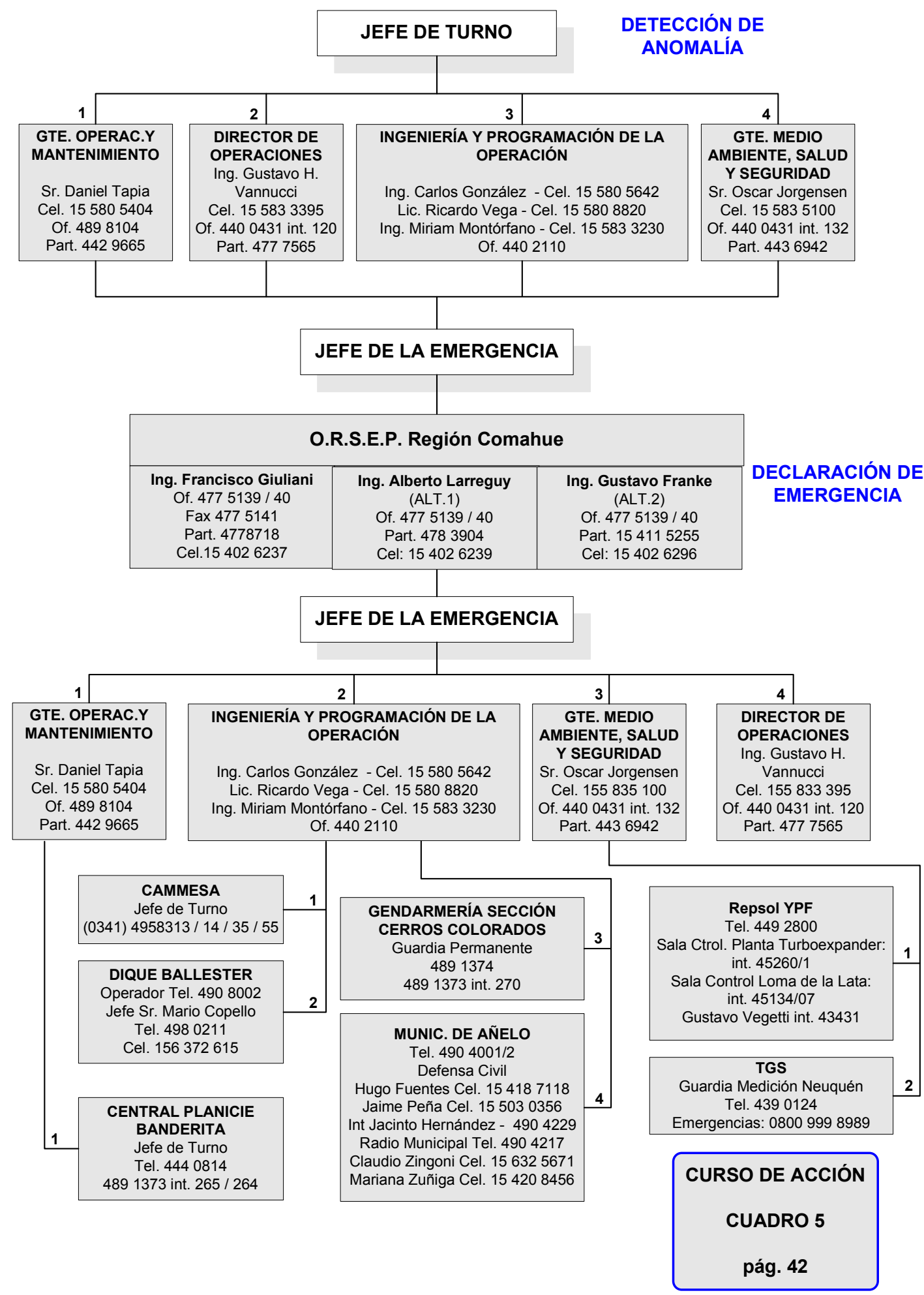

Figura 3.13: Diagrama de Fluxo de Comunicação para alerta Vermelho na barragem Portezuelo Grande. 


\begin{tabular}{|c|c|c|c|}
\hline $\begin{array}{l}\text { Actividad de } \\
\text { comunicación a: }\end{array}$ & Persona a contactar & Teléfonos & $\begin{array}{l}\text { Responsable de la } \\
\text { Ilamada }\end{array}$ \\
\hline \multirow[t]{3}{*}{$\begin{array}{l}\text { ORSEP Región } \\
\text { Comahue }\end{array}$} & Ing. Francisco Giuliani & $\begin{array}{ll}\text { Of. } & 4775139 / 40 \\
\text { Fax } & 4775141 \\
\text { Part. } & 4778718 \\
\text { Cel. } & 154026237\end{array}$ & \multirow{3}{*}{ Jefe de la Emergen } \\
\hline & Ing. Alberto Larreguy (Alt. 1) & $\begin{array}{ll}\text { Of. } & 4775139 / 40 \\
\text { Part. } & 4783904 \\
\text { Cel. } & 154026239 \\
\end{array}$ & \\
\hline & Ing. Gustavo Franke (Alt. 2) & $\begin{array}{lr}\text { Of. } & 4775139 / 40 \\
\text { Part. } & 154115255 \\
\text { Cel. } & 154026296\end{array}$ & \\
\hline $\begin{array}{l}\text { Central Planicie } \\
\text { Banderita }\end{array}$ & Jefe de Turno & $\begin{array}{l}\text { Tel. } 4440814 \\
\text { Tel. } 4891373 \text { int. } 265 \text { / } 264\end{array}$ & $\begin{array}{l}\text { Gerente de } \\
\text { Operaciones y } \\
\text { Mantenimiento }\end{array}$ \\
\hline CAMMESA & Jefe de Turno & $\begin{array}{l}\text { Tel. (0341) } 4958313 \text { / } 14 \text { / } \\
35 \text { / } 55\end{array}$ & \begin{tabular}{|l|l} 
Ingeniería y \\
Programación de a \\
Operación
\end{tabular} \\
\hline \multirow[t]{2}{*}{ Dique Ballester } & Operador. & Tel. 4908002 & \multirow{2}{*}{$\begin{array}{l}\text { Ingeniería y } \\
\text { Programación de a } \\
\text { Operación }\end{array}$} \\
\hline & Jefe: Sr. Mario Copello & $\begin{array}{l}\text { Tel. } 4980211 \\
\text { Cel: } 156372615\end{array}$ & \\
\hline $\begin{array}{l}\text { Gendarmería } \\
\text { Sección Cerros } \\
\text { Colorados } \\
\end{array}$ & Guardia Permanente & $\begin{array}{l}\text { Tel. } 4891374 \\
\text { Tel. } 4891373 \text { int. } 270\end{array}$ & \begin{tabular}{l|l} 
Ingeniería y \\
Programación de a \\
Operación
\end{tabular} \\
\hline \multirow{4}{*}{$\begin{array}{l}\text { Municipalidad de } \\
\text { Añelo }\end{array}$} & Municipalidad & Tel. 490 4001/2 & \multirow{4}{*}{$\begin{array}{l}\text { Ingeniería y } \\
\text { Programación de a } \\
\text { Operación }\end{array}$} \\
\hline & \begin{tabular}{|l} 
Defensa Civil: \\
Sr. Hugo Fuentes \\
Sr. Jaime Peña
\end{tabular} & $\begin{array}{l}\text { Cel. } 154187118 \\
\text { Cel. } 155030356\end{array}$ & \\
\hline & $\begin{array}{l}\text { Intendente: Jacinto } \\
\text { Hernández }\end{array}$ & Tel. 4904229 & \\
\hline & $\begin{array}{l}\text { Radio Municipal: } \\
\text { Claudio Zingoni } \\
\text { Mariana Zúñiga }\end{array}$ & $\begin{array}{l}\text { Tel. } 4904217 \\
\text { Cel. } 156325671 \\
\text { Cel. } 154208456 \\
\end{array}$ & \\
\hline \multirow[t]{3}{*}{ Repsol YPF } & $\begin{array}{l}\text { Sala de Control Planta } \\
\text { Turboexpander }\end{array}$ & Tel. 4492800 int. 45260 / 1 & \multirow{3}{*}{$\begin{array}{l}\text { Medio Ambiente, } \$ \\
\text { y Seguridad }\end{array}$} \\
\hline & $\begin{array}{l}\text { Sala de Control Loma de la } \\
\text { Lata }\end{array}$ & Tel. 4492800 int. 45134 / 07 & \\
\hline & $\begin{array}{l}\text { Referentes: } \\
\text { Gustavo Vegetti }\end{array}$ & $\begin{array}{l}\text { Tel. } 4492800 \\
\text { int. } 43431\end{array}$ & \\
\hline \multirow[t]{2}{*}{ TGS } & Emergencias & Tel. 08009998989 & \multirow{2}{*}{$\begin{array}{l}\text { Medio Ambiente, } \\
\text { y Seguridad }\end{array}$} \\
\hline & Guardia Medición Neuquén & Tel. 4390124 & \\
\hline
\end{tabular}

Figura 3.14: Quadro de responsabilidades das comunicações em caso de ocorrência de alerta Vermelho em Portezuelo Grande - Argentina 


\subsubsection{Plano de Ações para Emergências Devido à Hipotética Ruptura de Dona Francisca}

A UHE Dona Francisca dispõe de um documento contendo ações e providências, do ponto de vista do proprietário e do operador do aproveitamento, para aplicação nas emergências ocasionais por potenciais acidentes envolvendo o barramento e o reservatório.
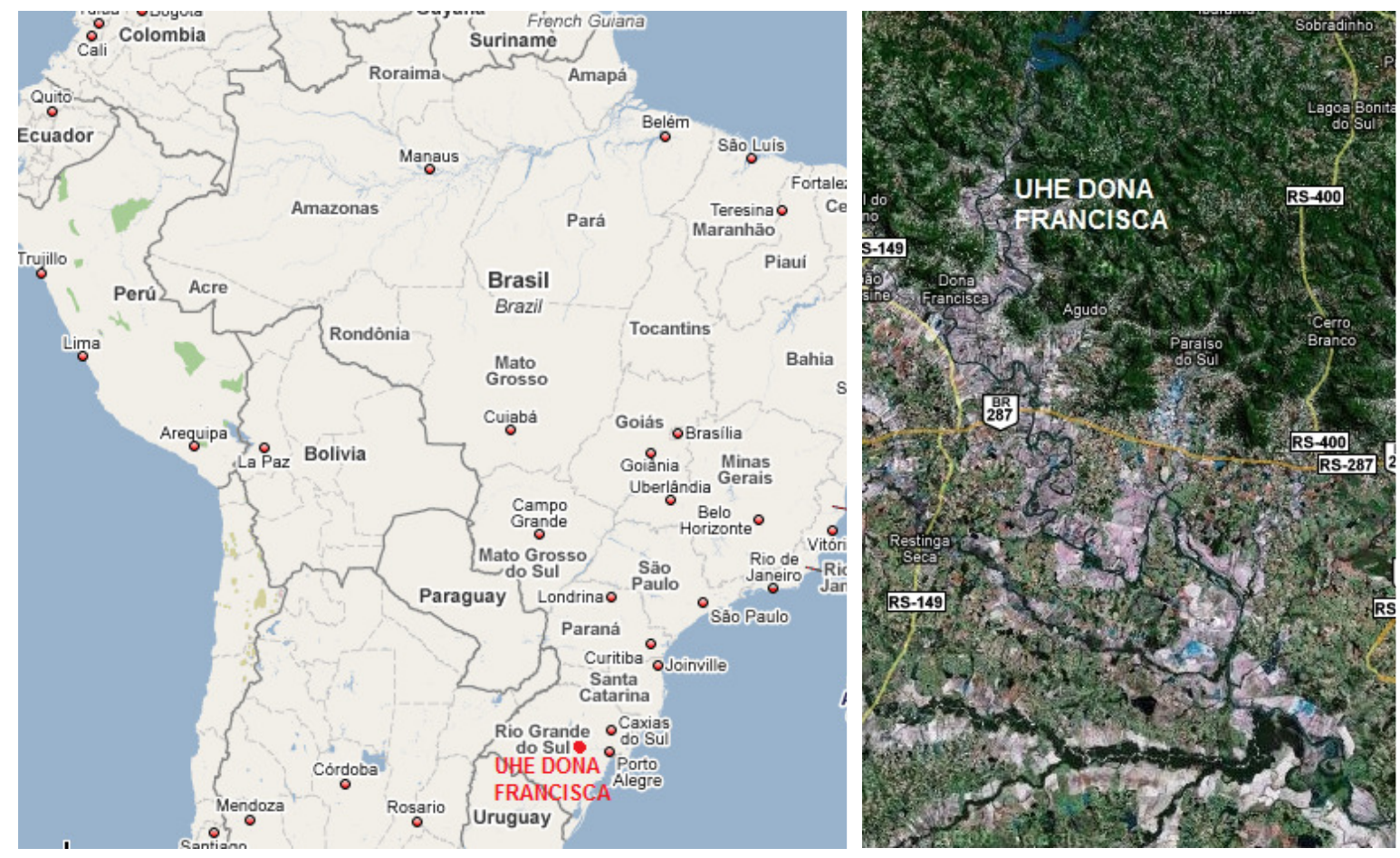

Figura 3.15: Localização da UHE Dona Francisca - RS - Brasil. Adaptado de Google (2009)

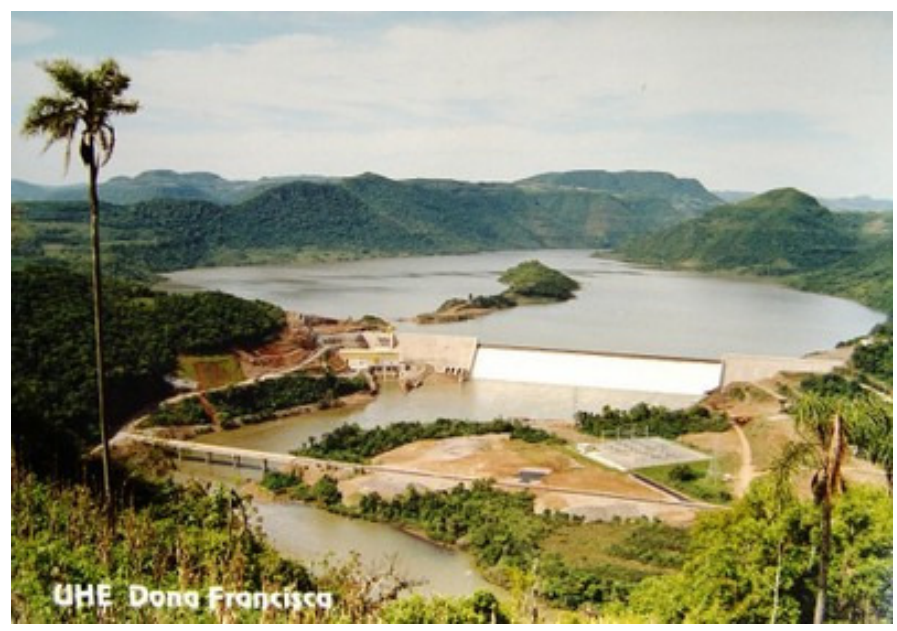

Figura 3.16: UHE Dona Francisca (http://www.camaraagudo.rs.gov.br/) 
Para elaboração deste PAE, foram consideradas como vazões de enchente na situação de emergência:

- 100 anos de recorrência (aproximadamente o máximo histórico);

- 1000 anos (situação intermediária);

- 10.000 anos (cheia de projeto);

- 100 anos com ruptura;

- 1000 anos com ruptura;

- 10.000 anos com ruptura;

- $\quad$ Diferença entre as situações de ruptura e de vazão de 10.000 anos de recorrência.

As simulações de ruptura foram realizadas com o modelo hidrodinâmico BOSSDAMBRK, um derivado do modelo NWS_FLDWAV, anteriormente descrito, donde foram obtidos os seguintes resultados:

- $\quad$ Níveis de água máximos;

- $\quad$ Tempo para ocorrência dos máximos níveis de água;

- Hidrogramas e limnigramas nas seções estudadas;

- $\quad$ Larguras de inundação com base nas cotas;

- $\quad$ Mapas de inundação.

Diante desses dados, considerando as situações emergenciais hipotéticas definidas como critério (períodos de recorrência de chuva com e sem ruptura) foram identificadas as emergência potenciais para cada localidade, em função da distância à barragem, da cota da estrutura avaliada, o nível de água atingido e o tempo do pico. Uma vez definidas as situações de emergência, foi elaborado o fluxo de informações a ser utilizado no caso de uma situação acima descrita.

Este PAE consta ainda, de uma lista de contatos da usina, das agencias e entidades envolvidas, dos agentes externos (órgãos estaduais, federais e municipais); um quadro de detecção avaliação e classificação das emergências, bem como o diagrama de situações de alerta e emergência, uma hierarquização das funções; regras para o monitoramento das estruturas; um programa de ações preventivas e indicações de rotas de fuga no caso de um acidente. 


\begin{tabular}{|c|c|c|c|}
\hline \multicolumn{4}{|c|}{$\begin{array}{c}\text { QUADRO } 6.1 \\
\text { GRADUAÇÃO DAS SITUAÇÕES E SUAS CONSEQÜÊNCIAS }\end{array}$} \\
\hline \multicolumn{3}{|c|}{ SITUAÇÃO } & \multirow{2}{*}{ CONSEQÜÊNCIAS } \\
\hline ATENÇÃO & ALERTA & EMERGÊNCIA & \\
\hline SIM & SIM & SIM & $\begin{array}{c}\text { Possibilidade de risco de } \\
\text { danos a jusante }\end{array}$ \\
\hline NÃO & SIM & SIM & $\begin{array}{l}\text { Constatação de danos a } \\
\text { jusante }\end{array}$ \\
\hline NÃO & NÃO & SIM & \begin{tabular}{|c|} 
Riscos de danos a \\
barragem e \\
possibilidade de ruptura
\end{tabular} \\
\hline \multicolumn{4}{|c|}{$\begin{array}{l}\text { Quando a posição frente às conseqüências for SIM a Defesa Civil, caso ainda não } \\
\text { esteja ciente, deverá ser acionada, mantendo-se integrada ao fluxo de } \\
\text { informações previsto. }\end{array}$} \\
\hline
\end{tabular}

Figura 3.17: Quadro de Situações e suas Emergências no PAE UHE Dona Francisca

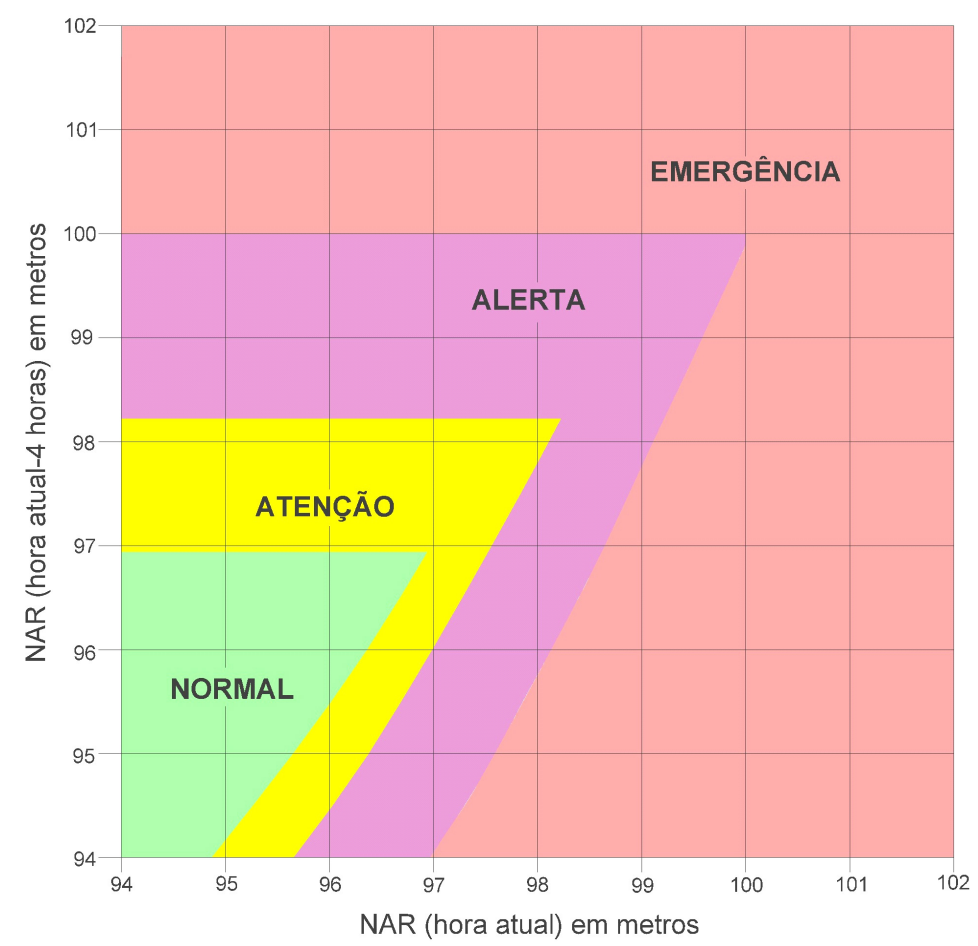

Figura 3.18: Diagrama de Situações de Emergência e Alerta do PAE UHE Dona Francisca

\subsubsection{Plano de Emergência da Barragem de Peti}

A usina hidrelétrica de Peti está localizada na bacia do rio Santa Bárbara, no município de São Gonçalo do Rio Abaixo - Minas Gerais. O aproveitamento 
hidrelétrico de Peti consta de uma barragem de concreto em arco simples, apoiada em suas extremidades em rocha.

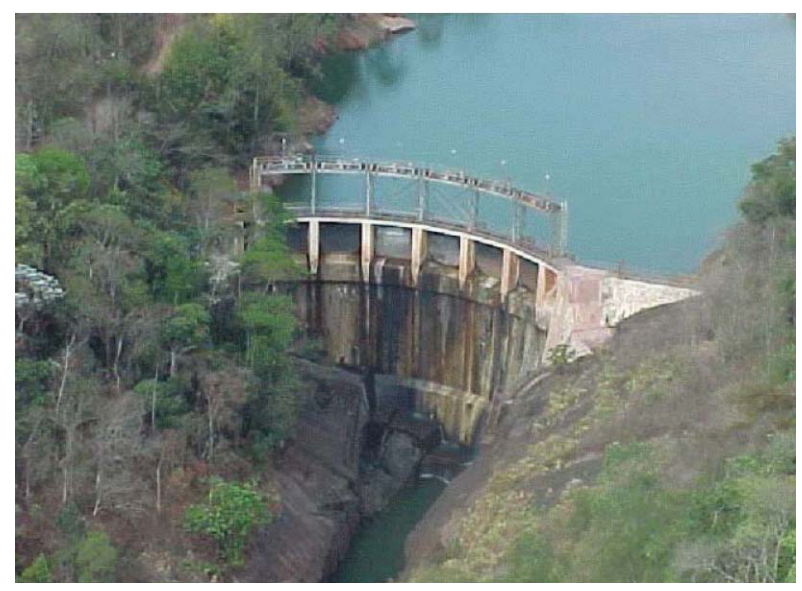

Figura 3.19: Vista da Barragem de Peti - MG (BALBI, 2008)

A elaboração deste PAE foi estruturada em 7 (BALBI, 2008) passos como se descreve:

Passo 1: Determinação dos cenários de ruptura - onde são apresentados os critérios para a escolha dos cenários a serem estudados tais como: formação da brecha, cálculo da onda de ruptura e determinação dos hidrogramas de ruptura. A propagação da onda de enchente foi realizada através do modelo matemático FLDWAV da NWS.

Passo 2: Mapeamento de áreas inundadas - onde foram elaborados mapas com manchas de inundação associadas à cartografia da região da barragem do Peti. As manchas de inundação foram desenhadas segundo dois critérios: o de profundidade máxima da inundação e do risco hidrodinâmico.

Passo 3: Eventos iniciadores de ações de emergência, ações e responsáveis: detecção, avaliação de ocorrências e definição dos níveis de segurança (verde, amarelo, laranja e vermelho), ações pré-planejadas e responsabilidades.

Passo 4: Coordenação do desenvolvimento do Plano de Emergência da Barragem, com outras equipes - indicação de que a usina deve construir um documento único, em concordância com os planos de combate a incêndios, de 
emergências ambientais, de atendimento a acidentes de trabalho, de emergências hidrológicas, de emergência de barragens.

Passo 5: Sistemas de comunicação - os sistemas de comunicação externa devem atender bem em situação de emergências, porém devem ser instalados em local seguro, fora da zona de inundação.

Passo 6: Fluxograma de notificações - fluxograma deve ser utilizado quando a ruptura já tiver ocorrido ou for inevitável. Ao se detectar anormalidades devem ser seguidos fluxos de comunicação próprios de cada nível de segurança atingido.

Passo 7: Conteúdo e estrutura - Esboço do plano

Volume I - Gestão de emergências. Procedimentos operacionais

Capa ou página de rosto; Identificação do documento; Apresentação e notas legais; Como usar este PEB; Detecção, avaliação e classificação das emergências;

Responsabilidades;

Procedimentos de ação; Apêndices.

Volume II - Memorial técnico Capa ou pagina de rosto; Identificação do documento; Apresentação e notas legais;

Estudos de ruptura e de propagação de cheias Critérios para elaboração dos mapas de inundação Monitoramento e manutenção

Resposta a possíveis condições emergenciais Organização dos recursos Sistemas de comunicação, alerta e aviso Procedimentos de divulgação, treinamento e atualização do PEB Volume III - Plano de comunicação externa Capa ou pagina de rosto; Identificação do documento;

Apresentação e notas legais;

Fluxo de notificações;

Responsabilidades;

Caracterização da região;

Avaliação do comportamento da barragem;

Sistemas de comunicação, alerta e aviso;

Programa de divulgação do plano;

Anexos. 
O Estado de São Paulo está organizado em 22 Unidades de Gerenciamento de Recursos Hídricos - UGRHI, sendo que sua Capital situa-se naquela considerada como em pior situação com relação aos conflitos de uso e de conservação dos recursos hídricos, a UGRHI - 6 (Figura 4.1), denominada de Bacia do Alto Tietê. Tendo que dar suporte a cerca de $50 \%$ da população do estado, 2/3 de suas indústrias e servir de referência principal para o Brasil, os problemas de gestão são vultuosos e demandam, além de boa dose de tecnologia, grandes investimentos financeiros.

O abastecimento de água na Região Metropolitana de São Paulo é basicamente feito por 4 sistemas principais e outros tantos secundários, interligados parcialmente através do próprio sistema adutor de água: Sistema Cantareira, Sistema Guarapiranga, Sistema Alto-Tietê e Sistema Cotia.

O território da bacia do Alto Tietê é quase o mesmo da RMSP. (ALTO TIETÊ, 2002), sendo ocupado por 39 municípios incluindo a cidade de São Paulo, com uma área territorial de aproximadamente $8.000 \mathrm{~km}^{2}$, sendo $2200 \mathrm{~km}^{2}$ de área urbanizada e população de aproximadamente 20.000 .000 de habitantes (IBGE, 2007).

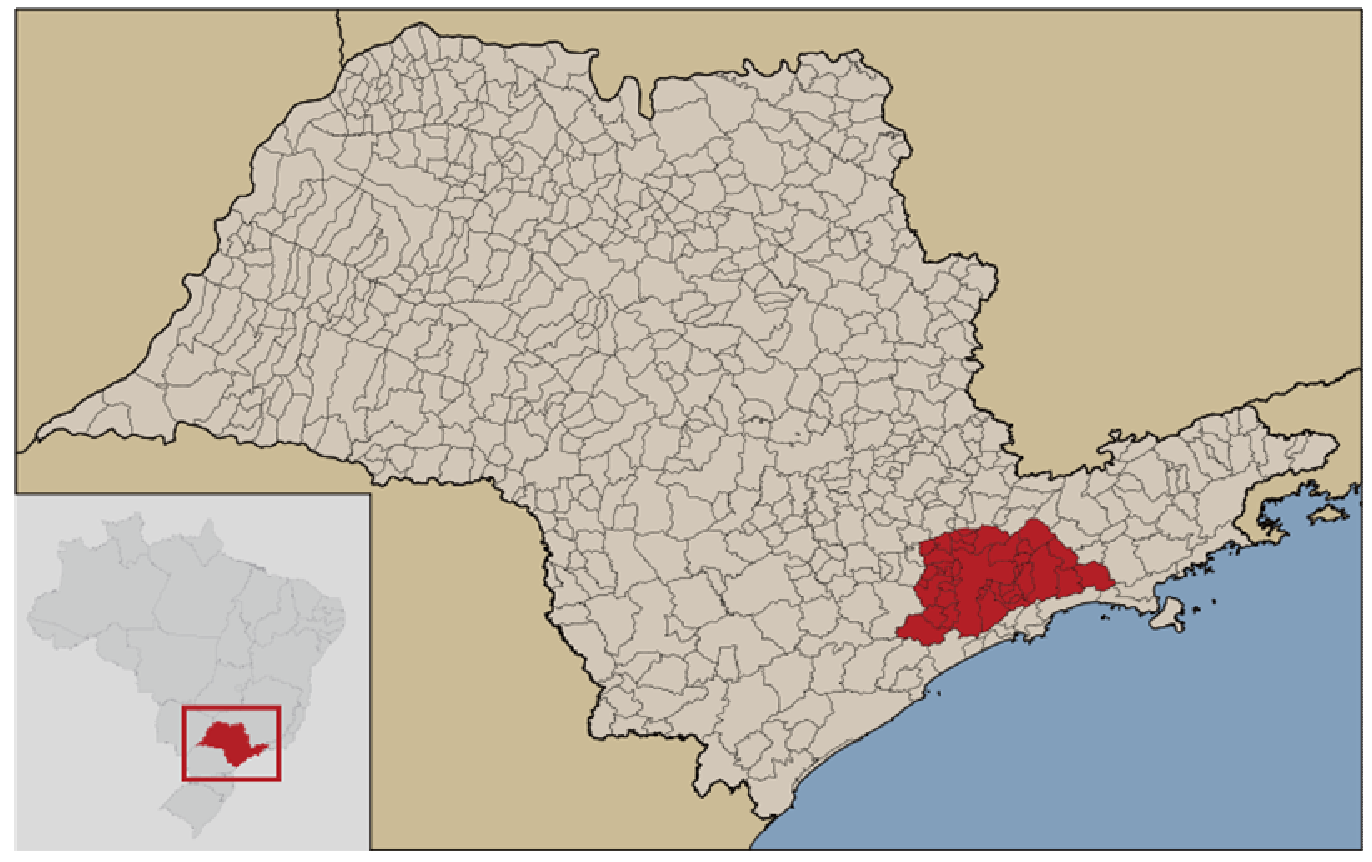

Figura 4.1: Região Metropolitana do Estado de São Paulo 
O Sistema Guarapiranga está localizado na zona Sul do município de São Paulo, sendo composto por um reservatório com altura máxima de aproximadamente $14 \mathrm{~m}$ (LIGHT, 1978). A barragem Guarapiranga foi construída entre 1906 e 1907 pela LIGHT S.A. com o objetivo de regularizar a vazão do rio Guarapiranga e permitir seu aproveitamento para geração de energia elétrica por meio da reversão de suas águas para o reservatório Billings, adjacentes a ela, além de contribuir para o abastecimento de água da cidade de São Paulo.

Esta barragem foi executada parcialmente através de aterro hidráulico e completada com aterro compactado, sendo dotada em sua ombreira esquerda três descargas de fundo com capacidade de cerca de $50 \mathrm{~m}^{3} / \mathrm{s}$ cada uma e um vertedouro escavado em rocha, com soleira na cota 732,60 m, e dotado de comportas tipo segmento.

Originalmente situada em área desocupada, a evolução da metrópole e as precárias condições de fiscalização e conservação adotadas no passado, fizeram com que suas margens fossem completamente urbanizadas, sendo atualmente fortemente ocupadas (Figura 4.4). Da mesma forma se comportou o vale a jusante, ocupado atualmente com importantes vias expressas, linhas férreas e metroviárias, além de entroncamento de 8 das principais rodovias do Brasil.

Componente do segundo maior sistema produtor de água de São Paulo, a represa Guarapiranga localiza-se próxima a Serra do Mar, sendo um subsistema da Bacia do Rio Pinheiros, afluente do Rio Tietê (Figura 4.2). O reservatório é formado pela contribuição dos rios Embu-Mirim, Embu-Guaçu, Santa Rita, Vermelho, Ribeirão Itaim, Capivari e Parelheiros e permite a regularização média anual para a produção de 14 $\mathrm{m}^{3} / \mathrm{s}$ de água, abastecendo as zonas sul e sudoeste da capital do Estado de São Paulo. 


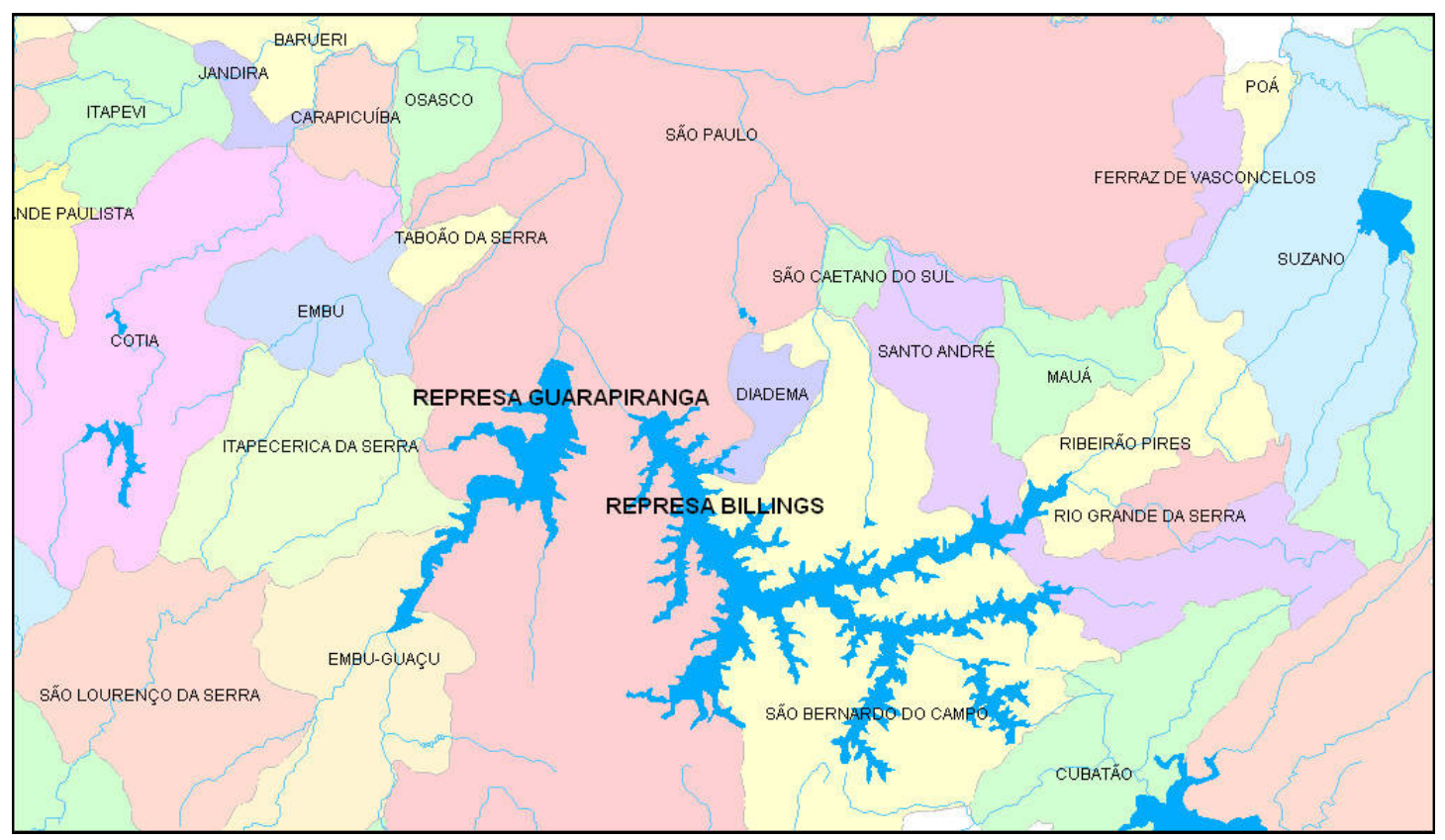

Figura 4.2: Esquema do Sistema Guarapiranga - Billings

Nos dias 27, 28 e 29 de janeiro de 1976 fortes chuvas fizeram com que o nível do reservatório Guarapiranga começasse a subir. Este "fenômeno" teve seu inicio a partir das 12 horas do dia 28 de janeiro de 1976, fazendo com que o nível de água no reservatório chegasse à cota 736,62m (cota da crista do vertedor) às 00:00h do dia 29 e a cota 736,67m (máximo atingido no evento) às 12:00h do dia 31 de janeiro de 1976. Durante esse período de 72 horas, o reservatório sofreu um acumulo adicional no seu volume de aproximadamente 67 milhões de metros cúbicos (cerca de $34 \%$ de sua capacidade máxima).

As comportas de fundo foram acionadas as partir das 21:30h do dia 29, com a última operação executada somente no dia 30 às 10:00h. Foram colocados sacos de areia com o intuito de garantir uma altura adicional de $0,88 \mathrm{~m}$ na possibilidade de ocorrência de mais chuva, permitindo um armazenamento de mais 30 milhões de metros cúbicos.

Medições de vazões realizadas no dia 31 de janeiro de 1976, em postos fluviométricos do Departamento de Águas e Energia Elétrica do Estado de São Paulo DAEE e pela então Companhia LIGHT, determinaram um valor aproximado de $91 \mathrm{~m} 3 / \mathrm{s}$ de vazão no canal Guarapiranga. O hidrograma de cheia foi constituído somando-se a vazão descarregada a jusante, a vazão aduzida pela Companhia de Saneamento 
Básico do Estado de São Paulo - SABESP e as vazões calculadas correspondentes às variações de volume do reservatório de Guarapiranga.

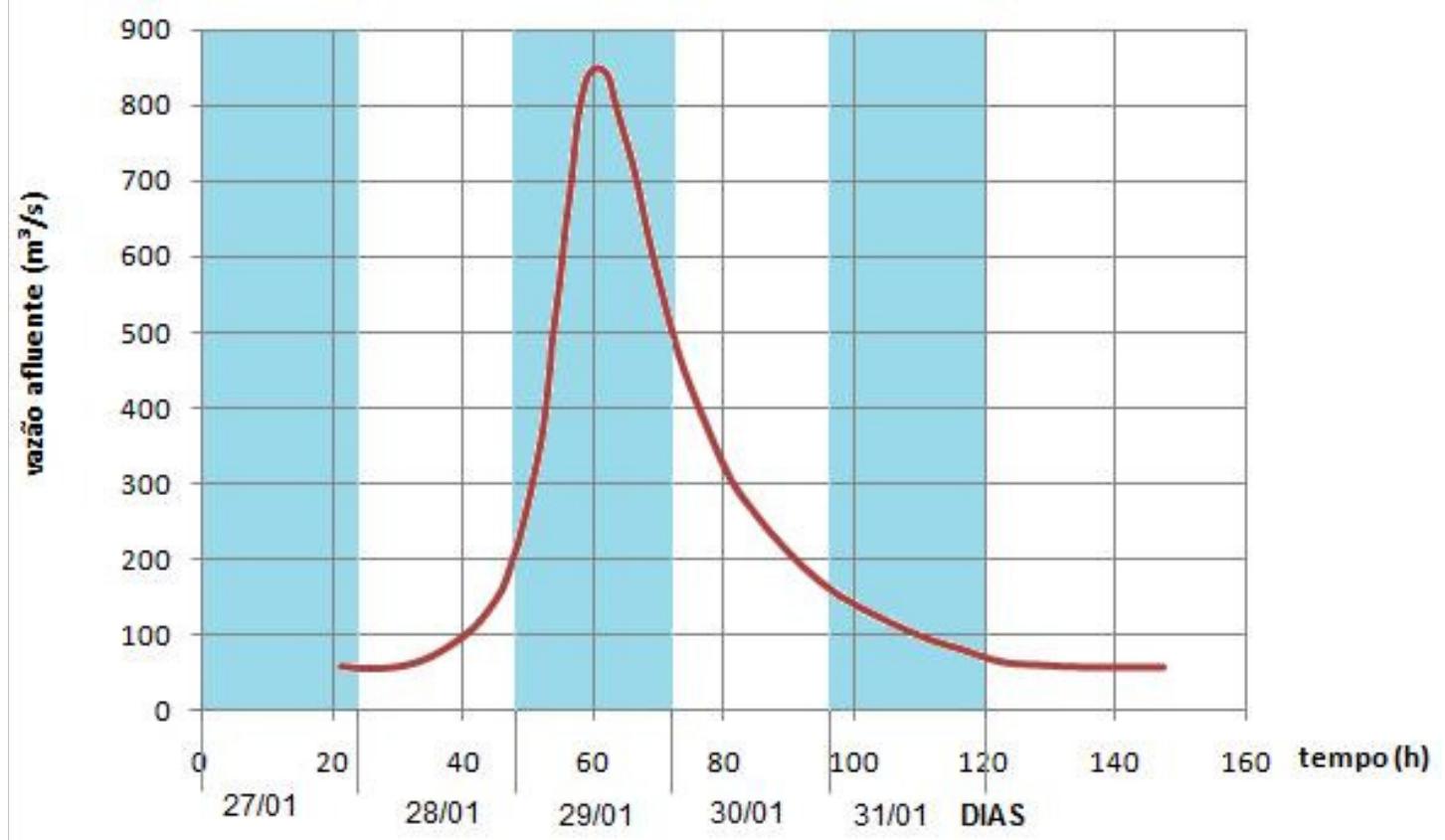

Figura 4.3: Hidrograma da Cheia de Janeiro de 1976 . Adaptado de LIGHT (1978)

A partir do hidrograma apresentado na Figura 4.3, pode-se observar que o pico da cheia fluente atingiu aproximadamente $850 \mathrm{~m} 3 / \mathrm{s}$ e a vazão média de 24 horas foi igual a aproximadamente $660 \mathrm{~m} / \mathrm{s}$. A enchente durou aproximadamente 30 horas e a vazante 70 horas. O volume total desta cheia resultou em 43\% (95 milhões de metros cúbicos) do volume do reservatório Guarapiranga. 


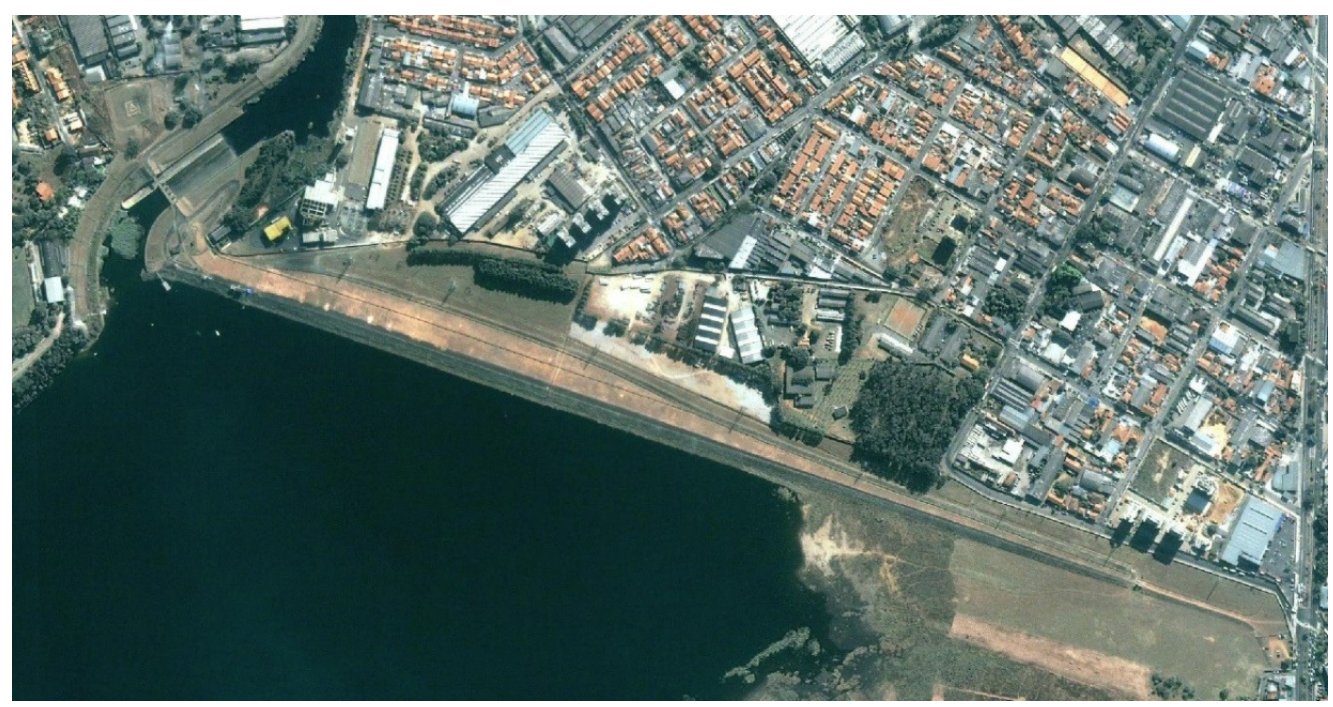

Figura 4.4: Barragem de Guarapiranga. (GOOGLE, 2009)

Desta forma, considerando-se tanto a importância do manancial para a Cidade de São Paulo, como a magnitude dos impactos diretos e desdobramentos de um eventual acidente que envolvesse a liberação do volume de água reservado, a Barragem Guarapiranga constitui-se num importante exemplo para este estudo metodológico.

\subsection{Características da Barragem e do Reservatório}

\section{Guarapiranga}

Algumas características da Barragem Guarapiranga são mostradas na Tabela 4.1

Tabela 4.1: Características da Barragem Guarapiranga

\begin{tabular}{lc}
\hline Volume do Aterro $\left(\mathrm{m}^{3}\right)$ & 490.000 \\
Cota da Crista $(\mathrm{m})$ & 738,60 \\
Cota da crista do vertedor $(\mathrm{m})$ & 736,62 \\
NA máximo normal $(\mathrm{m})$ & 735,00 \\
NA máximo maximorum $(\mathrm{m})$ & 738,10 \\
Fim das Obras & 1909 \\
Área de Drenagem $\left(\mathrm{km}^{2}\right)$ & 631,00 \\
Volume Útil $\left(\mathrm{m}^{3}\right)$ & 200.000 .000 \\
\hline
\end{tabular}


Após o evento ocorrido em 1976, a Eletropaulo S.A., sucessora da Ligth S.A., promoveu a implantação de reformas na estrutura vertente, mantendo-se as descargas de fundo e implementando-se em parte do vertedouro existente uma nova soleira, desta feita livre, na cota 736,60m, com cerca de $45 \mathrm{~m}$ de extensão. Foram mantidas 4 comportas originais, num vão total de 24 m. As Figura 4.5 e Figura 4.6 apresentam as curvas de descarga das comportas e do canal de fuga. O canal a jusante apresenta-se sem revestimento e não há dissipadores de energia.

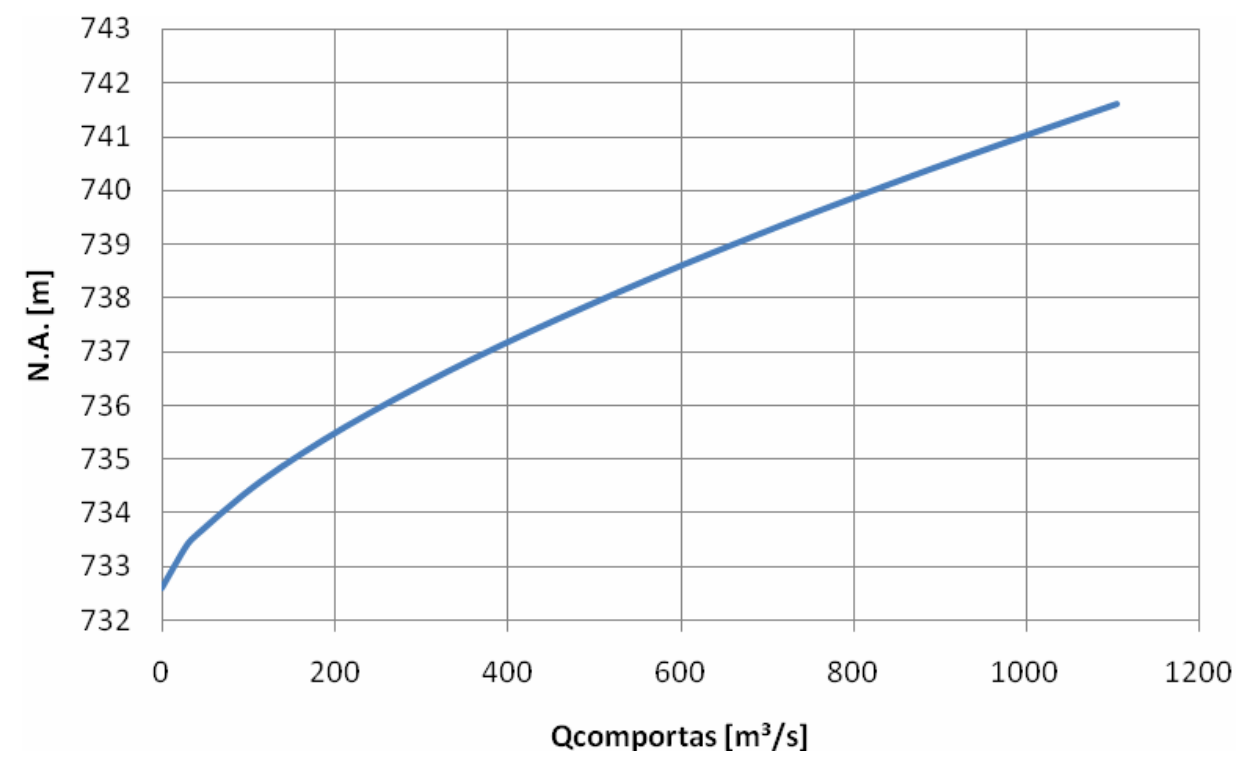

Figura 4.5: Curva Cota-Descarga das Comportas da Barragem Guarapiranga (EMAE, 2001) 


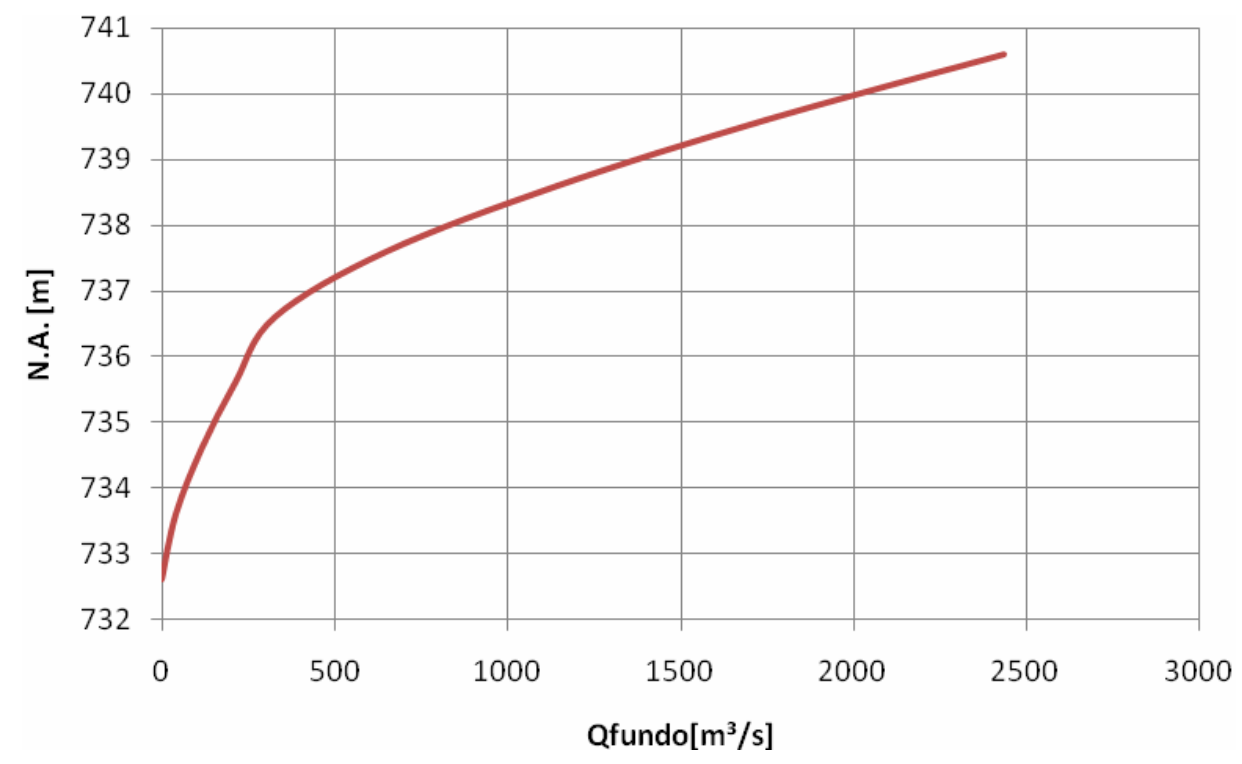

Figura 4.6: Curva Cota-Descarga do Canal de Fuga da Barragem Guarapiranga (EMAE, 2001)

O maciço da barragem Guarapiranga está situado sobre duas unidades geológicas distintas: o Quaternário representado por aluviões recentes da calha do canal Guarapiranga e solos derivados da decomposição "in situ" de gnaises e micaxistos do pré-Cambriano (LIGHT, 1978). É composto no seu núcleo, de silte argiloso, seguido de areia siltosa pouco argilosa. As figuras a seguir mostram as seções transversais, planta e cortes do vertedor e da barragem Guarapiranga.

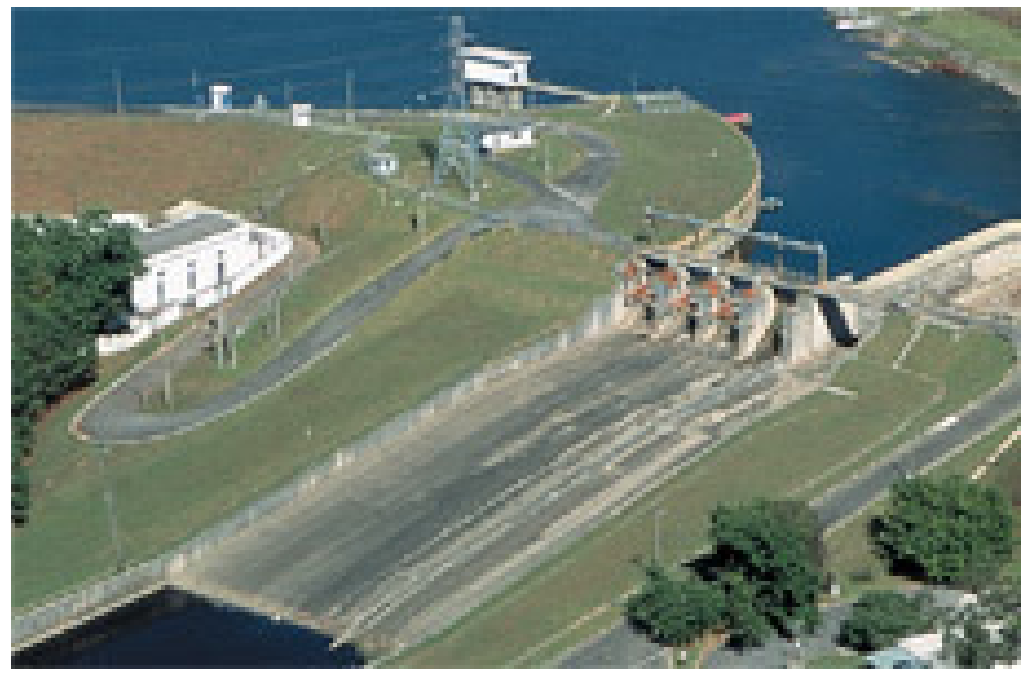

Figura 4.7: Vertedores da Barragem Guarapiranga (EMAE, 2001) 


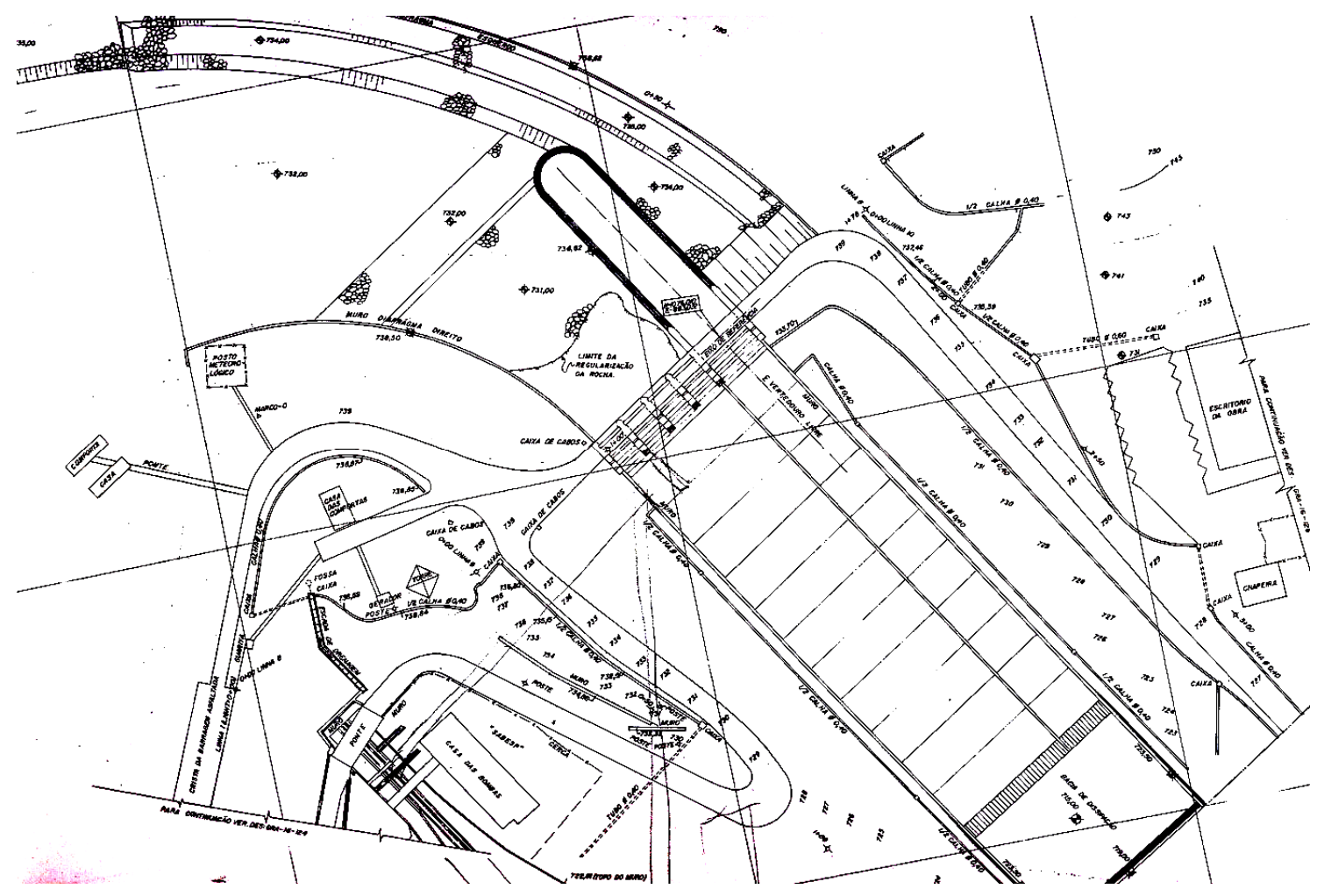

Figura 4.8: Planta geral do Vertedor da Barragem Guarapiranga. (LIGHT, 1978) 


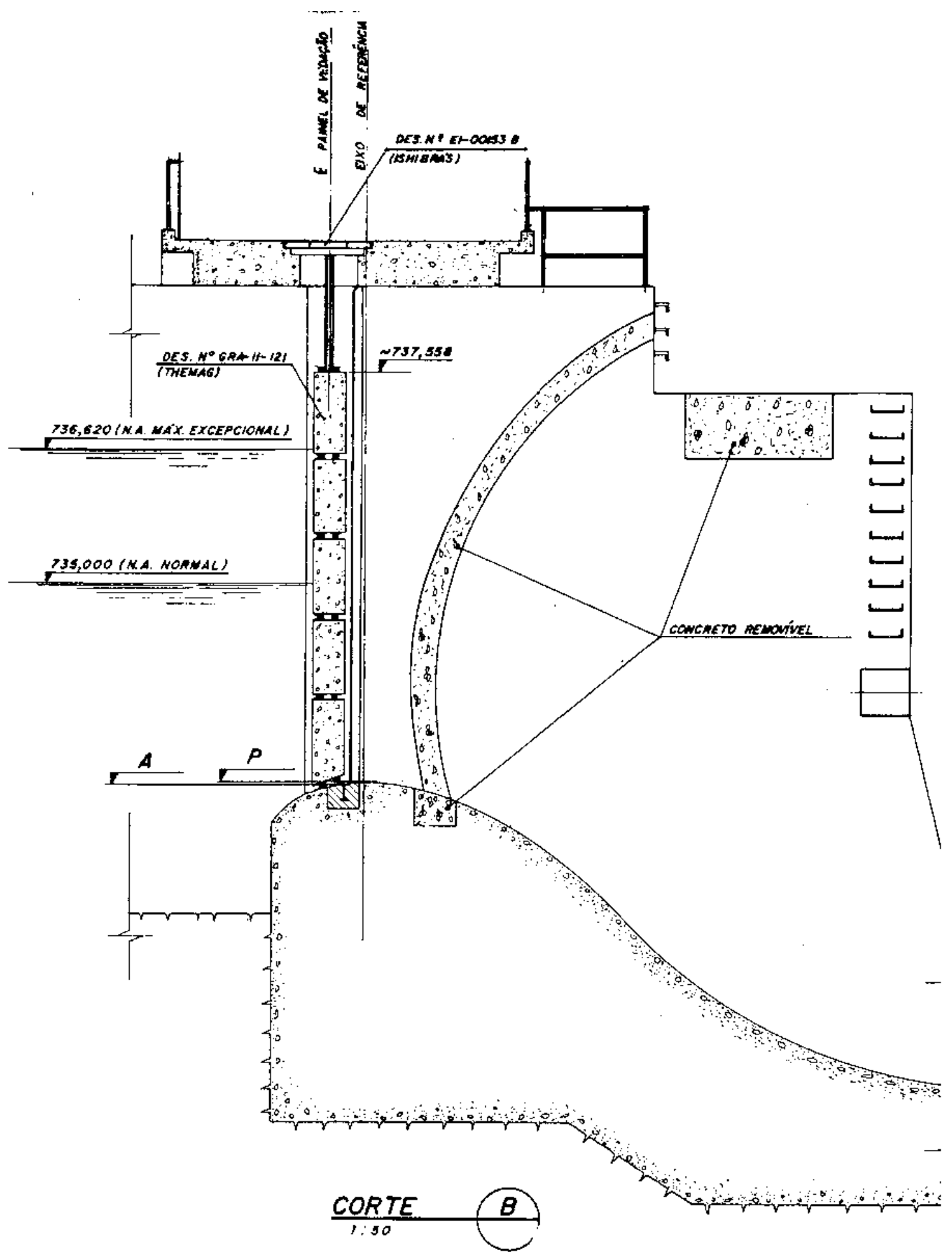

Figura 4.9: Corte do Vertedor da Barragem Guarapiranga. (LIGHT, 1978) 


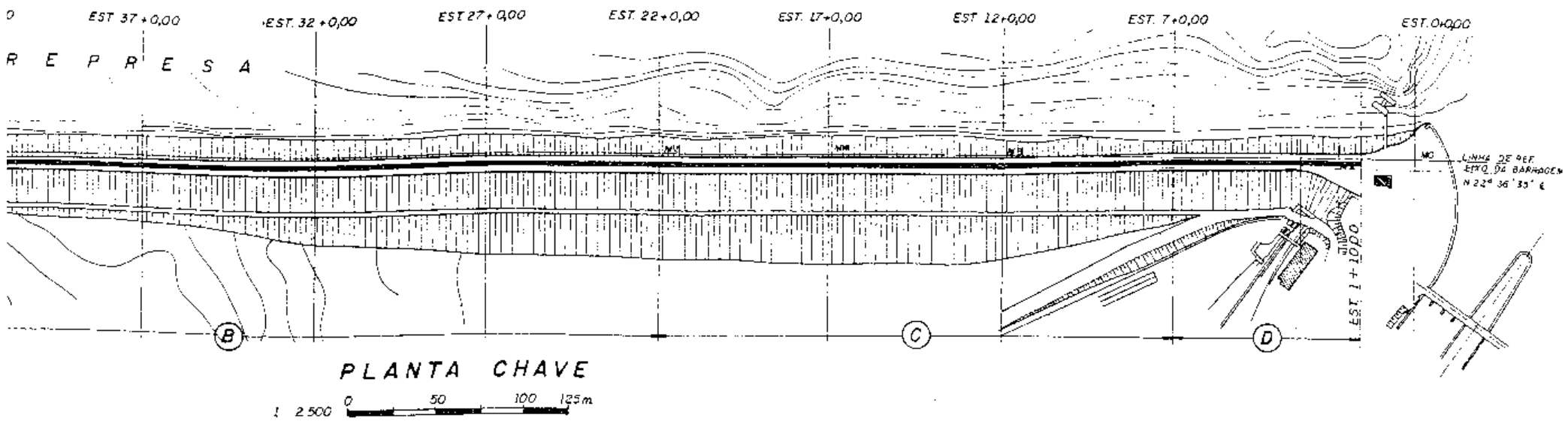

Figura 4.10: Planta da Barragem Guarapiranga - parte 1-2 (LIGHT, 1978)

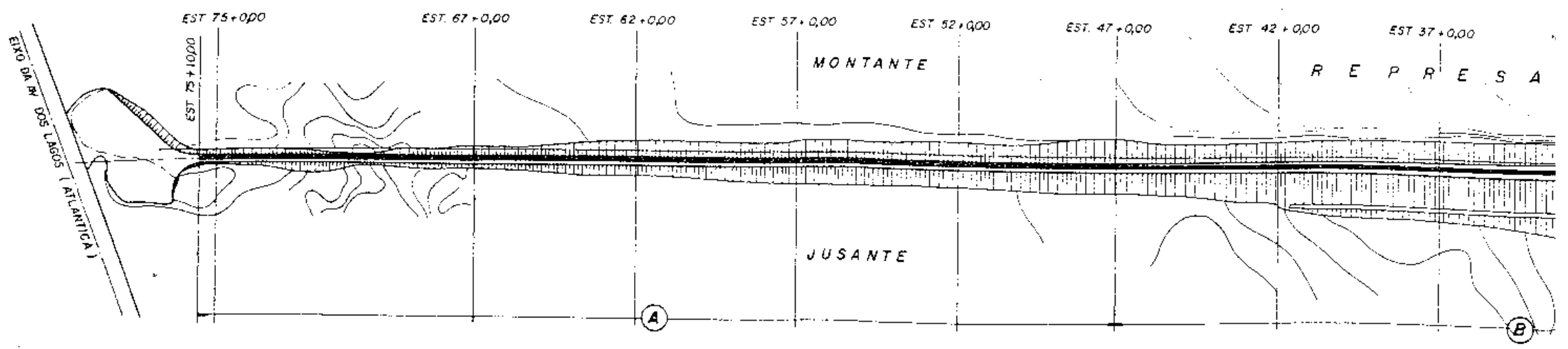

Figura 4.11: Planta da Barragem Guarapiranga - parte 2-2 (LIGHT, 1978) 


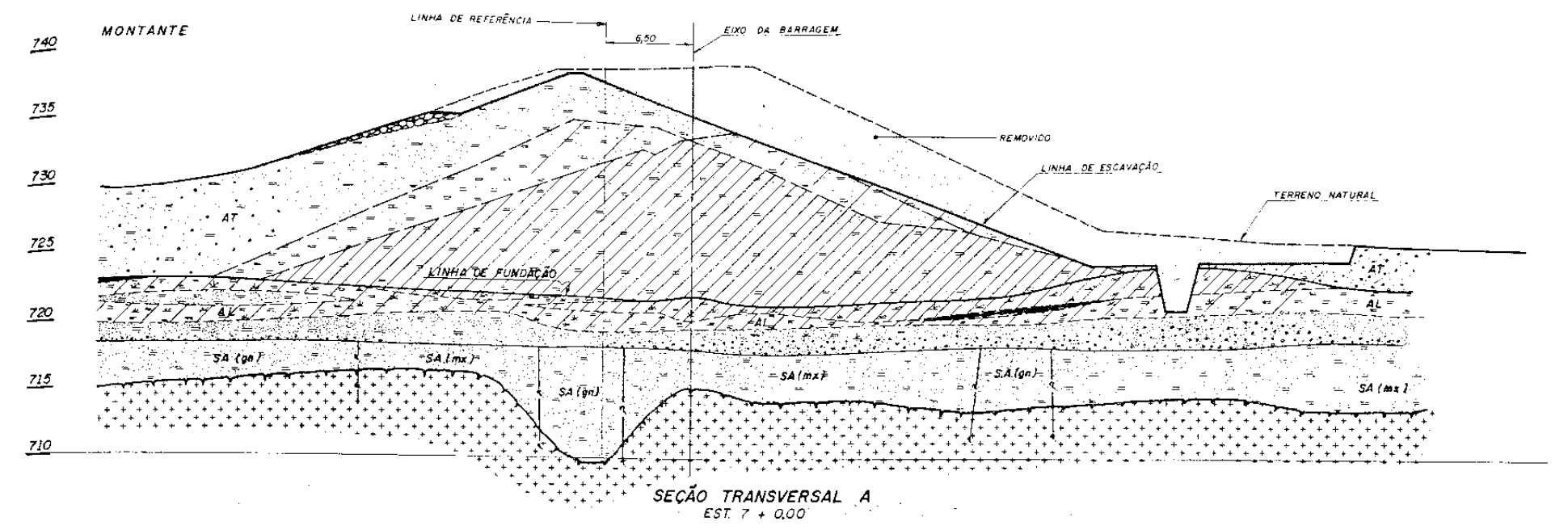

Figura 4.12: Seção Transversal A - estaca 7+0,00 (LIGHT, 1978)

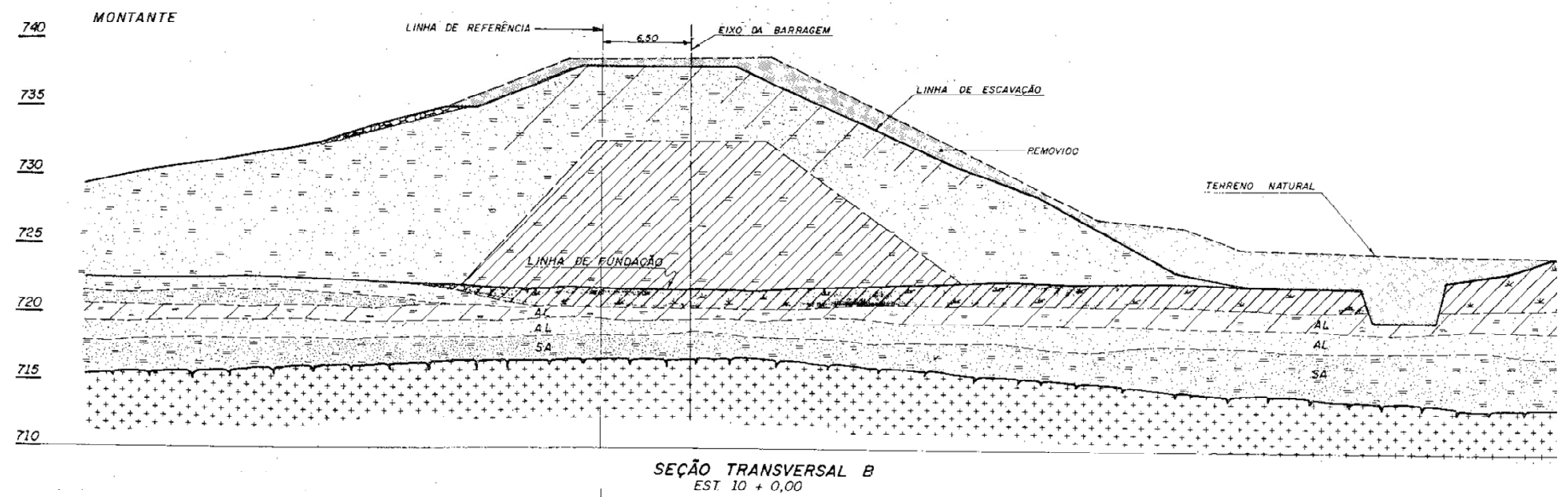

Figura 4.13: Seção Transversal B - estaca 10 + 0,00( (LIGHT, 1978) 


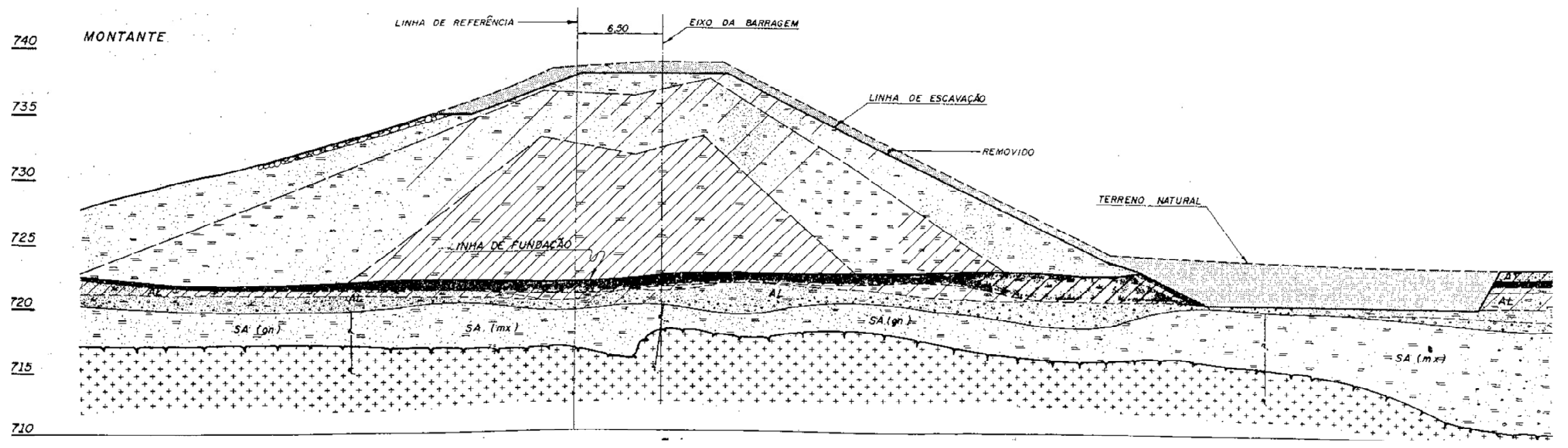

Figura 4.14: Seção Transversal C - estaca 17 + 0,00( (LIGHT, 1978)

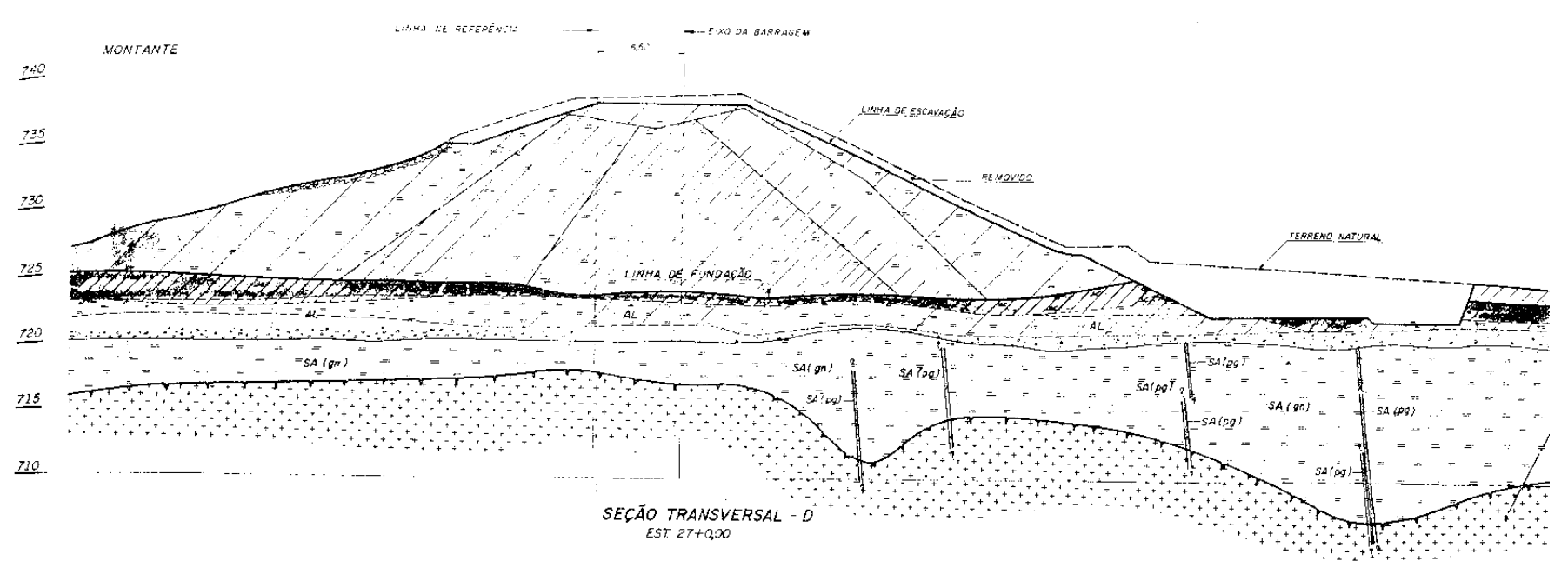

Figura 4.15: Seção Transversal D - estaca 27 + 0,00 (LIGHT, 1978)

Uemura, S.; Instrumentos de Avaliação e Gestão de Impactos Gerados por Rupturas de Barragens 


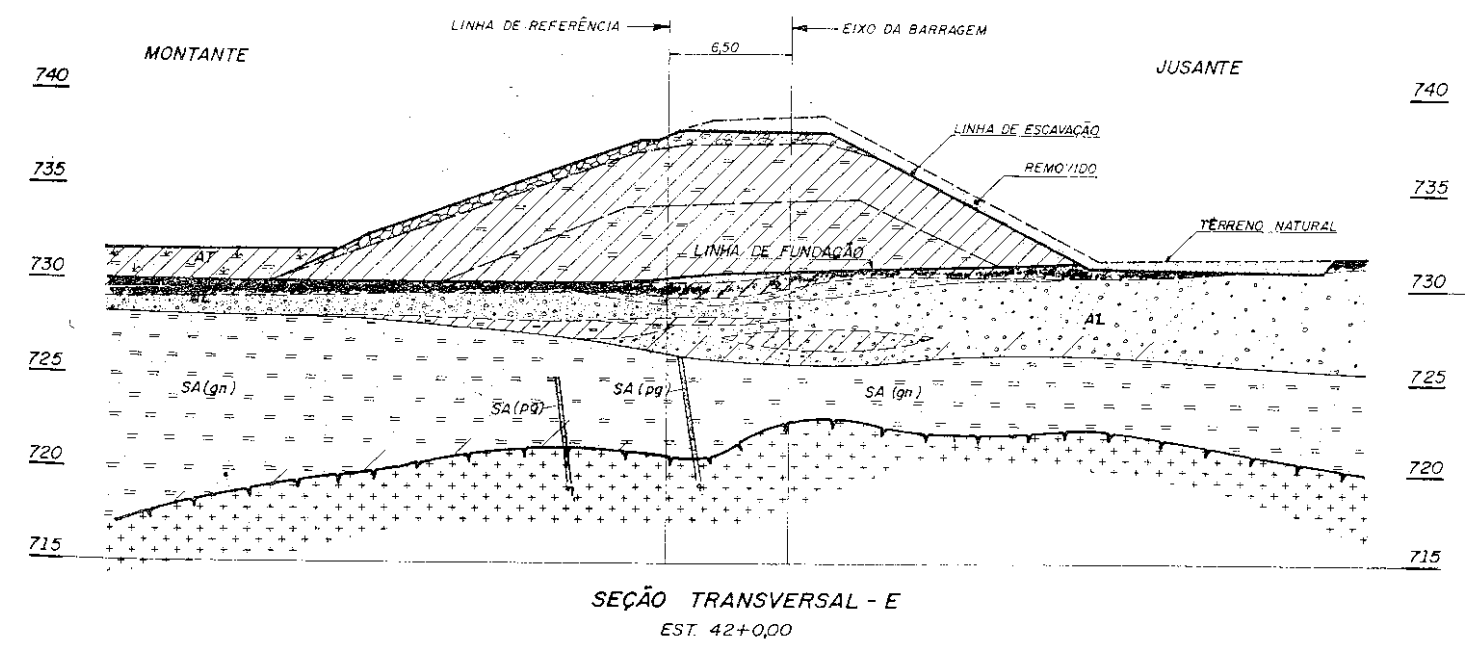

Figura 4.16: Seção Transversal E - estaca 42 + 0,00 (LIGHT, 1978)

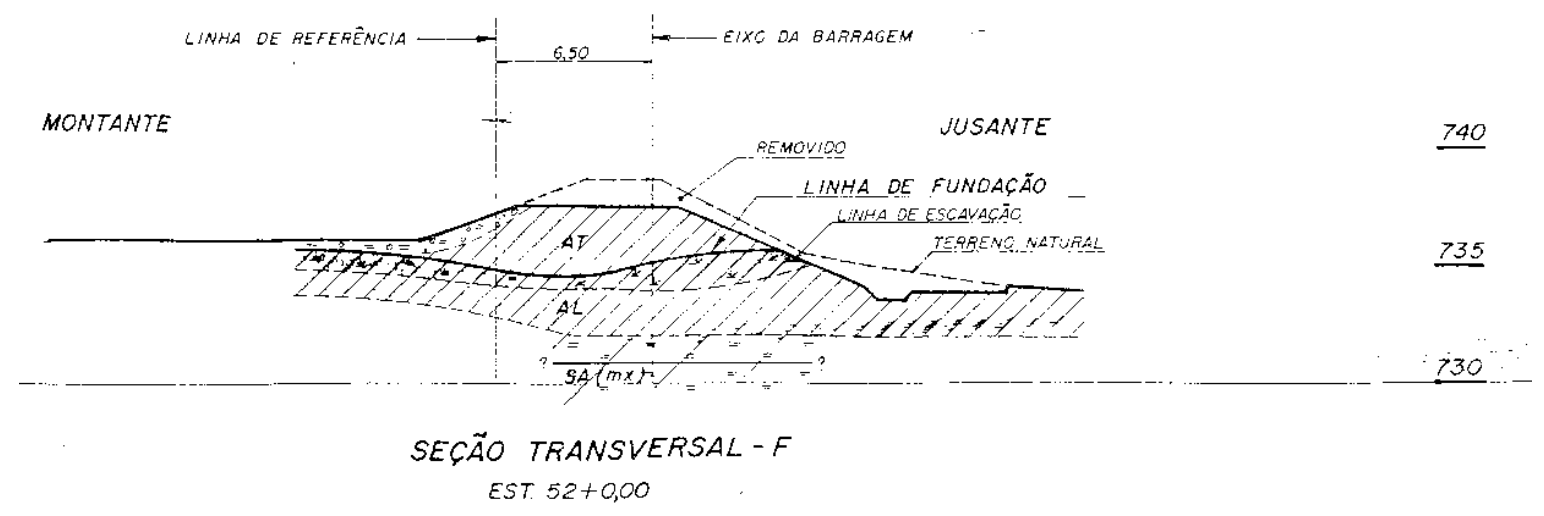

Figura 4.17: Seção Transversal F - estaca 52 + 0,00 (LIGHT, 1978) 


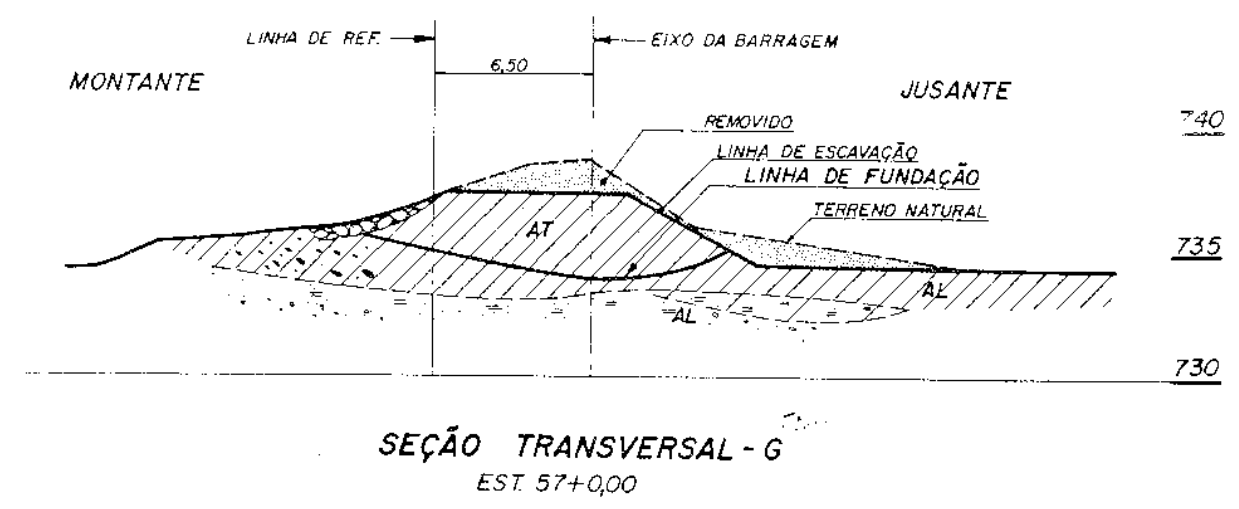

Figura 4.18: Seção Transversal G - estaca 57 + 0,00 (LIGHT, 1978)

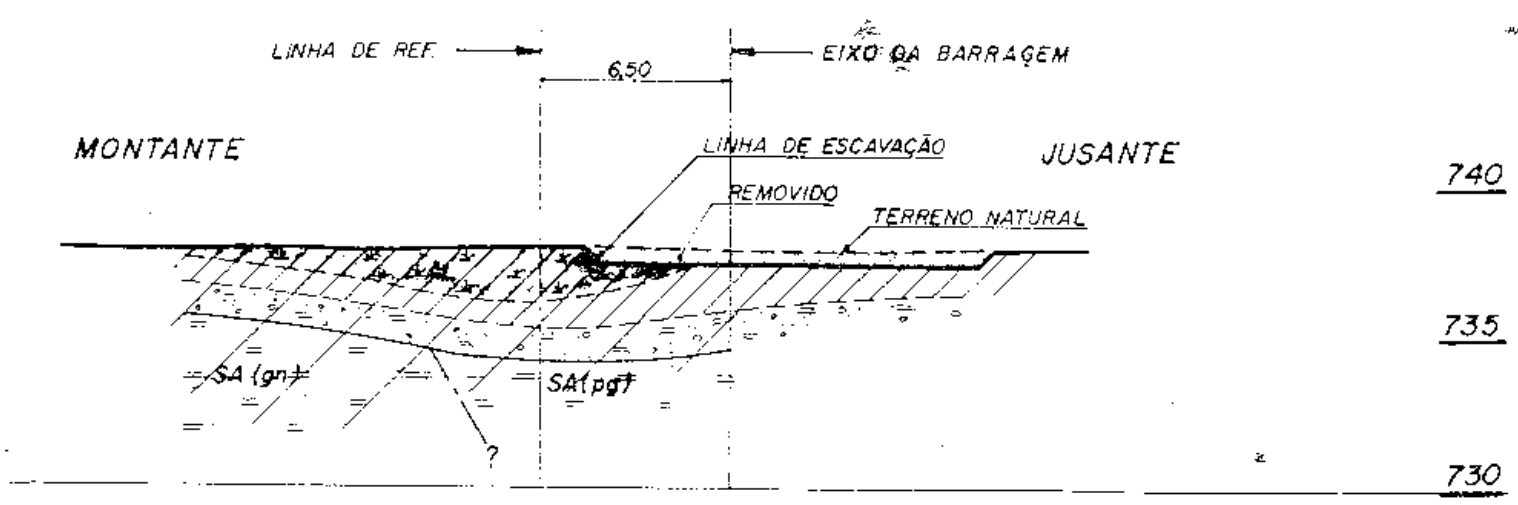

SECÄO TRANSVERSAL - $H$

EST $72+0,00$

Figura 4.19: Seção Transversal H - estaca 72 + 0,00 (LIGHT, 1978) 
As áreas inundadas pelo reservatório formado e o volume acumulado são determinados em função do nível d'água através das curvas apresentadas na Figura 4.20 .

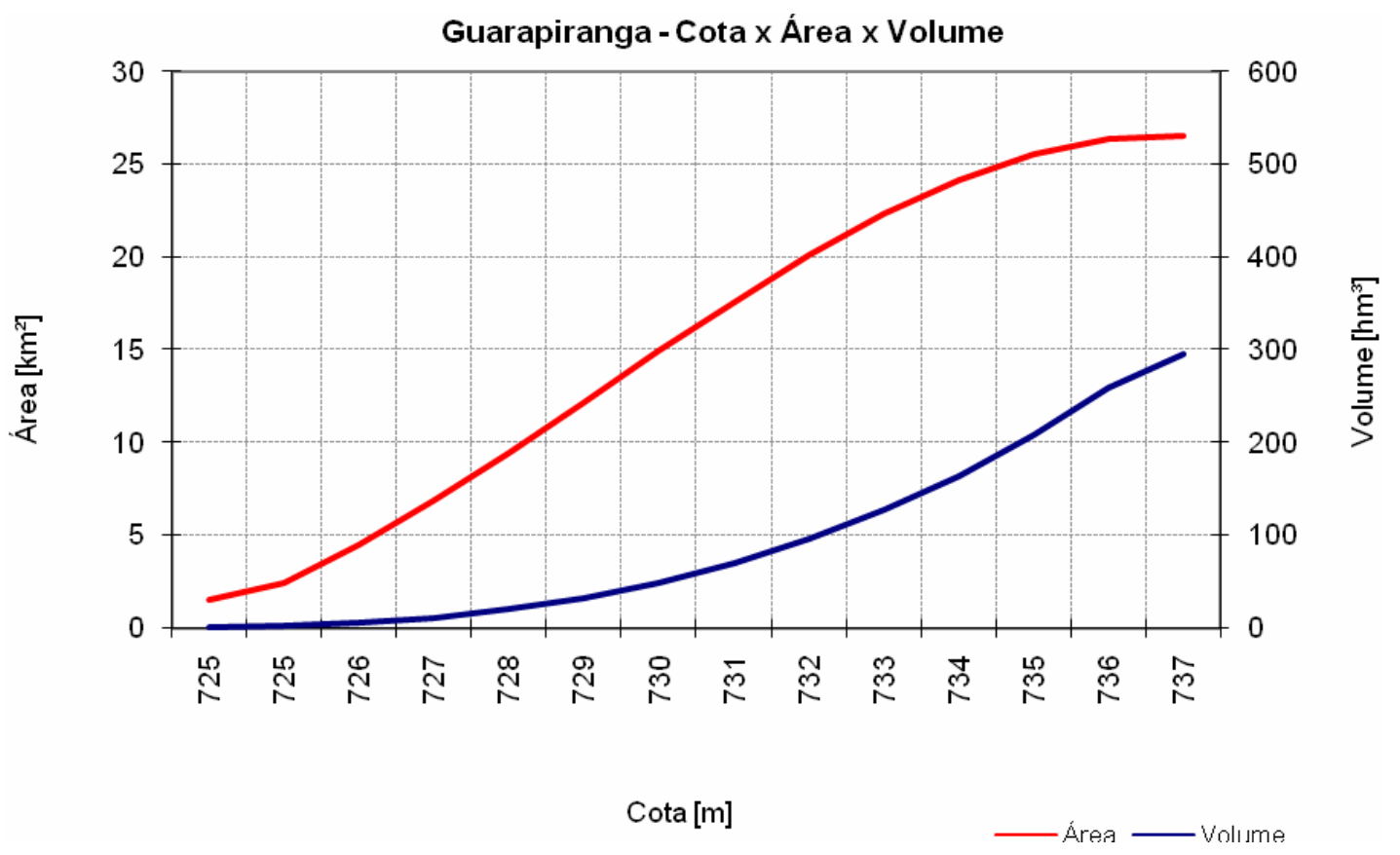

Figura 4.20: Curva Cota-Área-Volume do Reservatório Guarapiranga

\subsection{Estudo das Hipóteses de Ruptura}

Neste item, são apresentados os resultados dos estudos que objetivaram definir os critérios e parâmetros de ruptura da barragem Guarapiranga. Os estudos desenvolvidos basearam-se na análise e estabelecimento de modelos de ruptura e na definição dos parâmetros necessários para a modelação da formação de brechas no maciço de terra e o conseqüente hidrograma efluente.

As hipóteses de ruptura consideradas são ligadas aos possíveis mecanismos de rompimento, ou seja, a falência estrutural do maciço de terra, que pode ser ocasionada, por exemplo, por processos retro-erosivos (piping) ou abalos sísmicos, e a ruptura por galgamento da estrutura ou overtopping. 


\subsubsection{Fatores que Condicionam a Formação de Brechas}

Vários fatores condicionam a formação de brechas em barragens de terra, em conseqüência de rupturas provocadas por galgamento ou falência estrutural. No caso de ruptura por galgamento, podem ser citados os seguintes fatores:

- $\quad$ O tipo de solo e as condições de compactação do maciço de terra;

- $\quad$ A presença se rockfill no maciço de jusante;

- $\quad$ O tipo e a forma de colocação dos materiais de proteção do talude de jusante;

- A inclinação do talude de jusante, que influencia a velocidade do fluxo d'água;

- A falta de nivelamento da crista da barragem, ao longo de seu comprimento, favorecendo o início do processo de abertura da brecha no ponto mais baixo;

- A lâmina d'água sobre a crista da barragem, imediatamente antes da formação da brecha.

No caso de ruptura estrutural, são fatores condicionantes:

- A ausência de sistemas de drenagem internos eficientes, como filtros horizontais tipo sanduíche, construídos com materiais pedregosos francamente permeáveis;

- As condições de compactação do maciço de terra;

- A ausência de transições adequadas entre solos e materiais granulares;

- A presença de fundações arenosas.

As principais características da barragem Guarapiranga avaliadas a partir das informações obtidas junto ao projeto 'Como Construído' (LIGHT, 1978) são resumidas na Tabela 4.2. 
Tabela 4.2: Dados gerais da barragem Guarapiranga.

\begin{tabular}{lc}
\hline Altura máxima da barragem $(\mathrm{m})$ & 14 \\
Comprimento da crista $(\mathrm{m})$ & 1600 \\
Taludes de montante & $3: 1$ \\
Taludes de jusante & $2: 1$ \\
Volume total da barragem de terra $\left(\mathrm{m}^{3}\right)$ & $4,9 \times 10^{5}$ \\
Volume do reservatório para NA max max $\left(\mathrm{m}^{3}\right)$ & $196 \times 10^{6}$ \\
Tipo de material & terra \\
Proteção do talude de jusante & Revestimento \\
Vazão máxima pelo vertedor no NA max $\max \left(\mathrm{m}^{3} / \mathrm{s}\right)$ & vegetal \\
\hline
\end{tabular}

A determinação das prováveis dimensões das brechas e do tempo de ruptura foi feita com base em fórmulas empíricas divulgadas por Fread (1977). Destaca-se que este estudo se restringe a considerar as condições documentadas obra, não levando em conta ensaios e variações nas condições de execução, como e grau de compactação do maciço de terra, praxe usual na análise de estruturas já construídas.

A partir dos estudos desenvolvidos por Fread \& Lewis (1998), considerando parâmetros como a largura da brecha, altura da barragem, volume do reservatório, é possível estimar o tempo de ruptura, bem como a vazão de pico no caso de ruptura da barragem. Para a barragem Guarapiranga foram analisadas duas possibilidades de altura de brecha considerando as seções transversais do maciço (ver Figura 4.11 a Figura 4.19). Sendo assim, foram consideradas duas situações: a primeira com a cota final da base da brecha, na cota 725,00m e a segunda com a cota final da base da brecha na cota $728,00 \mathrm{~m}$.

Para as duas situações foi estimada a altura de água sobre a brecha $\left(\mathrm{h}_{\mathrm{d}}\right)$ subtraindose da cota da crista da barragem pela cota final da base da brecha. Sendo assim:

Situação 1: $h_{d}=10,60 m$;

Situação 2: $h_{d}=13,60 m$;

Considerando a cota da crista da barragem igual a 738,60m e o volume de água correspondente igual a 429,19 $\mathrm{hm}^{3}$, foi possível determinar, através das formulas empíricas de Fread \& Lewis (1998), a largura média da brecha. Os valores resultantes para as situações apresentadas acima são:

Situação 1: b= 171m; 
Situação 2: b=182m;

O tempo de ruptura foi estimado levando em consideração o volume do reservatório no inicio da ruptura e a altura de água sobre a brecha.

Situação 1: $\tau=9$,8 horas - aproximadamente 9 horas e 50 minutos;

Situação 2: $\tau=7,8$ horas - aproximadamente 7 horas e 50 minutos;

Uma vez definidos os parâmetros 'tempo de evolução da brecha' e 'largura da brecha', puderam ser elaborados alguns cenários de ruptura visando à simulação no modelo matemático Cliv Plus e a determinação de linhas d'água e áreas inundáveis resultantes.

\subsubsection{Simulações de Ruptura por Overtopping}

Para as simulações de overtopping foram elaborados cenários considerando a variação dos parâmetros: expoente de evolução da brecha, largura da brecha e tempo de ruptura. Os cenários foram elaborados com o propósito de avaliar a sensibilidade dos parâmetros adotados e sua influência na cheia resultante.

Para todos os cenários simulados, foi considerado o evento ocorrido em janeiro de 1976, cujo hidrograma está apresentado na Figura 4.3 e que, tanto na situação original das obras, como sob as novas condições das estruturas, isto é, a reforma e aplicação promovida em 1978, não resultam em potencial galgamento. A condição de overtopping foi obtida simulando-se uma condição na qual o reservatório, no inicio do evento, foi admitido como no máximo de sua capacidade, isto é na cota 736,00m e, portanto acima do nível meta de controle de cheias usual, 735,00m.

Cabe ressaltar que os cenários apresentados a seguir representam uma situação hipotética de ruptura da barragem Guarapiranga, uma vez que, após o evento ocorrido em 1976, as estruturas de vertimento da barragem foram reforçadas devido a construção de em vertedor supelementar garantindo a segurança da estrutura.

a ocorrência do rompimento desta barragem considerando esses cenários é remota.

Os cenários 1 a 8 avaliaram a sensibilidade do modelo quanto ao expoente de evolução da brecha ou seja, sua linearidade (FREAD D. , 1977). Estas simulações consideraram o parâmetro variando entre $0,7,1,0,1,5$ e 3,0. Sendo assim, os 
cenários 1, 2, 3 e 4 representam a ruptura da barragem Guarapiranga na situação em que a base da brecha se encontra na cota 728,00 .

\section{$\underline{\text { Cenário } 1}$}

Este cenário simula o rompimento da Barragem Guarapiranga segundo os parâmetros da Tabela 4.3. Os resultados obtidos da simulação do cenário 1 são apresentados na Tabela 4.4 e na Figura 4.21 a seguir.

Tabela 4.3: Parâmetros utilizados no Cenário 1

\begin{tabular}{|lc|}
\hline Altura de Água sobre a Brecha & (m) 10,6 \\
Expoente de Evolução da Brecha & 0,7 \\
Largura da Brecha & (m) 171,0 \\
Tempo de Ruptura & (h) 9,8 \\
\hline
\end{tabular}

Tabela 4.4: Resultados da Simulação do Cenário 1

\begin{tabular}{lcccc}
\hline & $\begin{array}{c}\text { Q Afluente } \\
\left(\mathrm{m}^{3} / \mathrm{s}\right)\end{array}$ & $\begin{array}{c}\text { Q Efluente } \\
\left(\mathrm{m}^{3} / \mathrm{s}\right)\end{array}$ & $\begin{array}{c}\text { NA Montante } \\
(\mathrm{m})\end{array}$ & $\begin{array}{c}\text { NA Jusante } \\
(\mathrm{m})\end{array}$ \\
\hline Máximo & 848,15 & 7779,33 & 738,60 & 733,46 \\
Mínimo & 56,14 & 30,00 & 724,97 & 733,33 \\
\hline
\end{tabular}

\section{Cenário 2}

Este cenário simula o rompimento da Barragem Guarapiranga segundo os parâmetros da Tabela 4.4. Os resultados obtidos da simulação do cenário 2 são apresentados na Tabela 4.6 e na Figura 4.22 a seguir.

Tabela 4.5: Parâmetros utilizados no Cenário 2

\begin{tabular}{|lc|}
\hline Altura de Água sobre a Brecha & (m) 10,6 \\
Expoente de Evolução da Brecha & 1,0 \\
Largura da Brecha & (m) 171,0 \\
Tempo de Ruptura & (h) 9,8
\end{tabular}

Tabela 4.6: Resultados da Simulação do Cenário 2

$\begin{array}{cccc}\begin{array}{c}\text { Q Afluente } \\ \left(\mathrm{m}^{3} / \mathrm{s}\right)\end{array} & \text { Q Efluente } & \text { NA Montante } & \text { NA Jusante } \\ & \left(\mathrm{m}^{3} / \mathrm{s}\right) & (\mathrm{m}) & (\mathrm{m})\end{array}$




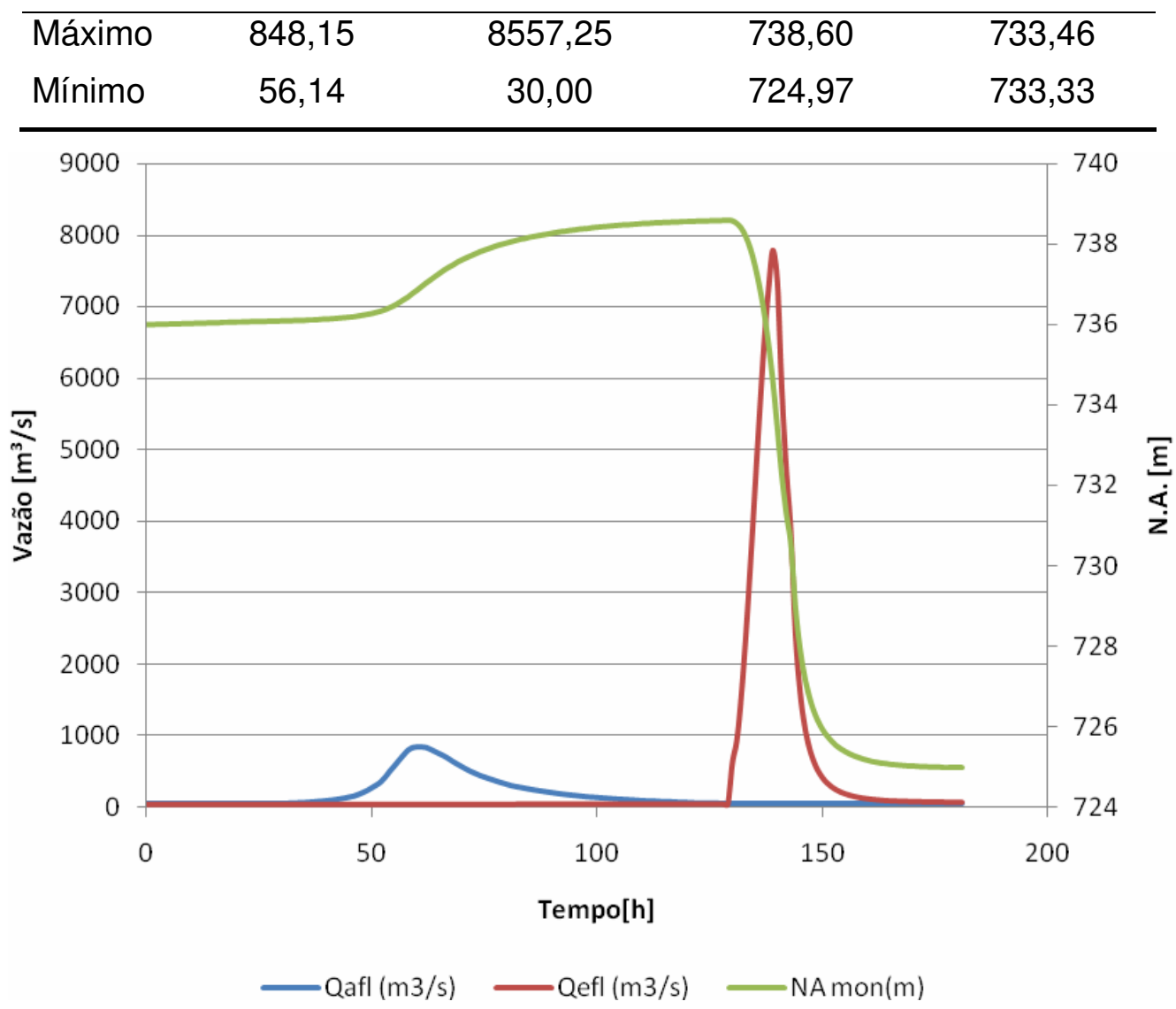

Figura 4.21: Resultados da Simulação do Cenário 1 


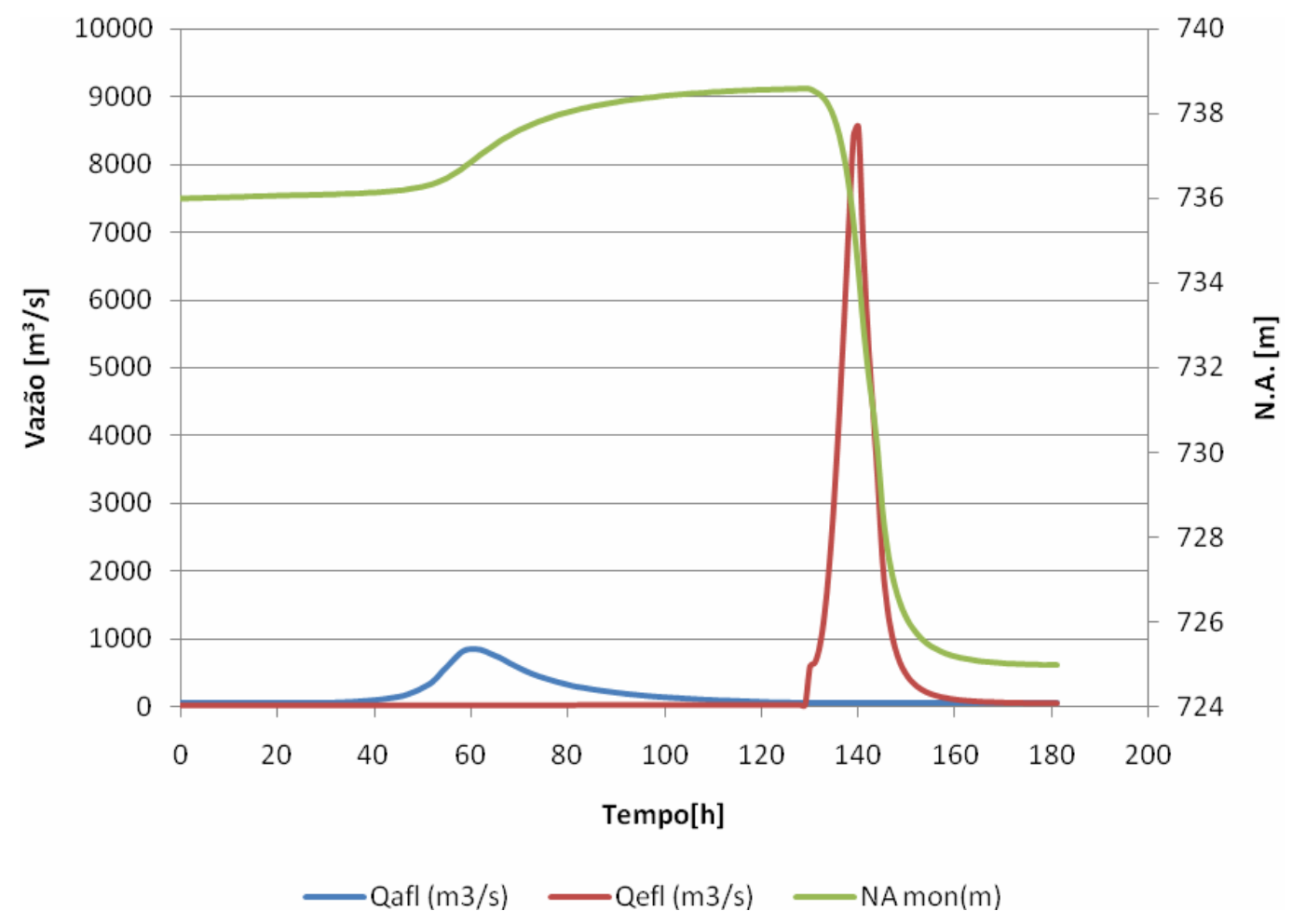

Figura 4.22: Resultados da Simulação do Cenário 2

\section{Cenário 3}

Este cenário simula o rompimento da Barragem Guarapiranga segundo os Tabela 4.5. Os resultados obtidos da simulação do cenário 3 são apresentados na Tabela 4.8 e na Figura 4.23 a seguir.

Tabela 4.7: Parâmetros utilizados no Cenário 3

\begin{tabular}{|ll|}
\hline Altura de Água sobre a Brecha & (m) 10,6 \\
Expoente de Evolução da Brecha & 1,5 \\
Largura da Brecha & (m) 171,0 \\
Tempo de Ruptura & (h) 9,8 \\
\hline
\end{tabular}

Tabela 4.8: Resultados da Simulação do Cenário 3

\begin{tabular}{lcccc}
\hline & $\begin{array}{c}\text { Q Afluente } \\
\left(\mathrm{m}^{3} / \mathrm{s}\right)\end{array}$ & $\begin{array}{c}\text { Q Efluente } \\
\left(\mathrm{m}^{3} / \mathrm{s}\right)\end{array}$ & $\begin{array}{c}\text { NA Montante } \\
(\mathrm{m})\end{array}$ & $\begin{array}{c}\text { NA Jusante } \\
(\mathrm{m})\end{array}$ \\
\hline Máximo & 848,15 & 9699,63 & 738,60 & 733,46 \\
Mínimo & 56,14 & 30,00 & 724,97 & 733,33 \\
\hline
\end{tabular}




\section{Cenário 4}

Este cenário simula o rompimento da Barragem Guarapiranga segundo os seguintes parâmetros:

Tabela 4.9: Parâmetros utilizados no Cenário 4

\begin{tabular}{|lc|}
\hline Altura de Água sobre a Brecha & (m) 10,6 \\
Expoente de Evolução da Brecha & 3,0 \\
Largura da Brecha & (m) 171,0 \\
Tempo de Ruptura & (h) 9,8 \\
\hline
\end{tabular}

Os resultados obtidos da simulação do cenário 4 são apresentados na Tabela 4.10 e na Figura 4.24 a seguir.

Tabela 4.10: Resultados da Simulação do Cenário 4

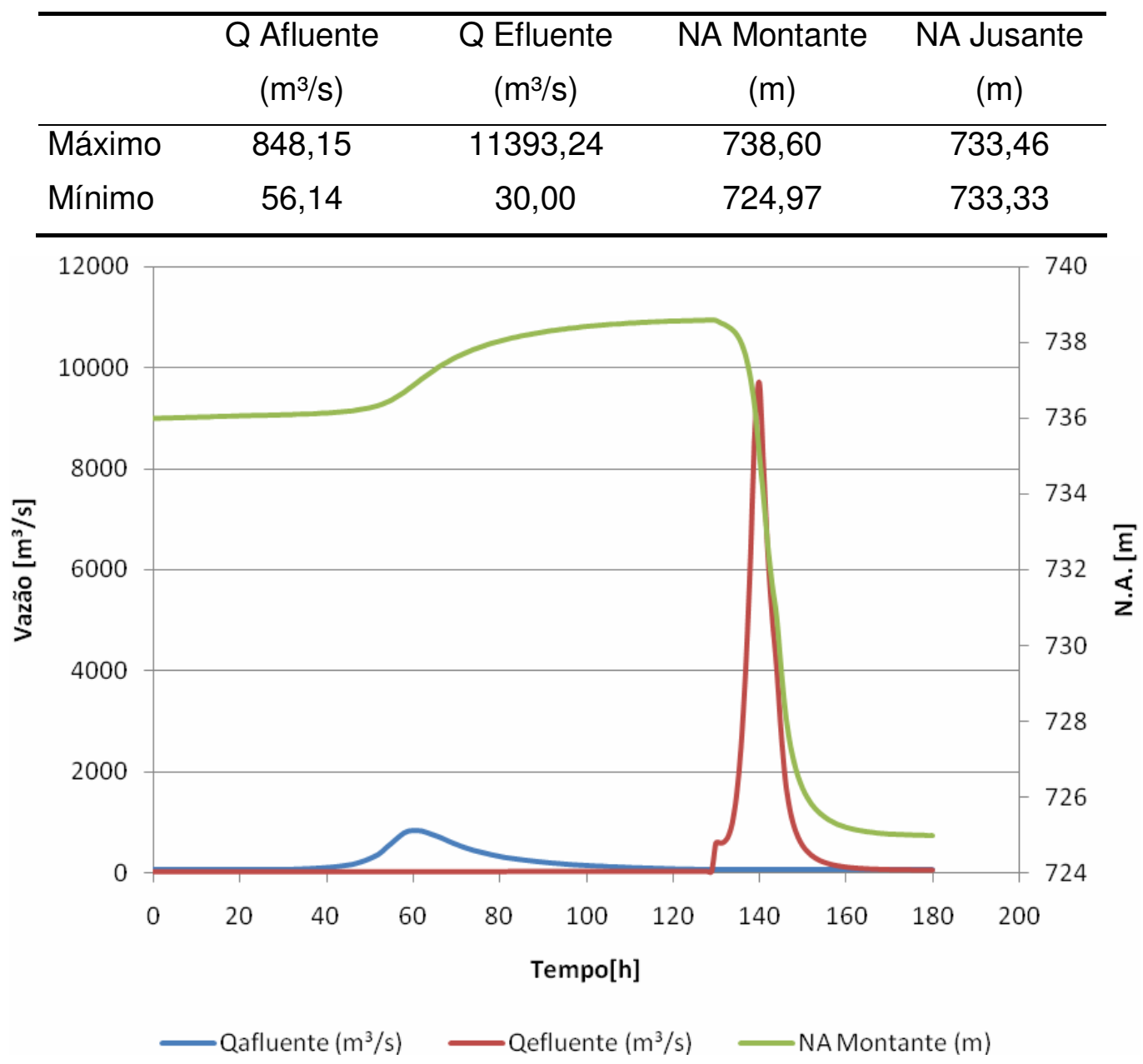

Figura 4.23: Resultados da Simulação do Cenário 3 


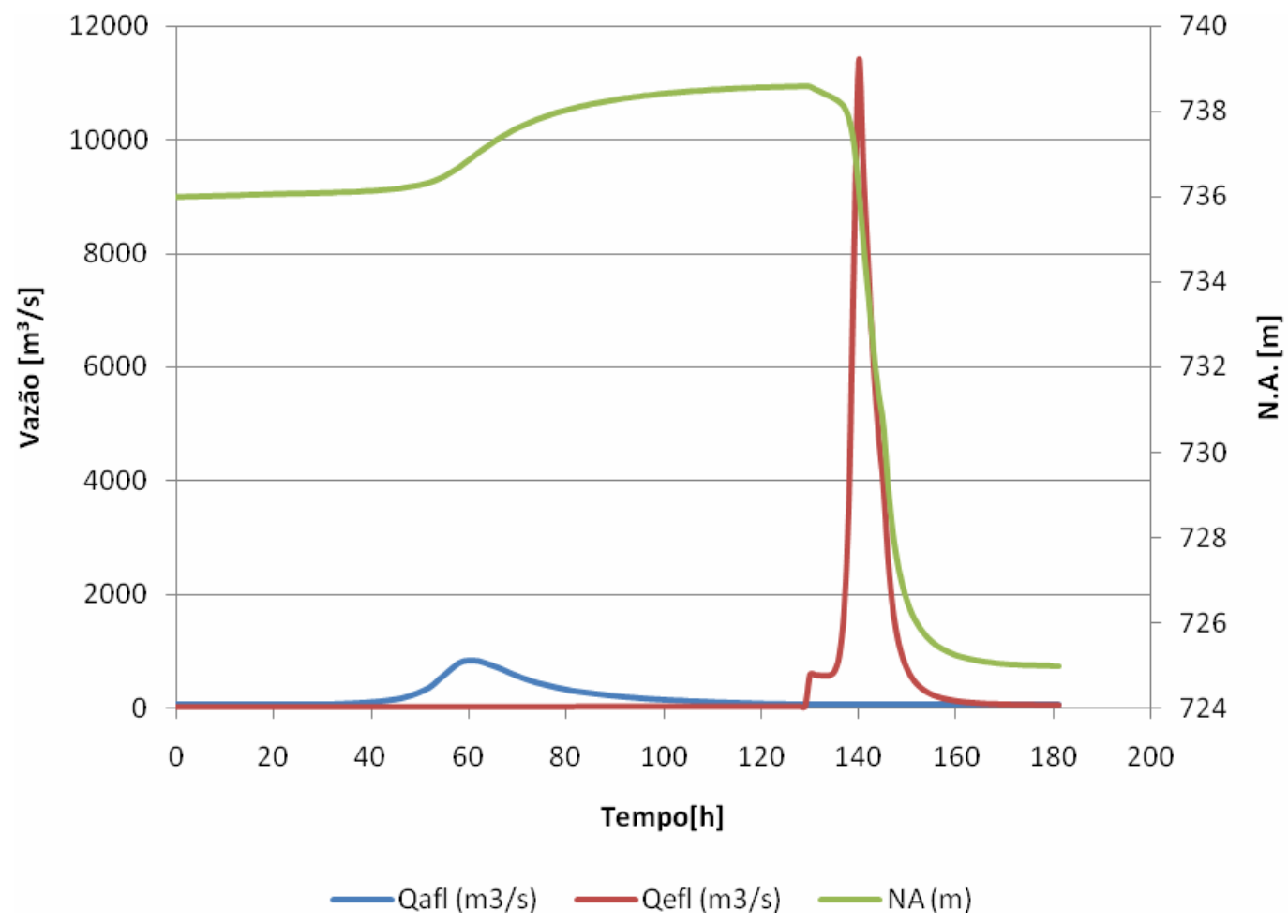

Figura 4.24: Resultados da Simulação do Cenário 4

Os cenários 5, 6, 7 e 8 consideraram a sensibilidade do modelo matemático em relação à variação do expoente de evolução da brecha $(0,7,1,0,1,5$ e 3,0) para a situação em que a base da brecha se encontra na cota 725,00.

\section{Cenário 5}

Este cenário simula o rompimento da Barragem Guarapiranga segundo os seguintes parâmetros:

Tabela 4.11: Parâmetros utilizados no Cenário 5

\begin{tabular}{|ll|}
\hline Altura de Água sobre a Brecha & (m) 13,6 \\
Expoente de Evolução da Brecha & 0,7 \\
Largura da Brecha & (m) 182,0 \\
Tempo de Ruptura & (h) 7,8 \\
\hline
\end{tabular}

Os resultados obtidos da simulação do cenário 5 são apresentados na Tabela $4.12 \mathrm{e}$ na Figura 4.25 a seguir.

Tabela 4.12: Resultados da Simulação do Cenário 5 


\begin{tabular}{lcccc}
\hline & $\begin{array}{c}\text { Q Afluente } \\
\left(\mathrm{m}^{3} / \mathrm{s}\right)\end{array}$ & $\begin{array}{c}\text { Q Efluente } \\
\left(\mathrm{m}^{3} / \mathrm{s}\right)\end{array}$ & $\begin{array}{c}\text { NA Montante } \\
(\mathrm{m})\end{array}$ & $\begin{array}{c}\text { NA Jusante } \\
(\mathrm{m})\end{array}$ \\
\hline Máximo & 848,15 & 8928,77 & 738,60 & 733,46 \\
Mínimo & 56,14 & 30,00 & 725,60 & 733,33 \\
\hline
\end{tabular}

\section{Cenário 6}

Este cenário simula o rompimento da Barragem Guarapiranga segundo os seguintes parâmetros:

Tabela 4.13: Parâmetros utilizados no Cenário 6

\begin{tabular}{|ll|}
\hline Altura de Água sobre a Brecha & (m) 13,6 \\
Expoente de Evolução da Brecha & 1,0 \\
Largura da Brecha & (m) 182,0 \\
Tempo de Ruptura & (h) 7,8 \\
\hline
\end{tabular}

Os resultados obtidos da simulação do cenário 6 são apresentados na Tabela 4.14 e na Figura 4.26 a seguir.

Tabela 4.14: Resultados da Simulação do Cenário 6

\begin{tabular}{lcccc}
\hline & $\begin{array}{c}\text { Q Afluente } \\
\left(\mathrm{m}^{3} / \mathrm{s}\right)\end{array}$ & $\begin{array}{c}\text { Q Efluente } \\
\left(\mathrm{m}^{3} / \mathrm{s}\right)\end{array}$ & $\begin{array}{c}\text { NA Montante } \\
(\mathrm{m})\end{array}$ & $\begin{array}{c}\text { NA Jusante } \\
(\mathrm{m})\end{array}$ \\
\hline Máximo & 848,15 & 9814,52 & 738,60 & 733,46 \\
Mínimo & 56,14 & 30,00 & 725,67 & 733,33 \\
\hline
\end{tabular}

\section{Cenário 7}

Este cenário simula o rompimento da Barragem Guarapiranga segundo os seguintes parâmetros:

Tabela 4.15: Parâmetros utilizados no Cenário 7

\begin{tabular}{|lc|}
\hline Altura de Água sobre a Brecha & (m) 13,6 \\
Expoente de Evolução da Brecha & 1,5 \\
Largura da Brecha & (m) 182,0 \\
Tempo de Ruptura & (h) 7,8 \\
\hline
\end{tabular}


Os resultados obtidos da simulação do cenário 7 são apresentados na Tabela 4.16 e na Figura 4.27 a seguir.

Tabela 4.16: Resultados da Simulação do Cenário 7

\begin{tabular}{lcccc}
\hline & $\begin{array}{c}\text { Q Afluente } \\
\left(\mathrm{m}^{3} / \mathrm{s}\right)\end{array}$ & $\begin{array}{c}\text { Q Efluente } \\
\left(\mathrm{m}^{3} / \mathrm{s}\right)\end{array}$ & $\begin{array}{c}\text { NA Montante } \\
(\mathrm{m})\end{array}$ & $\begin{array}{c}\text { NA Jusante } \\
(\mathrm{m})\end{array}$ \\
\hline Máximo & 848,15 & 10957,68 & 738,60 & 733,46 \\
Mínimo & 56,14 & 30,00 & 725,75 & 733,33 \\
\hline
\end{tabular}

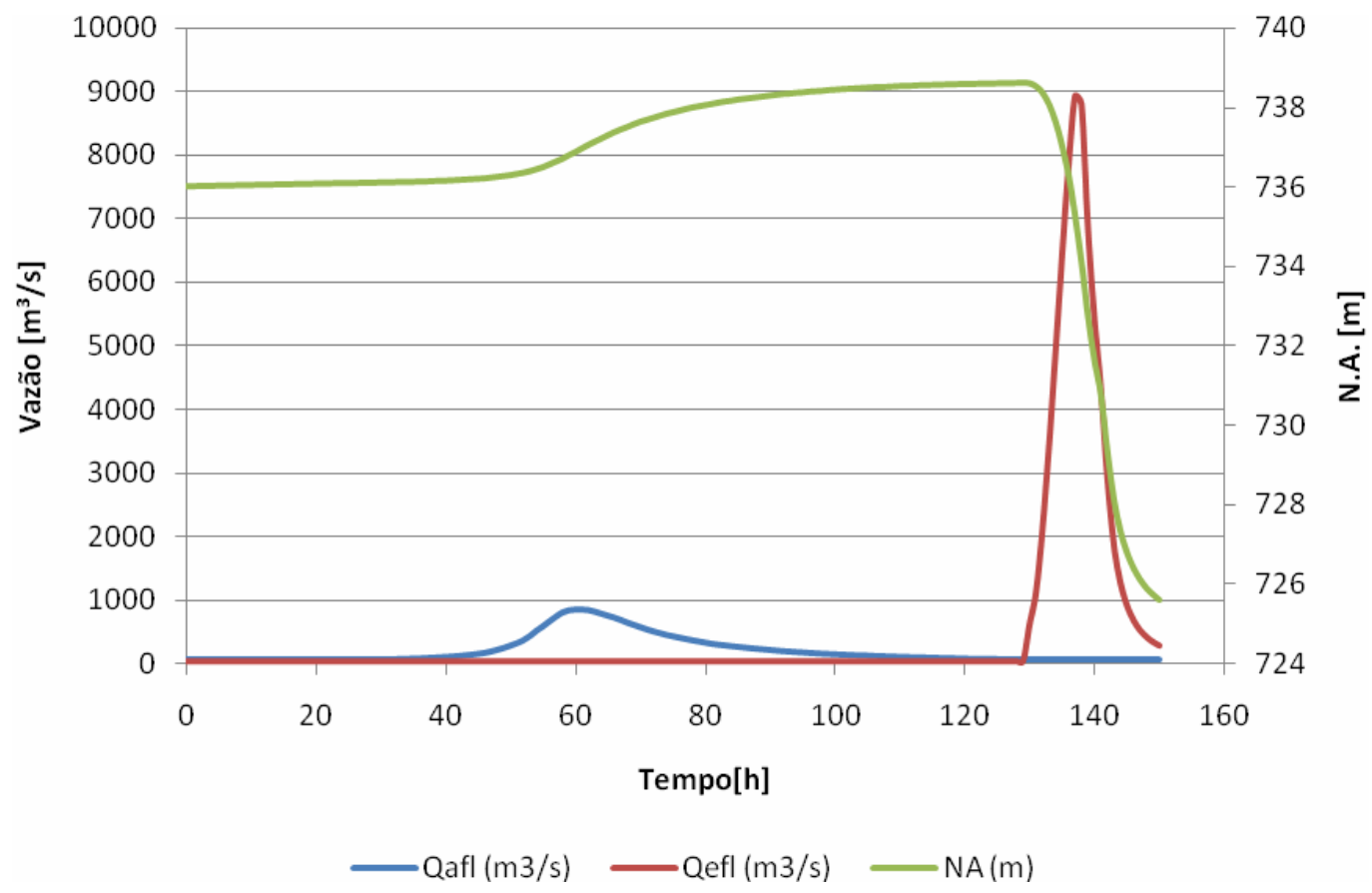

Figura 4.25: Resultados da Simulação do Cenário 5 


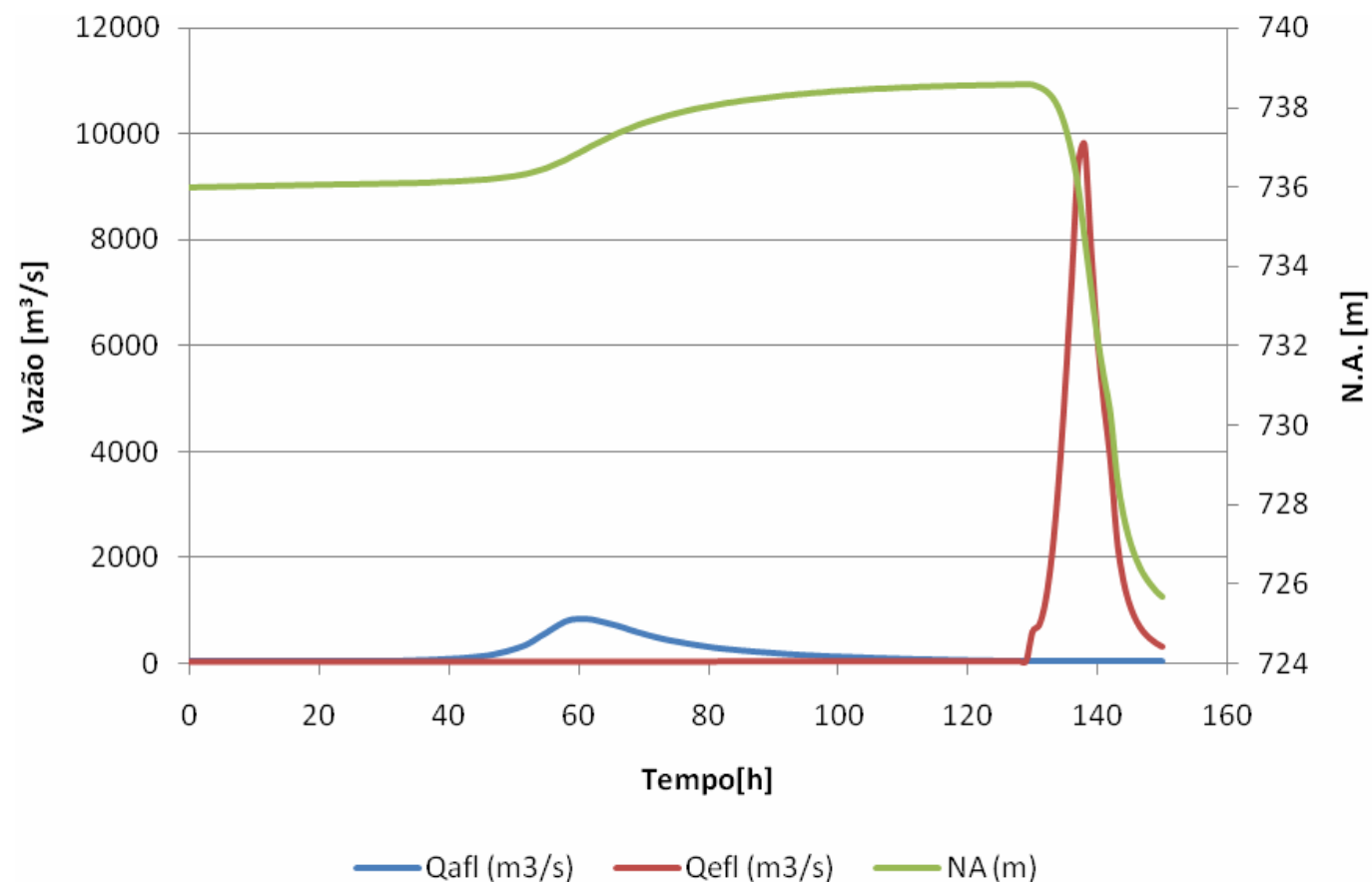

Figura 4.26: Resultados da Simulação do Cenário 6

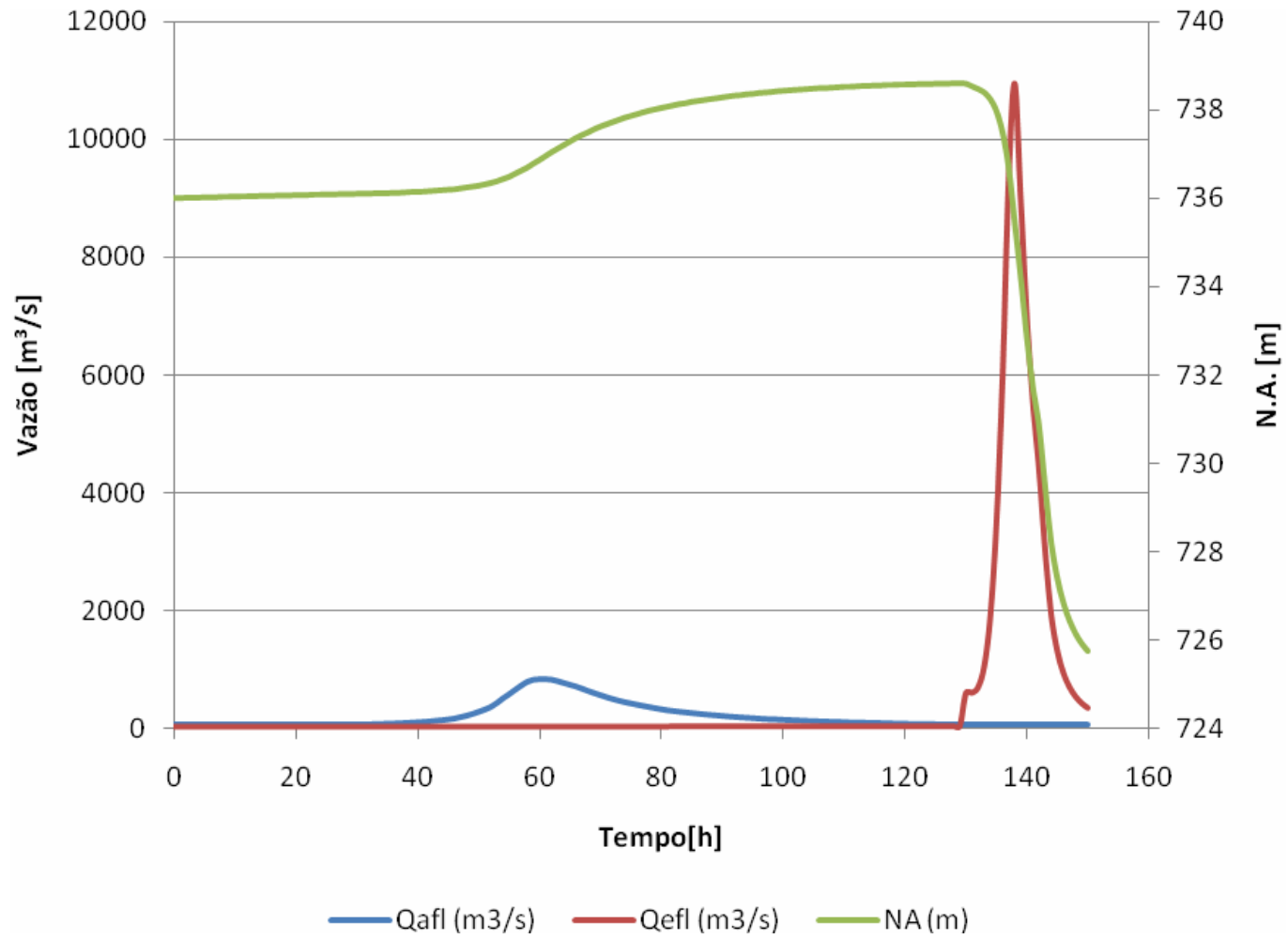

Figura 4.27: Resultados da Simulação do Cenário 7 


\section{Cenário 8}

Este cenário simula o rompimento da Barragem Guarapiranga segundo os parâmetros da Tabela 4.17. Os resultados obtidos da simulação do cenário 8 são apresentados na Tabela 4.18 e na Figura 4.28 a seguir.

Tabela 4.17: Parâmetros utilizados no Cenário 8

\begin{tabular}{|ll|}
\hline Altura de Água sobre a Brecha & (m) 13,6 \\
Expoente de Evolução da Brecha & 3,0 \\
Largura da Brecha & (m) 182,0 \\
Tempo de Ruptura & (h) 7,8 \\
\hline
\end{tabular}

Tabela 4.18: Resultados da Simulação do Cenário 8

\begin{tabular}{lcccc}
\hline & $\begin{array}{c}\text { Q Afluente } \\
\left(\mathrm{m}^{3} / \mathrm{s}\right)\end{array}$ & $\begin{array}{c}\text { Q Efluente } \\
\left(\mathrm{m}^{3 / \mathrm{s}}\right)\end{array}$ & $\begin{array}{c}\text { NA Montante } \\
(\mathrm{m})\end{array}$ & $\begin{array}{c}\text { NA Jusante } \\
(\mathrm{m})\end{array}$ \\
\hline Máximo & 848,15 & 12506,93 & 738,60 & 733,46 \\
Mínimo & 56,14 & 30,00 & 725,86 & 733,33 \\
\hline
\end{tabular}

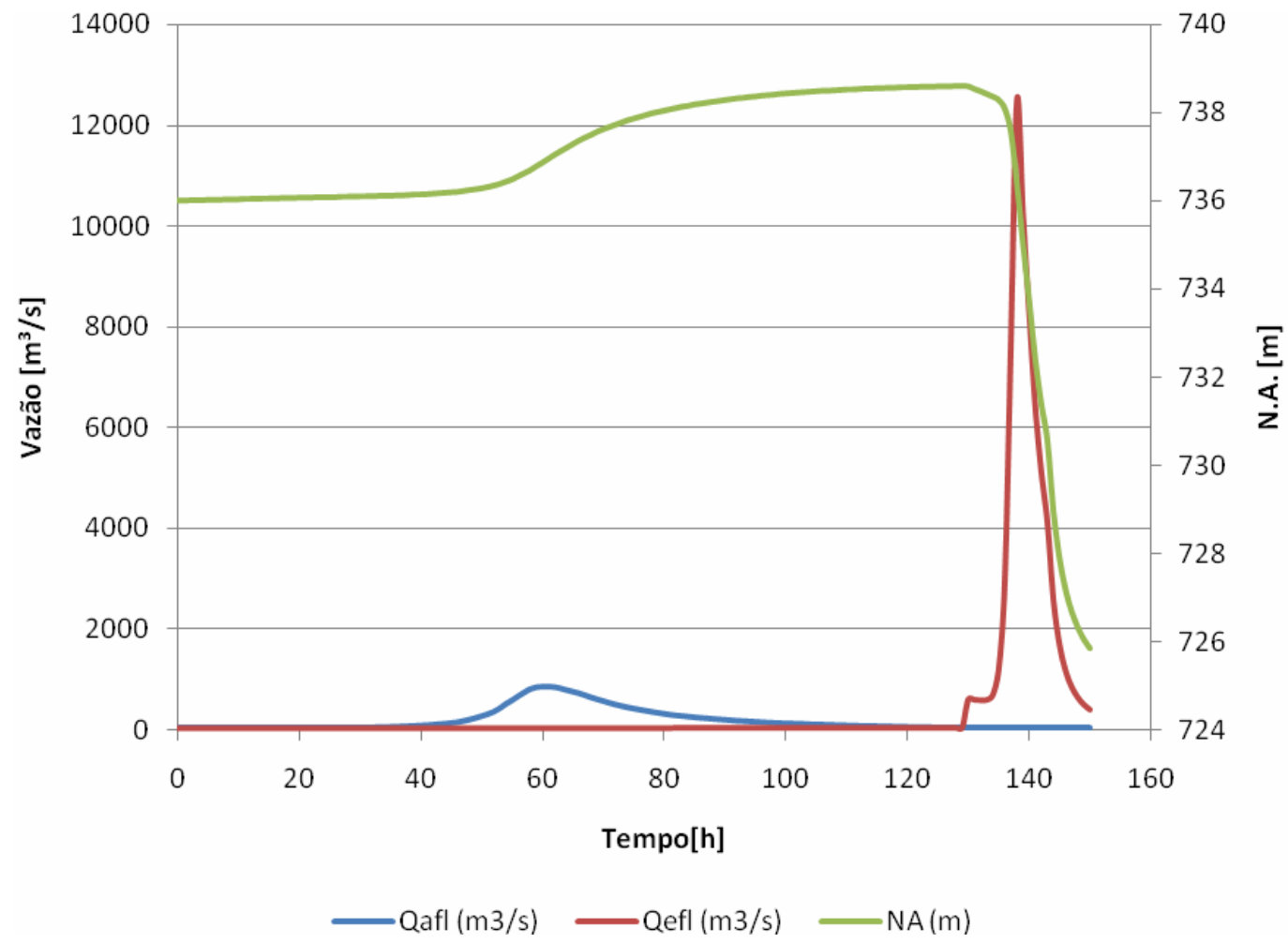

Figura 4.28: Resultados da Simulação do Cenário 8 
Através dessas simulações observa-se que os valores de vazões máximos efluentes variam entre $7800 \mathrm{~m}^{3} / \mathrm{s}$ (para o cenário 1) a $12.500 \mathrm{~m}^{3} / \mathrm{s}$ (para o cenário 8). Ao analisar a Figura 4.29, observa-se que ambas as curvas possuem o mesmo comportamento apresentando maior variação no valor da vazão entre o expoente de evolução da brecha igual a 0,7 e 1,5 e uma certa atenuação da curva a partir do expoente de evolução da brecha 1,5. Sendo assim, pode-se atribuir ao expoente 1,5 o ponto de inflexão das curvas apresentadas na Figura 4.29, adotando este como parâmetro relacionado ao expoente de evolução da brecha.

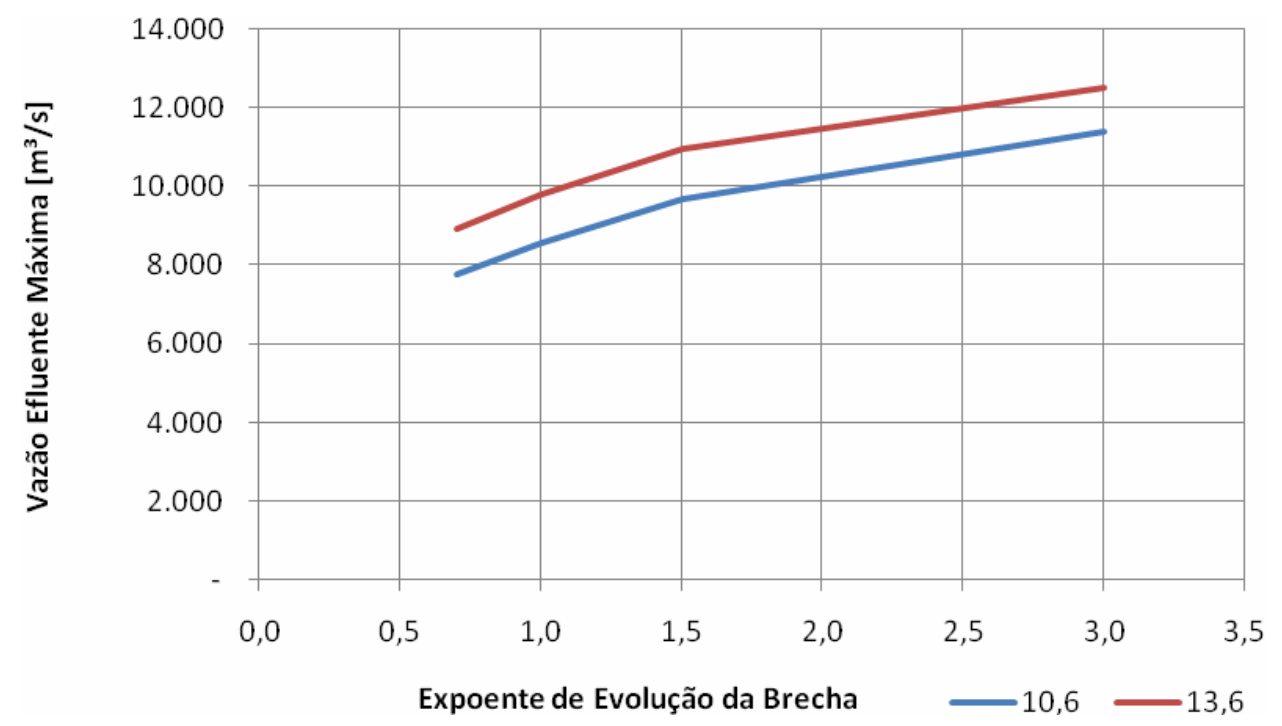

Figura 4.29: Vazões máximas efluentes obtidas nas simulações dos cenários 1 a 8

No que diz respeito à largura da brecha, também foi analisada a sensibilidade do modelo quanto à sua variação. Neste caso, a largura da brecha considerados foram iguais a 50m, 171m/182m (função do $h_{d}$ ) e 300m. Nos cenários 9 a 15 foram simuladas as combinações destes parâmetros nas situações em que a altura de água sobre a brecha é igual a 10,6 e 13,6, considerando o expoente de evolução da brecha igual a 1,5 .

\section{Cenário 9}

A simulação realizada neste cenário considerou os seguintes parâmetros:

Tabela 4.19: Parâmetros utilizados no Cenário 9 


\begin{tabular}{|ll|}
\hline Altura de Água sobre a Brecha & (m) 10,6 \\
Expoente de Evolução da Brecha & 1,5 \\
Largura da Brecha & (m) 50,0 \\
Tempo de Ruptura & (h) 9,8 \\
\hline
\end{tabular}

Os resultados obtidos da simulação deste cenário estão apresentados na Tabela 4.20 e na Figura 4.30

Tabela 4.20: Resultados da Simulação do Cenário 9

\begin{tabular}{ccccc}
\hline & $\begin{array}{c}\text { Q Afluente } \\
\left(\mathrm{m}^{3} / \mathrm{s}\right)\end{array}$ & $\begin{array}{c}\text { Q Efluente } \\
\left(\mathrm{m}^{3} / \mathrm{s}\right)\end{array}$ & $\begin{array}{c}\text { NA Montante } \\
(\mathrm{m})\end{array}$ & $\begin{array}{c}\text { NA Jusante } \\
(\mathrm{m})\end{array}$ \\
\hline Máximo & 848,15 & 4257,21 & 738,60 & 733,46 \\
Mínimo & 56,14 & 30,00 & 725,43 & 733,33 \\
\hline
\end{tabular}

\section{Cenário 10}

A simulação realizada neste cenário considerou os seguintes parâmetros:

Tabela 4.21: Parâmetros utilizados no Cenário 10

\begin{tabular}{|lc|}
\hline Altura de Água sobre a Brecha & (m) 10,6 \\
Expoente de Evolução da Brecha & 1,5 \\
Largura da Brecha & (m) 171 \\
Tempo de Ruptura & (h) 9,8 \\
\hline
\end{tabular}

Os resultados obtidos da simulação deste cenário estão apresentados na Tabela 4.22 e na Figura 4.31 a seguir

Tabela 4.22: Resultados da Simulação do Cenário 10

\begin{tabular}{ccccc}
\hline & $\begin{array}{c}\text { Q Afluente } \\
\left(\mathrm{m}^{3} / \mathrm{s}\right)\end{array}$ & $\begin{array}{c}\text { Q Efluente } \\
\left(\mathrm{m}^{3} / \mathrm{s}\right)\end{array}$ & $\begin{array}{c}\text { NA Montante } \\
(\mathrm{m})\end{array}$ & $\begin{array}{c}\text { NA Jusante } \\
(\mathrm{m})\end{array}$ \\
\hline Máximo & 848,15 & 9699,63 & 738,60 & 733,46 \\
Mínimo & 56,14 & 30,00 & 724,97 & 733,33 \\
\hline
\end{tabular}




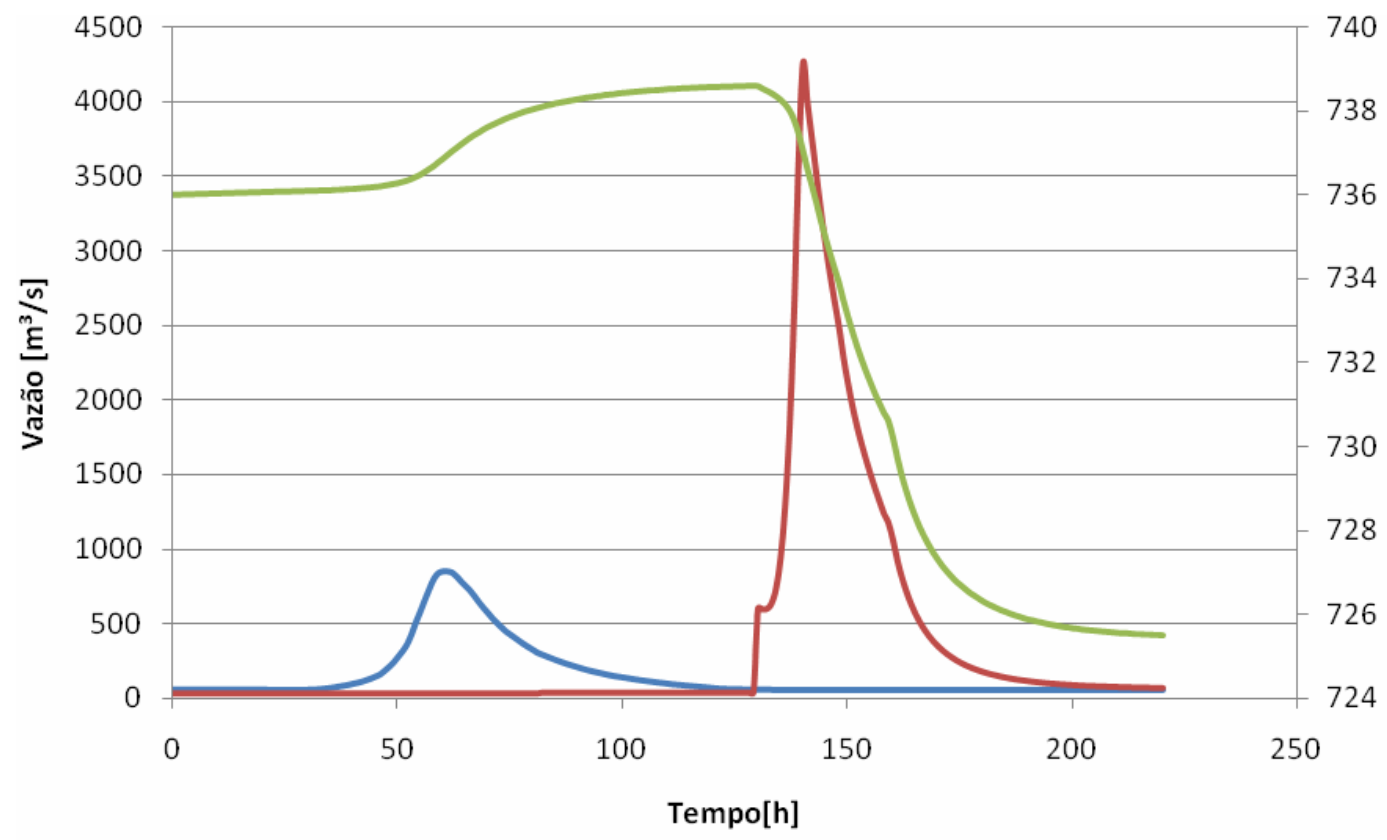

Qafluente $\left(\mathrm{m}^{3} / \mathrm{s}\right) \longrightarrow$ Qefluente $\left(\mathrm{m}^{3} / \mathrm{s}\right) \quad$ NAMontante $(\mathrm{m})$

Figura 4.30: Resultados da Simulação do Cenário 9

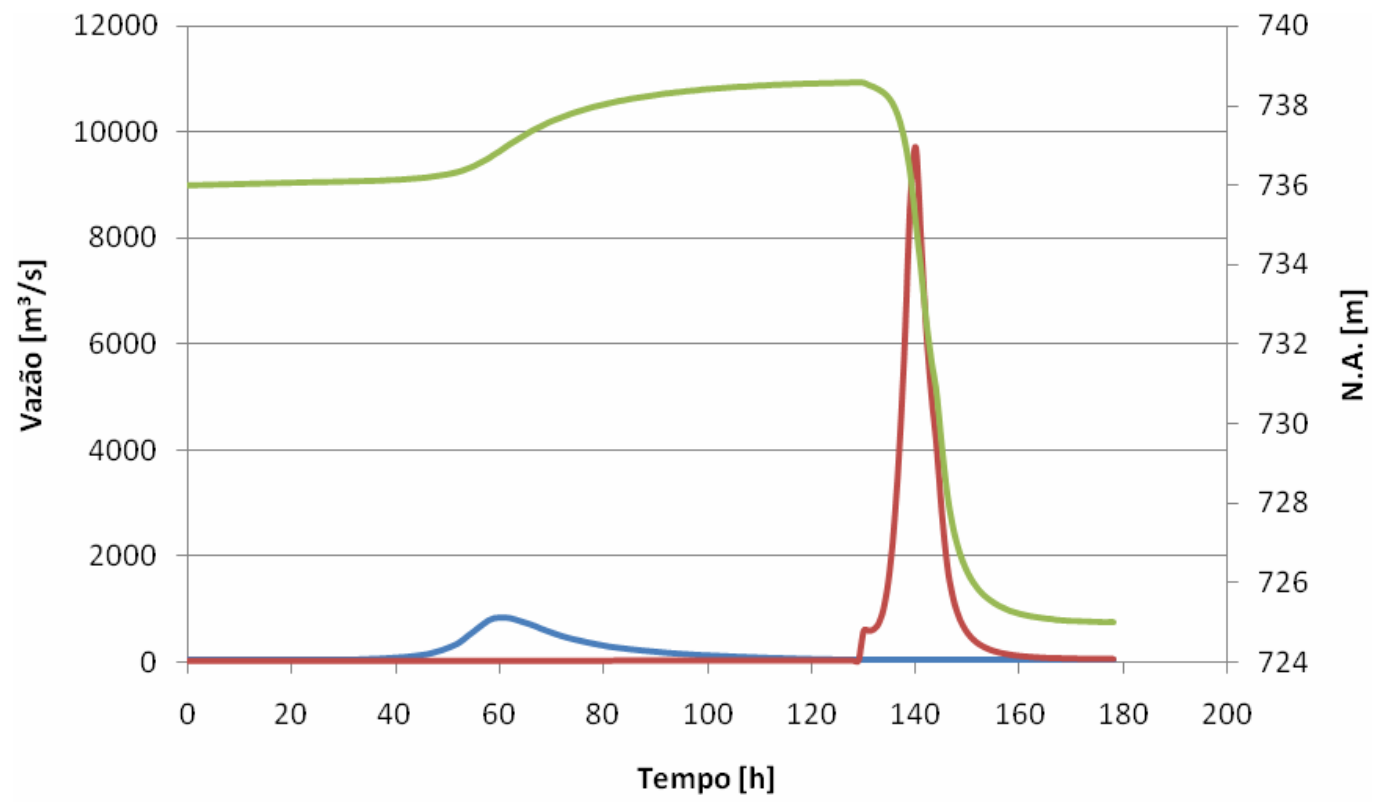

Qafluente $\left(\mathrm{m}^{3} / \mathrm{s}\right) \quad$ Qefluente $\left(\mathrm{m}^{3} / \mathrm{s}\right) \quad$ NA Montante $(\mathrm{m})$

Figura 4.31: Resultados da Simulação do Cenário 10 


\section{Cenário 11}

A simulação realizada neste cenário considerou os seguintes parâmetros:

Tabela 4.23: Parâmetros utilizados no Cenário 11

\begin{tabular}{|ll|}
\hline Altura de Água sobre a Brecha & (m) 10,6 \\
Expoente de Evolução da Brecha & 1,5 \\
Largura da Brecha & (m) 300 \\
Tempo de Ruptura & (h) 9,8 \\
\hline
\end{tabular}

Os resultados obtidos da simulação deste cenário estão apresentados na Tabela 4.24 e na Figura 4.32 .

Tabela 4.24: Resultados da Simulação do Cenário 11

\begin{tabular}{ccccc}
\hline $\begin{array}{c}\text { Q Afluente } \\
\left(\mathrm{m}^{3} / \mathrm{s}\right)\end{array}$ & $\begin{array}{c}\text { Q Efluente } \\
\left(\mathrm{m}^{3 / \mathrm{s}}\right)\end{array}$ & $\begin{array}{c}\text { NA Montante } \\
(\mathrm{m})\end{array}$ & $\begin{array}{c}\text { NA Jusante } \\
(\mathrm{m})\end{array}$ \\
\hline Máximo & 848,15 & 12307,00 & 738,60 & 733,46 \\
Mínimo & 56,14 & 30,00 & 724,85 & 733,33 \\
\hline
\end{tabular}

\section{Cenário 12}

A simulação realizada neste cenário considerou os parâmetros da Tabela 4.26. Os resultados obtidos da simulação deste cenário estão apresentados na Tabela 4.26 e na Figura 4.33.

Tabela 4.25: Parâmetros utilizados no Cenário 12

\begin{tabular}{|ll|}
\hline Altura de Água sobre a Brecha & (m) 13,6 \\
Expoente de Evolução da Brecha & 1,5 \\
Largura da Brecha & (m) 50,0 \\
Tempo de Ruptura & (h) 7,8 \\
\hline
\end{tabular}

Tabela 4.26: Resultados da Simulação do Cenário 12

\begin{tabular}{lcccc}
\hline $\begin{array}{c}\text { Q Afluente } \\
\left(\mathrm{m}^{3} / \mathrm{s}\right)\end{array}$ & $\begin{array}{c}\text { Q Efluente } \\
\left(\mathrm{m}^{3} / \mathrm{s}\right)\end{array}$ & $\begin{array}{c}\text { NA Montante } \\
(\mathrm{m})\end{array}$ & $\begin{array}{c}\text { NA Jusante } \\
(\mathrm{m})\end{array}$ \\
\hline Máximo & 848,15 & 4415,96 & 738,60 & 733,46 \\
Mínimo & 56,14 & 30,00 & 725,45 & 733,33 \\
\hline
\end{tabular}




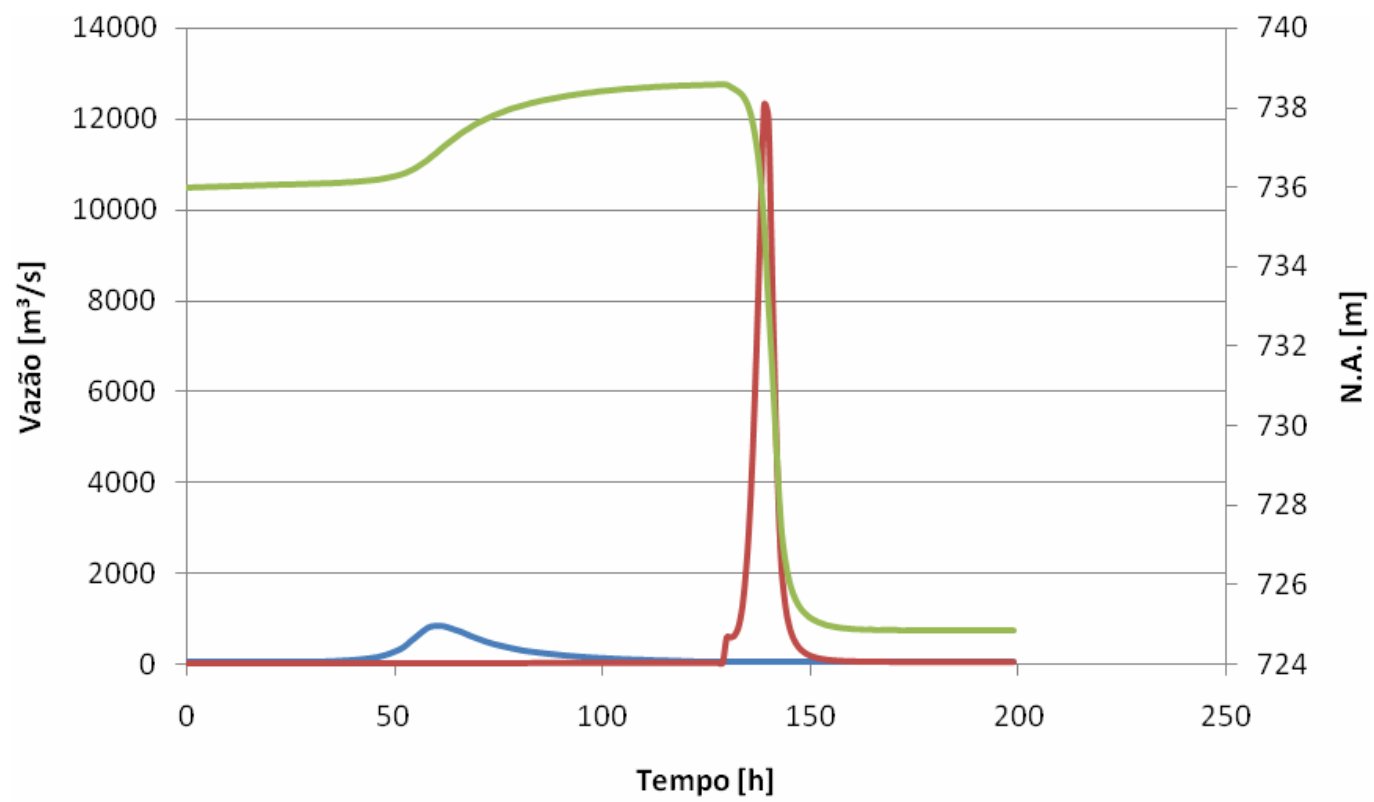

-Qafluente $\left(\mathrm{m}^{3} / \mathrm{s}\right) \quad$ Qefluente $\left(\mathrm{m}^{3} / \mathrm{s}\right) \quad$ NAMontante $(\mathrm{m})$

Figura 4.32: Resultados da Simulação do Cenário 11

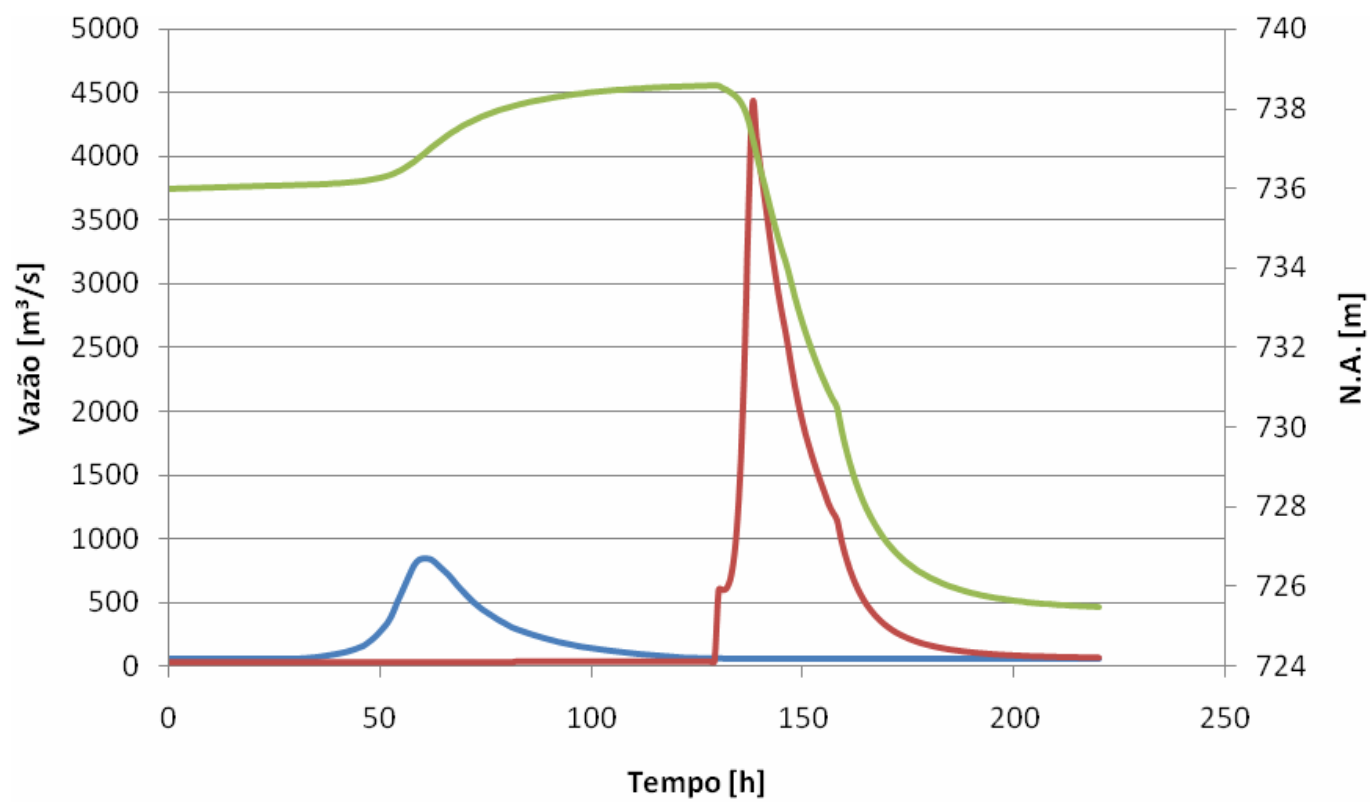

- Qafluente $\left(\mathrm{m}^{3} / \mathrm{s}\right) \quad$ Qefluente $\left(\mathrm{m}^{3} / \mathrm{s}\right) \quad$ NAMontante $(\mathrm{m})$

Figura 4.33: Resultados da Simulação do Cenário 12 


\section{Cenário 13}

A simulação realizada neste cenário considerou os seguintes parâmetros:

Tabela 4.27: Parâmetros utilizados no Cenário 13

\begin{tabular}{|lc|}
\hline Altura de Água sobre a Brecha & (m) 13,6 \\
Expoente de Evolução da Brecha & 1,5 \\
Largura da Brecha & (m) 182 \\
Tempo de Ruptura & (h) 7,8 \\
\hline
\end{tabular}

Os resultados obtidos da simulação deste cenário estão apresentados na Tabela 4.28 e na Figura 4.34.

Tabela 4.28: Resultados da Simulação do Cenário 13

\begin{tabular}{lcccc}
\hline & $\begin{array}{c}\text { Q Afluente } \\
\left(\mathrm{m}^{3} / \mathrm{s}\right)\end{array}$ & $\begin{array}{c}\text { Q Efluente } \\
\left(\mathrm{m}^{3} / \mathrm{s}\right)\end{array}$ & $\begin{array}{c}\text { NA Montante } \\
(\mathrm{m})\end{array}$ & $\begin{array}{c}\text { NA Jusante } \\
(\mathrm{m})\end{array}$ \\
\hline Máximo & 848,15 & 10957,68 & 738,60 & 733,46 \\
Mínimo & 56,14 & 30,00 & 724,98 & 733,33 \\
\hline
\end{tabular}

\section{Cenário 14}

A simulação realizada neste cenário considerou os seguintes parâmetros:

Tabela 4.29: Parâmetros utilizados no Cenário 14

\begin{tabular}{|lc|}
\hline Altura de Água sobre a Brecha & (m) 13,6 \\
Expoente de Evolução da Brecha & 1,5 \\
Largura da Brecha & (m) 300 \\
Tempo de Ruptura & (h) 7,8 \\
\hline
\end{tabular}

Os resultados obtidos da simulação deste cenário estão apresentados na Tabela 4.30 e na Figura 4.35 a seguir

Tabela 4.30: Resultados da Simulação do Cenário 14

\begin{tabular}{ccccc}
\hline & $\begin{array}{c}\text { Q Afluente } \\
\left(\mathrm{m}^{3} / \mathrm{s}\right)\end{array}$ & $\begin{array}{c}\text { Q Efluente } \\
\left(\mathrm{m}^{3} / \mathrm{s}\right)\end{array}$ & $\begin{array}{c}\text { NA Montante } \\
(\mathrm{m})\end{array}$ & $\begin{array}{c}\text { NA Jusante } \\
(\mathrm{m})\end{array}$ \\
\hline Máximo & 848,15 & 14162,41 & 738,60 & 733,46 \\
Mínimo & 56,14 & 30,00 & 724,89 & 733,33 \\
\hline
\end{tabular}




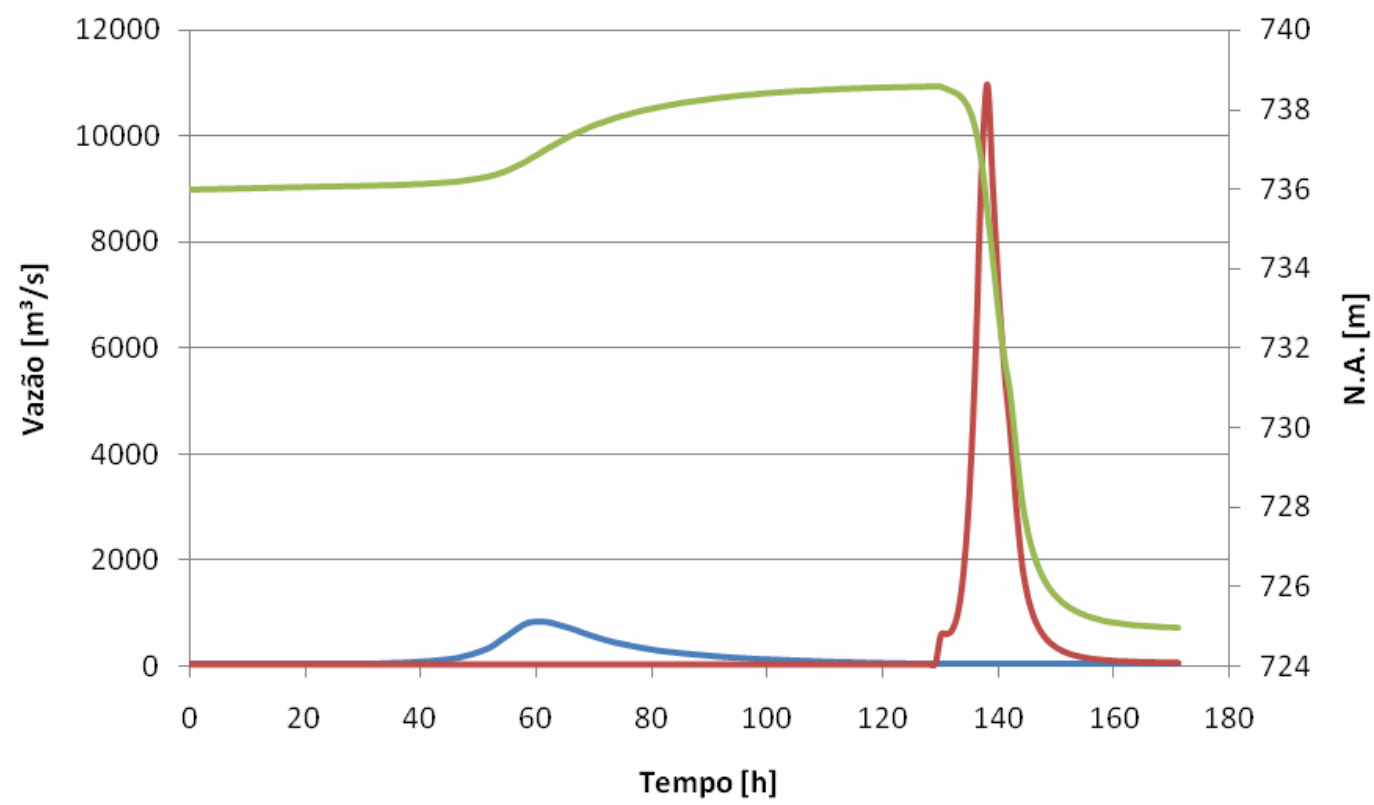

Qafluente $\left(\mathrm{m}^{3} / \mathrm{s}\right) \quad$ Qefluente $\left(\mathrm{m}^{3} / \mathrm{s}\right) \quad$ NAMontante $(\mathrm{m})$

Figura 4.34: Resultados da Simulação do Cenário 13

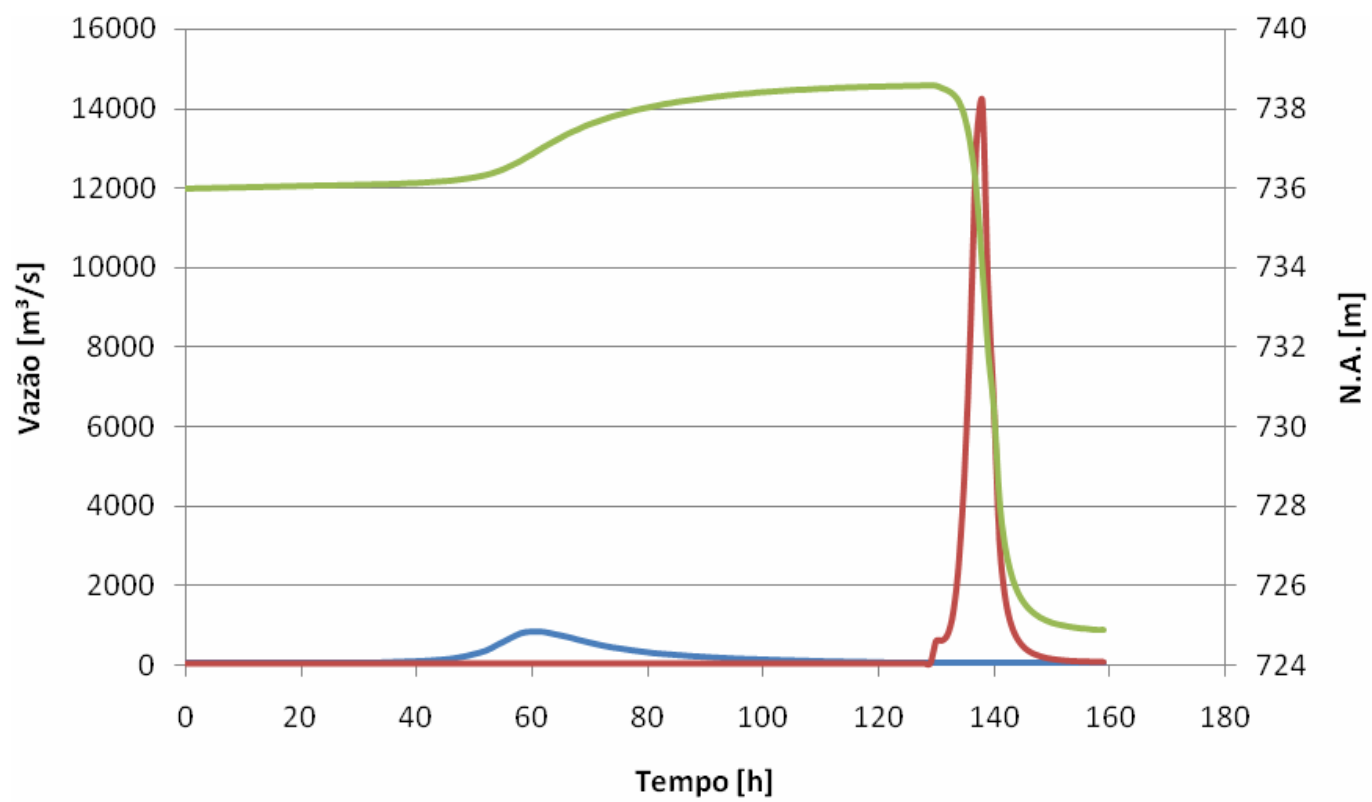

Qafluente $\left(\mathrm{m}^{3} / \mathrm{s}\right) \quad$ Qefluente $\left(\mathrm{m}^{3} / \mathrm{s}\right) \quad$ NA Montante $(\mathrm{m})$

Figura 4.35: Resultados da Simulação do Cenário 14 
Os resultados obtidos através das simulações considerando a sensibilidade do modelo quanto à largura da brecha, mostram que este parâmetro está diretamente relacionado à vazão máxima efluente como pode ser observado na Figura 4.36.

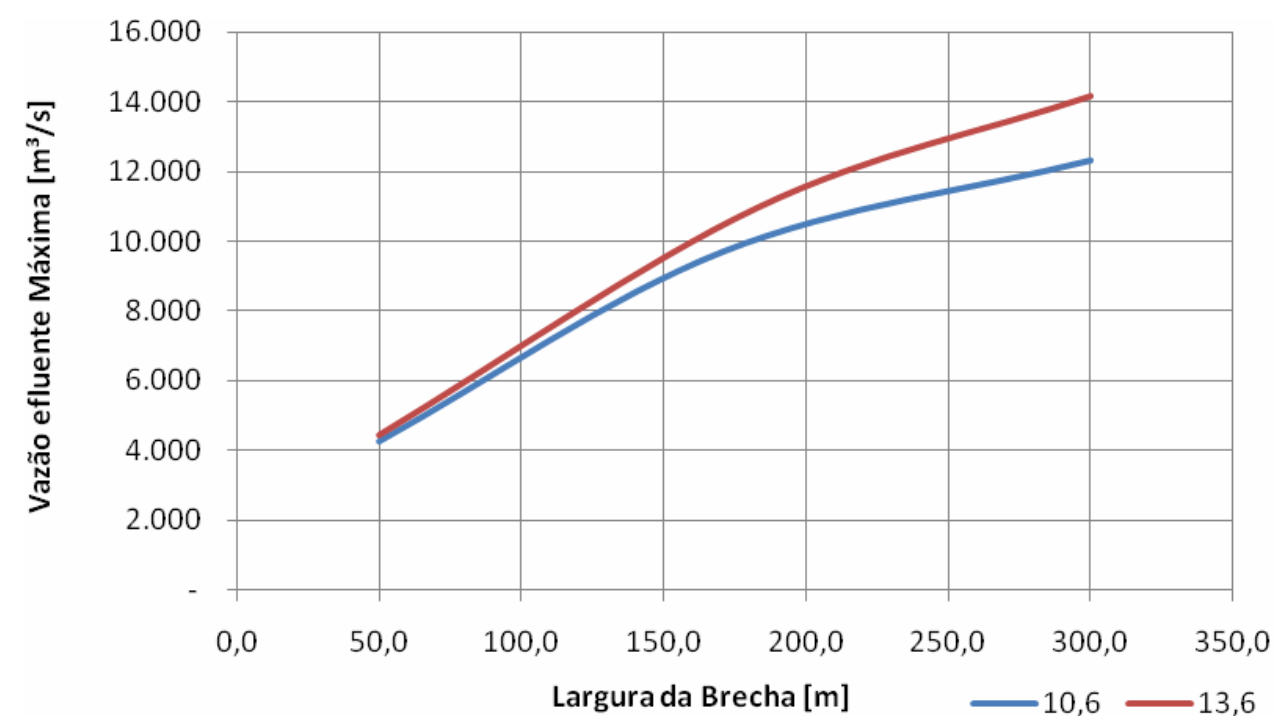

Figura 4.36: Vazões máximas efluentes obtidas nas simulações dos cenários 9 a 14.

O tempo de ruptura é um parâmetro fundamental que depende da altura de água sobre a brecha e do volume de água no reservatório correspondente (FREAD \& LEWIS, 1998). As simulações realizadas para analisar a sensibilidade do modelo CLiv Plus quanto à variação do tempo de ruptura, consideraram o tempo variando entre 4,0h, 7,8/9,8 (função do $h_{d}$ ) e 15 horas.

\section{Cenário 15}

A simulação realizada neste cenário considerou os parâmetros da Tabela 4.31:

Tabela 4.31: Parâmetros utilizados no Cenário 15

\begin{tabular}{|ll|}
\hline Altura de Água sobre a Brecha & (m) 10,6 \\
Expoente de Evolução da Brecha & 1,5 \\
Largura da Brecha & (m) 171,0 \\
Tempo de Evolução da Brecha & (h) 4,0 \\
\hline
\end{tabular}


Os resultados obtidos da simulação deste cenário estão apresentados na Tabela 4.32 e na Figura 4.37.

Tabela 4.32: Resultados da Simulação do Cenário 15

\begin{tabular}{lcccc}
\hline & $\begin{array}{c}\text { Q Afluente } \\
\left(\mathrm{m}^{3} / \mathrm{s}\right)\end{array}$ & $\begin{array}{c}\text { Q Efluente } \\
\left(\mathrm{m}^{3} / \mathrm{s}\right)\end{array}$ & $\begin{array}{c}\text { NA Montante } \\
(\mathrm{m})\end{array}$ & $\begin{array}{c}\text { NA Jusante } \\
(\mathrm{m})\end{array}$ \\
\hline Máximo & 848,15 & 12769,66 & 738,60 & 733,46 \\
Mínimo & 56,14 & 30,00 & 724,97 & 733,33 \\
\hline
\end{tabular}

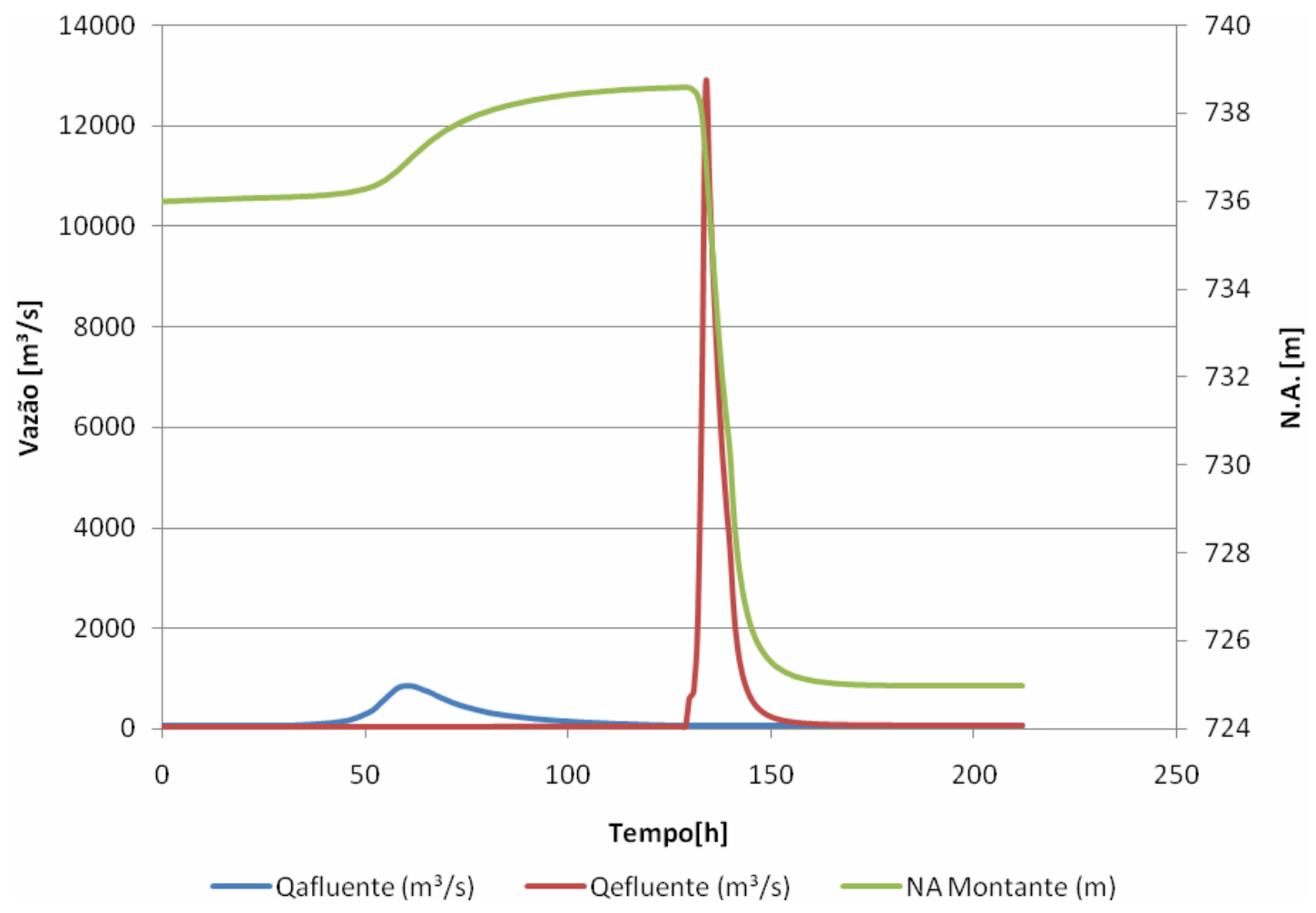

Figura 4.37: Resultados da Simulação do Cenário 15

\section{Cenário 16}

A simulação realizada neste cenário considerou os parâmetros da Tabela 4.34.

Tabela 4.33: Parâmetros utilizados no Cenário 16

\begin{tabular}{|lc|}
\hline Altura de Água sobre a Brecha & (m) 10,6 \\
Expoente de Evolução da Brecha & 1,5 \\
Largura da Brecha & (m) 171,0 \\
Tempo de Evolução da Brecha & (h) 9,8
\end{tabular}


Os resultados obtidos da simulação deste cenário estão apresentados na Tabela 4.34 e na Figura 4.38.

Tabela 4.34: Resultados da Simulação do Cenário 16

\begin{tabular}{ccccc}
\hline & $\begin{array}{c}Q \text { Afluente } \\
\left(\mathrm{m}^{3} / \mathrm{s}\right)\end{array}$ & $\begin{array}{c}\text { Q Efluente } \\
\left(\mathrm{m}^{3} / \mathrm{s}\right)\end{array}$ & $\begin{array}{c}\text { NA Montante } \\
(\mathrm{m})\end{array}$ & $\begin{array}{c}\text { NA Jusante } \\
(\mathrm{m})\end{array}$ \\
\hline Máximo & 848,15 & 9699,63 & 738,60 & 733,46 \\
Mínimo & 56,14 & 30,00 & 724,97 & 733,33 \\
\hline
\end{tabular}

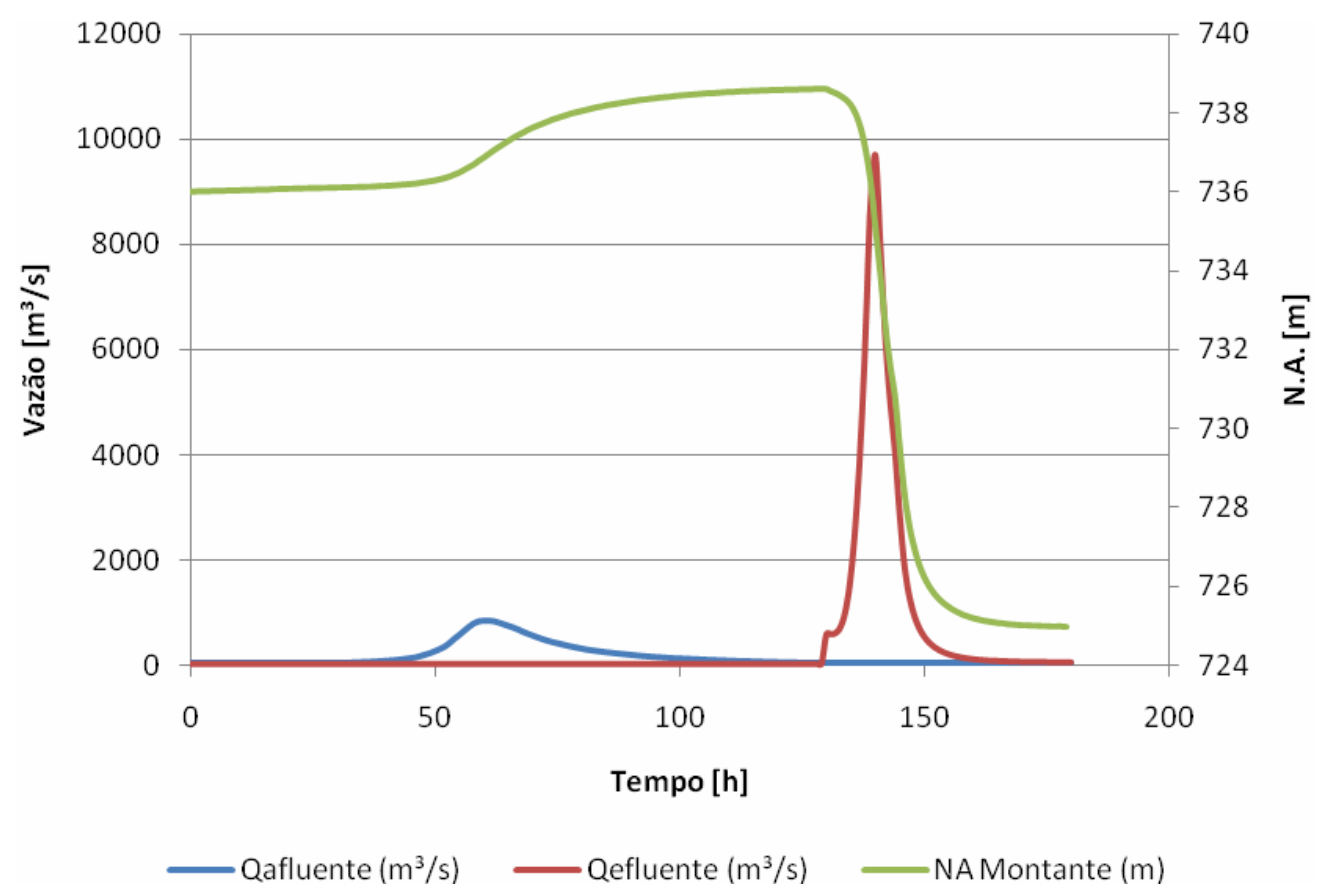

Figura 4.38: Resultados da Simulação do Cenário 16

\section{Cenário 17}

A simulação realizada neste cenário considerou os parâmetros da Tabela 4.35.

Tabela 4.35: Parâmetros utilizados no Cenário 17

\begin{tabular}{|lc|}
\hline Altura de Água sobre a Brecha & (m) 10,6 \\
Expoente de Evolução da Brecha & 1,5 \\
Largura da Brecha & (m) 171,0 \\
Tempo de Evolução da Brecha & (h) 15,0 \\
\hline
\end{tabular}


Os resultados obtidos da simulação deste cenário estão apresentados na Tabela 4.36 e na Figura 4.39 a seguir

Tabela 4.36: Resultados da Simulação do Cenário 17

\begin{tabular}{ccccc}
\hline $\begin{array}{c}\text { Q Afluente } \\
\left(\mathrm{m}^{3} / \mathrm{s}\right)\end{array}$ & $\begin{array}{c}\text { Q Efluente } \\
\left(\mathrm{m}^{3} / \mathrm{s}\right)\end{array}$ & $\begin{array}{c}\text { NA Montante } \\
(\mathrm{m})\end{array}$ & $\begin{array}{c}\text { NA Jusante } \\
(\mathrm{m})\end{array}$ \\
\hline Máximo & 848,15 & 8224,10 & 738,60 & 733,46 \\
Mínimo & 56,14 & 30,00 & 724,97 & 733,33 \\
\hline
\end{tabular}

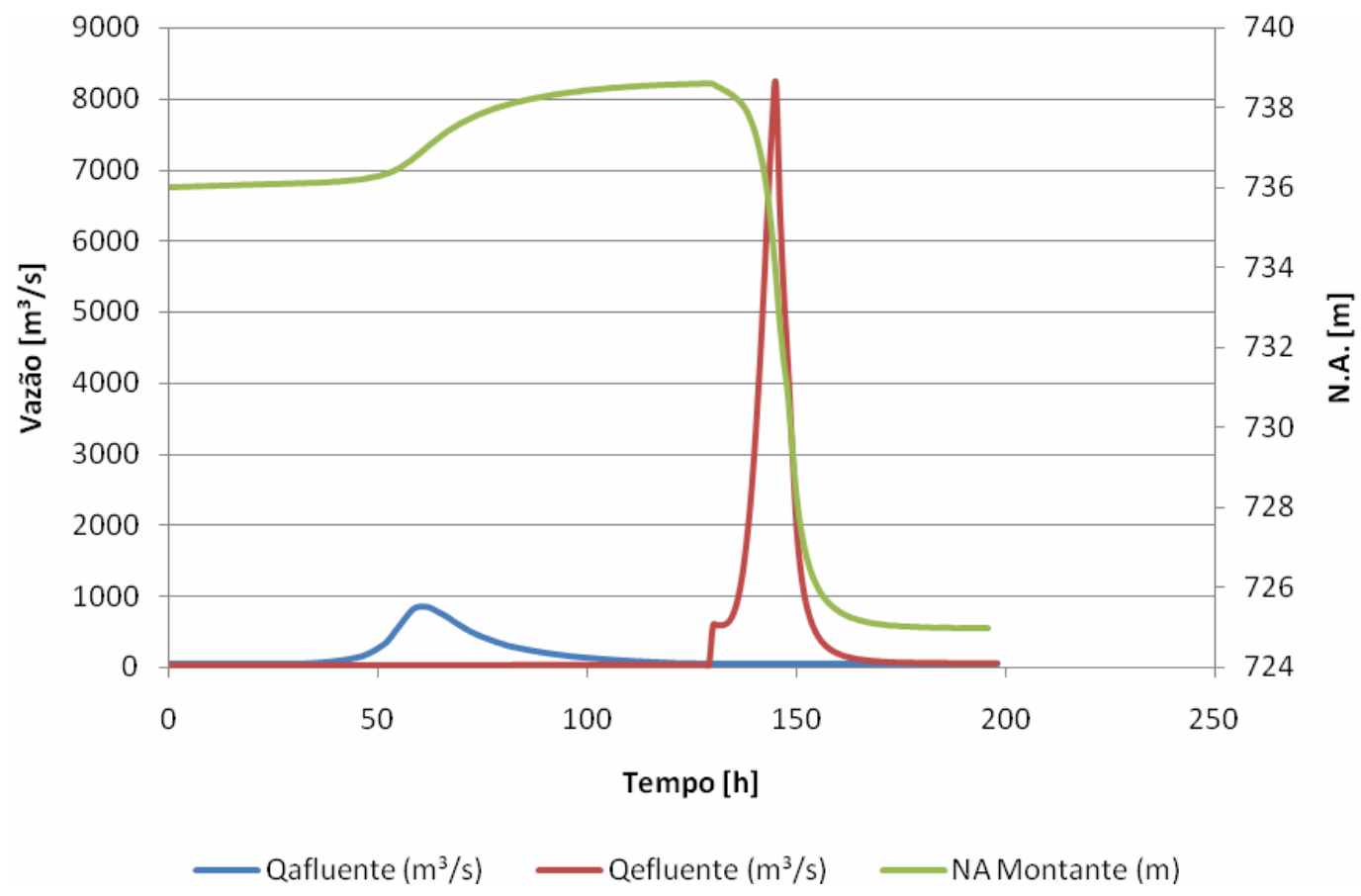

Figura 4.39: Resultados da Simulação do Cenário 17

\section{$\underline{\text { Cenário } 18}$}

A simulação realizada neste cenário considerou os parâmetros da Tabela 4.37.

Tabela 4.37: Parâmetros utilizados no Cenário 18

\begin{tabular}{|lc|}
\hline Altura de Água sobre a Brecha & (m) 13,6 \\
Expoente de Evolução da Brecha & 1,5 \\
Largura da Brecha & (m) 182,0 \\
Tempo de Evolução da Brecha & (h) 7,8 \\
\hline
\end{tabular}


Os resultados obtidos da simulação deste cenário estão apresentados na Tabela 4.38 e na Figura 4.40.

Tabela 4.38: Resultados da Simulação do Cenário 18

\begin{tabular}{lcccc}
\hline & $\begin{array}{c}\text { Q Afluente } \\
\left(\mathrm{m}^{3} / \mathrm{s}\right)\end{array}$ & $\begin{array}{c}\text { Q Efluente } \\
\left(\mathrm{m}^{3} / \mathrm{s}\right)\end{array}$ & $\begin{array}{c}\text { NA Montante } \\
(\mathrm{m})\end{array}$ & $\begin{array}{c}\text { NA Jusante } \\
(\mathrm{m})\end{array}$ \\
\hline Máximo & 848,15 & 10957,68 & 738,60 & 733,46 \\
Mínimo & 56,14 & 30,00 & 725,01 & 733,33 \\
\hline
\end{tabular}

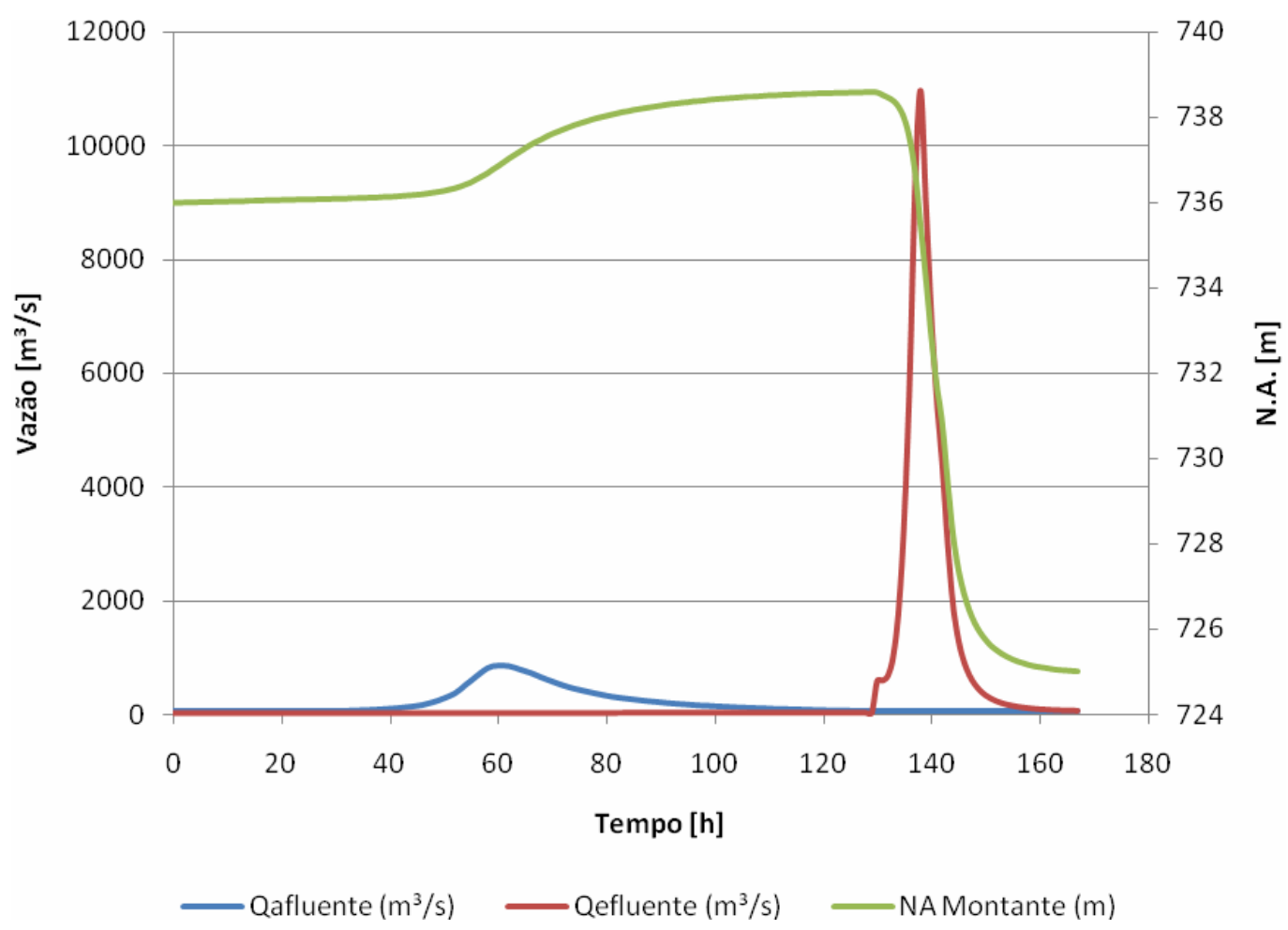

Figura 4.40: Resultados da Simulação do Cenário 18

\section{$\underline{\text { Cenário } 19}$}

A simulação realizada neste cenário considerou os parâmetros da Tabela 4.39.

Tabela 4.39: Parâmetros utilizados no Cenário 19

\begin{tabular}{|lc|}
\hline Altura de Água sobre a Brecha & (m) 13,6 \\
Expoente de Evolução da Brecha & 1,5 \\
Largura da Brecha & (m) 182,0 \\
Tempo de Evolução da Brecha & (h) 4,0 \\
\hline
\end{tabular}


Os resultados obtidos da simulação deste cenário estão apresentados na Tabela 4.40 e na Figura 4.41 a seguir

Tabela 4.40: Resultados da Simulação do Cenário 19

\begin{tabular}{lcccc}
\hline $\begin{array}{c}\text { Q Afluente } \\
\left(\mathrm{m}^{3} / \mathrm{s}\right)\end{array}$ & $\begin{array}{c}\text { Q Efluente } \\
\left(\mathrm{m}^{3} / \mathrm{s}\right)\end{array}$ & $\begin{array}{c}\text { NA Montante } \\
(\mathrm{m})\end{array}$ & $\begin{array}{c}\text { NA Jusante } \\
(\mathrm{m})\end{array}$ \\
\hline Máximo & 848,15 & 13406,04 & 738,60 & 733,46 \\
Mínimo & 56,14 & 30,00 & 725,13 & 733,33 \\
\hline
\end{tabular}

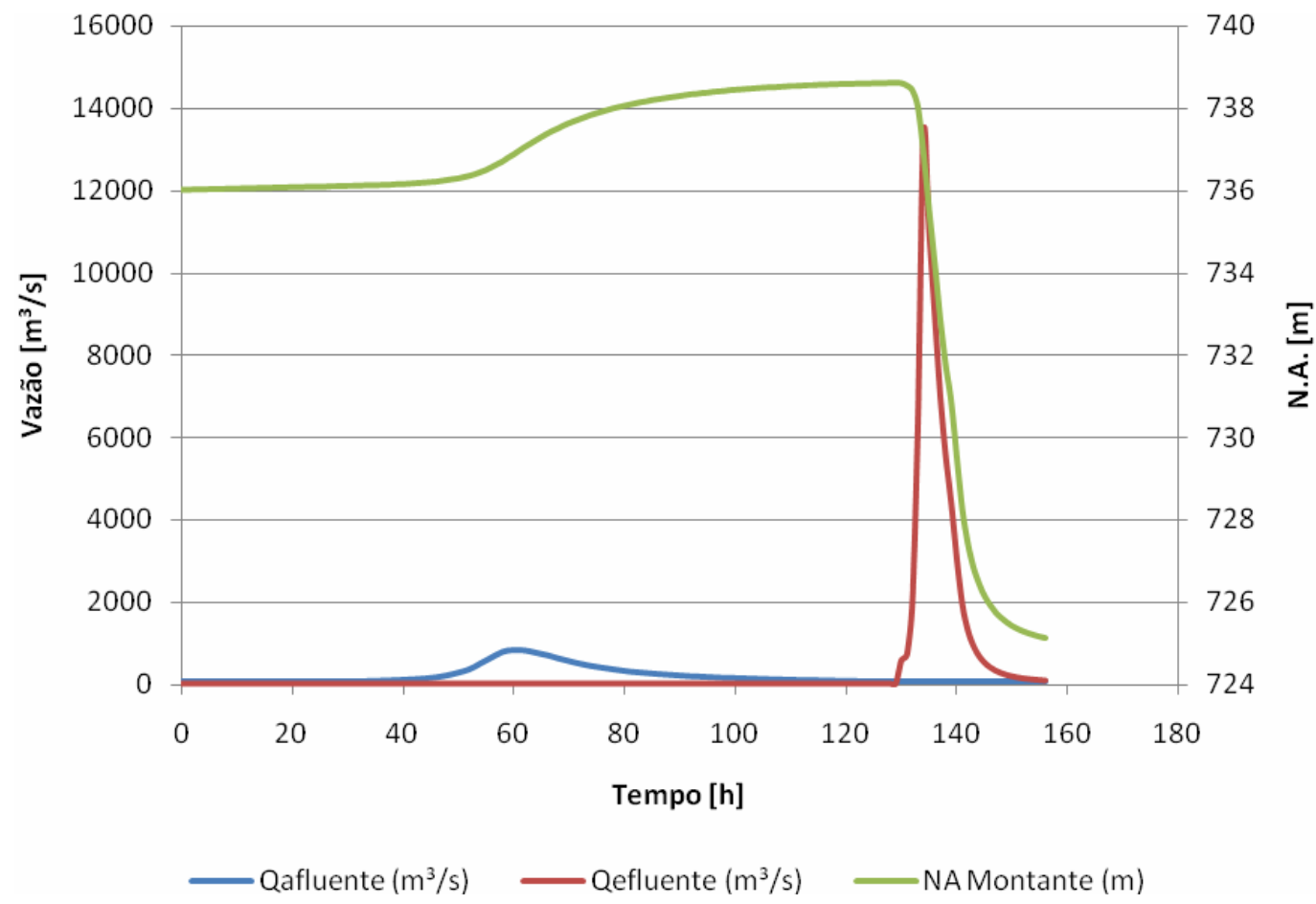

Figura 4.41: Resultados da Simulação do Cenário 19

\section{Cenário 20}

A simulação realizada neste cenário considerou os parâmetros da Tabela 4.41.

Tabela 4.41: Parâmetros utilizados no Cenário 20

\begin{tabular}{|lc|}
\hline Altura de Água sobre a Brecha & (m) 13,6 \\
Expoente de Evolução da Brecha & 1,5 \\
Largura da Brecha & (m) 182,0 \\
Tempo de Evolução da Brecha & (h) 15,0 \\
\hline
\end{tabular}


Os resultados obtidos da simulação deste cenário estão apresentados na Tabela 4.42 e na Figura 4.42.

Tabela 4.42: Resultados da Simulação do Cenário 20

\begin{tabular}{ccccc}
\hline & $\begin{array}{c}\text { A Afluente } \\
\left(\mathrm{m}^{3} / \mathrm{s}\right)\end{array}$ & $\begin{array}{c}\text { Q Efluente } \\
\left(\mathrm{m}^{3} / \mathrm{s}\right)\end{array}$ & $\begin{array}{c}\text { NA Montante } \\
(\mathrm{m})\end{array}$ & $\begin{array}{c}\text { NA Jusante } \\
(\mathrm{m})\end{array}$ \\
\hline Máximo & 848,15 & 8380,48 & 738,60 & 733,46 \\
Mínimo & 56,14 & 30,00 & 724,96 & 733,33 \\
\hline
\end{tabular}

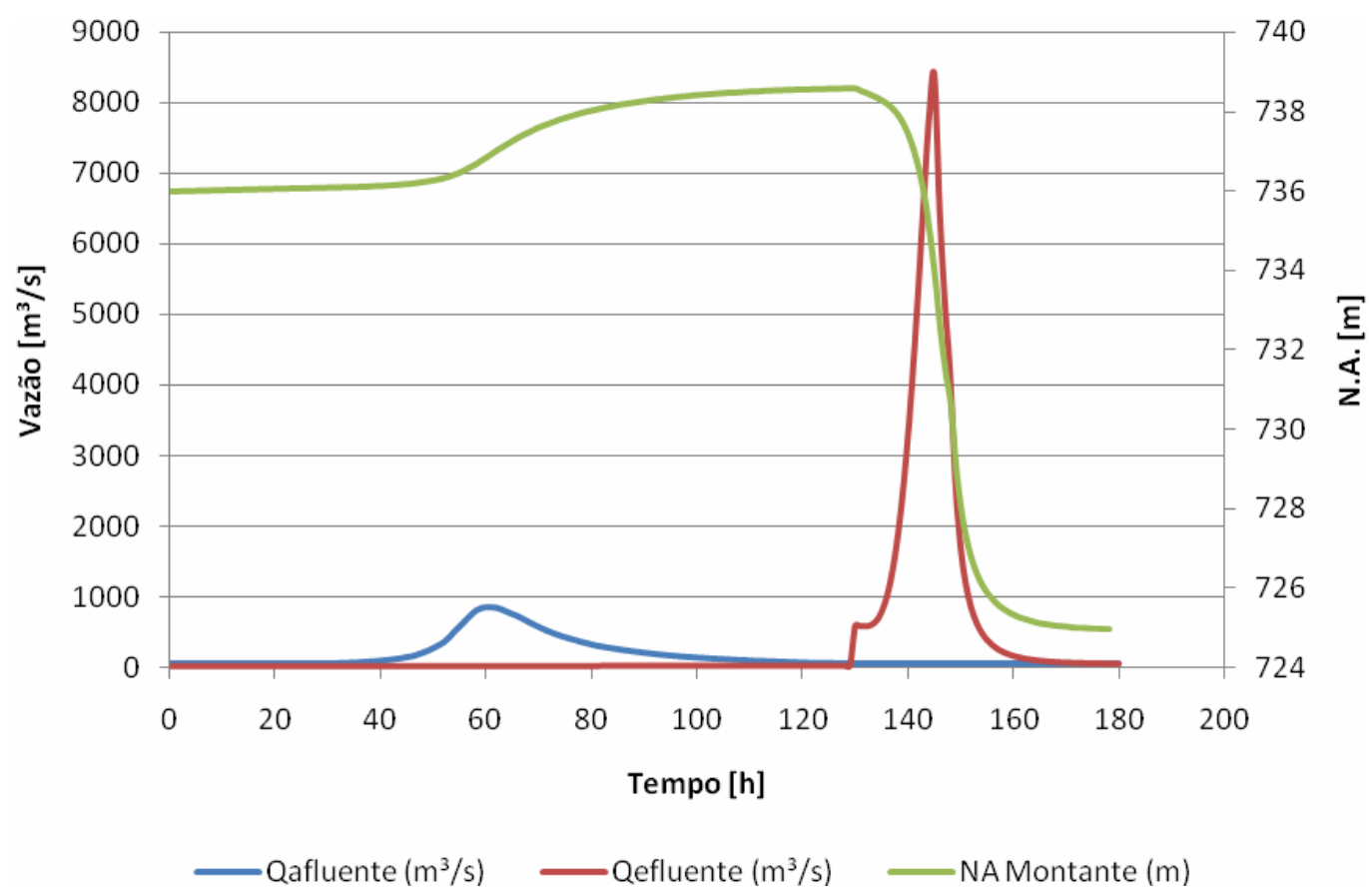

Figura 4.42: Resultados da Simulação do Cenário 20

Os resultados dessas simulações mostram (Figura 4.43) um comportamento inversamente proporcional entre as vazões máximas efluentes e o tempo de ruptura adotado. 


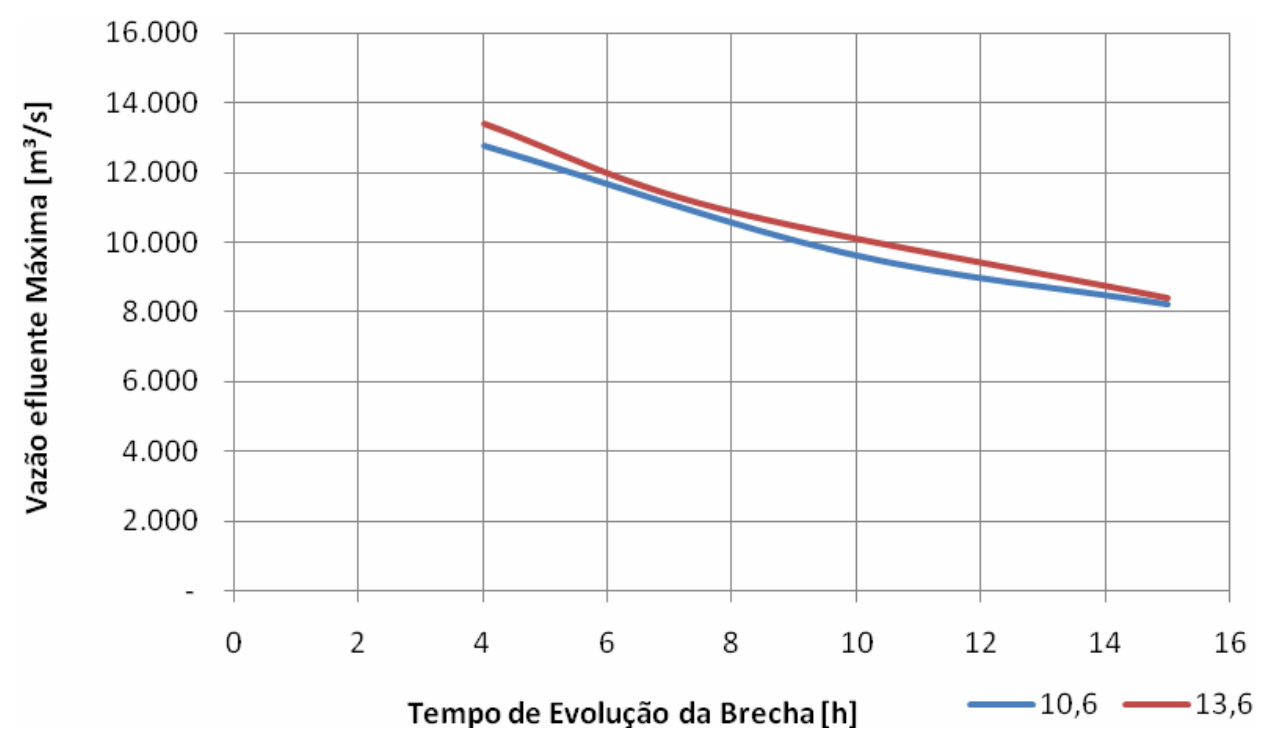

Figura 4.43: Vazões máximas efluentes obtidas nas simulações dos cenários 15 a 20.

\subsubsection{Simulações de Ruptura por Piping}

A elaboração dos cenários para a simulação de piping levou em consideração o volume de água presente no reservatório. Sendo assim, foram considera três situações, correspondentes ao reservatório cheio, isto é, no N.A. meta de 735,00 m, que reserva a faixa de $1 \mathrm{~m}$ para controle de cheias, o segundo considerando $70 \%$ do volume do reservatório e o terceiro, considerando o reservatório operando com $40 \%$ de sua capacidade.

\section{Cenário 21}

Para a simulação neste cenário, foi considerado o volume do reservatório Guarapiranga operando no N.A. meta $=735,00 \mathrm{~m}$. A simulação realizada neste cenário considerou os parâmetros da Tabela 4.43

Tabela 4.43: Parâmetros utilizados no Cenário 21

\begin{tabular}{|ll|}
\hline N.A. meta & (m) 735,00 \\
Expoente de Evolução da Brecha & 1,5 \\
Largura da Brecha & (m) 171,0 \\
Tempo de Evolução da Brecha & (h) 4,0 \\
\hline
\end{tabular}


Os resultados obtidos da simulação deste cenário estão apresentados na Tabela 4.44 e na Figura 4.44.

Tabela 4.44: Resultados da Simulação do Cenário 21

\begin{tabular}{ccccc}
\hline & $\begin{array}{c}\text { Q Afluente } \\
\left(\mathrm{m}^{3} / \mathrm{s}\right)\end{array}$ & $\begin{array}{c}\text { Q Efluente } \\
\left(\mathrm{m}^{3} / \mathrm{s}\right)\end{array}$ & $\begin{array}{c}\text { NA Montante } \\
(\mathrm{m})\end{array}$ & $\begin{array}{c}\text { NA Jusante } \\
(\mathrm{m})\end{array}$ \\
\hline Máximo & 58,95 & $7.487,09$ & 735,00 & 733,33 \\
Mínimo & 56,14 & 30,00 & 725,03 & 733,33 \\
\hline
\end{tabular}

\section{Cenário 22}

Para a simulação neste cenário, foi considerado o volume do reservatório operando com $70 \%$ de sua capacidade, ou seja o N.A. correspondente a este volume na cota 733,62m. A simulação realizada neste cenário considerou os seguintes parâmetros:

Tabela 4.45: Parâmetros utilizados no Cenário 22

\begin{tabular}{|lc|}
\hline N.A. (vol. 70\% capacidade do reserv.) & (m) 733,62 \\
Expoente de Evolução da Brecha & 1,5 \\
Largura da Brecha & (m) 171,0 \\
Tempo de Evolução da Brecha & (h) 4,0 \\
\hline
\end{tabular}

Os resultados obtidos da simulação deste cenário estão apresentados na Tabela 4.46 e na Figura 4.45.

Tabela 4.46: Resultados da Simulação do Cenário 22

\begin{tabular}{ccccc}
\hline & $\begin{array}{c}\text { Q Afluente } \\
\left(\mathrm{m}^{3} / \mathrm{s}\right)\end{array}$ & $\begin{array}{c}\text { Q Efluente } \\
\left(\mathrm{m}^{3} / \mathrm{s}\right)\end{array}$ & $\begin{array}{c}\text { NA Montante } \\
(\mathrm{m})\end{array}$ & $\begin{array}{c}\text { NA Jusante } \\
(\mathrm{m})\end{array}$ \\
\hline Máximo & 58,95 & 5768,52 & 733,63 & 732,60 \\
Mínimo & 56,14 & 0,05 & 725,02 & 732,60 \\
\hline
\end{tabular}

\section{Cenário 23}

Para a simulação neste cenário, foi considerada a situação mais freqüente no reservatório Guarapiranga. Devido à demanda da RMSP, o sistema da SABESP mantém o reservatório operando com $40 \%$ de sua capacidade. Sendo assim, o N.A. 
correspondente a este volume encontra-se na cota 731,80m. A simulação realizada neste cenário considerou os seguintes parâmetros:

Tabela 4.47: Parâmetros utilizados no Cenário 23

\begin{tabular}{|lll|}
\hline N.A. (vol. 40\% capacidade do reserv.) & (m) & 731,80 \\
Expoente de Evolução da Brecha & & 1,5 \\
Largura da Brecha & (m) 171,0 \\
Tempo de Evolução da Brecha & (h) 4,0 \\
\hline
\end{tabular}

Os resultados obtidos da simulação deste cenário estão apresentados na Tabela 4.48 e na Figura 4.46.

Tabela 4.48: Resultados da Simulação do Cenário 23

\begin{tabular}{ccccc}
\hline & $\begin{array}{c}\text { Q Afluente } \\
\left(\mathrm{m}^{3} / \mathrm{s}\right)\end{array}$ & $\begin{array}{c}\text { Q Efluente } \\
\left(\mathrm{m}^{3} / \mathrm{s}\right)\end{array}$ & $\begin{array}{c}\text { NA Montante } \\
(\mathrm{m})\end{array}$ & $\begin{array}{c}\text { NA Jusante } \\
(\mathrm{m})\end{array}$ \\
\hline Máximo & 58,95 & 4233,55 & 731,83 & 732,60 \\
Mínimo & 56,14 & 0,05 & 725,01 & 732,60 \\
\hline
\end{tabular}

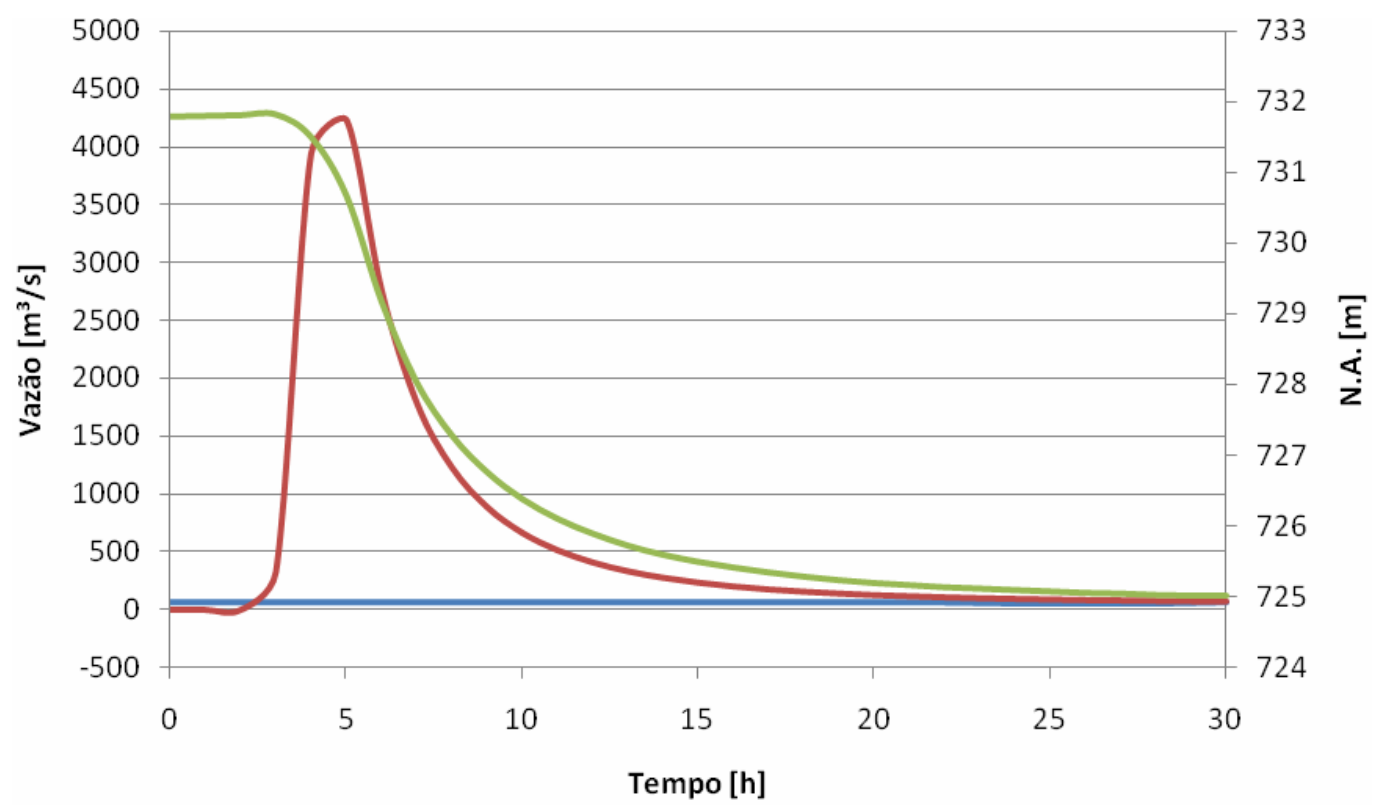

- Qafluente $\left(\mathrm{m}^{3} / \mathrm{s}\right) \quad$ Qefluente $\left(\mathrm{m}^{3} / \mathrm{s}\right) \quad$ NAMontante $(\mathrm{m})$

Figura 4.44: Resultados da Simulação do Cenário 21 


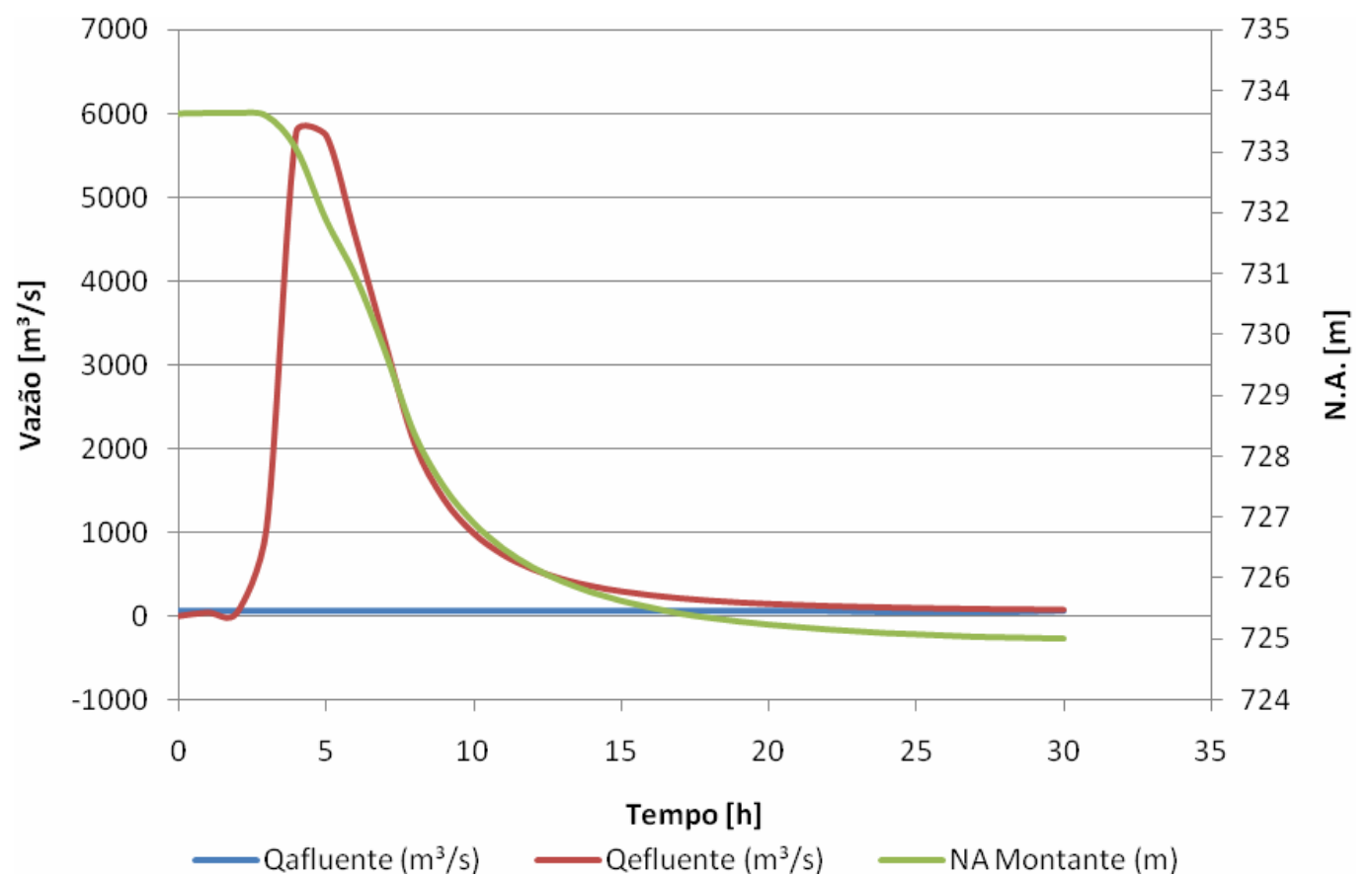

Figura 4.45: Resultados da Simulação do Cenário 22

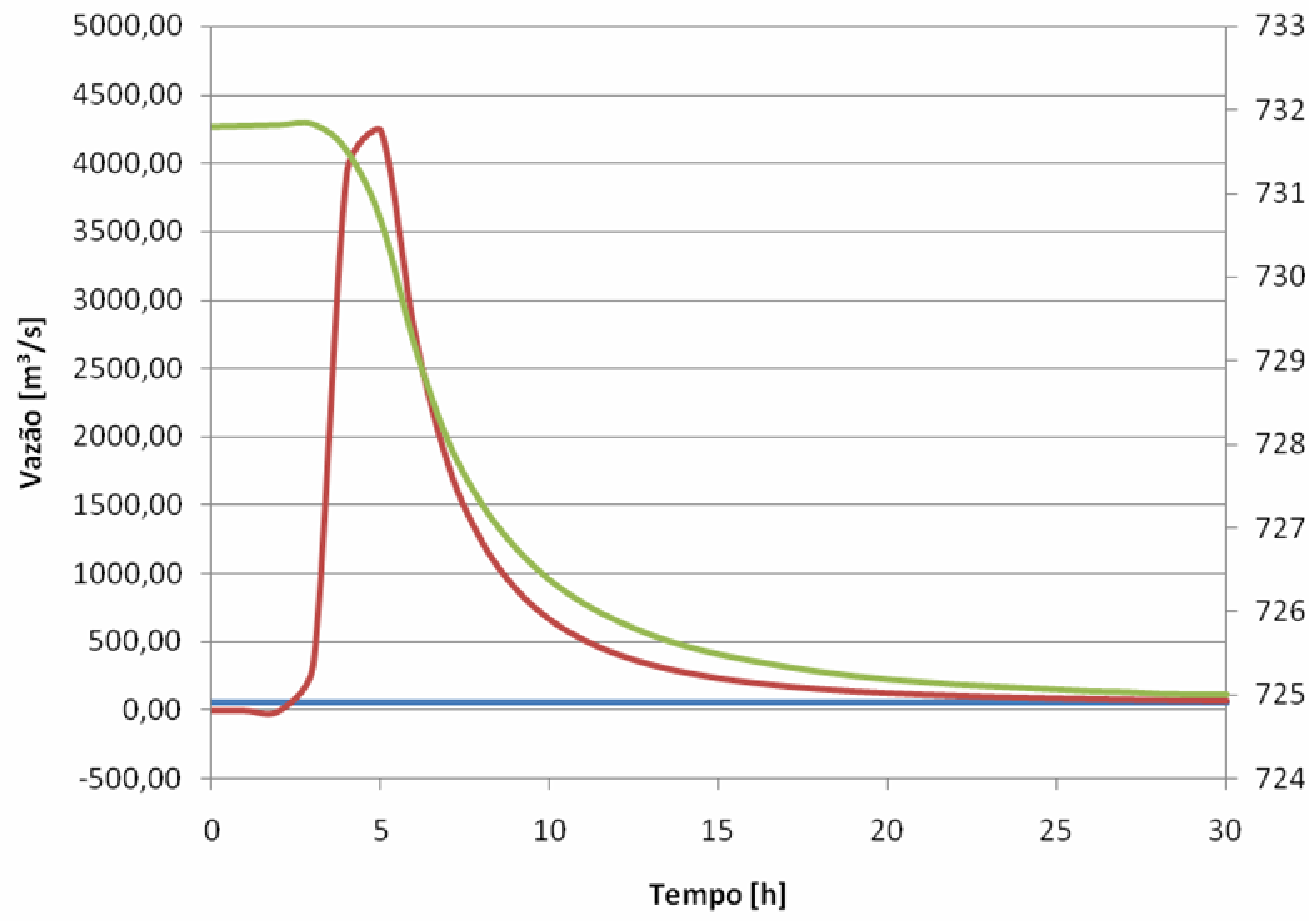

—Qfluente $\left(\mathrm{m}^{3} / \mathrm{s}\right) \quad$ Qefluente $\left(\mathrm{m}^{3} / \mathrm{s}\right) \quad$ NA Montante $(\mathrm{m})$

Figura 4.46: Resultados da Simulação do Cenário 23 
Os cenários 1 a 23 foram elaborados com o intuito de avaliar a sensibilidade dos parâmetros 'expoente de evolução da brecha', 'largura da brecha' e 'tempo de ruptura da barragem', bem como a quantidade de água armazenada no reservatório. Os valores extremos obtidos de cada resultado estão apresentados na Tabela 4.49.

Tabela 4.49: Valores Máximos Obtidos das Simulações de Rompimento da Barragem Guarapiranga

\begin{tabular}{|c|c|c|c|c|c|}
\hline \multirow{21}{*}{$\begin{array}{l}\frac{2}{0} \\
\frac{2}{2} \\
\frac{2}{2} \\
0 \\
0\end{array}$} & & $\begin{array}{c}\text { Qafluente } \\
\mathrm{m}^{3} / \mathrm{s}\end{array}$ & $\begin{array}{c}\text { Qefluente } \\
\mathrm{m}^{3} / \mathrm{s}\end{array}$ & $\begin{array}{c}\text { N.A. montante } \\
\mathrm{m}\end{array}$ & $\begin{array}{c}\text { N.A. jusante } \\
m\end{array}$ \\
\hline & Cenário 1 & 848,15 & 7779,33 & 738,6 & 733,46 \\
\hline & Cenário 2 & 848,15 & 8557,25 & 738,6 & 733,46 \\
\hline & Cenário 3 & 848,15 & 9699,63 & 738,6 & 733,46 \\
\hline & Cenário 4 & 848,15 & 11393,24 & 738,6 & 733,46 \\
\hline & Cenário 5 & 848,15 & 8928,77 & 738,6 & 733,46 \\
\hline & Cenário 6 & 848,15 & 9814,52 & 738,6 & 733,46 \\
\hline & Cenário 7 & 848,15 & 10957,68 & 738,6 & 733,46 \\
\hline & Cenário 8 & 848,15 & 12506,93 & 738,6 & 733,46 \\
\hline & Cenário 9 & 848,15 & 4257,21 & 738,6 & 733,46 \\
\hline & Cenário 10 & 848,15 & 9699,63 & 738,6 & 733,46 \\
\hline & Cenário 11 & 848,15 & 12307 & 738,6 & 733,46 \\
\hline & Cenário 12 & 848,15 & 4415,96 & 738,6 & 733,46 \\
\hline & Cenário 13 & 848,15 & 10957,68 & 738,6 & 733,46 \\
\hline & Cenário 14 & 848,15 & 14162,41 & 738,6 & 733,46 \\
\hline & Cenário 15 & 848,15 & 12769,66 & 738,6 & 733,46 \\
\hline & Cenário 16 & 848,15 & 9699,63 & 738,6 & 733,46 \\
\hline & Cenário 17 & 848,15 & 8224,1 & 738,6 & 733,46 \\
\hline & Cenário 18 & 848,15 & 10957,68 & 738,6 & 733,46 \\
\hline & Cenário 19 & 848,15 & 13406,04 & 738,6 & 733,46 \\
\hline & Cenário 20 & 848,15 & 8380,48 & 738,6 & 733,46 \\
\hline \multirow{3}{*}{ Piping } & Cenário 21 & 58,95 & 7487,09 & 735 & 733,33 \\
\hline & Cenário 22 & 58,95 & 5768,52 & 733,63 & 732,6 \\
\hline & Cenário 23 & 58,95 & 4233,55 & 731,83 & 732,6 \\
\hline
\end{tabular}




\subsection{Simulação da Onda de Enchente Efluente}

Com base nos estudos elaborados anteriormente foram selecionados três cenários para a avaliação da propagação da cheia efluente no sistema de rios a jusante. Para as simulações de overtopping, foram selecionados três cenários compreendendo uma situação extrema, uma intermediaria e outra menos severa. São estas:

Cenário7: Este cenário apresenta os valores estimados segundo as fórmulas empíricas apresentadas por Fread \& Lewis (1998) cujos parâmetros largura da brecha e tempo de ruptura são $182,0 \mathrm{~m}$ e $7,8 \mathrm{~h}$ respectivamente;

Cenário 12: Onde o parâmetro largura da brecha foi fator determinante para esta escolha. O hidrograma efluente desta simulação apresentou uma vazão de pico inferior a $4.500 \mathrm{~m}^{3} / \mathrm{s}$;

Cenário 19: Cujo parâmetro determinante foi o tempo de ruptura da barragem. O hidrograma efluente desta simulação apresentou uma vazão efluente máxima superior a $13.000 \mathrm{~m} 3 / \mathrm{s}$ para o tempo de ruptura igual a 4 horas.

Para complementar os cenários de simulação das cheias resultantes, foram considerados os três cenários de piping foram elaborados, com o intuito de avaliar a sensibilidade do modelo no que diz respeito ao volume de água em que se encontrava o reservatório. Neste caso, serão apresentadas nos itens a seguir a propagação dos hidrogramas gerados e a mancha de inundação, para estes três cenários.

\subsubsection{A Rede de Canais}

A simulação da propagação da onda contemplou o canal Guarapiranga, toda extensão do Rio Pinheiros, desde a Barragem Pedreira/Billings até a barragem reguladora denominada Estrutura de Retiro, seguindo até a confluência com o Rio Tietê. Este foi considerado deste uma seção situada $6 \mathrm{~km}$ a montante da confluência, desde a Ponte do Limão, até a Barragem Edgard de Souza.

Para uma adequada representação das características geométricas do canal Guarapiranga e do Rio Pinheiros localizados imediatamente a jusante da estrutura de Guarapiranga, foram utilizadas seções batimétricas para o canal Guarapiranga e Rio 
Pinheiros, cobrindo todo o leito do escoamento e com espaçamento adequado para representar os pontos notáveis do traçado. Assim foram consideradas 71 seções transversais, cujos dados são apresentados no APÊNDICE deste trabalho. Tais seções foram obtidas através de estudos realizados pela Empresa Metropolitana de Águas e Energia S.A. - EMAE, que dispõe de levantamentos batimétricos periódicos de seções transversais, (SANTOS, 2005) para controle da evolução de assoreamento no leito do canal Guarapiranga e Rio Pinheiros, com espaçamento variando entre $20 \mathrm{e}$ 50 metros. Além das seções transversais do canal Guarapiranga e Rio Pinheiros, foram adquiridas também seções batimétricas do Rio Tietê (apresentadas no APÊNDICE), fornecidas pelo Departamento de Águas e Energia Elétrica do Estado de São Paulo - DAEE.

A delimitação da área de inundação é feita sobre uma superfície topográfica previamente gerada por meio de uma modelagem digital de terreno (MDT), que consiste na geração de uma malha de pontos igualmente espaçados a partir de coordenadas de pontos conhecidos, adquiridos segundo uma distribuição irregular, ou seja, pontos obtidos de um levantamento batimétrico, curvas de nível, etc. Para a geração das áreas inundadas resultantes do rompimento da Barragem Guarapiranga, foi utilizada parte do MDT desenvolvido pela FUNCATE (2003). O modelo gerado foi baseado em cartas 1:10.000 e 1:25.000 e possui resolução altimétrica de 5,0m e $10,0 \mathrm{~m}$, para as áreas conurbadas e periféricas da RMSP respectivamente (Figura 4.47 e Figura 4.48), e resolução horizontal de 20. Cabe ressaltar que as seções batimétricas fornecidas pela EMAE são niveladas a partir do RN da LIGHT, que se encontra a 1,15m abaixo do Modelo Digital de Terreno gerado pela FUNCATE (2003), o que exigiu a correção de todos os dados referentes às seções do Rio Pinheiros e Guarapiranga. 


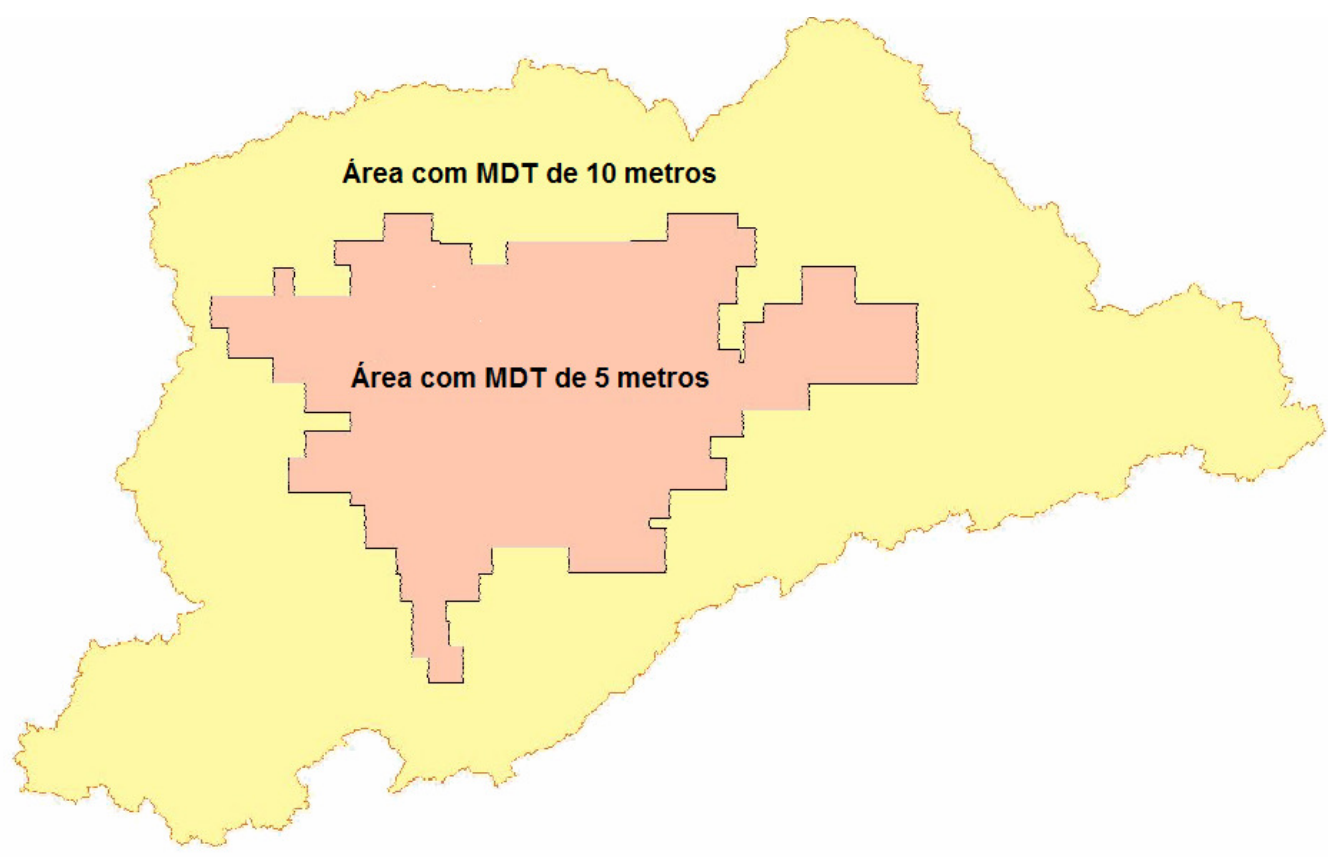

Figura 4.47: Resolução do MDT gerado pela FUNCATE (2003).

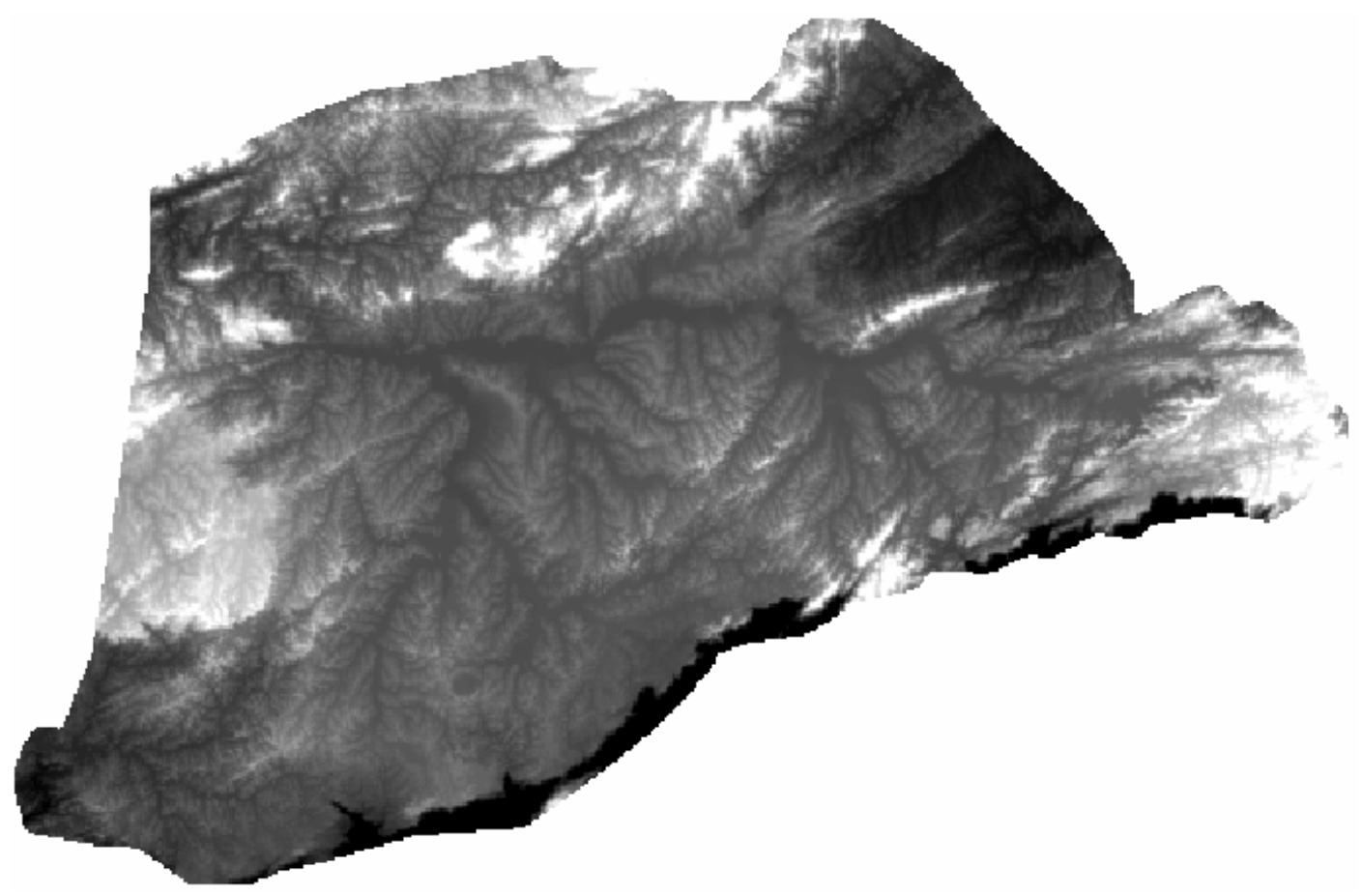

Figura 4.48: MDT da Bacia do Alto Tietê gerado pela FUNCATE (2003). 


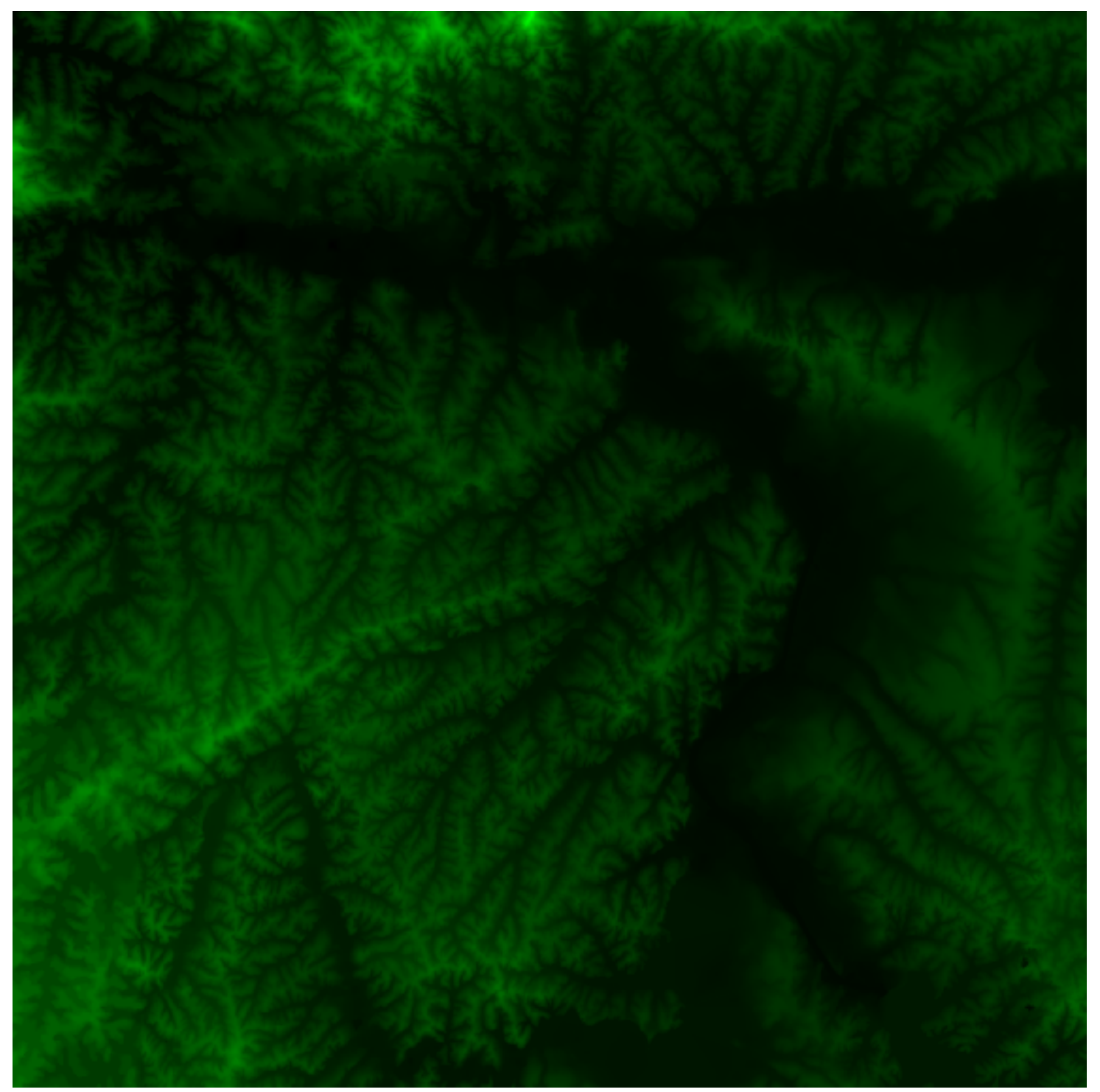

Figura 4.49: Porção do MDT gerado pela FUNCATE (2003) na região do estudo, observando-se nas zonas escuras os vales do Canal Guarapiranga,Rio Pinheiros e Rio Tietê.

Os valores dos níveis de águas calculados na simulação são confrontados com essa superfície topográfica e nos pontos onde o N.A. ficar acima da cota do terreno, estes pontos são considerados inundados. Este processo foi efetuado para os níveis máximos ocorridos ao longo do canal.

Para a simulação da propagação da onda de cheia ao longo do cala Guarapiranga, Rio Pinheiros e Rio Tietê, foi concebido uma rede de fluxo composta de nós e trechos, como apresentada na Figura 4.50. Nesta rede estão estabelecidos nós que representam as condições de contorno que foram determinadas para o calculo. Em 
cada nó da rede são definidas as condições externas a serem consideradas nos cálculos. Aos trechos são associados os dados hidrogeométricos, tais como seções transversais (APÊNDICE).

O nó Guarapiranga representa a Barragem Guarapiranga, onde são atribuídas todas as características físicas da barragem e do reservatório Guarapiranga, além dos dados referentes às estruturas hidráulicas da barragem (incluindo os dados hidráulicos dos vertedores), os parâmetros de ruptura e o hidrograma afluente da cheia utilizada para simulação do acidente por overtopping.

O nó Pedreira representa a descarga da Barragem Pedreira no Rio Pinheiros, sendo admitido um valor constante correspondente a uma descarga usual de $7 \mathrm{~m} / \mathrm{s}$ embora as condições operacionais deste reservatório sejam variáveis em função da reversão para geração de energia.

A confluência entre o canal Guarapiranga e o Rio Pinheiros é representada pelo nó denominado GUARA-BIL, que é tratado pelo modelo como uma condição de igualdade de níveis para os três trechos vinculados na confluência.

Os nós denominados Traição Retiro, consideram estruturas que usualmente funcionam como controladoras do nível do canal para possibilitar a reversão das águas e a geração de energia. Desta forma estas estruturas foram modeladas de forma a operar com o objetivo de manter um nível d'água máximo como meta, e a partir daí, permitirem a descarga até o limite de sua capacidade. Por serem estruturas de concreto, foi considerado que as mesmas podem ser galgadas sem sofrerem colapso, o que se trata de uma simplificação aceitável para este estudo. Desta forma, as leis de descarga consideradas nestes casos estão apresentadas na Figura 4.51 para a Estrutura da Traição e na Figura 4.52 para a estrutura de Retiro. 


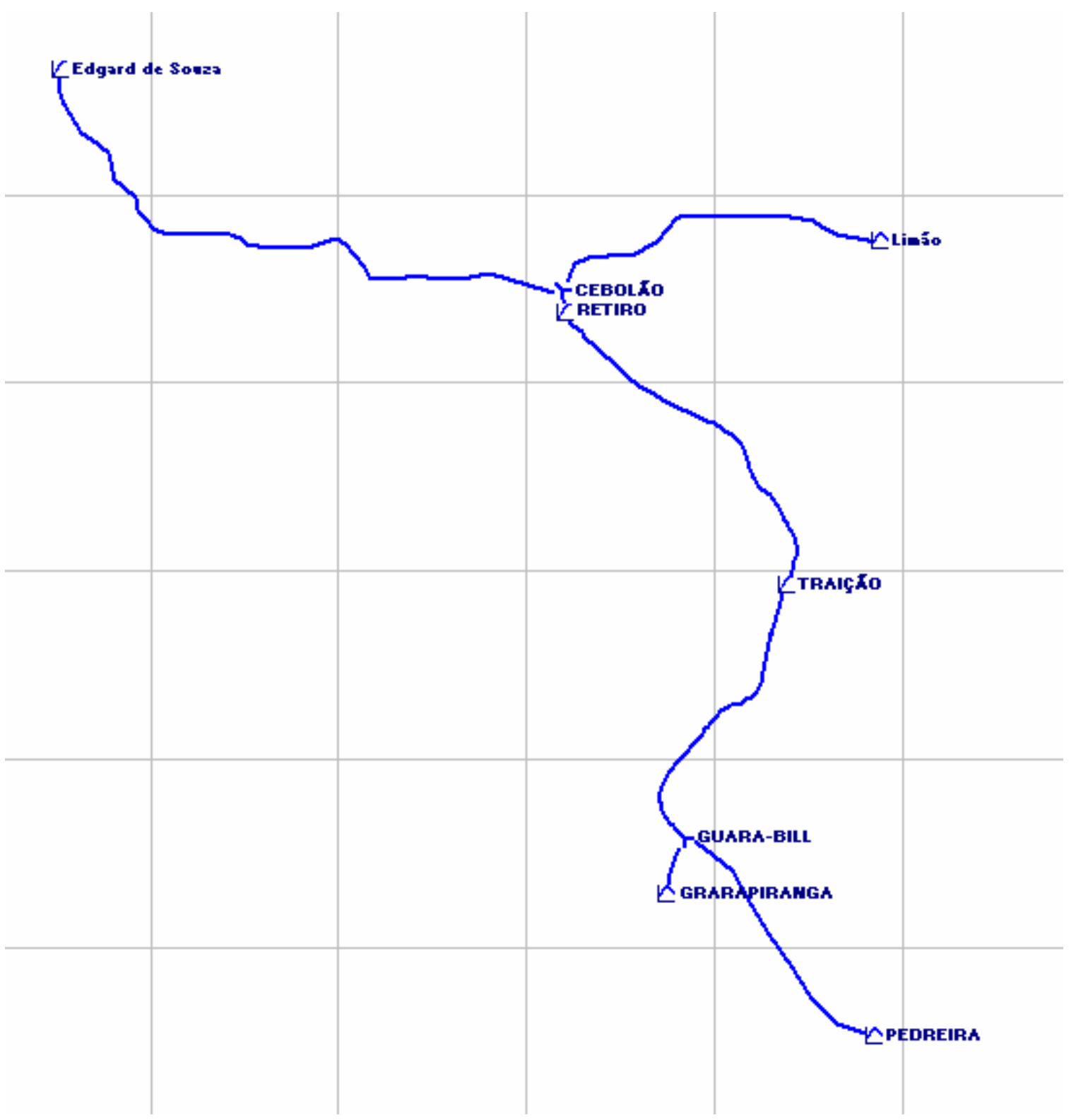

Figura 4.50: Rede de simulação da onda de enchente Efluente resultante do rompimento da Barragem Guarapiranga. 


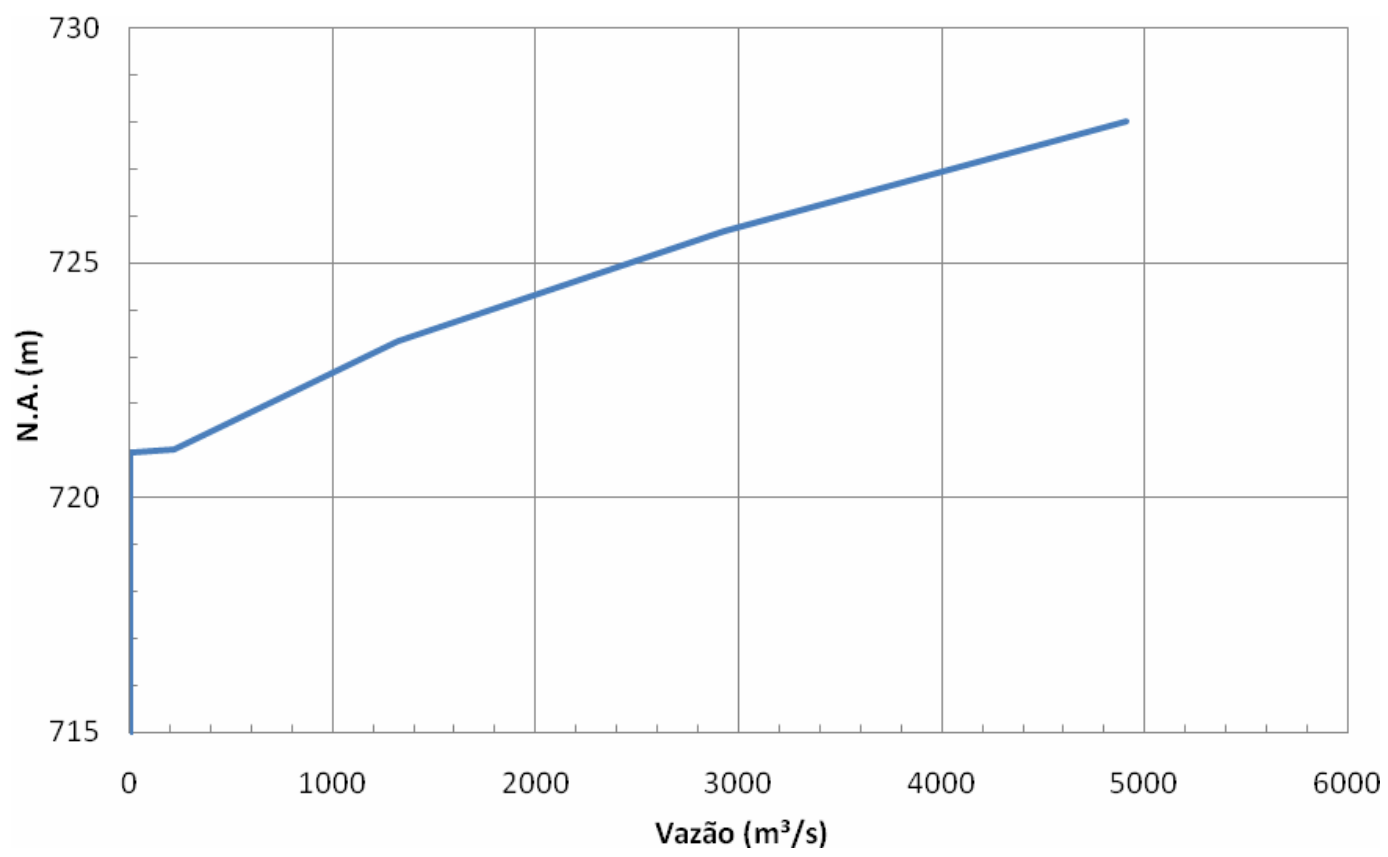

Figura 4.51: Curva-Chave da Estação Elevatória de Traição

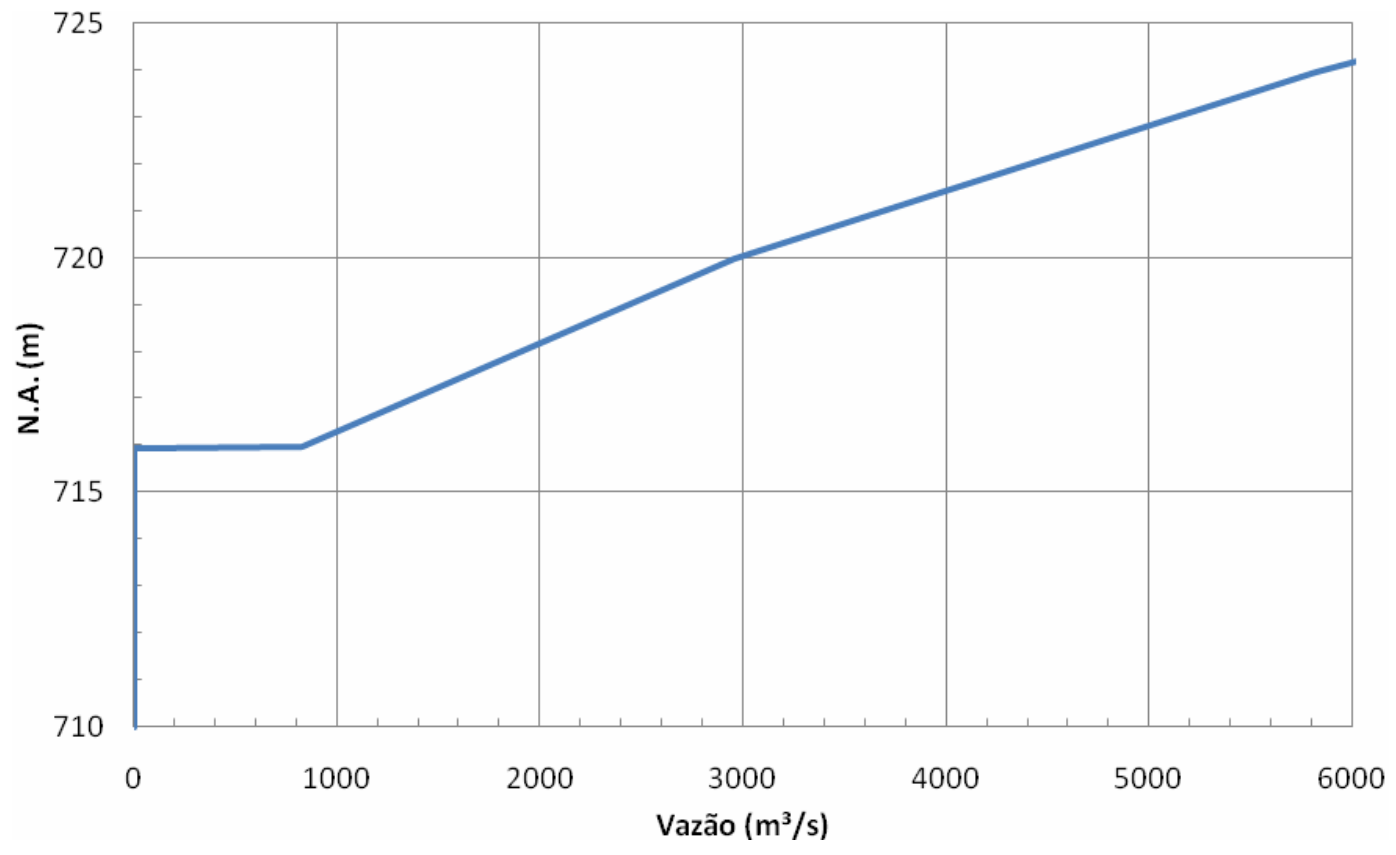

Figura 4.52: Curva-Chave da Estrutura de Retiro

O Nó Limão representa a contribuição do Rio Tietê na simulação, tendo sido atribuída uma descarga constante igual a $100 \mathrm{~m} / \mathrm{s}$, correspondente a uma vazão típica média Uemura, S.; Instrumentos de Avaliação e Gestão de Impactos Gerados por Rupturas de Barragens 
anual no trecho. O nó denominado Cebolão representa a confluência entre o Rio Tietê e Pinheiros e o nó denominado Edgar de Souza caracteriza uma barragem existente, controlada por um descarregador de fundo que permite o controle de nível préestabelecido. A Figura 4.53 indica esta situação.

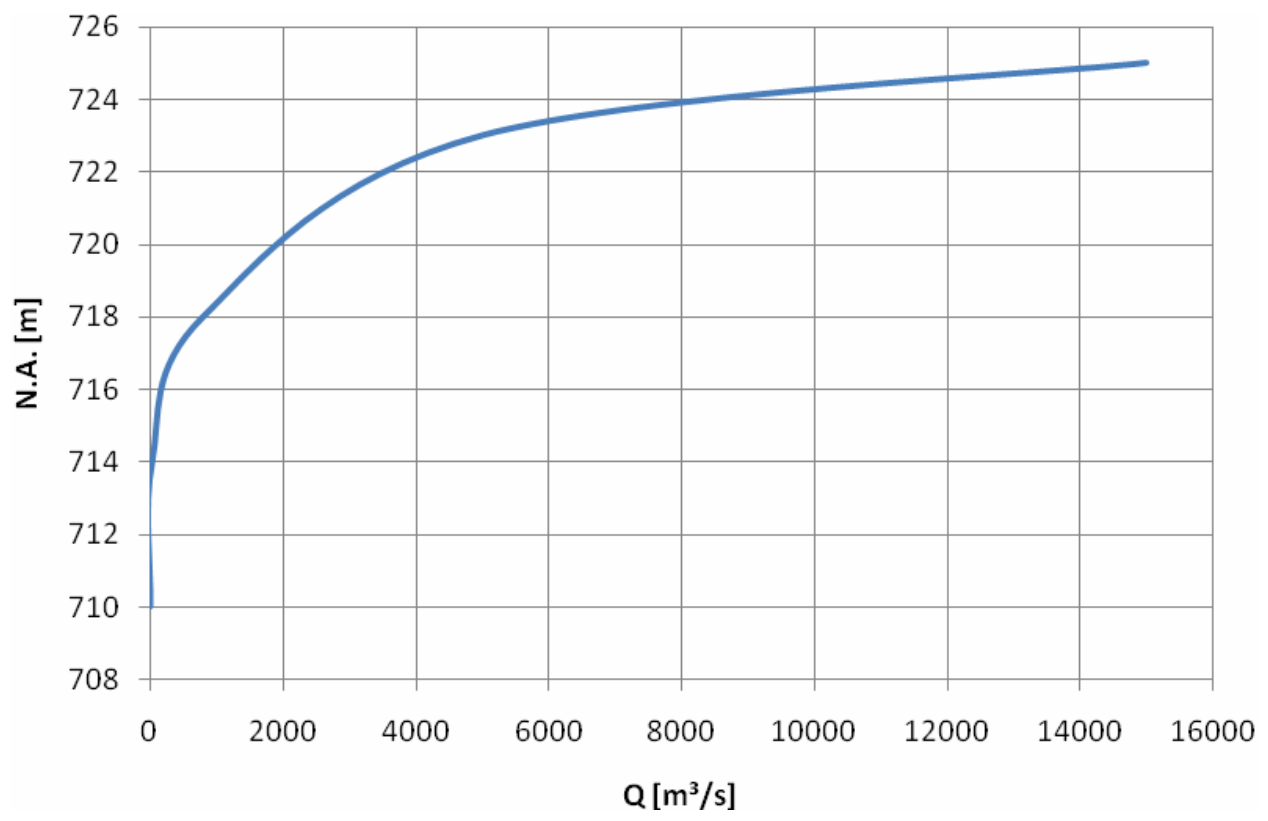

Figura 4.53: Curva-Chave da Barragem Edgard de Souza

\subsubsection{Simulações de Cálculo da Linha d'água}

Uma vez montada a rede de canais, foram processados os hidrogramas dos cenários selecionados previamente, registrando-se aos níveis d'água e vazões em cada nó de interesse. Para cada evento foi efetuada uma simulação de 200 horas, abrangendo o efluente do rompimento propriamente dito e um tempo suplementar para avaliação da depleção dos níveis nos rios. O intervalo de tempo adotado foi de 20 segundos, registrando-se os resultados a cada 20 minutos. Para adoção deste parâmetro foram feitos diversos testes com vistas à definição do maior intervalo possível sem a geração de distorções nos valores máximos, e por outro lado, permitir minimizar o armazenamento dos dados. 
Através dos resultados registrados puderam ser determinados os hidrogramas e limnigramas em cada seção de interesse, bem como a linha d'água máxima, que é a representação longitudinal do nível máximo atingido em cada nó durante o evento completo (200 horas). Estas linhas d'água máximas são então empregadas para estimativa das áreas potencialmente inundáveis, projetando-se os níveis resultantes sobre o modelo digital de terreno anteriormente apresentado

A Figura 4.54, a seguir ilustra o comportamento dos níveis d'água máximos ao longo do canal Guarapiranga, nas simulações das cheias efluentes dos cenários de overtopping e piping estudados. Verifica-se que, no trecho a montante da Estrutura da Traição, os níveis sofrem maior sobrelevação, refletindo uma maior capacidade de retenção dos volumes nas largas planícies existentes. Esta conclusão é corroborada pela Figura 4.55, onde se pode observar o comportamento das vazões máximas registradas pelas simulações nos mesmos cenários. Verifica-se que, a partir da confluência entre os Rios Guarapiranga e Pinheiros ocorre à maior atenuação.

As figuras Figura 4.56 a Figura 4.61 ilustram as áreas potencialmente inundáveis com o emprego de um aplicativo simples de SIG, neste caso o Google Earth, que pode ser facilmente manipulado através da internet. Este aplicativo permite a importação de polígonos referenciados por coordenadas geográficas através de arquivos texto tipo 'tagged files', já usualmente empregados nos aplicativos de busca na internet, denominados browsers.

Para a geração destas imagens utiliza-se a malha de pontos contendo as áreas inundáveis geradas pelo modelo CLiv e, através de uma rotina de conversão do sistema de coordenadas UTM (Projeção Transversa de Mercator) para o sistema de coordenadas geográficas, constrói-se o arquivo de dados a ser lido pelo GoogleEarth. Como a base de dados utilizada pelo CLiv emprega o sistema UTM com DATUM Horizontal referenciado ao SAD-69, Meridiano Central $45^{\circ}$, foi necessária a introdução de correções de forma a adaptar o resultado ao sistema utilizado pelo GoogleEarth.

Os resultados, embora altamente ilustrativos da potencialidade das ferramentas de simulação e de visualização, também apresentam limitações, como mostram as próprias figuras citadas, na delimitação das áreas atingidas. Resultados melhores puderam ser obtidos com o emprego de um aplicativo de CAD - Desenho Assistido por Computador, através dos arquivos de intercambio tipo DXF (Drawing Interchange File). Neste exemplo foi utilizado o AutoCAD 2007, para o qual foi transferido o 
polígono de inundação gerado pelo modelo matemático Cliv, plotando-se o mesmo sobre a imagem digital referenciada. Estes resultados podem ser vistos da Figura 4.96 a Figura 4.99. 


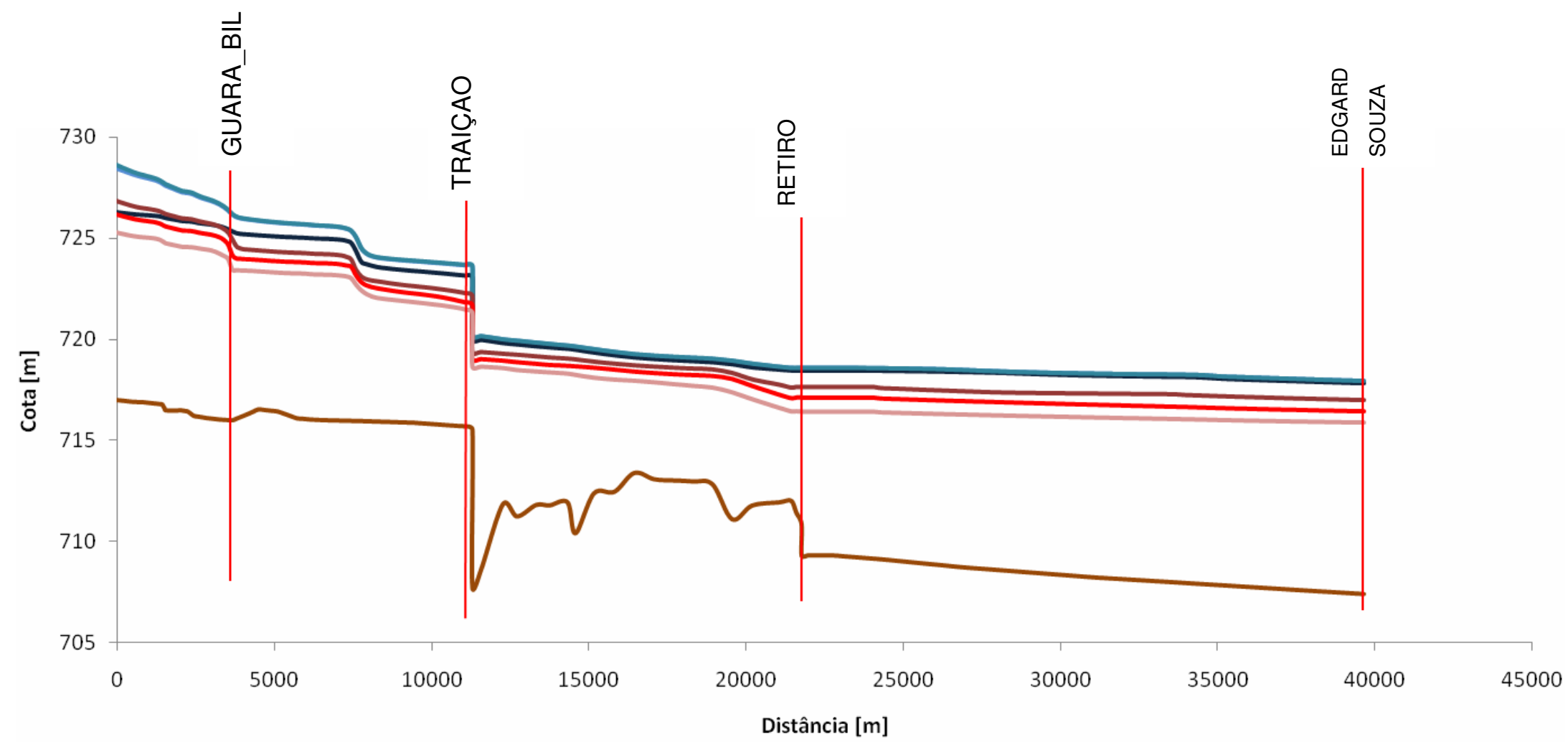

- N.A. Cenário $7-$ N.A. Cenário $12-$ N.A. Cenário $19-$ N.A. Cenário $21 \longrightarrow$ N.A. Cenário $22 \longrightarrow$ N.A. Cenário $23 \longrightarrow$ Cota de Fundo

Figura 4.54: Envoltória de N.A. no canal Guarapiranga, Rio Pinheiros e Rio Tietê 


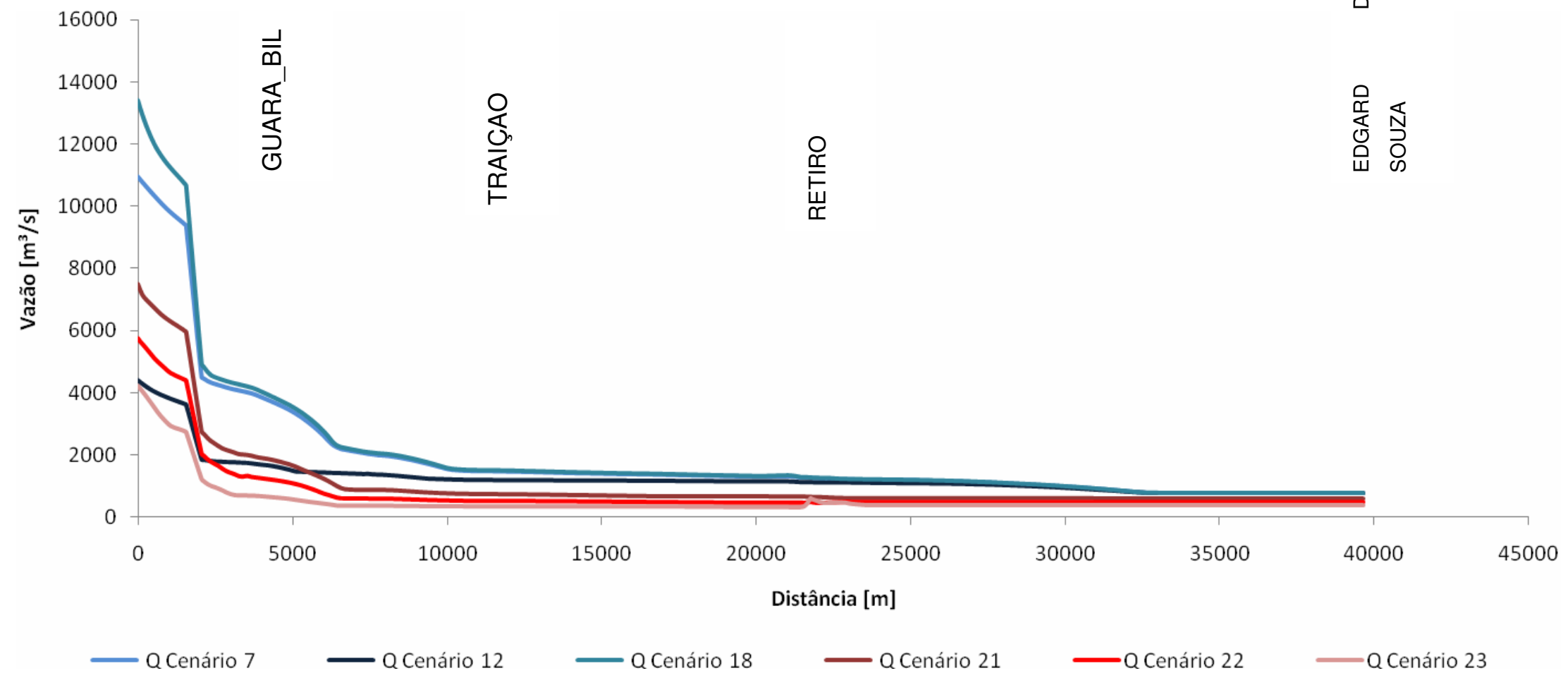

Figura 4.55: Envoltória de Q no canal Guarapiranga, Rio Pinheiros e Rio Tietê 


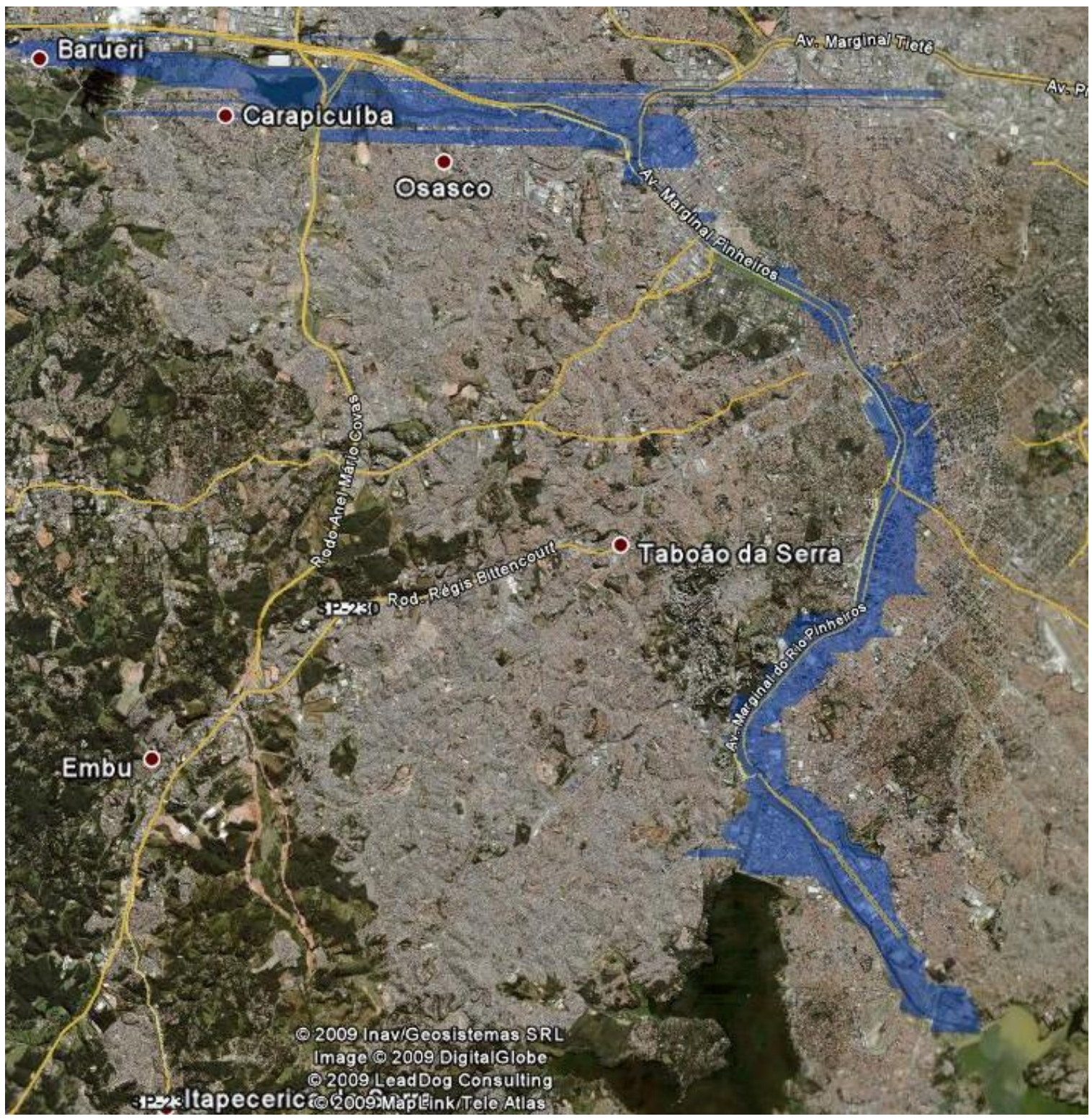

Figura 4.56: Área Inundada para o Rompimento da Barragem Guarapiranga no Cenário 7. Adaptado de Google Earth (2009) 


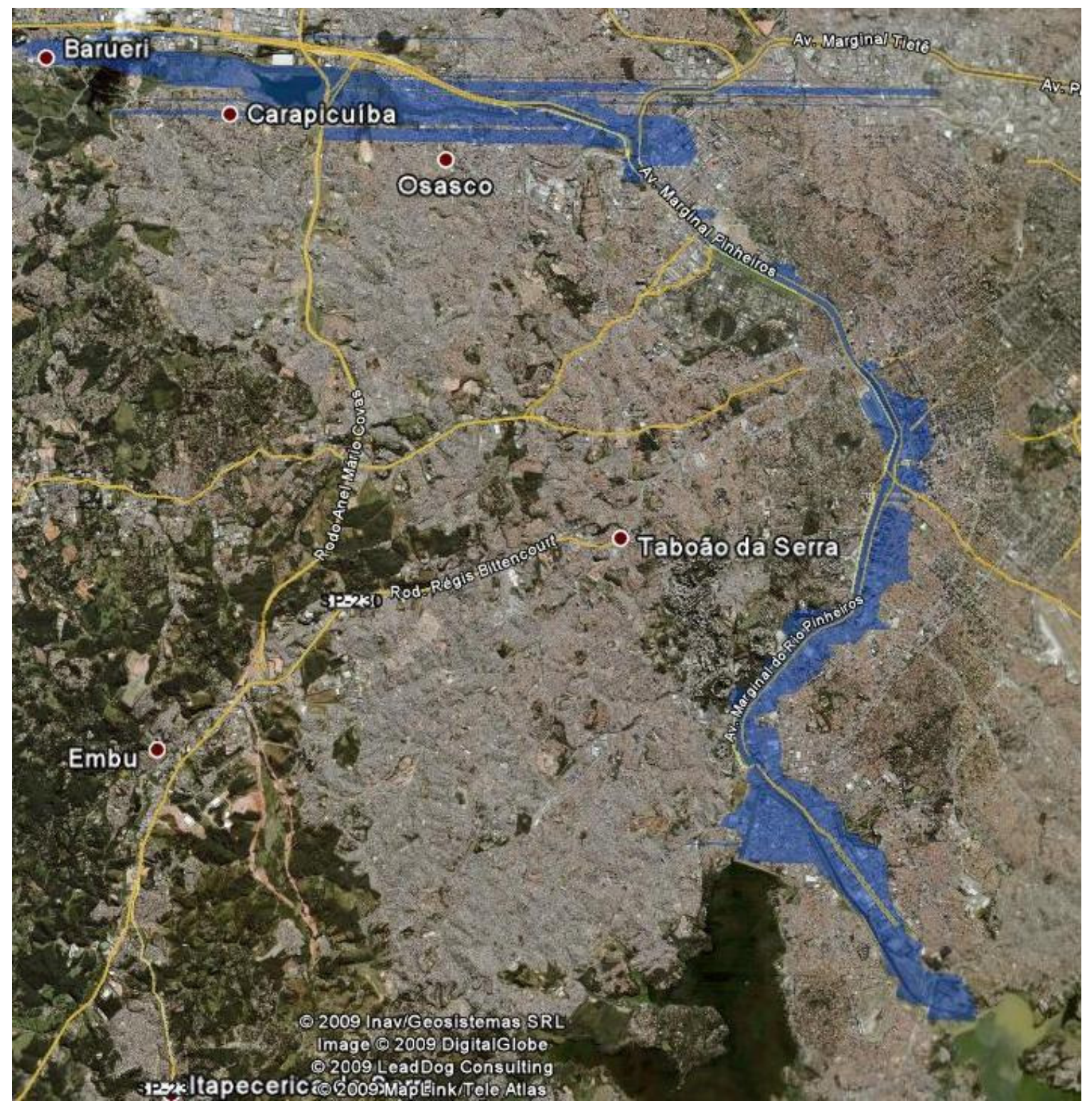

Figura 4.57: Área Inundada para o Rompimento da Barragem Guarapiranga no Cenário 12. Adaptado de Google Earth (2009) 


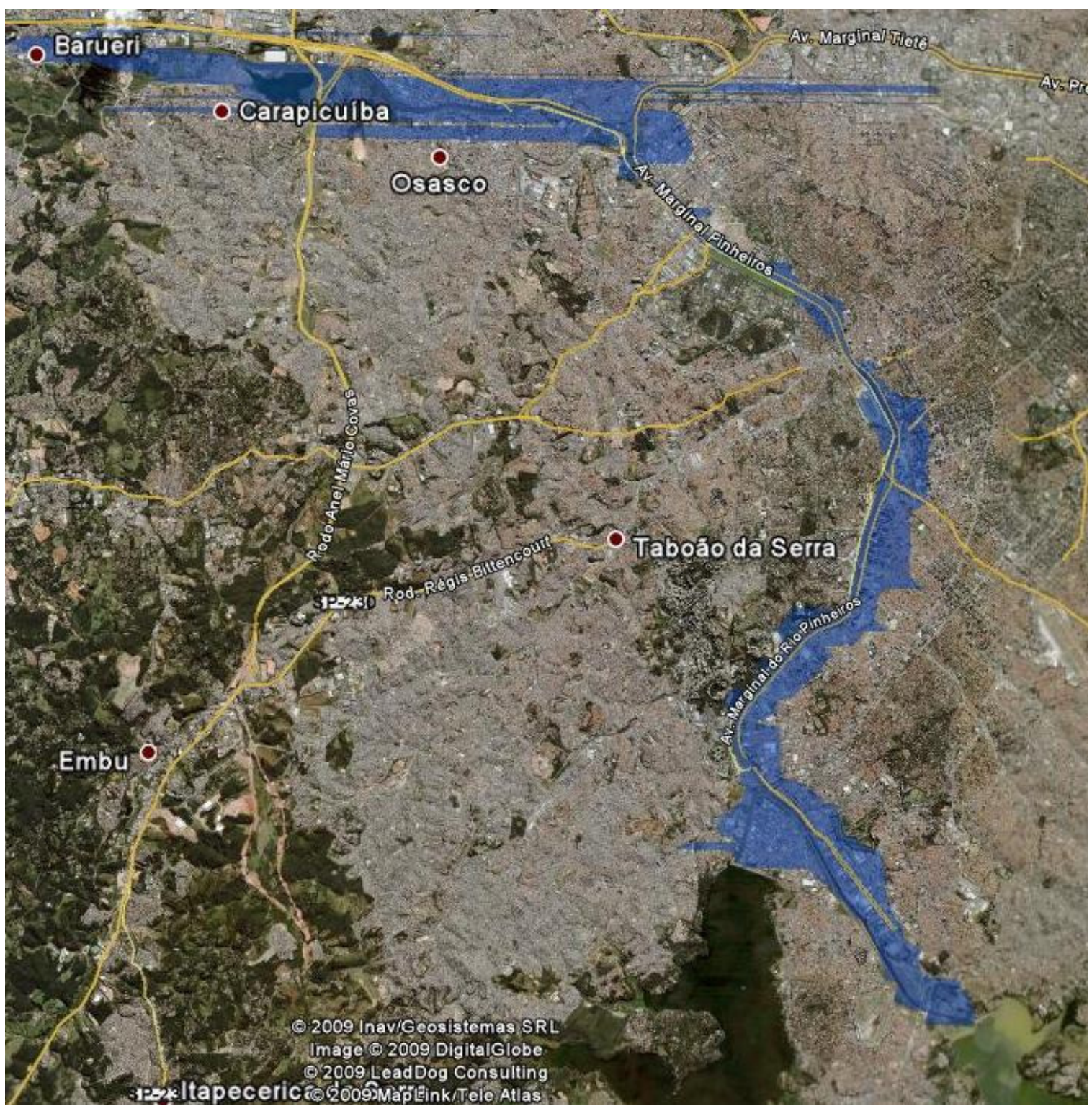

Figura 4.58: Área Inundada para o Rompimento da Barragem Guarapiranga no Cenário 18. Adaptado de Google Earth (2009) 


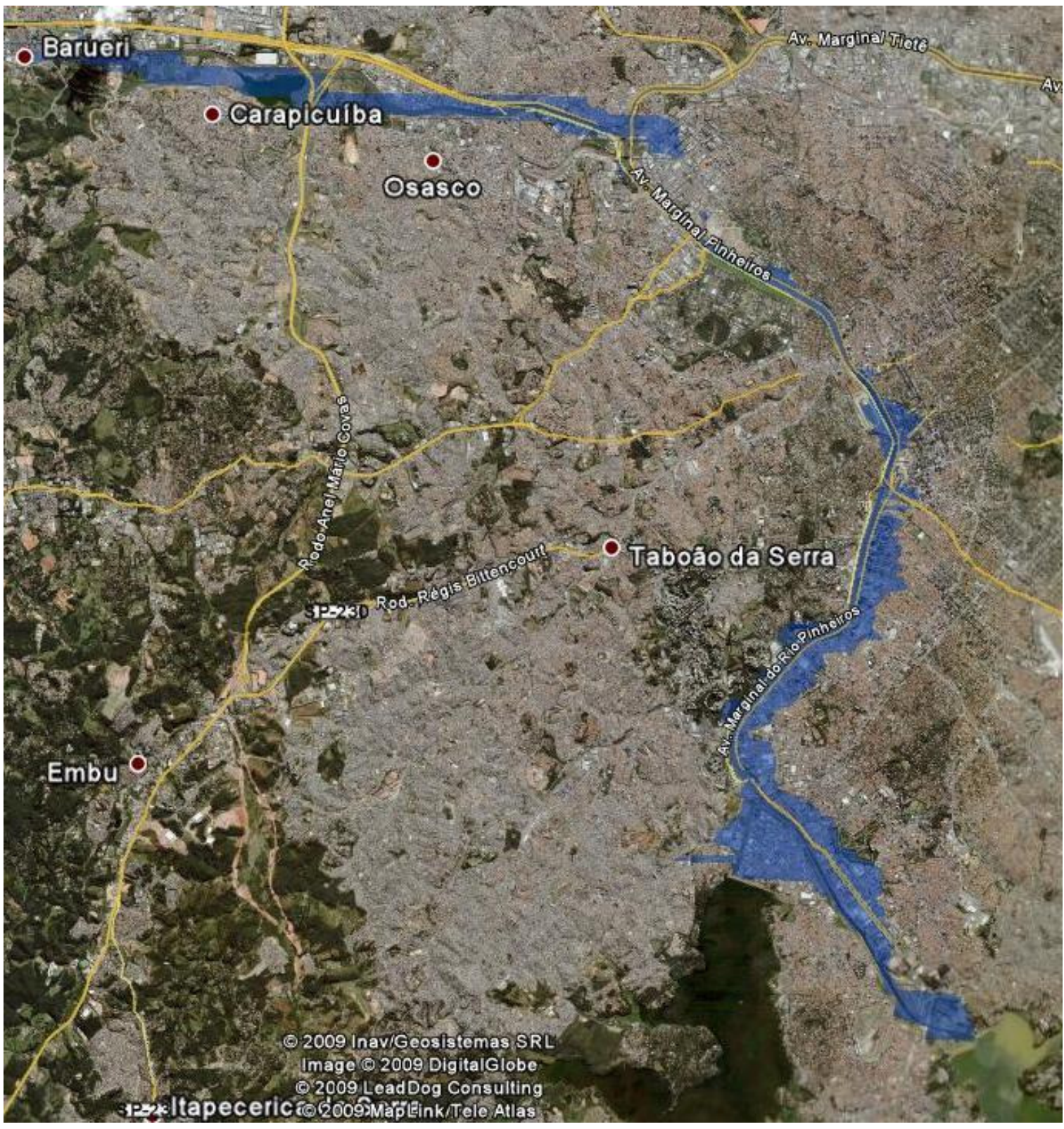

Figura 4.59: Área Inundada para o Rompimento da Barragem Guarapiranga no Cenário 21. Adaptado de Google Earth (2009) 


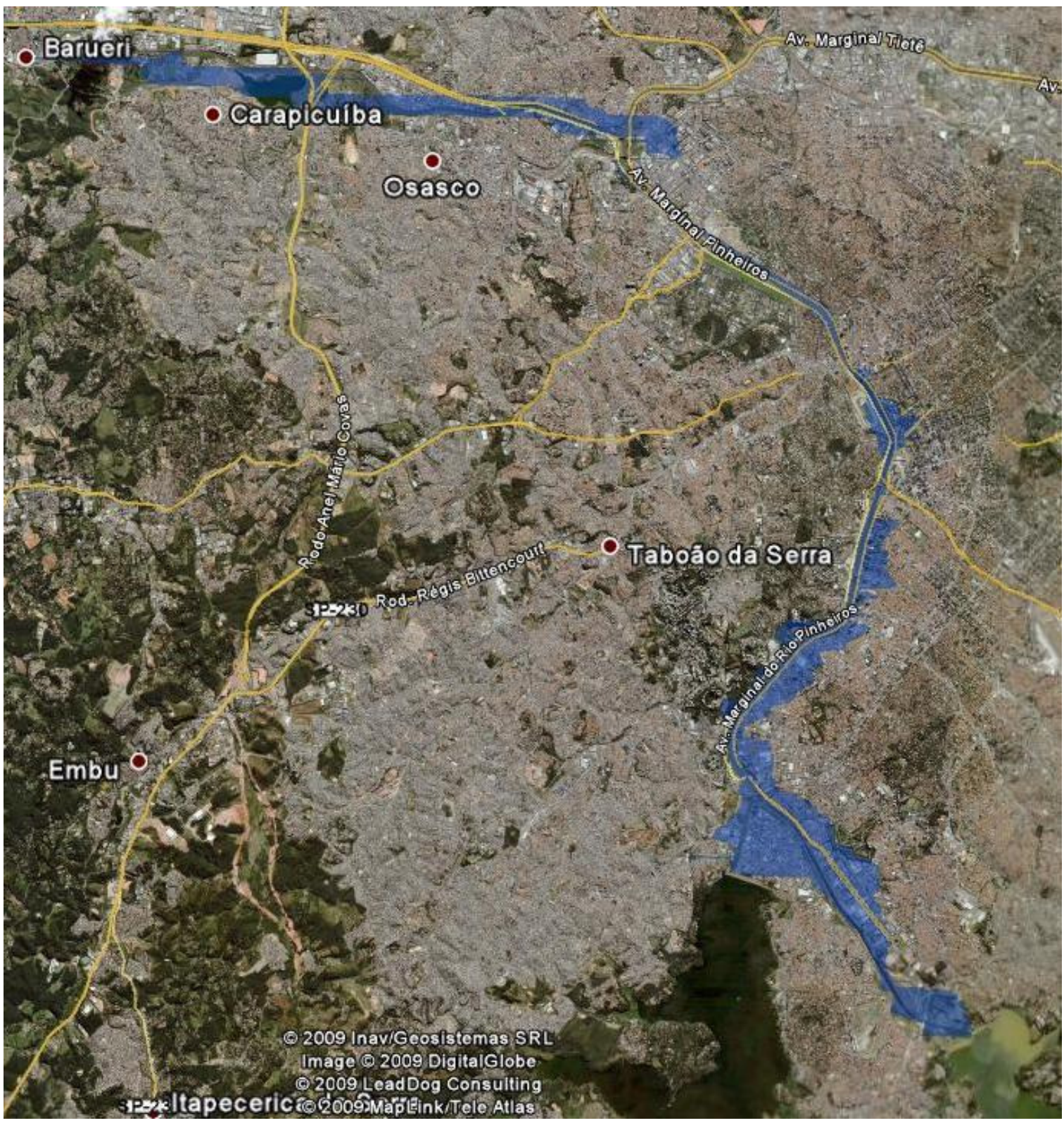

Figura 4.60: Área Inundada para o Rompimento da Barragem Guarapiranga no Cenário 22. Adaptado de Google Earth (2009) 


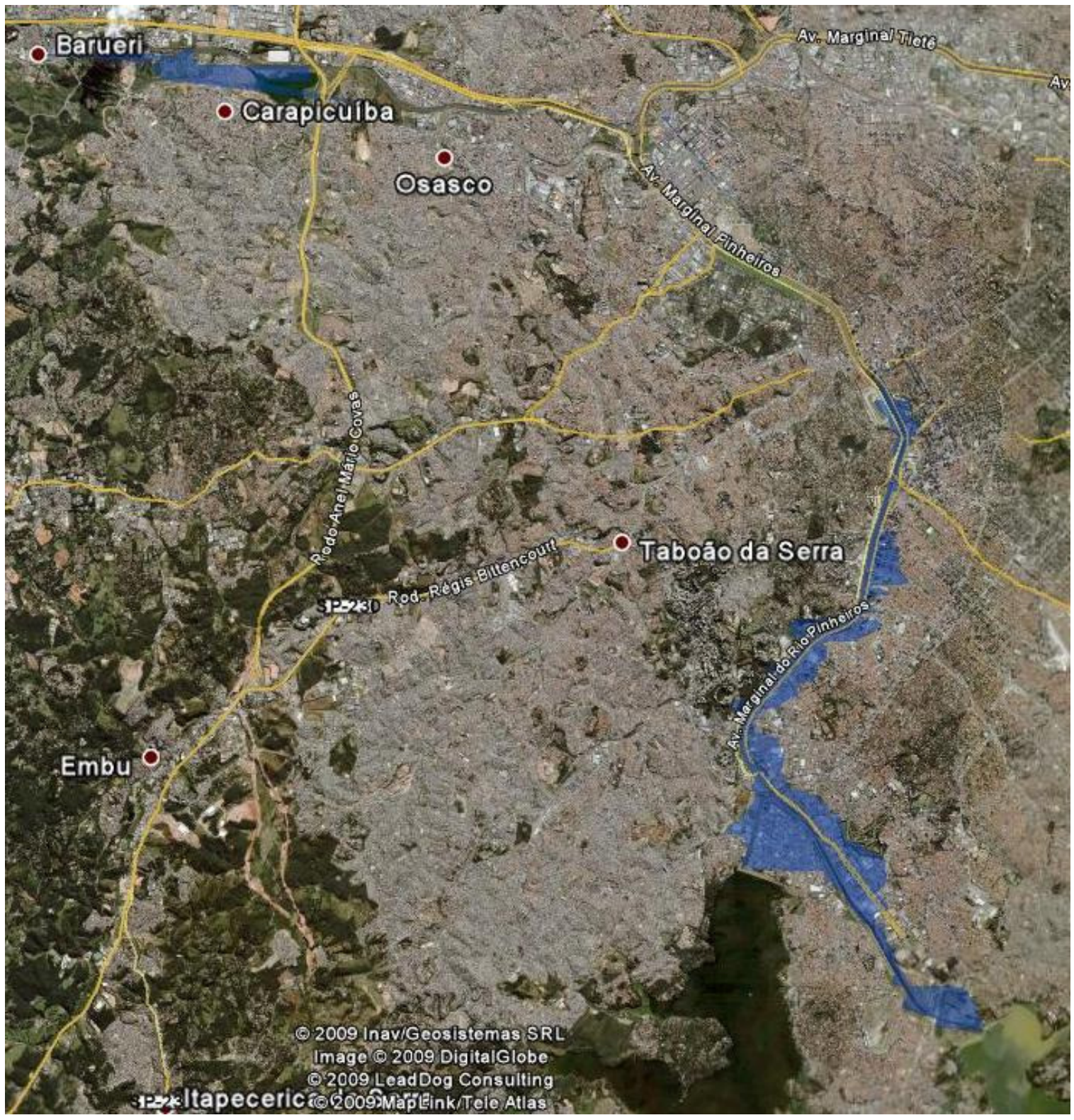

Figura 4.61: Área Inundada para o Rompimento da Barragem Guarapiranga no Cenário 23. Adaptado de Google Earth (2009) 


\subsubsection{Interpretação dos Resultados}

Os resultados acima podem ser interpretados com vistas a identificação de impactos e ao estabelecimento de ações preventivas e emergenciais sobre a bacia. Embora desenvolvidas para este caso especifico, tais ações exemplificam o método proposto para elaboração destes planos.

Para o presente estudo foram identificados alguns pontos notáveis ao longo do canal Guarapiranga e do Rio Pinheiros, que merecem ser interpretados para a obtenção de informações para a construção dos planos de ação. A seleção destes pontos foi norteada por fatores como:

- localização de equipamentos urbanos fundamentais ou que possam apresentar grande ocupação de pessoas, como hospitais, escolas, praças esportivas, estações metroviárias ou ferroviárias

- $\quad$ corredores de trafego rodoviário vitais para entrada e saída das áreas atingidas

corredores de acesso aos hospitais e demais locais destinados ao tratamento de emergência, alojamentos provisórios e centros de decisão - $\quad$ centros de abastecimento

- $\quad$ estações de tratamento de água, elevatórias, subestações elétricas - $\quad$ infra-estrutura aeroportuária, ferroviária e rodoviária urbana

Para cada ponto foram obtidos, a partir do modelo matemático, as informações relativas aos instantes de inicio e fim de inundação, níveis e vazões máximos atingidos bem como tempo em que o equipamento ou infra-estrutura fica inacessível.

A título de exemplo, foram selecionados os seguintes pontos: Barragem Guarapiranga, confluência entre o canal Guarapiranga e o Rio Pinheiros, Ponte Estaiada (Av. Jornalista Roberto Marinho/Água Espraiada), Ponte da Av. Eusébio Matoso, Ponte Jaguaré, Cebolão (confluência entre os Rios Pinheiros e Tietê). A Figura 4.62 apresenta a localização destes pontos notáveis. 


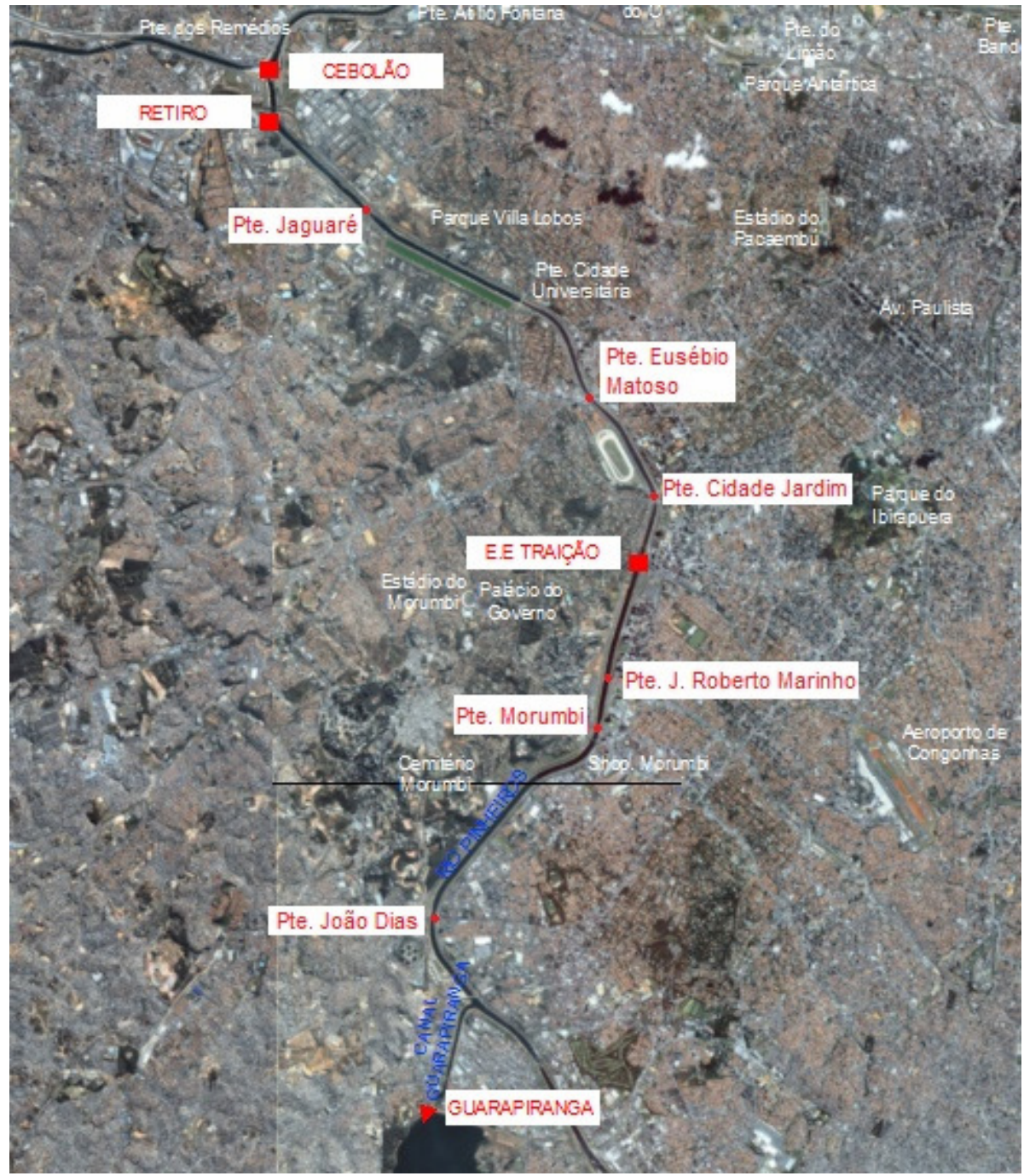

Figura 4.62: Pontos Notáveis no Canal Pinheiros

Os resultados obtidos para cada ponto notável são apresentados nas Figura 4.63 a Erro! Fonte de referência não encontrada.. Observa-se que, para os hidrogramas do nó Guarapiranga (Figura 4.63), que representa a a barragem Guarapiranga e a captação de abastecimento de água principal da região, os picos de níveis e vazoes são mais acentuados, situando-se em torno de 9 a 14 horas após o inicio do evento, respectivamente para os cenários de overtopping e piping.

$\mathrm{Na}$ confluência entre o Canal Guarapiranga e o Rio Pinheiros observa-se uma peculiaridade interessante, na qual o trecho localizado entre o pé da barragem Pedreira (montante da confluência no Rio Pinheiros) e a confluência funciona como reservatório de armazenamento, como se pode observar na Figura 4.67, onde o hidrograma apresenta valores de vazões negativos. 
Como se pode observar na Figura 4.75, os níveis d'água resultantes do rompimento de Guarapiranga permanecem acima da cota da Av. Jornalista Roberto Marinho/Água Espraiada (cota $722,00 \mathrm{~m}$ ) por aproximadamente $70 \%$ do tempo total do evento, isto é, 128 horas, para os cenários de overtopping e 74 horas (40\%) para os cenários de piping. Isto significa que o acesso ao corredor para transposição do rio ficará interditado por cerca de 4 a 6 dias. Este resultado indica que novas alternativas para cruzamento da faixa potencialmente inundável deverão ser avaliadas quando da elaboração das estratégias de ação durante a emergência, como por exemplo, a preparação de uma das pontes de forma a garantir o trafego em quaisquer situações.

O principal corredor viário da região é o da ponte Eusébio Matoso, cujos níveis e vazões estão indicados na Figura 4.80 e Figura 4.81 respectivamente. Observa-se que as curvas de N.A. versus tempo possuem um formato menos acentuado que os demais pontos localizados a montante, os níveis se mantém mais altos por mais tempo. Cabe ressaltar que este corredor é um dos principais acessos rodoviários ao complexo Hospitalar Clinicas, que é a referência para atendimento em saúde na cidade.

As figuras Figura 4.82 e Figura 4.83 representam a região próxima a Ponte do Jaguaré, onde está localizado o principal centro de distribuição de alimentos da cidade de São Paulo (CEASA). Nesta região, os picos de vazão ocorrem de forma mais retardada, cerca de 35 horas após o inicio do evento, para os cenários de overtopping e 40 horas para os cenários de piping. Estas informações se fazem importantes para o manejo dos alimentos que abastecerão a cidade de São Paulo.

O ponto notável representado pelo "Cebolão" apresenta em seus hidrogramas, picos característicos em função do armazenamento de água na calha do Tietê a montante do local, como pode ser observado na Figura 4.90, devido a uma grande área de planície existente na região. Do mesmo modo, o limnigrama apresentado nas Figura 4.89, demonstra que os níveis tem tempo de rebaixamento muito mais longo.

A síntese de todos os resultados apresentados nas figuras anteriormente citadas é apresentada na Tabela 4.50 a Tabela 4.52. 
- $\quad$ Barragem Guarapiranga

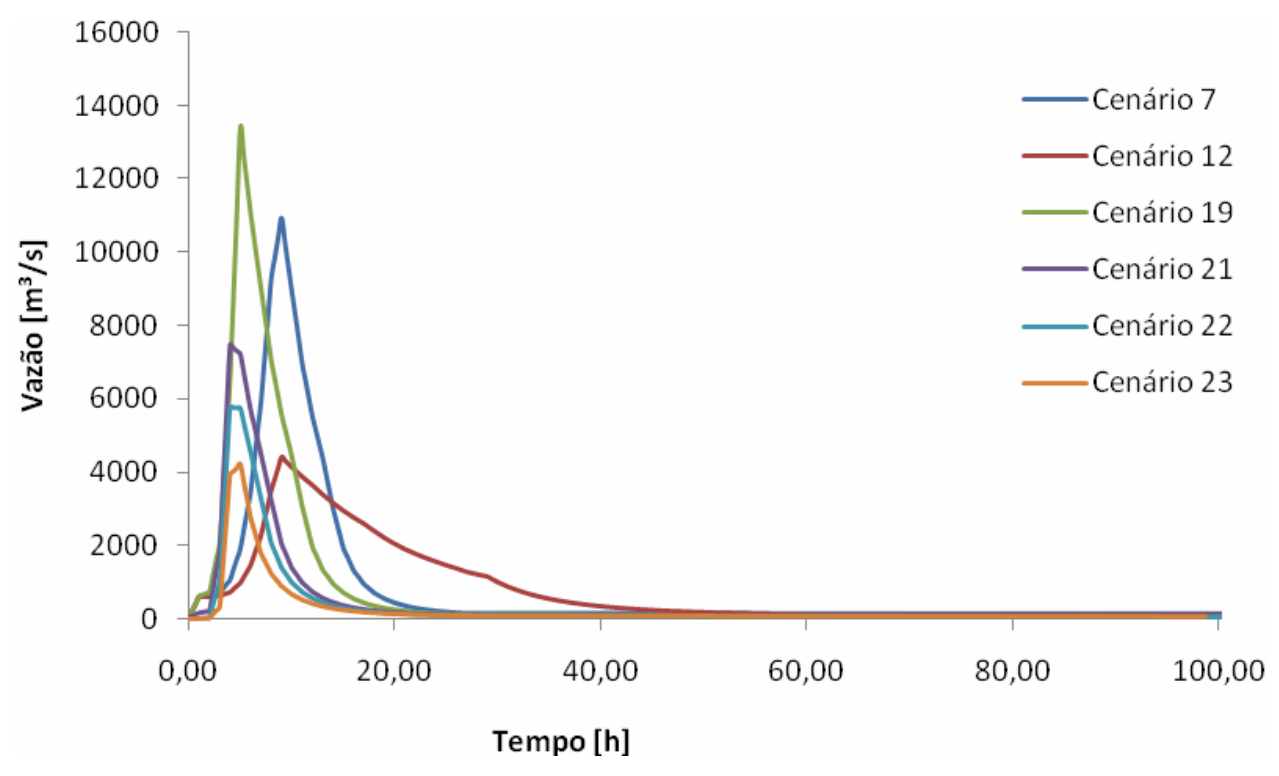

Figura 4.63: Hidrograma da Barragem Guarapiranga

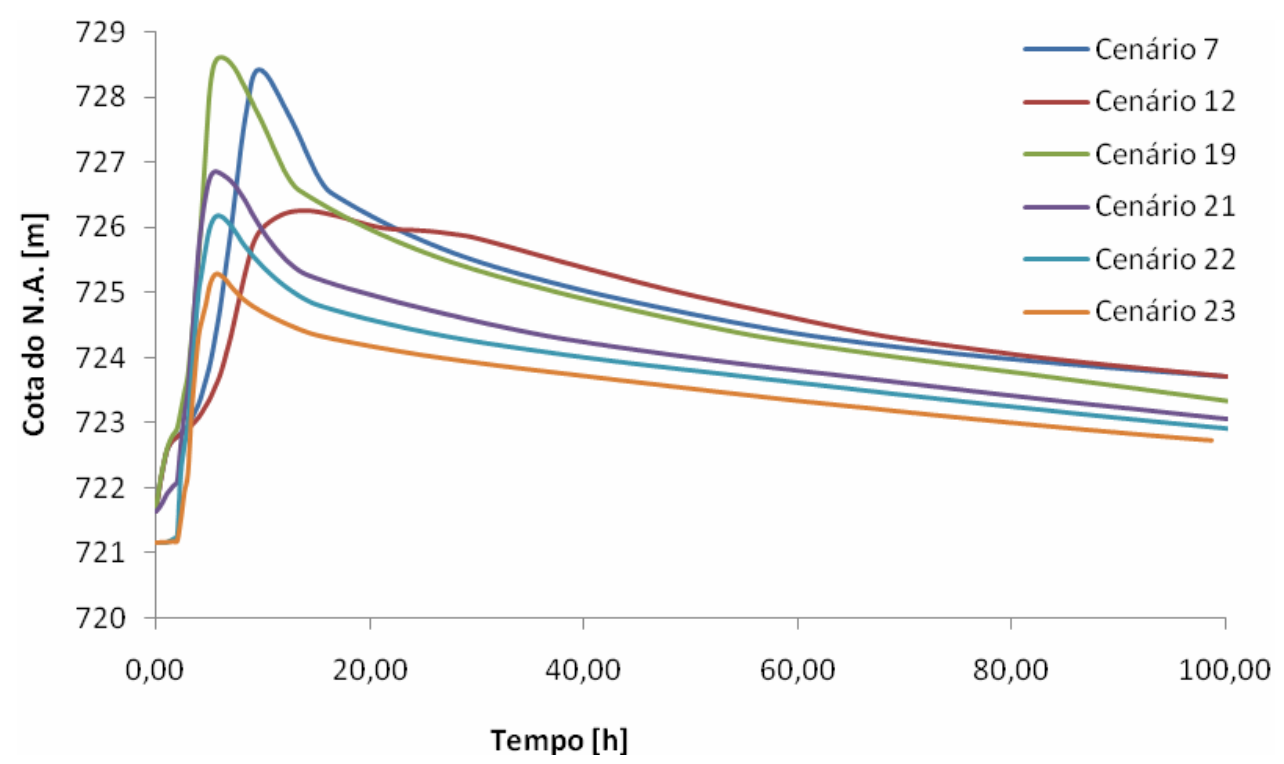

Figura 4.64: Limnigrama da Barragem Guarapiranga 


\section{- $\quad$ Confluência do Canal Guarapiranga com o Rio Pinheiros}

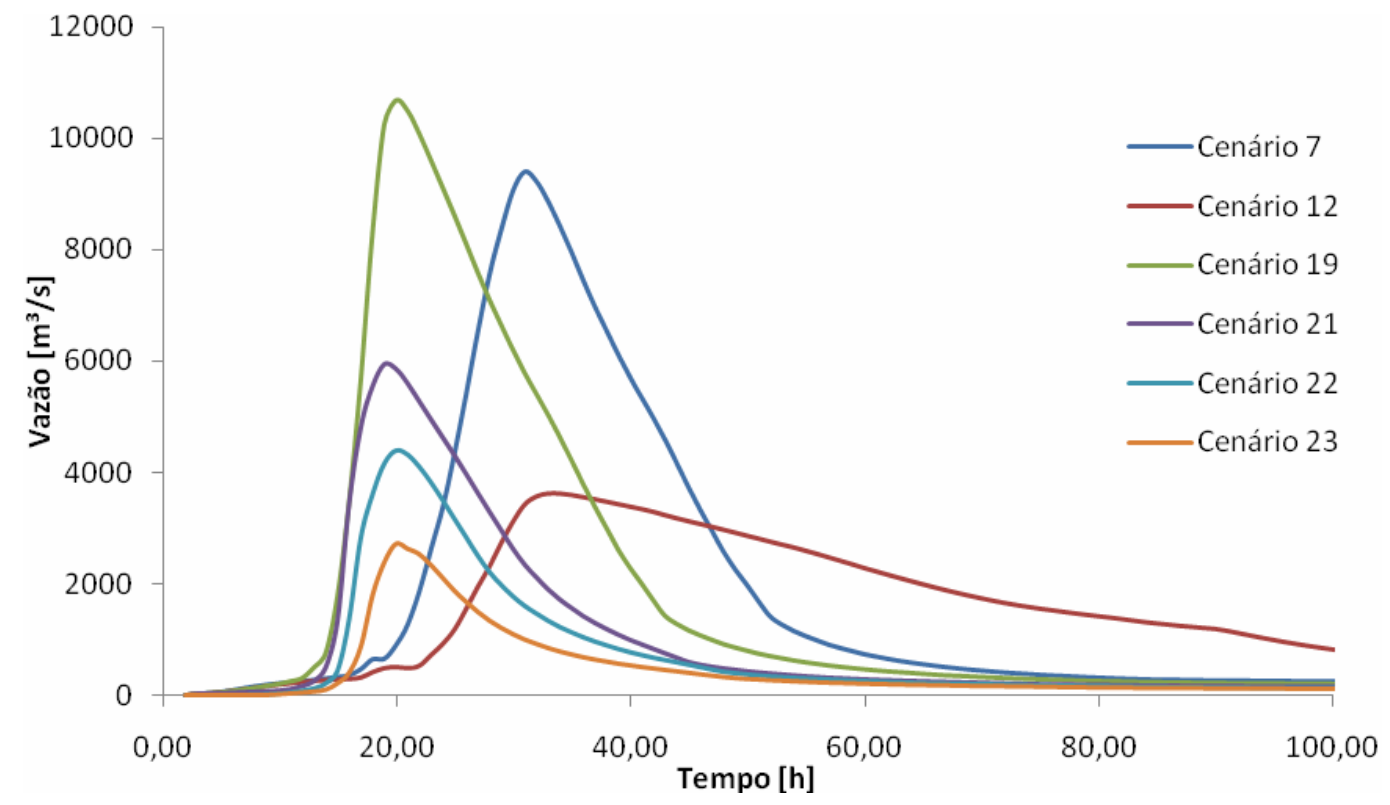

Figura 4.65: Hidrograma da Confluência do Canal Guarapiranga com o Rio Pinheiros - Trecho: Montante do Canal Guarapiranga

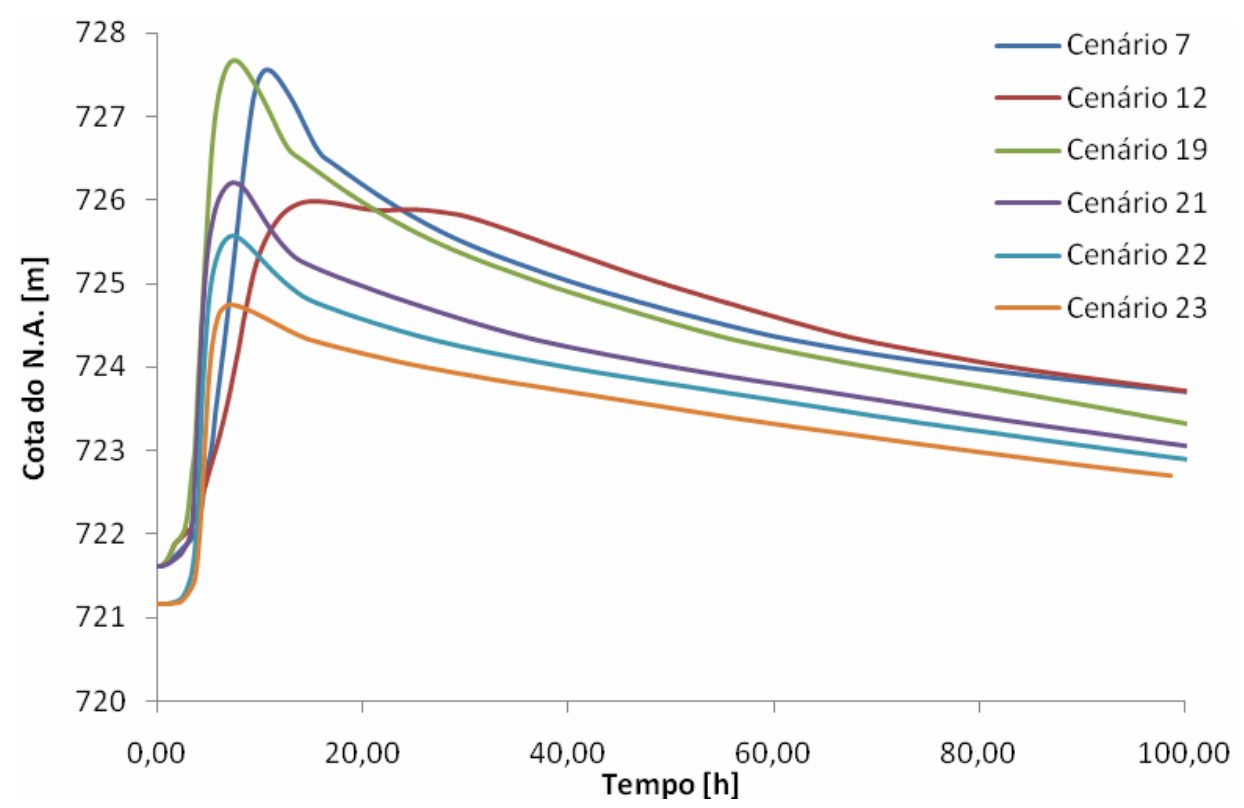

Figura 4.66: Limnigrama da Confluência do Canal Guarapiranga com o Rio Pinheiros - Trecho: Montante do Canal Guarapiranga 


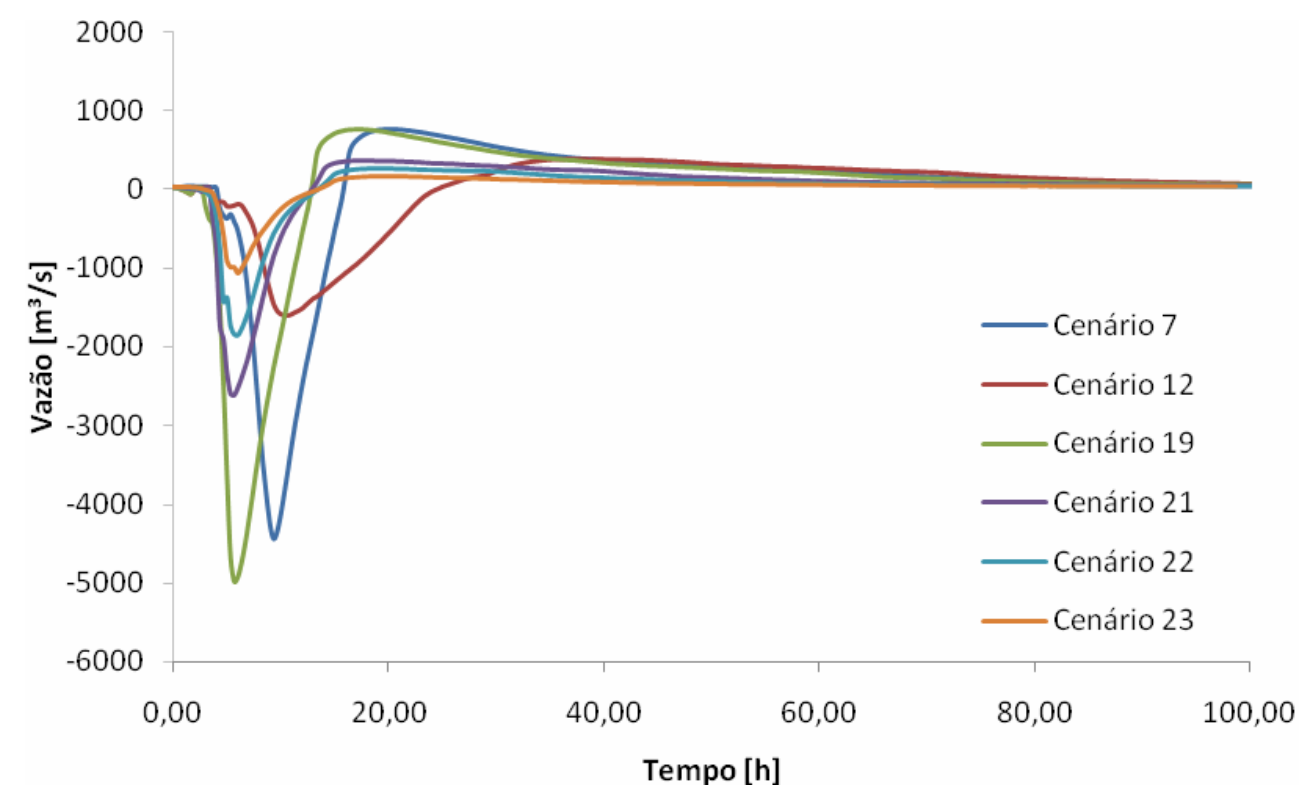

Figura 4.67: Hidrograma da Confluência do Canal Guarapiranga com o Rio Pinheiros - Trecho: Montante do Rio Pinheiros

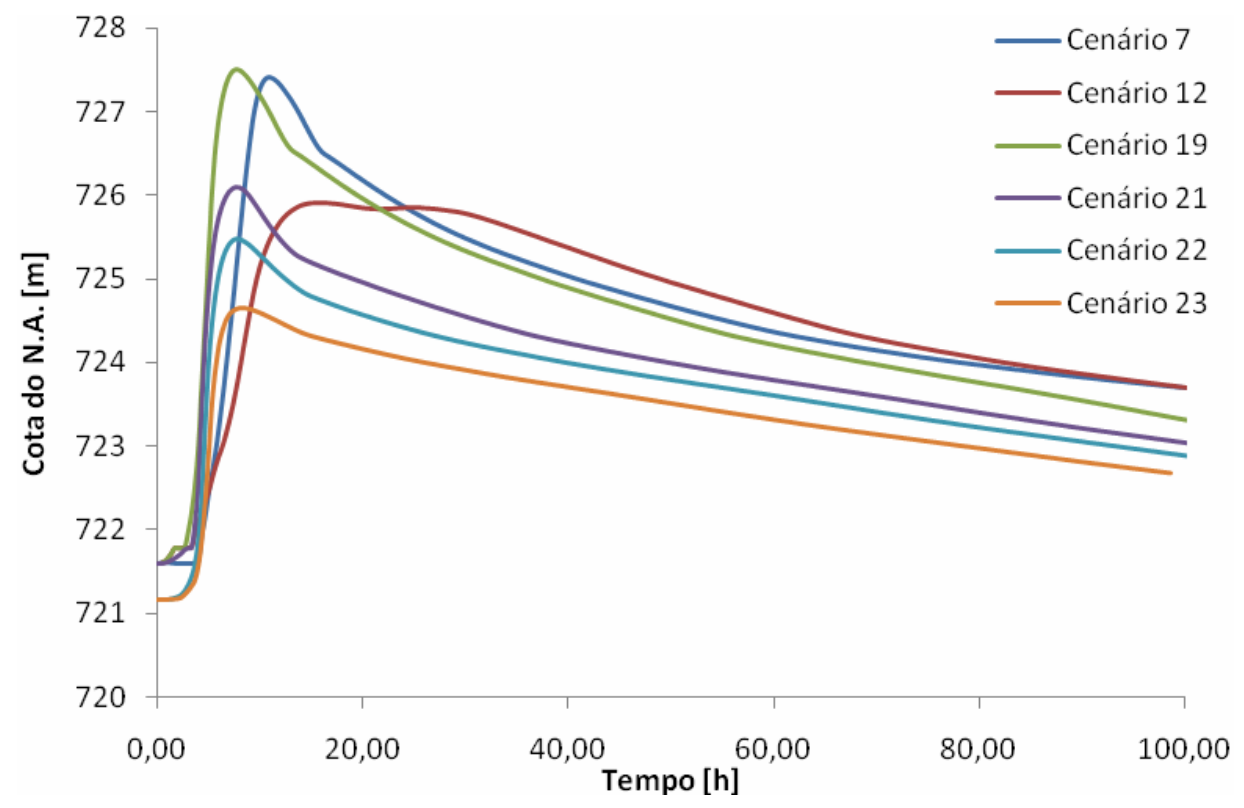

Figura 4.68: Limnigrama da Confluência do Canal Guarapiranga com o Rio Pinheiros - Trecho: Montante do Rio Pinheiros 


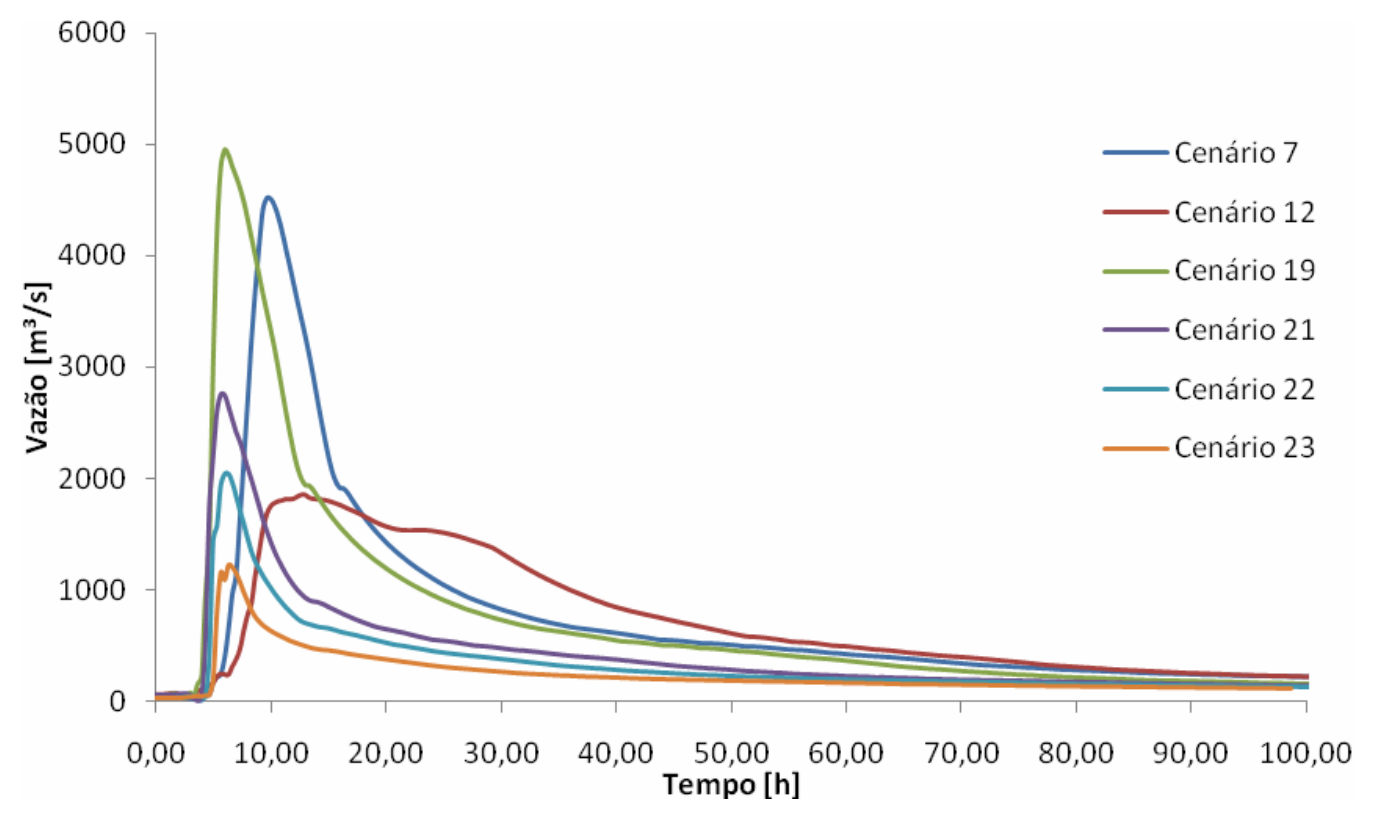

Figura 4.69: Hidrograma da Confluência do Canal Guarapiranga com o Rio Pinheiros - Trecho: Jusante do Rio Pinheiros

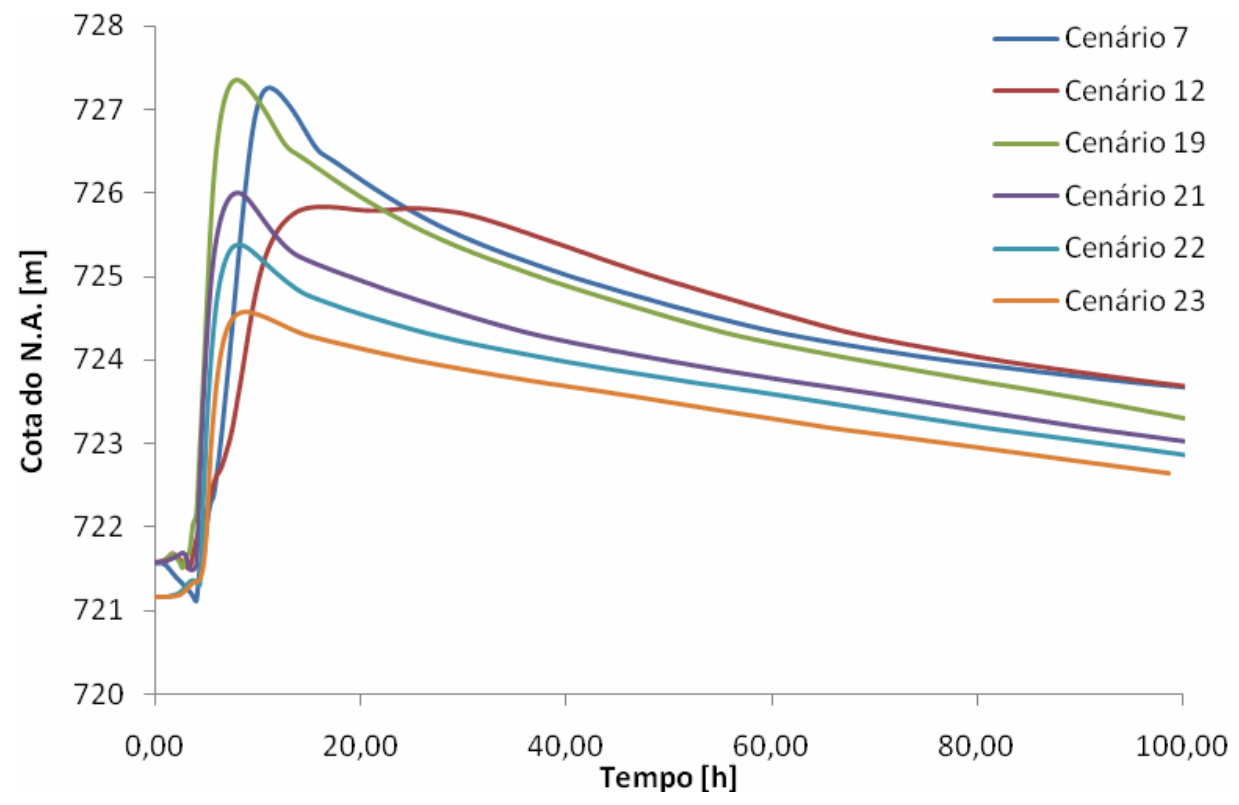

Figura 4.70: Hidrograma da Confluência do Canal Guarapiranga com o Rio Pinheiros - Trecho: Jusante do Rio Pinheiros 


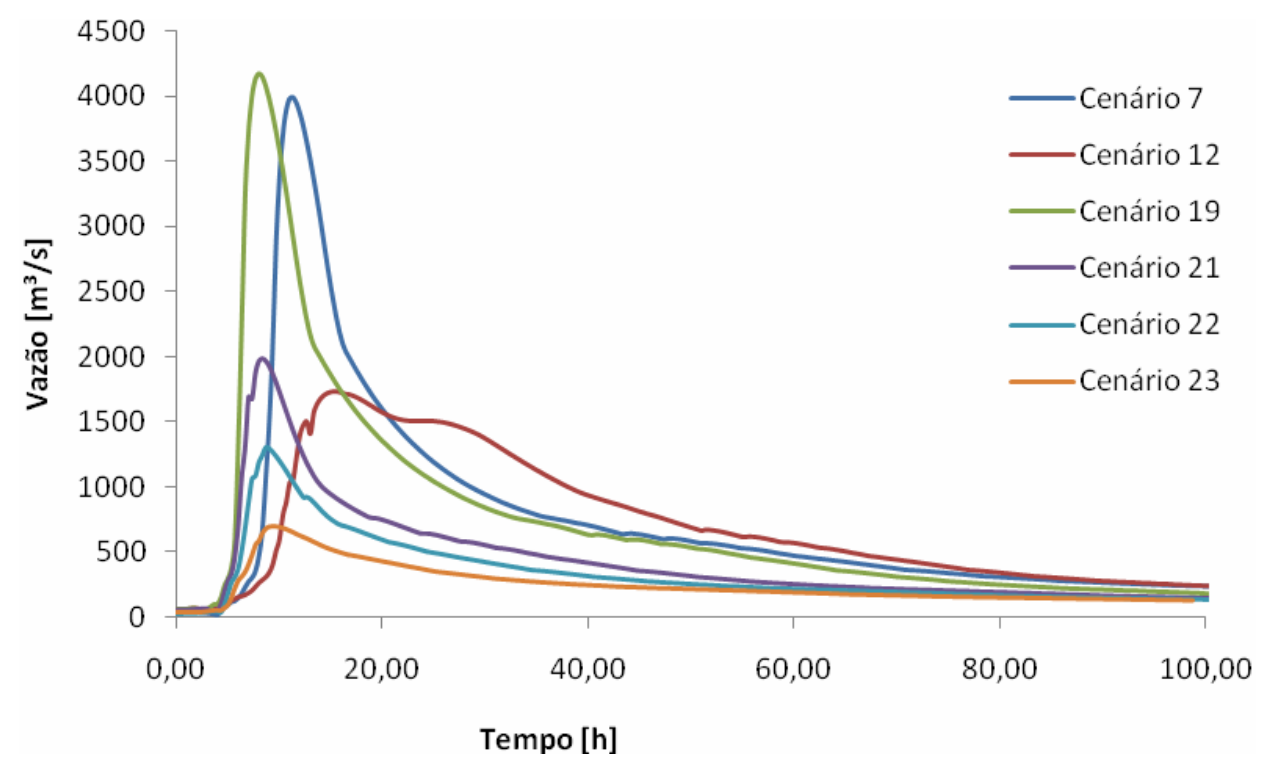

Figura 4.71: Hidrograma na Ponte João Dias

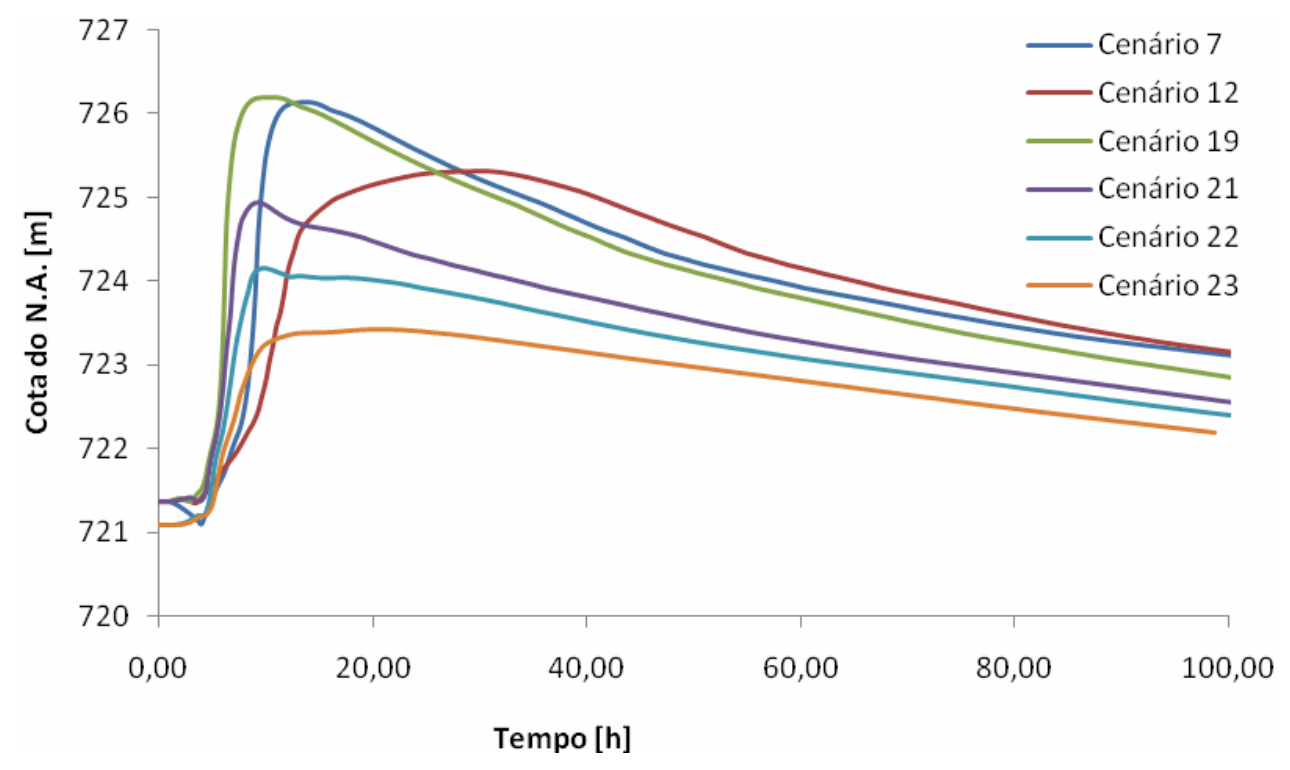

Figura 4.72: Limnigrama na Ponte João Dias 


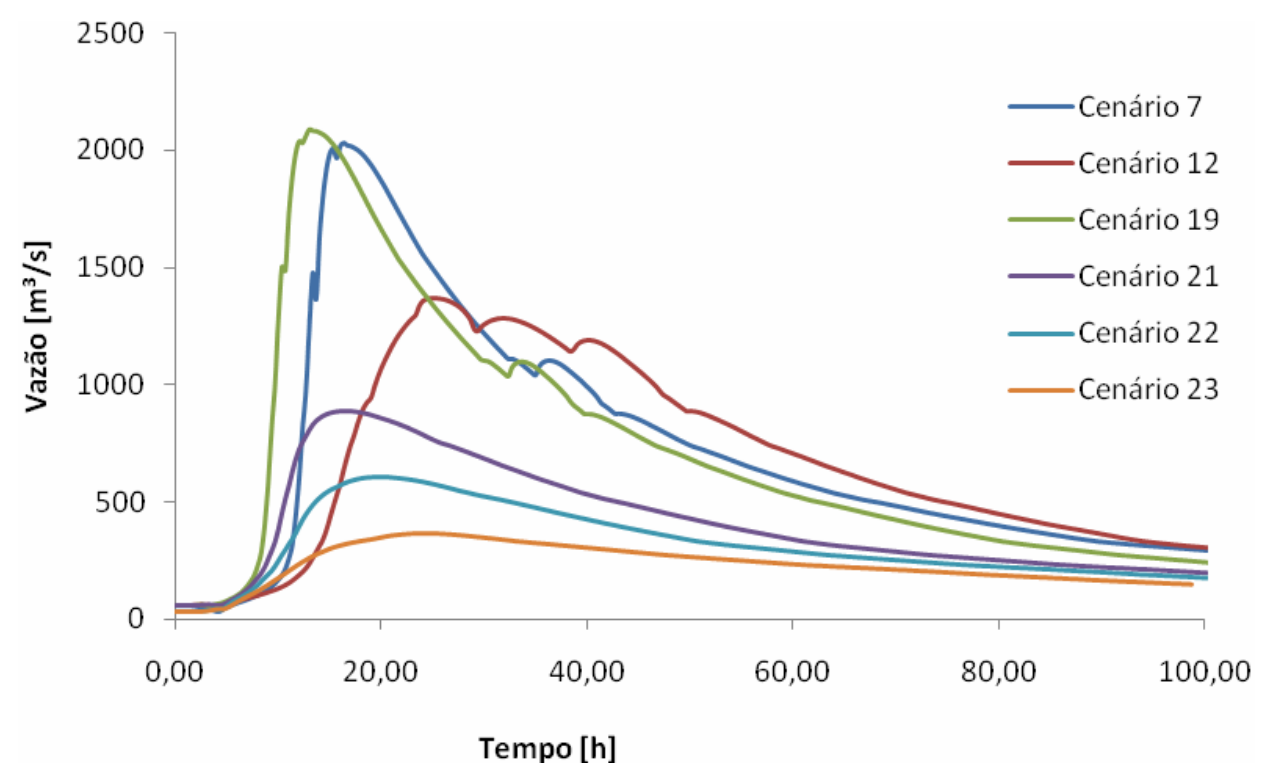

Figura 4.73: Hidrograma na Ponte Estaiada - Av. Jorn. Roberto Marinho/Água Espraiada

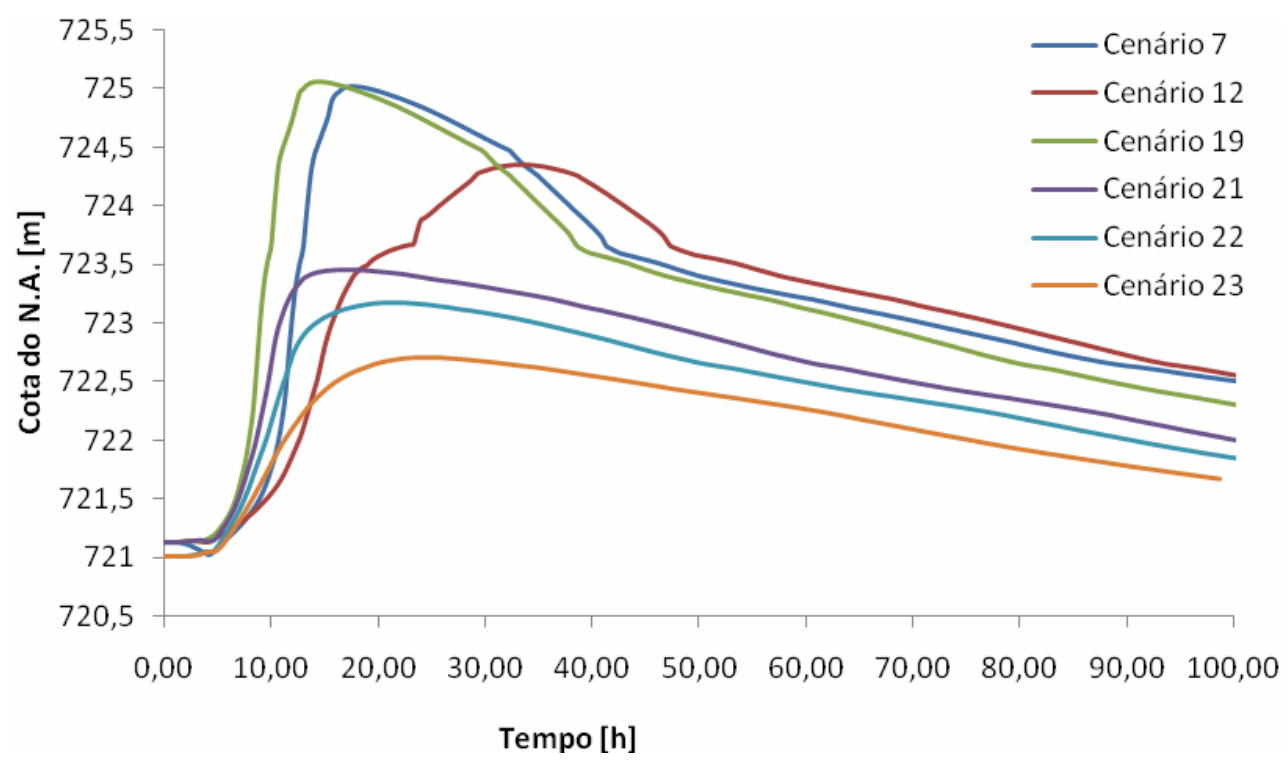

Figura 4.74: Limnigrama na Ponte Estaiada - Av. Jorn. Roberto Marinho/Água Espraiada 


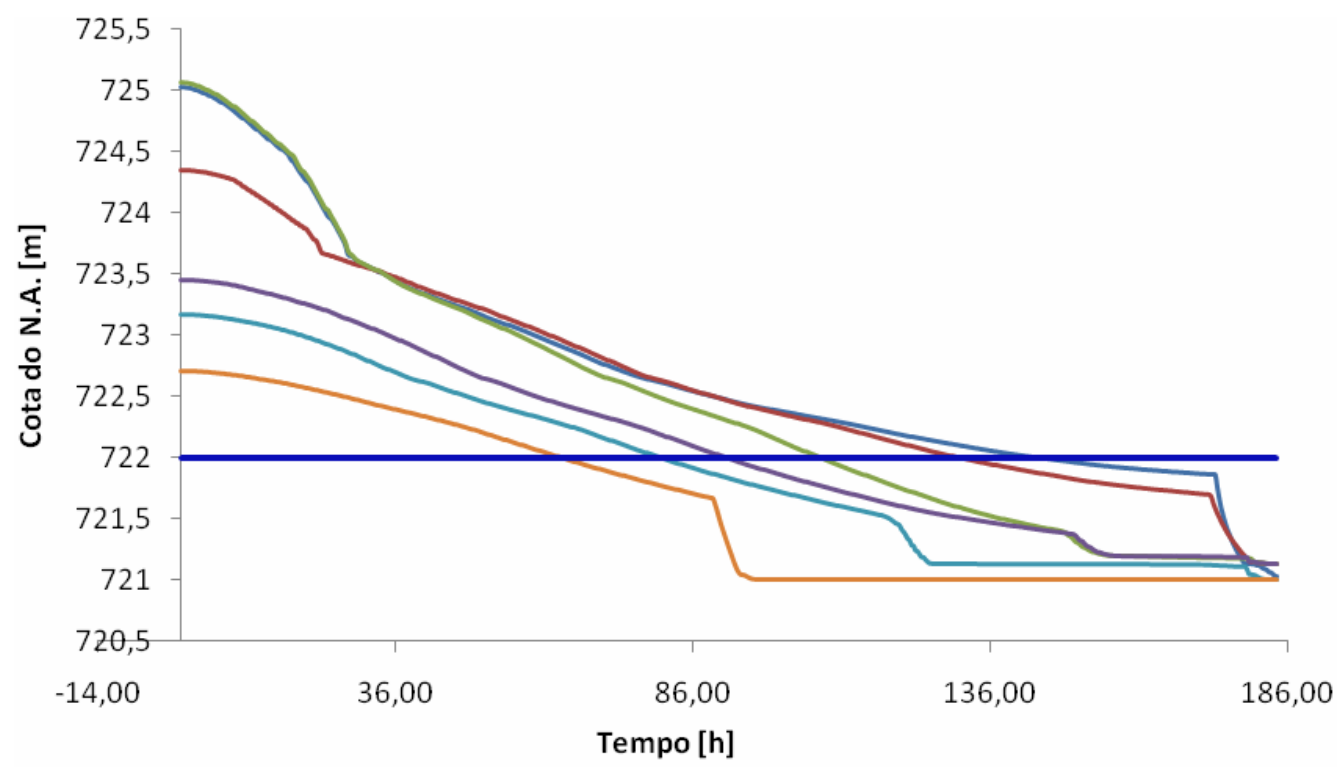

- Cenário 7

- Cenário 12

Cenário 19

- Cenário 21

Cenário 22

Cenário 23

-Av. Jorn. Roberto Marinho

Figura 4.75: Curva de Permanência de N.A. na Ponte Estaiada - Av. Jorn. Roberto Marinho/Água Espraiada

\section{- $\quad$ Usina Elevatória de Traição - Acesso à Av. Bandeirantes}

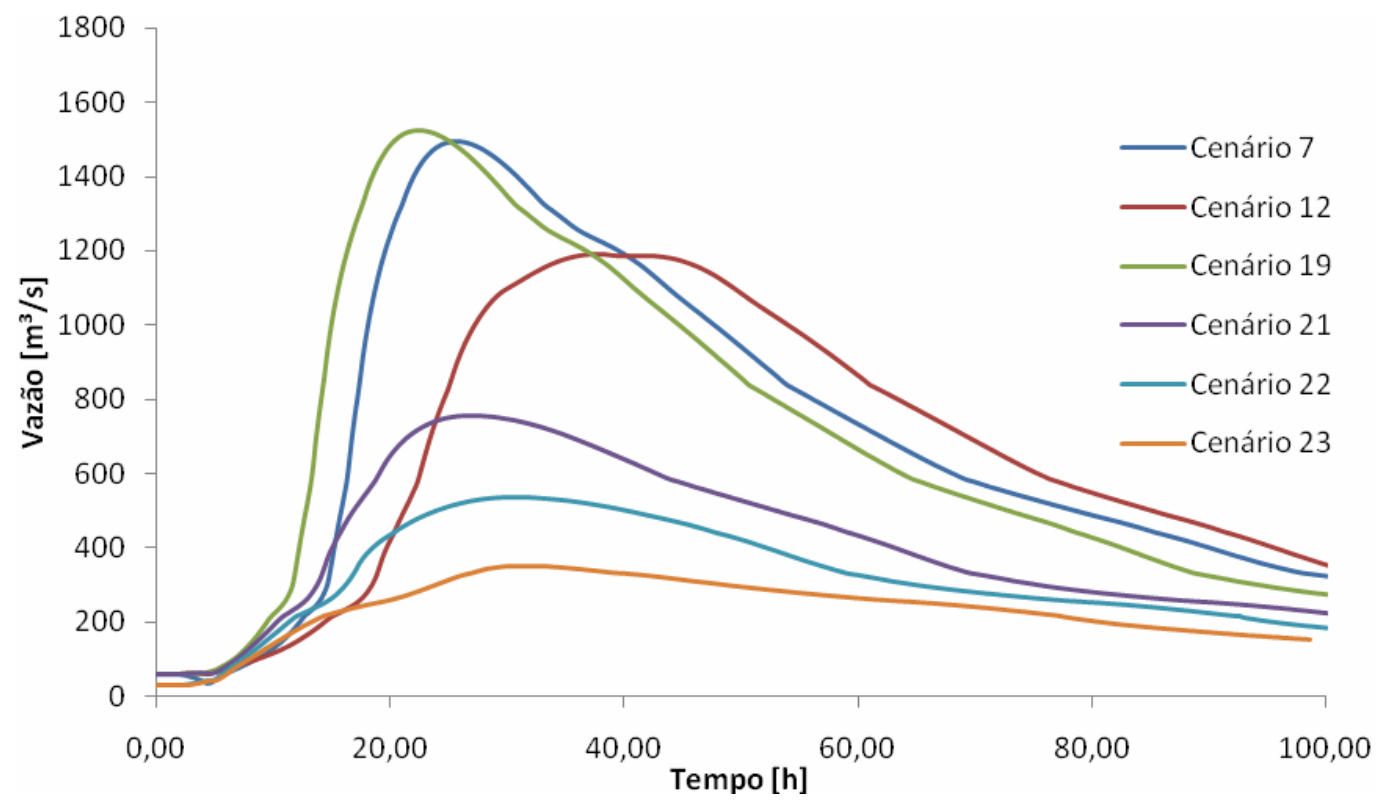

Figura 4.76: Hidrograma a Usina Elevatória de Traição - Trecho: Montante do Rio Pinheiros 


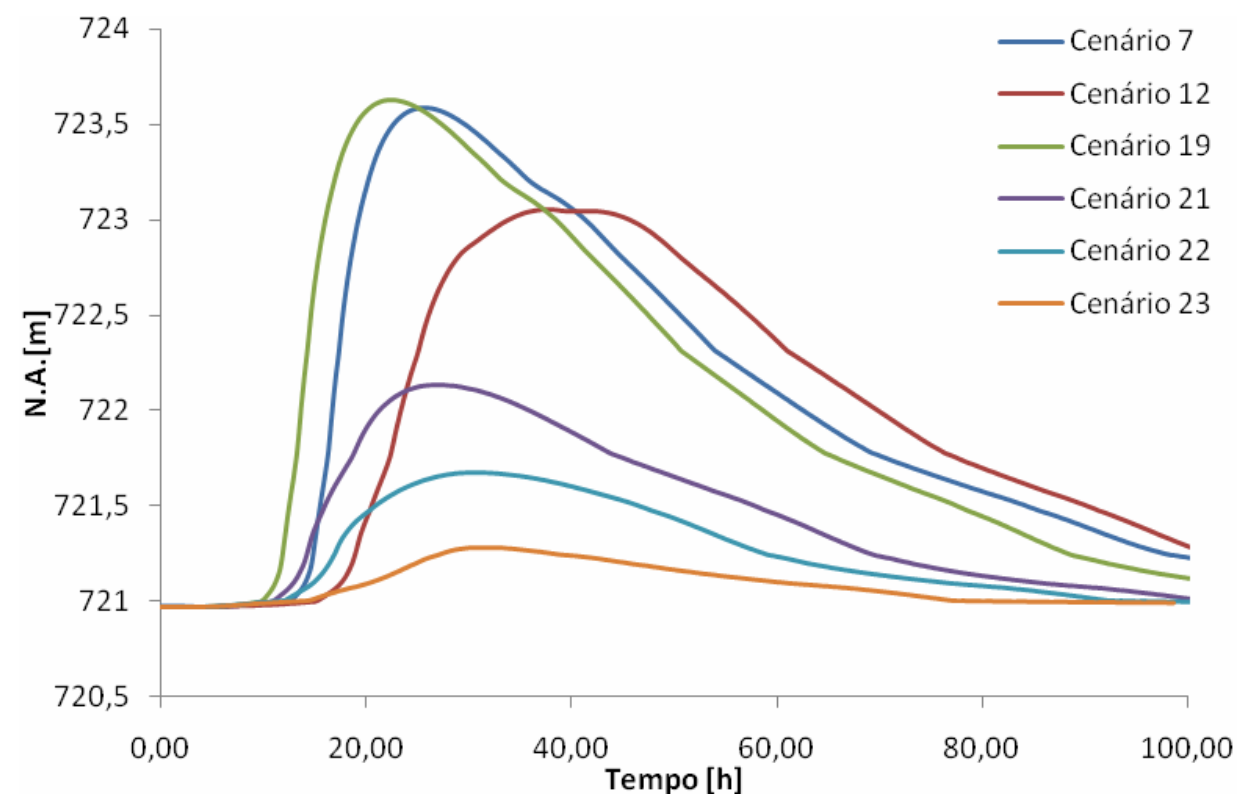

Figura 4.77: Limnigrama a Usina Elevatória de Traição - Trecho: Montante do Rio Pinheiros

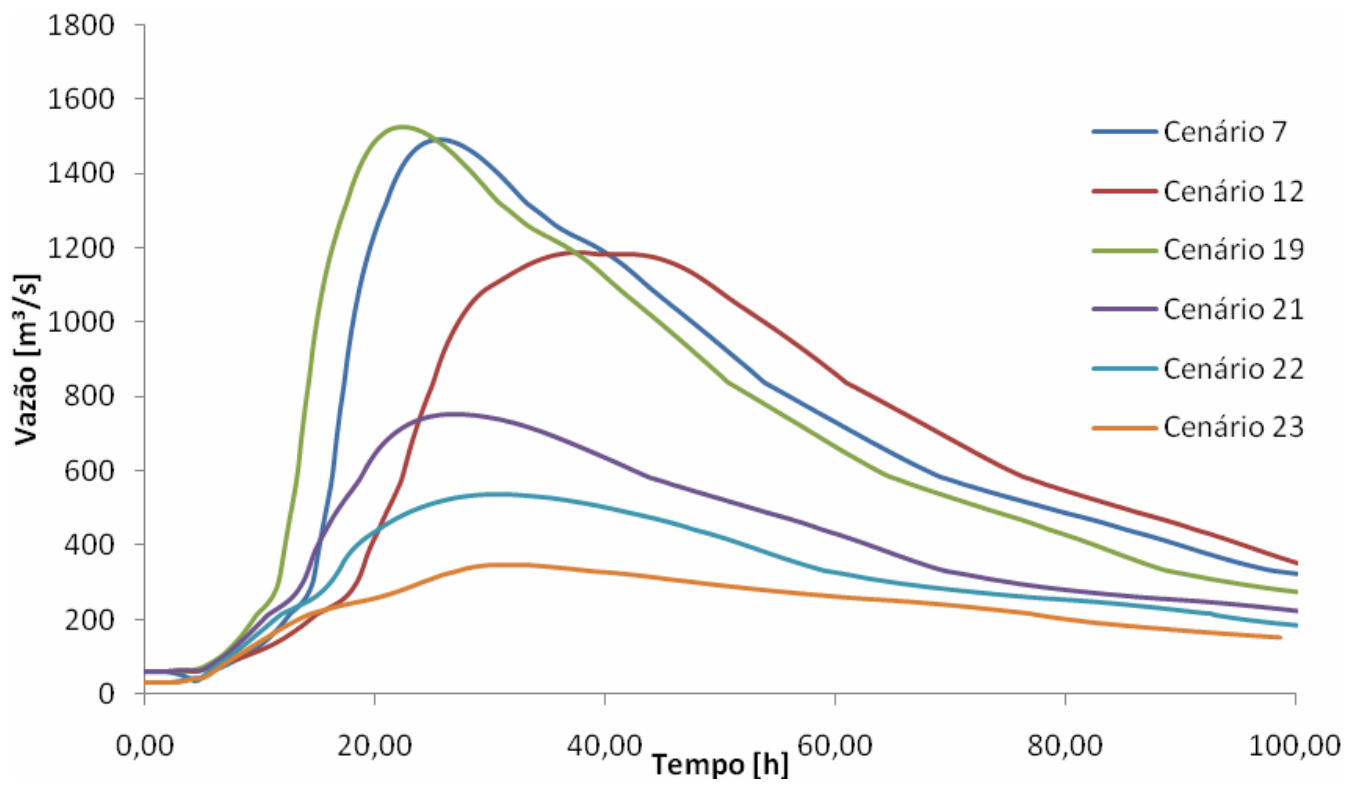

Figura 4.78: Hidrograma a Usina Elevatória de Traição - Trecho: Jusante do Rio Pinheiros 


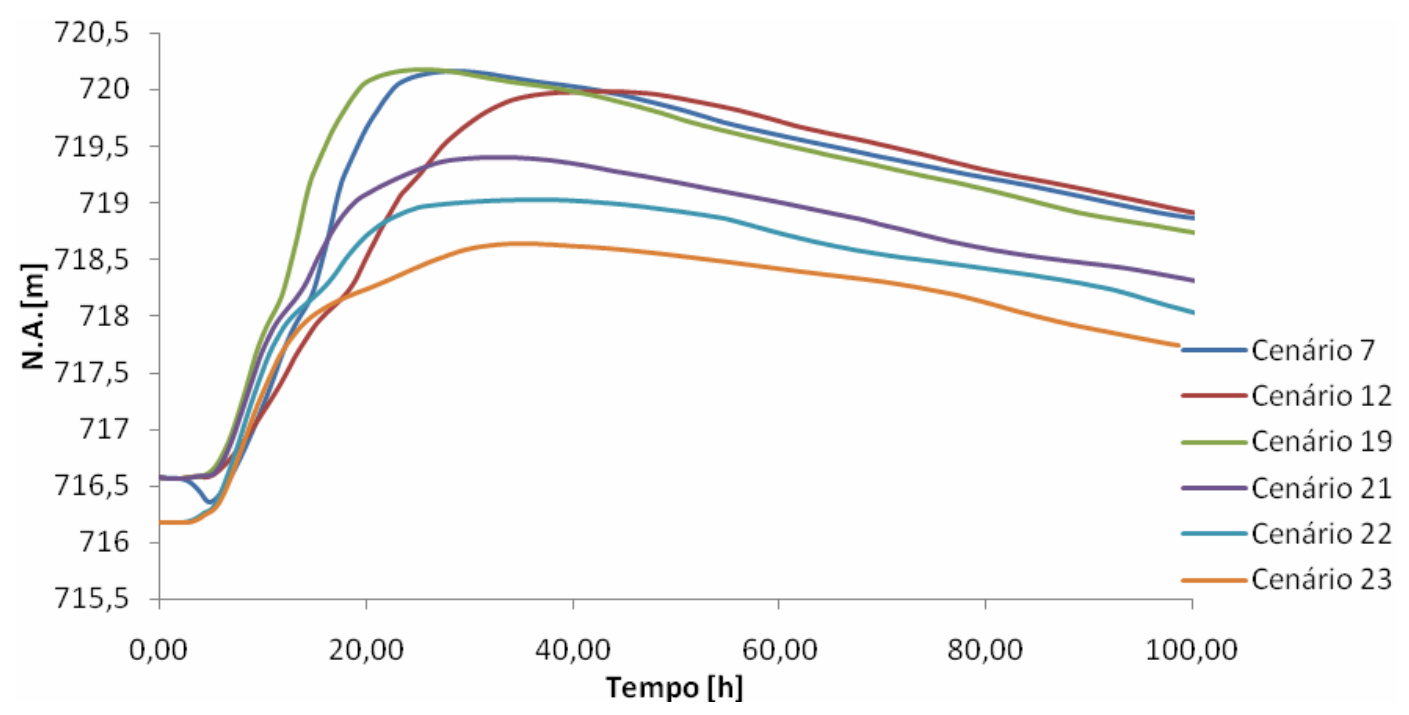

Figura 4.79: Hidrograma a Usina Elevatória de Traição - Trecho: Jusante do Rio Pinheiros

$\bullet$ Ponte da Av. Eusébio Matoso

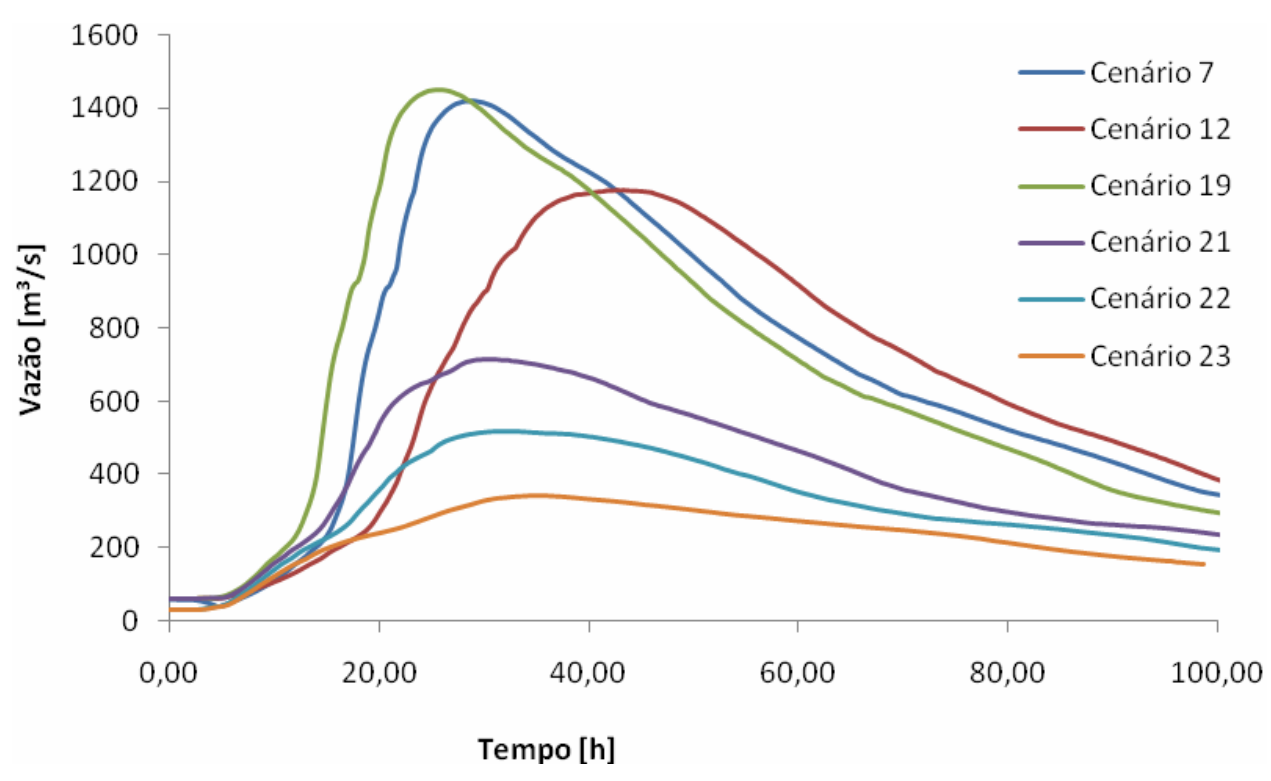

Figura 4.80: Hidrograma na Ponte da Av. Eusébio Matoso 


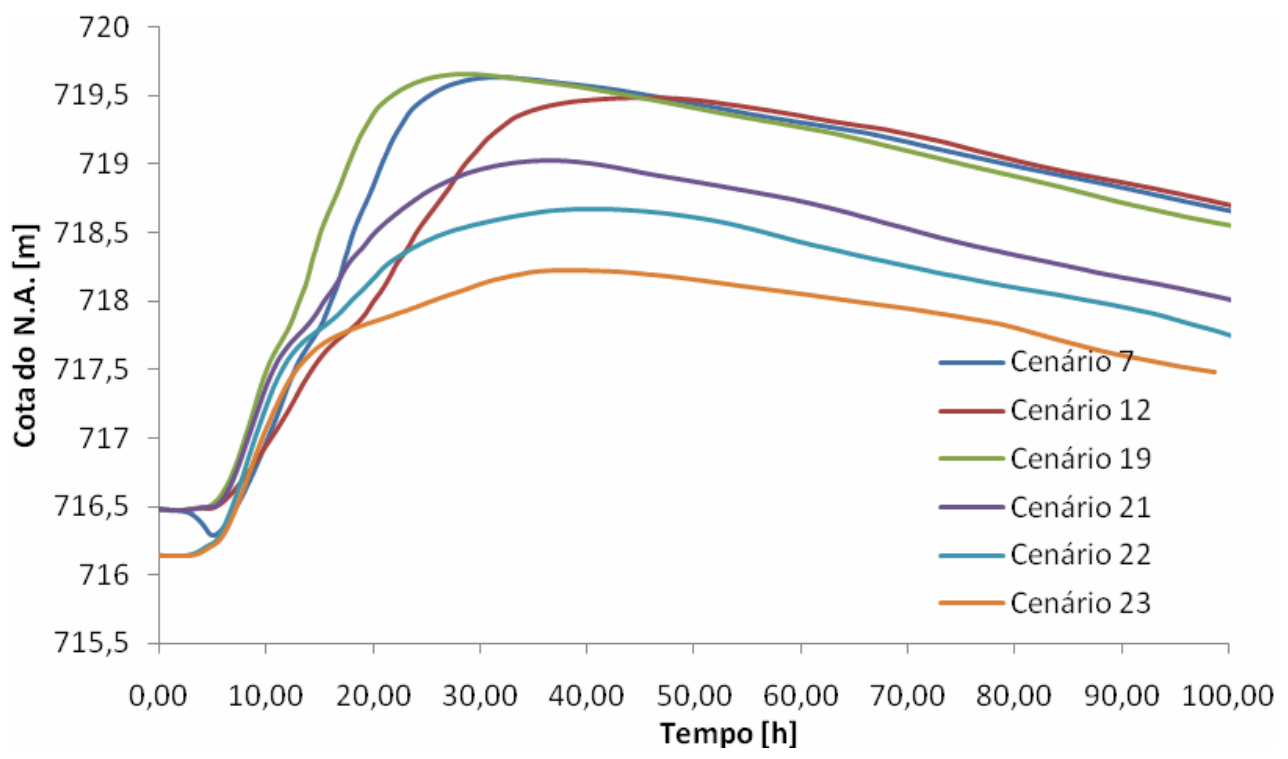

Figura 4.81: Limnigrama na Ponte da Av. Eusébio Matoso

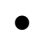

Ponte da Av. Jaguaré

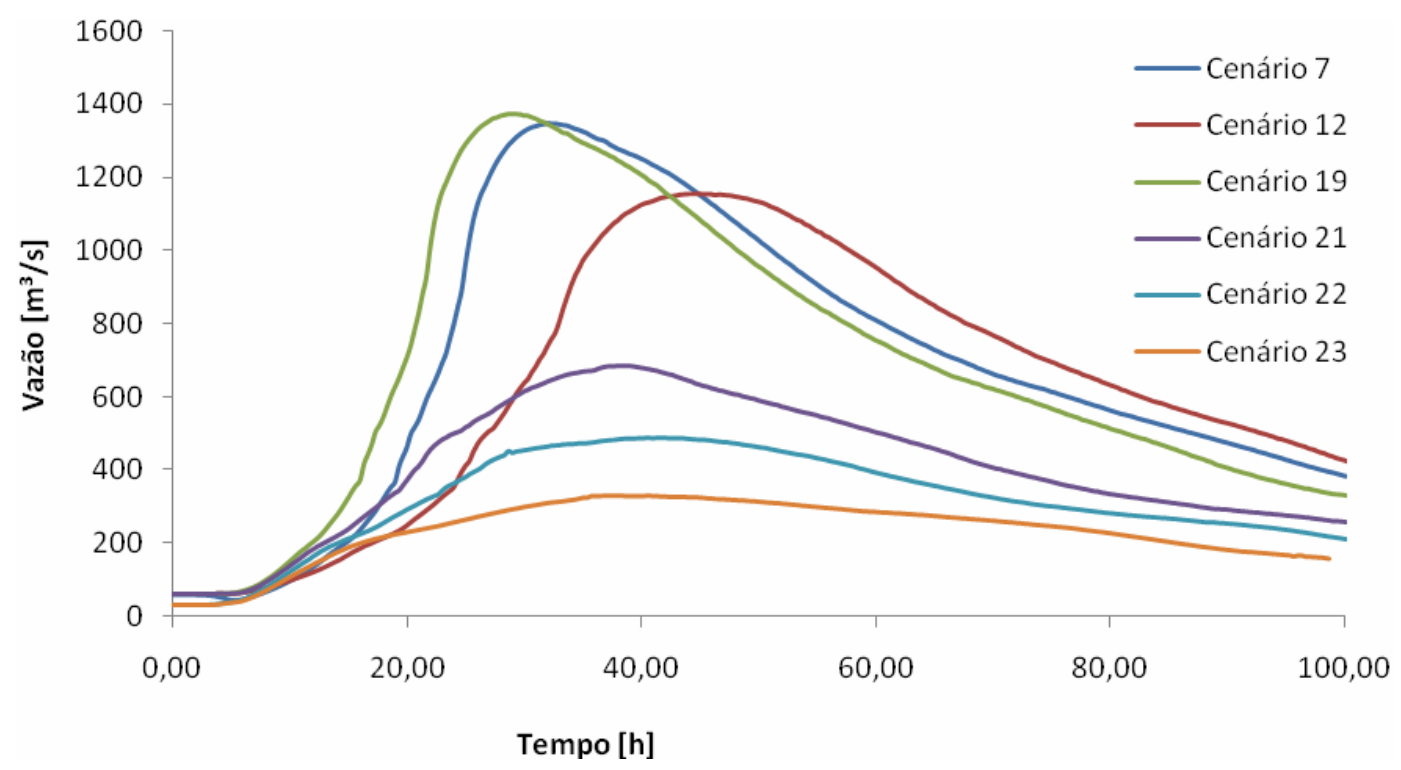

Figura 4.82: Hidrograma na Ponte da Av. Jaguaré 


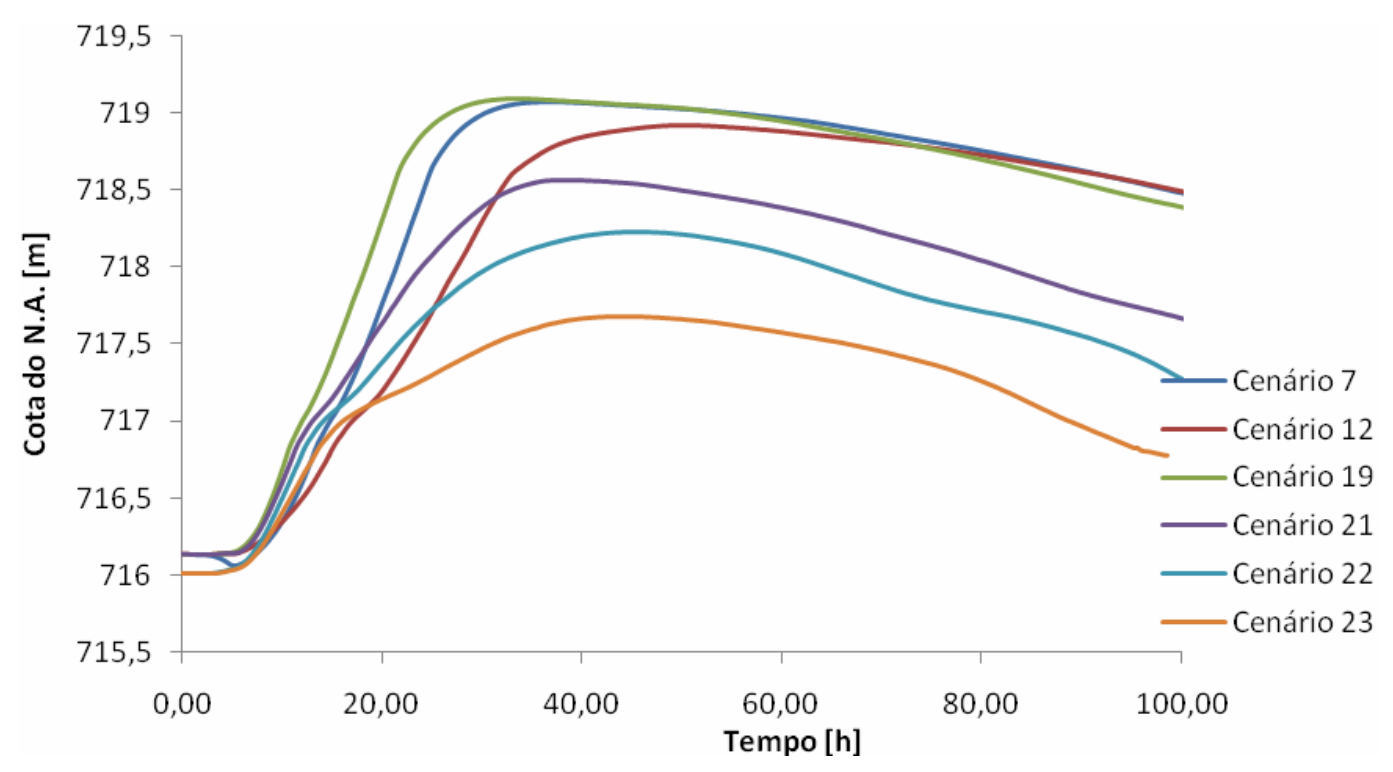

Figura 4.83: Limnigrama na Ponte da Av. Jaguaré

$\bullet$

\section{Estrutura de Retiro}

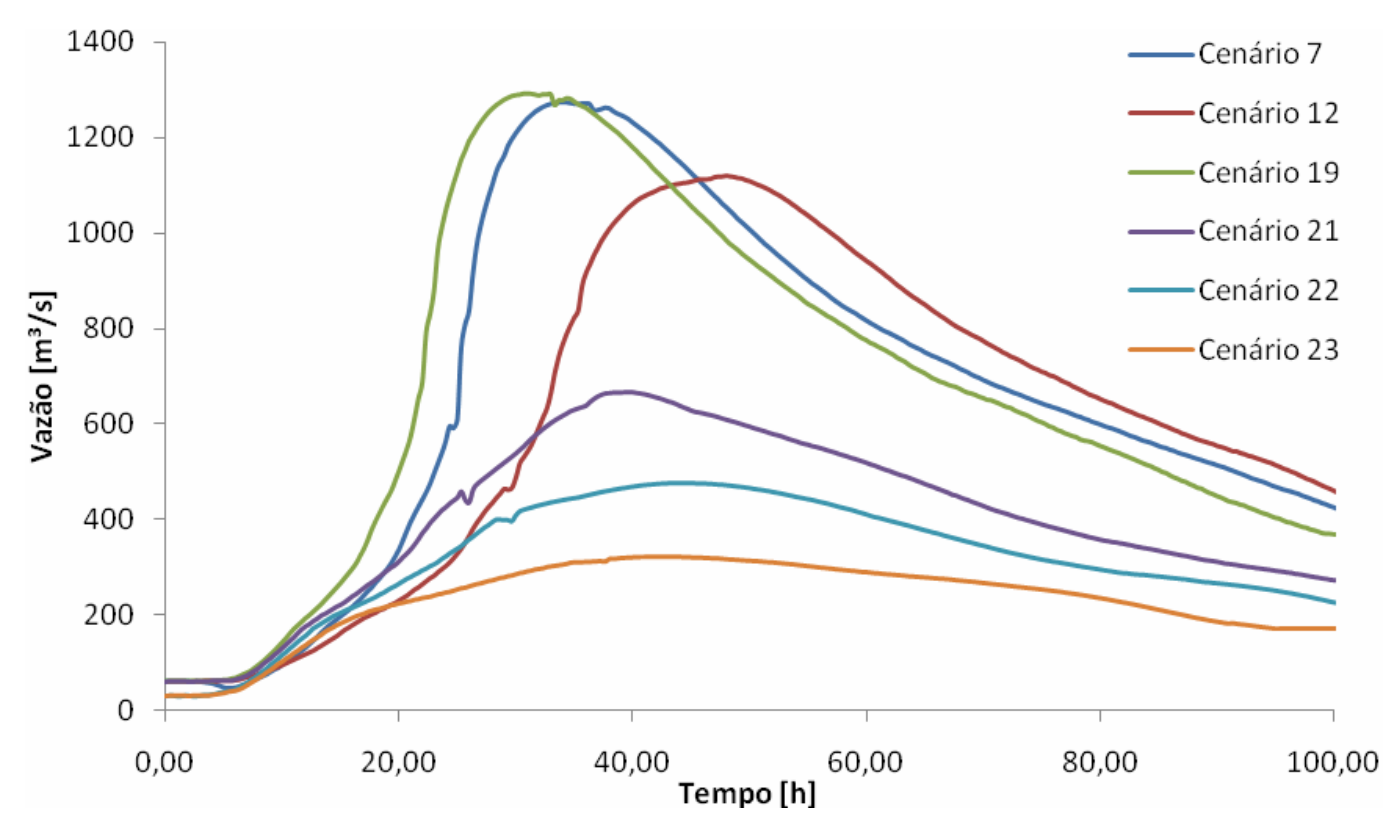

Figura 4.84: Hidrograma na Estrutura de Retiro. Trecho: Montante do Rio Pinheiros 


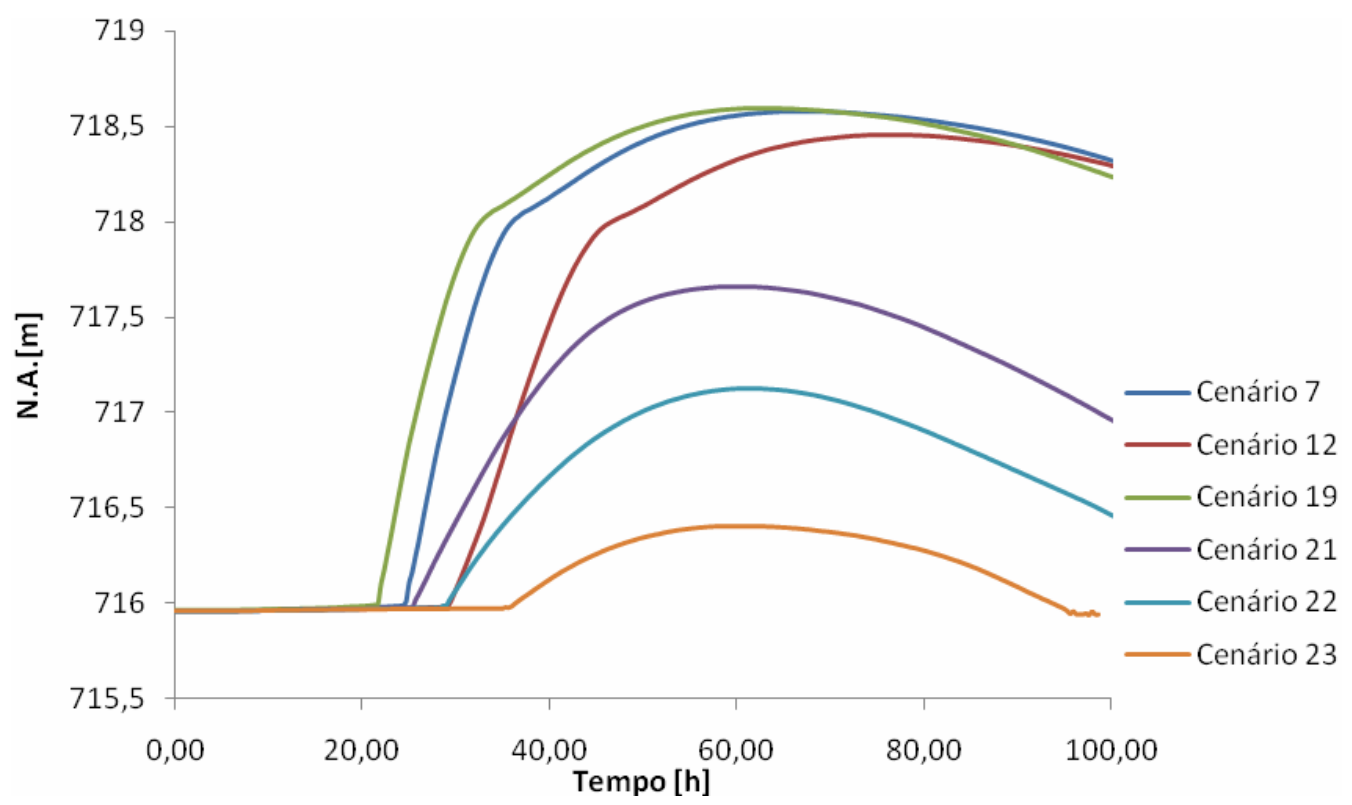

Figura 4.85: Limnigrama na Estrutura de Retiro. Trecho: Montante do Rio Pinheiros

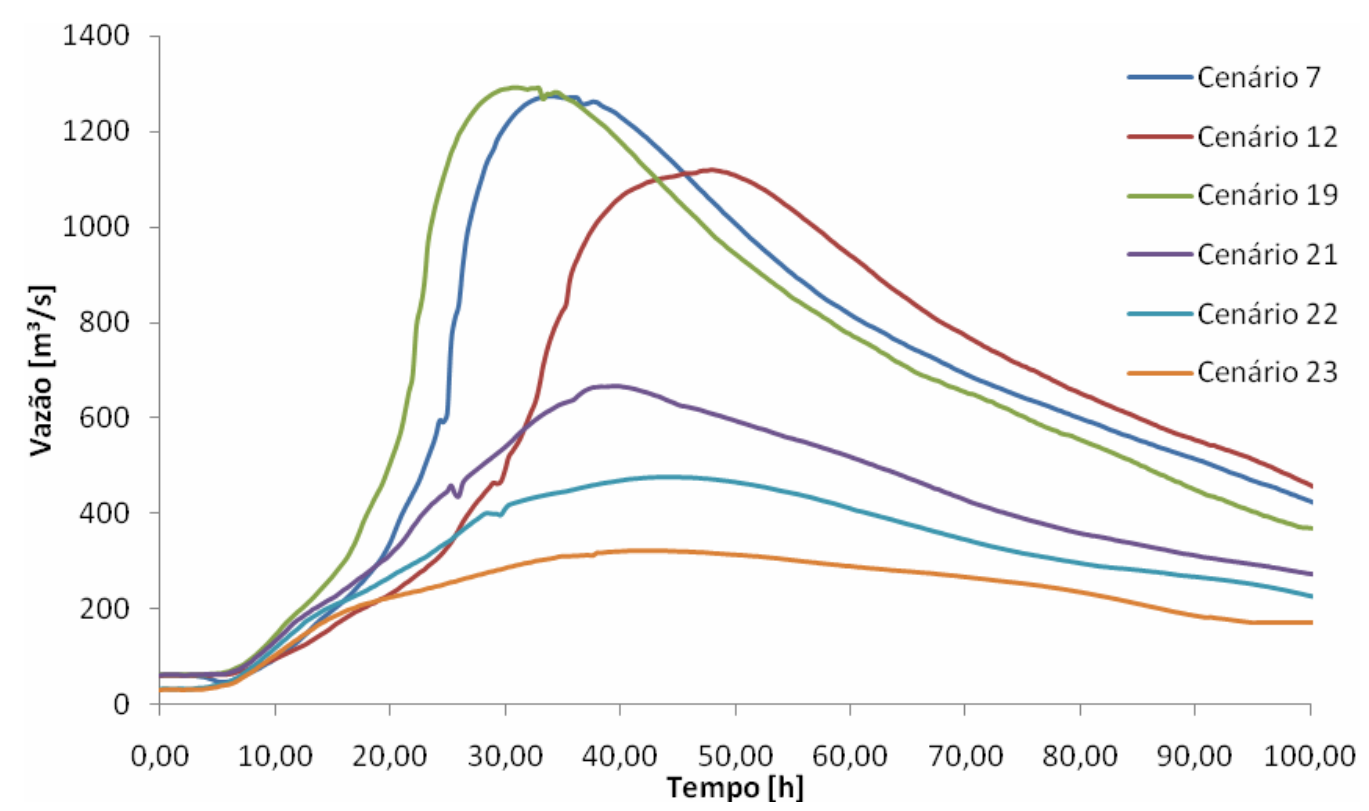

Figura 4.86: Hidrograma na Estrutura de Retiro. Trecho: Jusante do Rio Pinheiros 


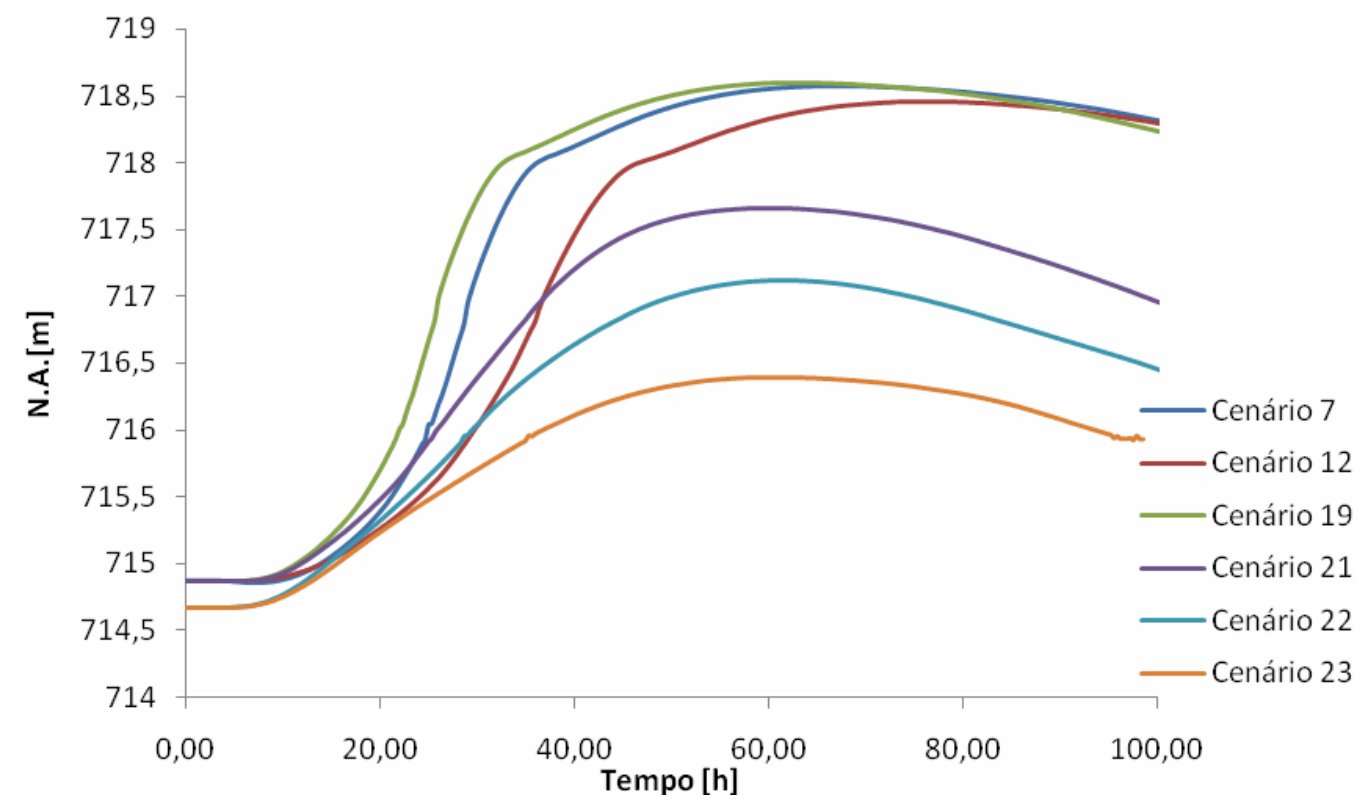

Figura 4.87: Limnigrama na Estrutura de Retiro. Trecho: Jusante do Rio Pinheiros

$\bullet$

"Cebolão" - Confluência do Rio Pinheiros com o Rio Tietê

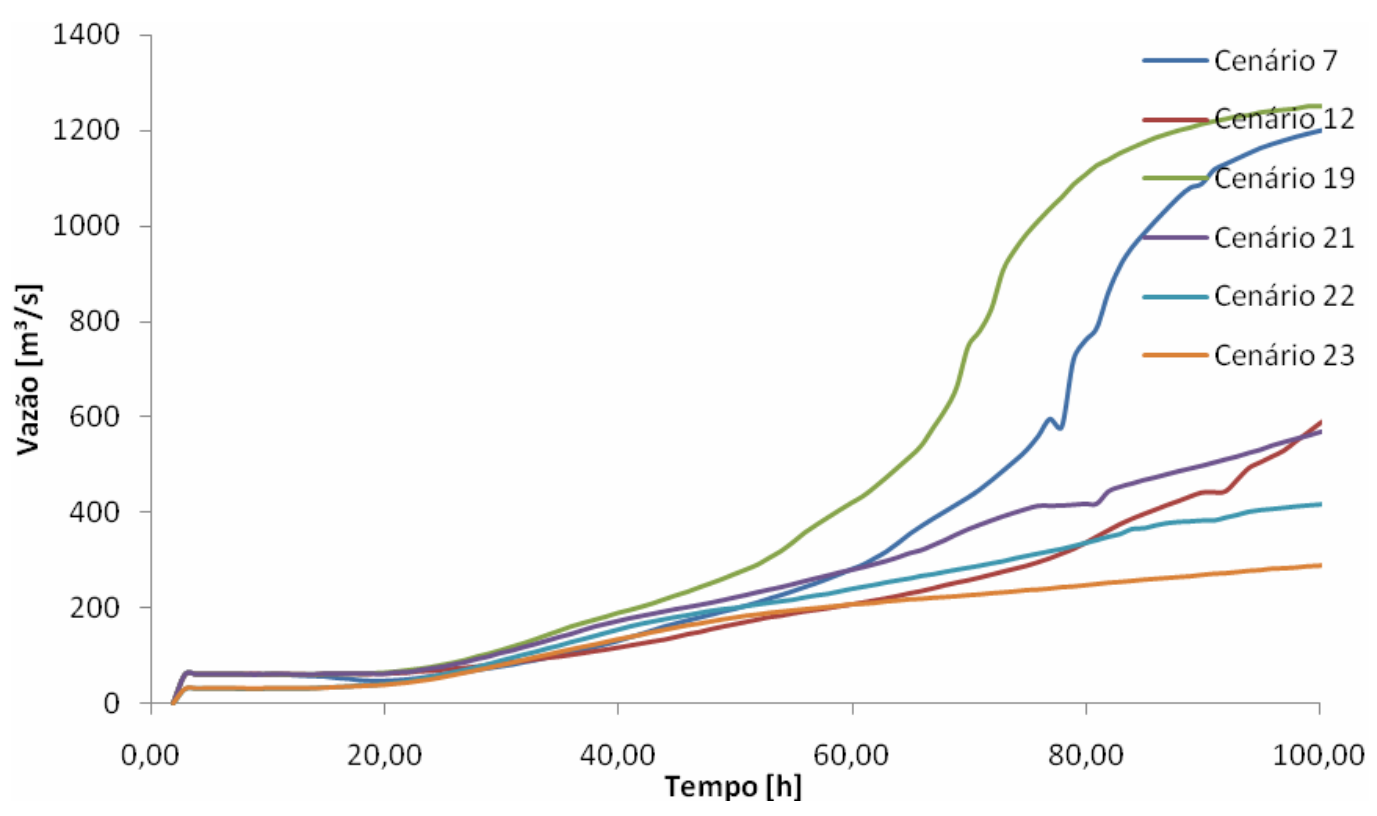

Figura 4.88: Hidrograma no Cebolão (confluência dos Rios Pinheiros e Tietê). Trecho: Rio Pinheiros 


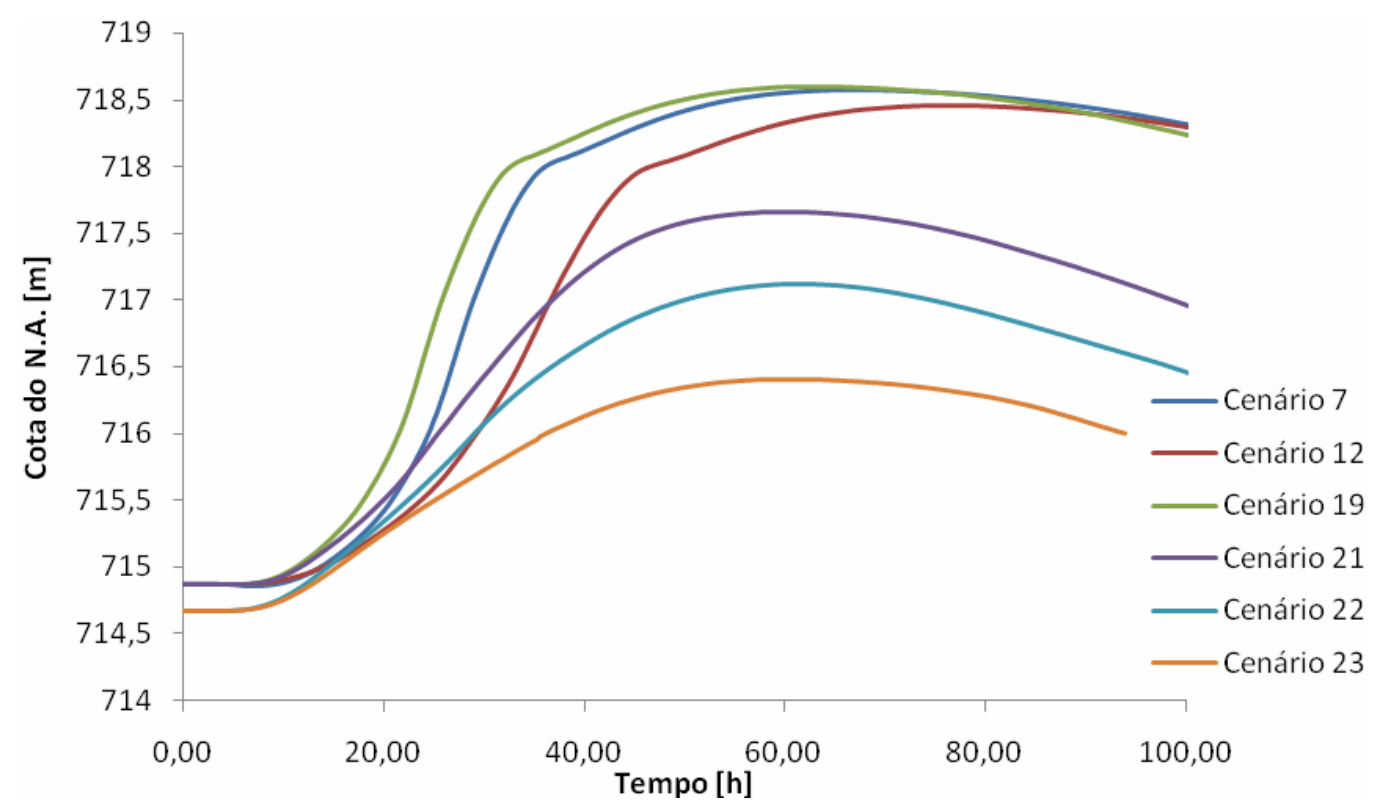

Figura 4.89: Limnigrama no Cebolão (confluência dos Rios Pinheiros e Tietê). Trecho: Rio Pinheiros

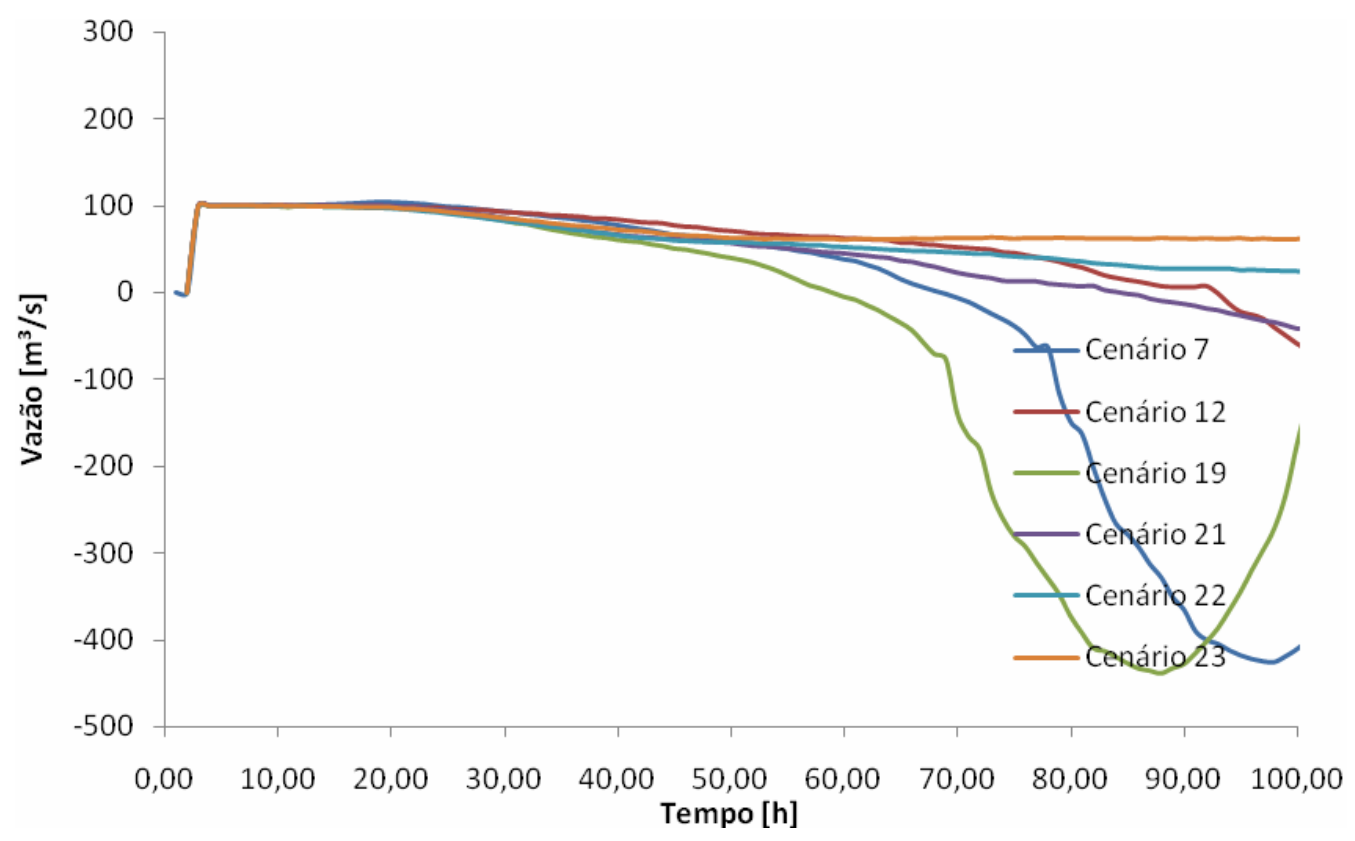

Figura 4.90: Hidrograma no Cebolão (confluência dos Rios Pinheiros e Tietê). Trecho: Rio Tietê Montante 


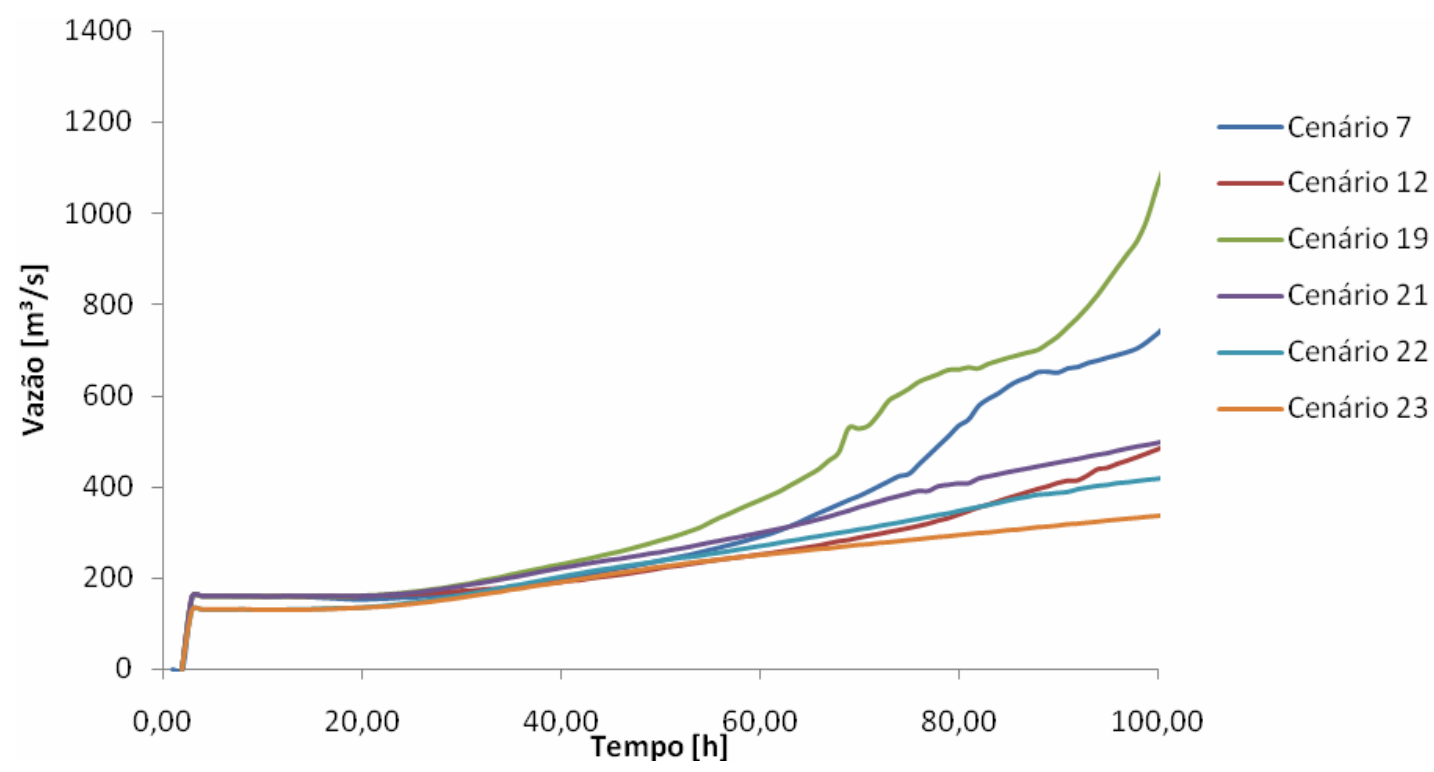

Figura 4.91: Hidrograma no Cebolão (confluência dos Rios Pinheiros e Tietê). Trecho: Rio Tietê Jusante 
Tabela 4.50: Resultados das Simulações da Onda de Enchente

\begin{tabular}{|c|c|c|c|c|c|c|c|}
\hline & & & & Conf. G & uarapiranga-Pi & nheiros & \\
\hline & & & Guarapiranga & $\begin{array}{c}\text { Canal } \\
\text { Guarapiranga }\end{array}$ & $\begin{array}{c}\text { Rio Pinheiros } \\
\text { Montante }\end{array}$ & $\begin{array}{l}\text { Rio Pinheiros } \\
\text { Jusante }\end{array}$ & João Dias \\
\hline N & Qmáx & {$\left[\mathrm{m}^{3} / \mathrm{s}\right]$} & 10957,68 & 9388,45 & 756,82 & 4515,29 & 3986,81 \\
\hline 은 & Tempo & [h] & 9,00 & 9,33 & 20,00 & 9,67 & 11,33 \\
\hline$\stackrel{\frac{\pi}{d}}{2}$ & NA máx & {$[\mathrm{m}]$} & 728,43 & 727,56 & 727,25 & 727,40 & 726,14 \\
\hline & Tempo & [h] & 9,67 & 10,67 & 11,00 & 11,00 & 13,67 \\
\hline I & Qmáx & {$\left[\mathrm{m}^{3} / \mathrm{s}\right]$} & 4415,96 & 3625,87 & 391,11 & 1851,39 & 1728,30 \\
\hline 은 & Tempo & [h] & 9,00 & 10,00 & 37,00 & 12,67 & 15,33 \\
\hline 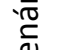 & NA máx & {$[\mathrm{m}]$} & 726,26 & 725,98 & 725,84 & 725,91 & 725,31 \\
\hline & Tempo & [h] & 13,67 & 15,33 & 16,33 & 15,67 & 30,00 \\
\hline g) & Qmáx & {$\left[\mathrm{m}^{3} / \mathrm{s}\right]$} & 13406,04 & 10669,80 & 774,09 & 4945,66 & 4177,63 \\
\hline 은 & Tempo & [h] & 5,00 & 5,67 & 17,33 & 6,00 & 8,00 \\
\hline$\stackrel{\bar{\pi}}{\complement}$ & NA máx & {$[\mathrm{m}]$} & 728,62 & 727,67 & 727,35 & 727,50 & 726,19 \\
\hline$\widetilde{U}$ & Tempo & [h] & 6,00 & 7,67 & 8,00 & 7,67 & 10,67 \\
\hline$\vec{\pi}$ & Qmáx & {$\left[\mathrm{m}^{3} / \mathrm{s}\right]$} & 7487,09 & 5942,53 & 363,41 & 2755,62 & 1982,45 \\
\hline 은 & Tempo & [h] & 4,00 & 5,33 & 17,67 & 5,67 & 8,33 \\
\hline$\frac{\sqrt{0}}{\frac{\pi}{d}}$ & NA máx & {$[\mathrm{m}]$} & 726,85 & 726,20 & 726,00 & 726,09 & 724,94 \\
\hline & Tempo & [h] & 5,67 & 7,33 & 8,00 & 7,67 & 9,33 \\
\hline$\approx$ & Qmáx & {$\left[\mathrm{m}^{3} / \mathrm{s}\right]$} & 5768,52 & 4399,90 & 269,52 & 2048,25 & 1305,94 \\
\hline 은 & Tempo & [h] & 4,00 & 5,67 & 18,67 & 6,33 & 8,67 \\
\hline$\underset{\frac{\pi}{0}}{\frac{\pi}{d}}$ & NA máx & {$[\mathrm{m}]$} & 726,17 & 724,75 & 725,39 & 725,47 & 724,15 \\
\hline 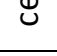 & Tempo & [h] & 6,00 & 7,00 & 8,00 & 7,67 & 9,67 \\
\hline $\mathscr{\sim}$ & Qmáx & {$\left[\mathrm{m}^{3} / \mathrm{s}\right]$} & 4233,55 & 2718,23 & 166,20 & 1227,88 & 692,94 \\
\hline 은 & Tempo & [h] & 5,00 & 5,67 & 19,67 & 6,33 & 9,33 \\
\hline$\stackrel{\sqrt[\pi]{0}}{\complement}$ & NA máx & {$[\mathrm{m}]$} & 725,29 & 724,58 & 724,58 & 724,65 & 723,44 \\
\hline $\mathcal{U}$ & Tempo & [h] & 5,67 & 8,67 & 8,67 & 8,33 & 20,67 \\
\hline
\end{tabular}


Tabela 4.51: Resultados das Simulações da Onda de Enchente (cont.)

\begin{tabular}{|c|c|c|c|c|c|c|c|}
\hline & & & & Usina Elevat & tória Traição & Ponte & \\
\hline & & & Estaiada & $\begin{array}{l}\text { Rio Pinheiros } \\
\text { Montante }\end{array}$ & $\begin{array}{l}\text { Rio Pinheiros } \\
\text { Jusante }\end{array}$ & $\begin{array}{l}\text { Eusébio } \\
\text { Matoso }\end{array}$ & Jaguaré \\
\hline & Qmáx & {$\left[\mathrm{m}^{3} / \mathrm{s}\right]$} & 2030,94 & 1492,49 & 1492,49 & 1421,38 & 1349,23 \\
\hline 은 & Tempo & [h] & 16,33 & 25,67 & 25,67 & 29,00 & 32,00 \\
\hline$\stackrel{\frac{\pi}{2}}{d}$ & NA máx & {$[\mathrm{m}]$} & 725,03 & 723,58 & 720,16 & 719,63 & 719,07 \\
\hline & Tempo & [h] & 17,67 & 25,67 & 28,33 & 31,33 & 37,00 \\
\hline ㄱำ & Qmáx & {$\left[\mathrm{m}^{3} / \mathrm{s}\right]$} & 1371,02 & 1188,45 & 1188,45 & 1175,91 & 1154,44 \\
\hline 은 & Tempo & [h] & 25,00 & 37,67 & 37,67 & 42,67 & 44,67 \\
\hline$\stackrel{-\pi}{\frac{\pi}{C}}$ & NA máx & [m] & 724,35 & 723,05 & 719,99 & 719,49 & 718,92 \\
\hline & Tempo & [h] & 33,33 & 37,33 & 42,33 & 45,33 & 49,33 \\
\hline$\sigma$ & Qmáx & {$\left[\mathrm{m}^{3} / \mathrm{s}\right]$} & 2087,52 & 1524,48 & 1524,48 & 1449,01 & 1372,09 \\
\hline 은 & Tempo & [h] & 13,00 & 22,33 & 22,33 & 25,67 & 28,67 \\
\hline$\frac{\sqrt[\pi]{\frac{\pi}{\alpha}}}{\alpha}$ & NA máx & [m] & 725,06 & 723,63 & 720,18 & 719,65 & 719,10 \\
\hline & Tempo & [h] & 14,33 & 22,67 & 25,00 & 29,00 & 33,00 \\
\hline$\underset{\sim}{ }$ & Qmáx & {$\left[\mathrm{m}^{3} / \mathrm{s}\right]$} & 889,38 & 754,74 & 754,74 & 715,67 & 683,04 \\
\hline 은 & Tempo & [h] & 16,33 & 27,33 & 27,33 & 30,33 & 39,00 \\
\hline$\frac{\sqrt{\pi}}{\frac{\pi}{2}}$ & NA máx & [m] & 723,45 & 722,14 & 719,40 & 719,02 & 718,57 \\
\hline & Tempo & [h] & 17,00 & 26,67 & 32,00 & 36,67 & 37,33 \\
\hline$\approx$ & Qmáx & {$\left[\mathrm{m}^{3} / \mathrm{s}\right]$} & 610,60 & 536,42 & 536,42 & 519,46 & 488,61 \\
\hline 은 & Tempo & [h] & 19,67 & 31,00 & 31,00 & 32,00 & 41,67 \\
\hline$\frac{\sqrt[\pi]{\frac{T}{U}}}{\alpha}$ & NA máx & [m] & 723,17 & 721,68 & 719,03 & 718,67 & 718,23 \\
\hline & Tempo & [h] & 20,67 & 30,00 & 35,67 & 39,67 & 45,33 \\
\hline$\tilde{\sim}$ & Qmáx & {$\left[\mathrm{m}^{3} / \mathrm{s}\right]$} & 369,44 & 348,80 & 348,80 & 342,64 & 328,46 \\
\hline 은 & Tempo & [h] & 24,00 & 32,33 & 32,33 & 35,00 & 38,00 \\
\hline - & NA máx & [m] & 722,71 & 721,28 & 718,64 & 718,23 & 717,68 \\
\hline$\circlearrowleft$ & Tempo & [h] & 24,33 & 32,33 & 34,33 & 37,67 & 43,67 \\
\hline
\end{tabular}


Tabela 4.52: Resultados das Simulações da Onda de Enchente (cont.)

\begin{tabular}{|c|c|c|c|c|c|c|c|}
\hline & & & Estrut. & Retiro & & Cebolão & \\
\hline & & & $\begin{array}{l}\text { Rio Pinheiros } \\
\text { Montante }\end{array}$ & $\begin{array}{l}\text { Rio Pinheiros } \\
\text { Jusante }\end{array}$ & Rio Pinheiros & $\begin{array}{l}\text { Rio Tietê } \\
\text { montante }\end{array}$ & $\begin{array}{l}\text { Rio Tietê } \\
\text { Jusante }\end{array}$ \\
\hline$\Lambda$ & Qmáx & {$\left[\mathrm{m}^{3} / \mathrm{s}\right]$} & 1275,16 & 1275,16 & 1239,34 & 1244,01 & 197,40 \\
\hline.$ㅇ$ & Tempo & [h] & 34,00 & 34,00 & 38,33 & 36,67 & 144,33 \\
\hline$\stackrel{\pi}{\frac{\pi}{0}}$ & NA máx & {$[\mathrm{m}]$} & 718,58 & 718,58 & 718,58 & 718,58 & 718,58 \\
\hline & Tempo & [h] & 65,67 & 66,00 & 65,33 & 65,33 & 65,67 \\
\hline$\stackrel{\sim}{\sim}$ & Qmáx & {$\left[\mathrm{m}^{3} / \mathrm{s}\right]$} & 1120,03 & 1120,03 & 1109,59 & 1117,62 & 201,14 \\
\hline 은 & Tempo & [h] & 48,00 & 48,00 & 48,00 & 46,67 & 144,33 \\
\hline$\stackrel{\frac{10}{\pi}}{\frac{10}{1}}$ & NA máx & {$[\mathrm{m}]$} & 718,46 & 718,46 & 718,46 & 718,46 & 718,46 \\
\hline & Tempo & [h] & 75,00 & 74,33 & 75,00 & 75,33 & 76,00 \\
\hline g & Qmáx & {$\left[\mathrm{m}^{3} / \mathrm{s}\right]$} & 1292,25 & 1292,25 & 1250,25 & 1246,15 & 231,06 \\
\hline 은 & Tempo & {$[\mathrm{h}]$} & 31,00 & 31,00 & 35,33 & 34,33 & 134,67 \\
\hline 京 & NA máx & {$[\mathrm{m}]$} & 718,59 & 718,59 & 718,59 & 718,59 & 718,59 \\
\hline & Tempo & [h] & 61,33 & 62,00 & 64,00 & 64,00 & 64,33 \\
\hline$\vec{\sim}$ & Qmáx & {$\left[\mathrm{m}^{3} / \mathrm{s}\right]$} & 667,82 & 667,82 & 646,78 & 627,35 & 168,27 \\
\hline 은 & Tempo & [h] & 39,67 & 39,67 & 39,67 & 54,00 & 88,33 \\
\hline$\stackrel{\sqrt[1]{\pi}}{\frac{1}{n}}$ & NA máx & {$[\mathrm{m}]$} & 717,66 & 717,66 & 717,66 & 717,66 & 717,66 \\
\hline & Tempo & [h] & 58,67 & 58,67 & 59,67 & 60,00 & 60,33 \\
\hline$\approx$ & Qmáx & {$\left[\mathrm{m}^{3} / \mathrm{s}\right]$} & 476,09 & 476,09 & 465,88 & 504,76 & 142,19 \\
\hline 은 & Tempo & [h] & 44,67 & 45,00 & 45,33 & 56,00 & 120,33 \\
\hline$\stackrel{\frac{1}{\pi}}{\frac{10}{01}}$ & NA máx & {$[\mathrm{m}]$} & 717,12 & 717,12 & 717,12 & 717,12 & 717,12 \\
\hline & Tempo & [h] & 60,67 & 61,67 & 62,33 & 62,00 & 62,67 \\
\hline$\stackrel{m}{\sim}$ & Qmáx & {$\left[\mathrm{m}^{3} / \mathrm{s}\right]$} & 321,41 & 321,41 & 315,86 & 391,16 & 123,76 \\
\hline 은 & Tempo & [h] & 41,67 & 41,67 & 42,00 & 54,33 & 88,00 \\
\hline 离 & NA máx & [m] & 716,40 & 716,39 & 716,40 & 716,40 & 716,40 \\
\hline u & Tempo & [h] & 58,33 & 59,00 & 60,33 & 61,00 & 60,67 \\
\hline
\end{tabular}

\subsection{Diretrizes para Elaboração do Plano de Ações}

\section{Emergenciais para a Barragem Guarapiranga}

Os eventos que podem elevar os níveis de segurança variam a cada estrutura e a cada situação. Para tanto de acordo com os cenários elaborados e simulados, segue um roteiro para elaboração de um Plano de Ações Emergenciais para a Barragem Guarapiranga baseado nos exemplos citados (capítulo 3.5). Sendo assim, o PAE Guarapiranga deve conter:

1. Lista de Atribuição de Responsabilidades 
No caso de uma eventual ruptura, devem responder quanto às responsabilidades da Barragem Guarapiranga:

- Empresa Metropolitana de Águas e Energia S.A. - EMAE (Proprietária da Barragem Guarapiranga) - que deve coordenar a comunicação oficial sobre o acidente, disponibilizar emergencialmente os recursos a serem utilizados, etc.

- $\quad$ Companhia de Saneamento Básico do Estado de São Paulo SABESP (Operadores da Barragem Guarapiranga) - que deve comunicar externamente a ocorrência do acidente, proporcionar apoio às equipes executivas, aprovar a aplicação do PAE, etc.

- $\quad$ Equipes Executivas - devem coordenar todas as ações referentes aos atendimentos emergenciais, bem como avaliar o estado da emergência, notificar a Defesa Civil do município de São Paulo, Prefeituras dos municípios de São Paulo, Guarulhos, Barueri, Carapicuíba, Complexos Hospitalares, Concessionárias rodoviárias (DERSA, ECOVIAS, VIA OESTE, AUTOBAN, Rodoanel), Companhia Paulista de Trens Metropolitanos (CPTM), Companhia do Metropolitano de São Paulo (METRO), Companhia de Engenharia de Trafego (CET), entre outros. Estes devem manter uma comunicação direta com os órgãos responsáveis pela operação da Barragem (SABESP).

- Equipe Local - deve operar e garantir o funcionamento dos equipamentos hidráulicos e os sistemas de comunicação/aviso, notificar a equipe executiva de quaisquer anormalidades, seguir 0 fluxo de informações.

- $\quad$ Observador - pessoa responsável que deverá notificar e avisar caso haja qualquer anormalidade nas operações da barragem Guarapiranga. Este deve também relatar toda e qualquer alteração no nível da represa, documentar os acontecimentos, etc.

2. Fluxo de Notificações

Este fluxo deve ser seguido no caso de constatado à situação de emergência na Barragem Guarapiranga. 


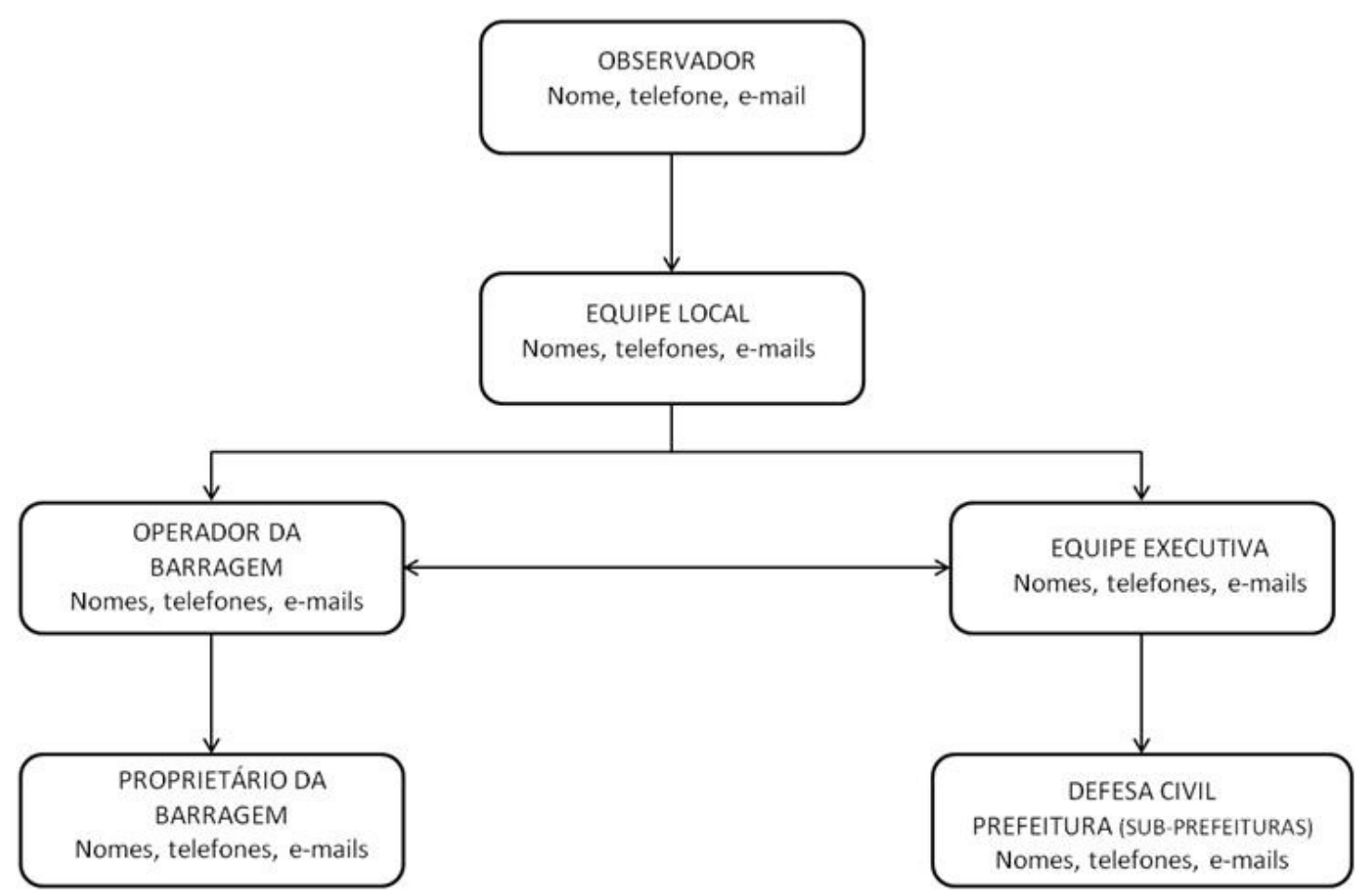

Figura 4.92: Fluxograma de Notificações

3. Sistemas de Comunicações

Devem estar disponíveis e em funcionamento todos os tipos de meios de comunicações, tais como rádios, telefones, celulares, e-mails, etc. de todas as pessoas envolvidas, principalmente àquelas cujos nomes constam nas atribuições de responsabilidades e fluxo de notificações.

4.

Acessos ao Local

Dentro do PAE, deve haver um mapa de localização da Barragem Guarapiranga, com a sua localização e principais vias de acesso. 


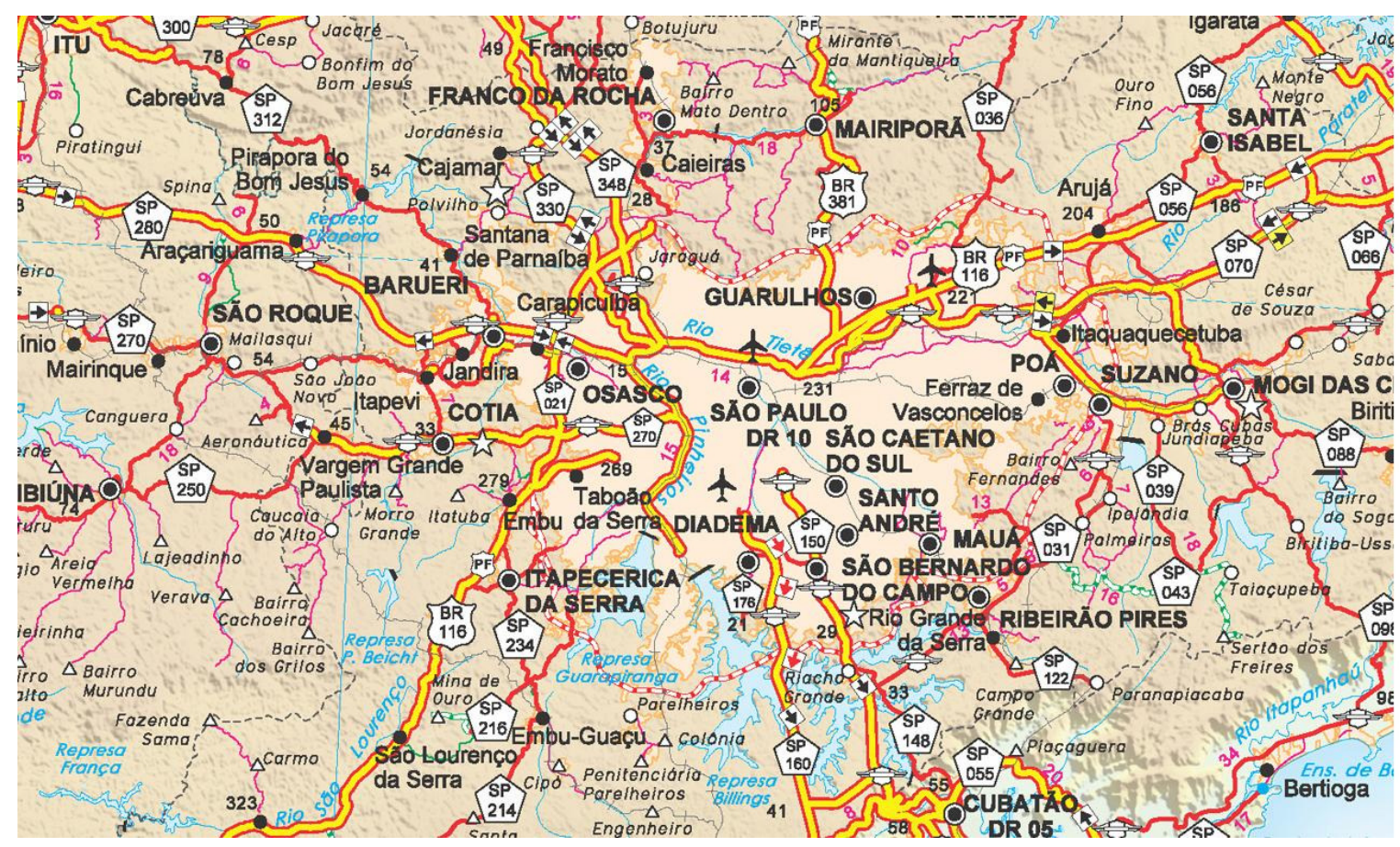

Figura 4.93: Mapa de Acesso a Barragem Guarapiranga (DER, 2008)

A barragem Guarapiranga está localizada no bairro do Socorro, zona Sul da cidade de São Paulo. O principal acesso a Barragem é feito pela Rua Vicente de Carvalho, próximo à Av. Guarapiranga (dando acesso à Marginal do Rio Pinheiros). Cabe ressaltar que a Marginal do Rio Pinheiros certamente será alvo das inundações provocadas pelo rompimento da Barragem Guarapiranga. Sendo assim, o Plano deverá conter acessos que permitam o transito das equipes que atuarão no combate as emergências.

5. Mapas de Inundação

O PAE Guarapiranga deve conter mapas de inundação com sinalizações dos principais pontos de interesse devidamente identificados e com indicações do tempo de chegada da onda de enchente efluente.

As figuras a seguir ilustram as áreas potencialmente atingidas pelas inundações causadas pelo rompimento da Barragem Guarapiranga. Foram selecionados três locais que compreendem na interdição de vias de trafego - por exemplo a Av. Luiz Carlos Berrini - importante centro empresarial da cidade (Figura 4.94 e Figura 4.95), no alagamento do principal centro de distribuição alimentícia da cidade - CEASA 
(Figura 4.96 e Figura 4.97) e na interdição de uma das principais vias de acesso ao complexo hospitalar Clinicas (Figura 4.98 e Figura 4.99).

Para a elaboração dos mapas de inundação, neste estudo, foram utilizados sistemas simplificados de informações espaciais com imagens de satélite. Estes sistemas são popularmente conhecidos como Ferramentas CAD e Google Earth/Maps.

6. Apêndices

Neste item deve conter:

- $\quad$ Descrição do projeto de execução da Barragem Guarapiranga;

- Estudos e análises de rompimento desenvolvidos para a Barragem Guarapiranga;

- $\quad$ Demais documentos.

O PAE deve servir como um documento que auxilia nas ações a serem tomadas no caso do rompimento da barragem Guarapiranga. 


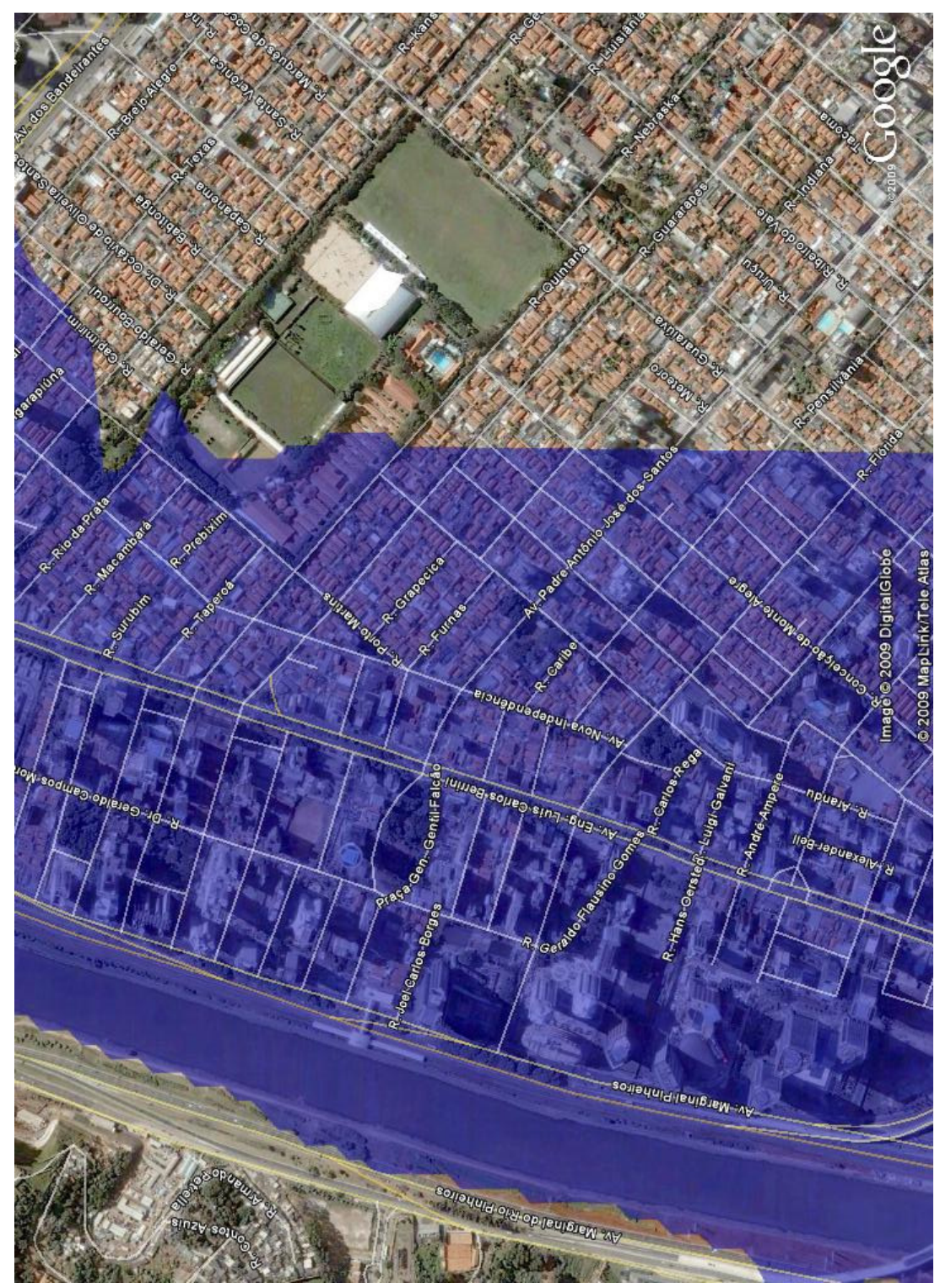

Figura 4.94: Av. Luiz Carlos Berrini - Área Potencialmente Inundada causada pelo Rompimento da Barragem Guarapiranga no cenário 19 


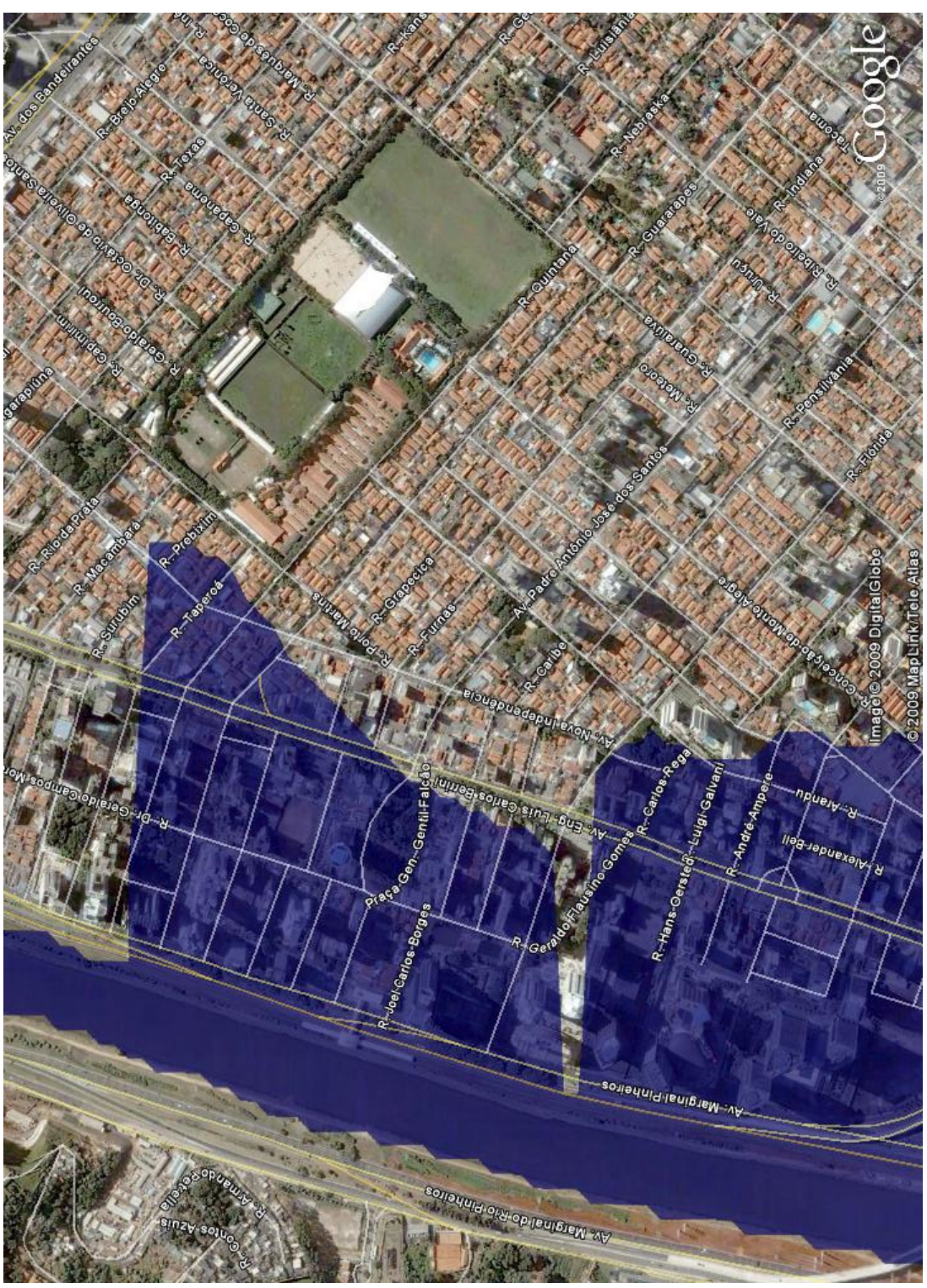

Figura 4.95: Av. Luiz Carlos Berrini - Área Potencialmente Inundada causada pelo Rompimento da Barragem Guarapiranga no cenário 22 


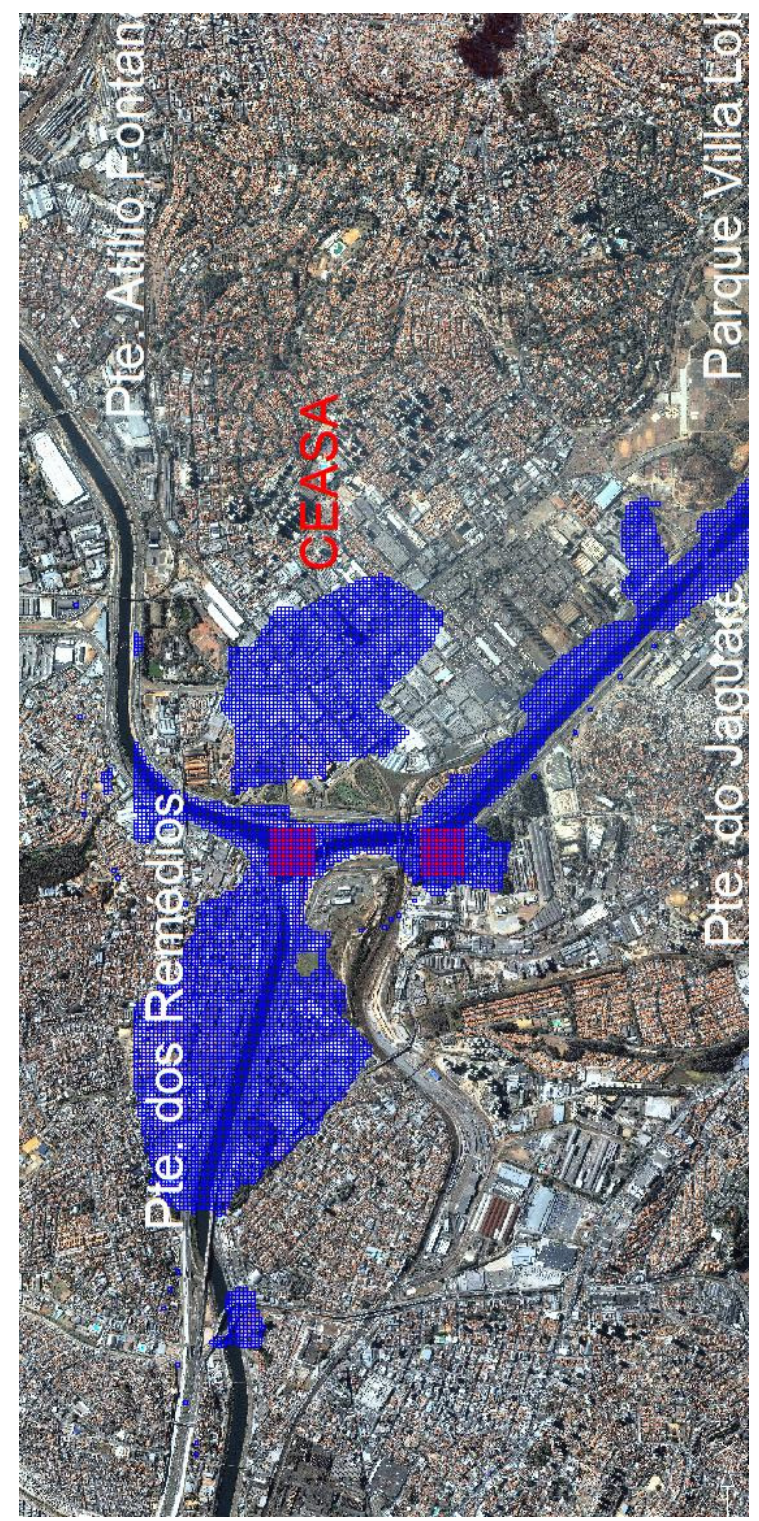

Figura 4.96: CEASA - Área Potencialmente Inundada causada pelo Rompimento da Barragem Guarapiranga no cenário 19 


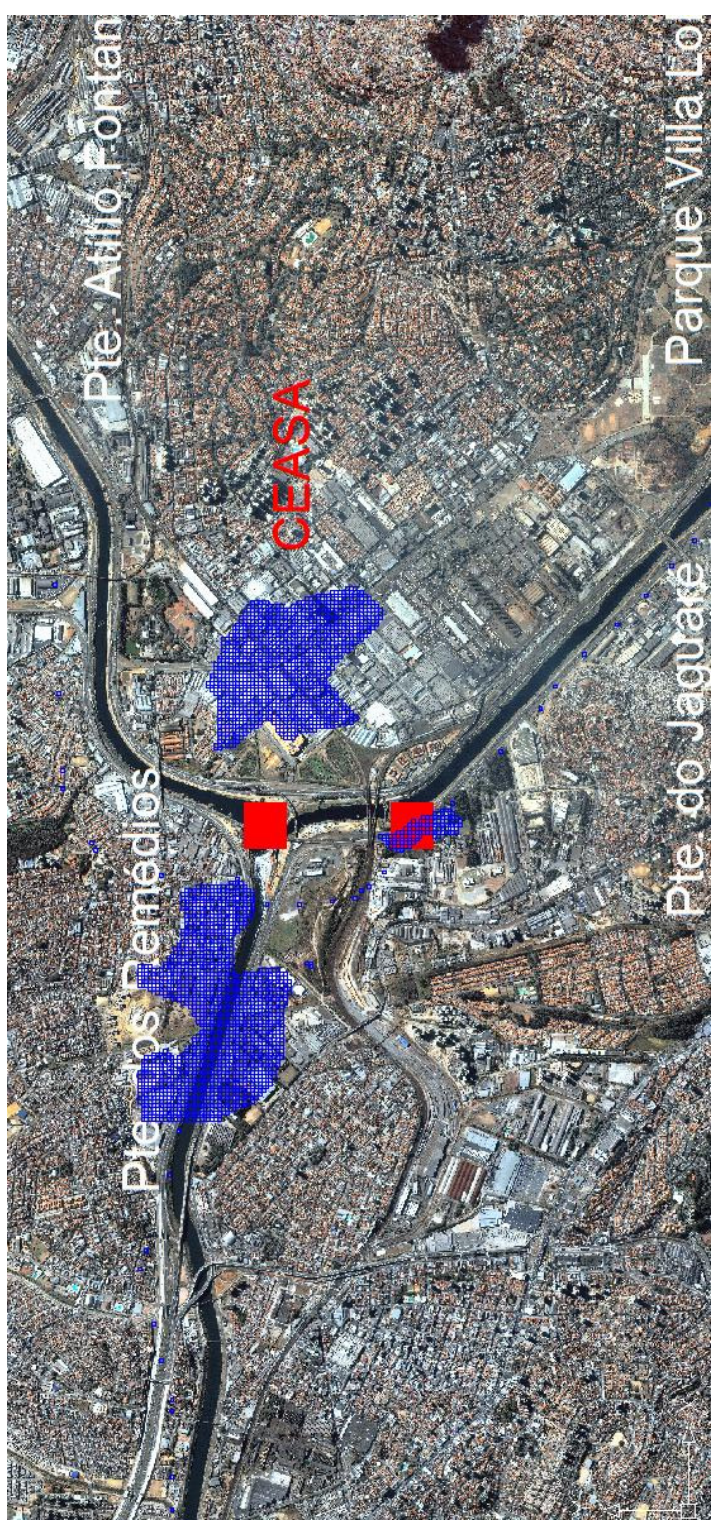

Figura 4.97: CEASA - Área Potencialmente Inundada causada pelo Rompimento da Barragem Guarapiranga no cenário 22 


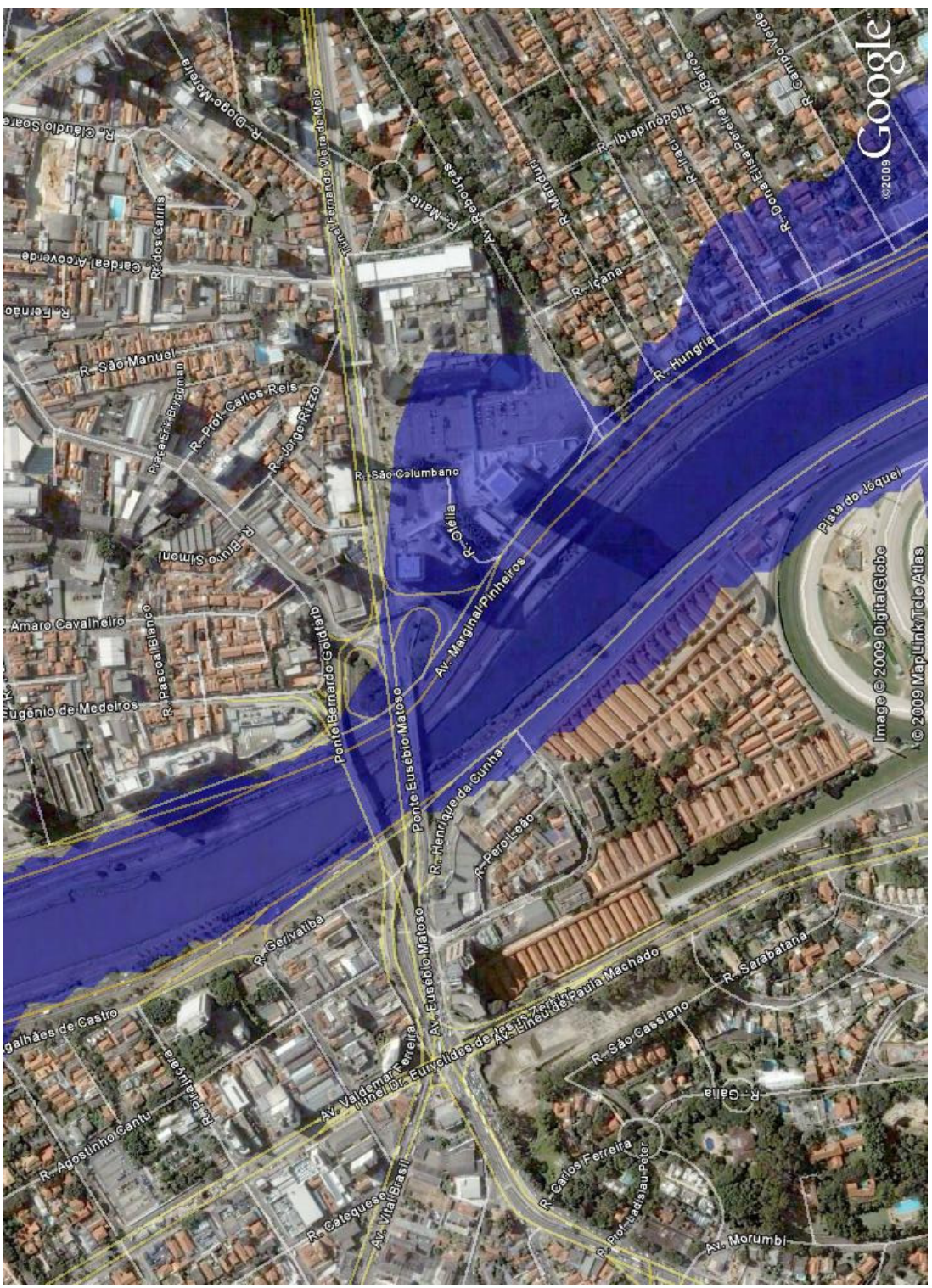

Figura 4.98: Ponte da Av. Eusébio Matoso - Área Potencialmente Inundada causada pelo Rompimento da Barragem Guarapiranga no cenário 19 


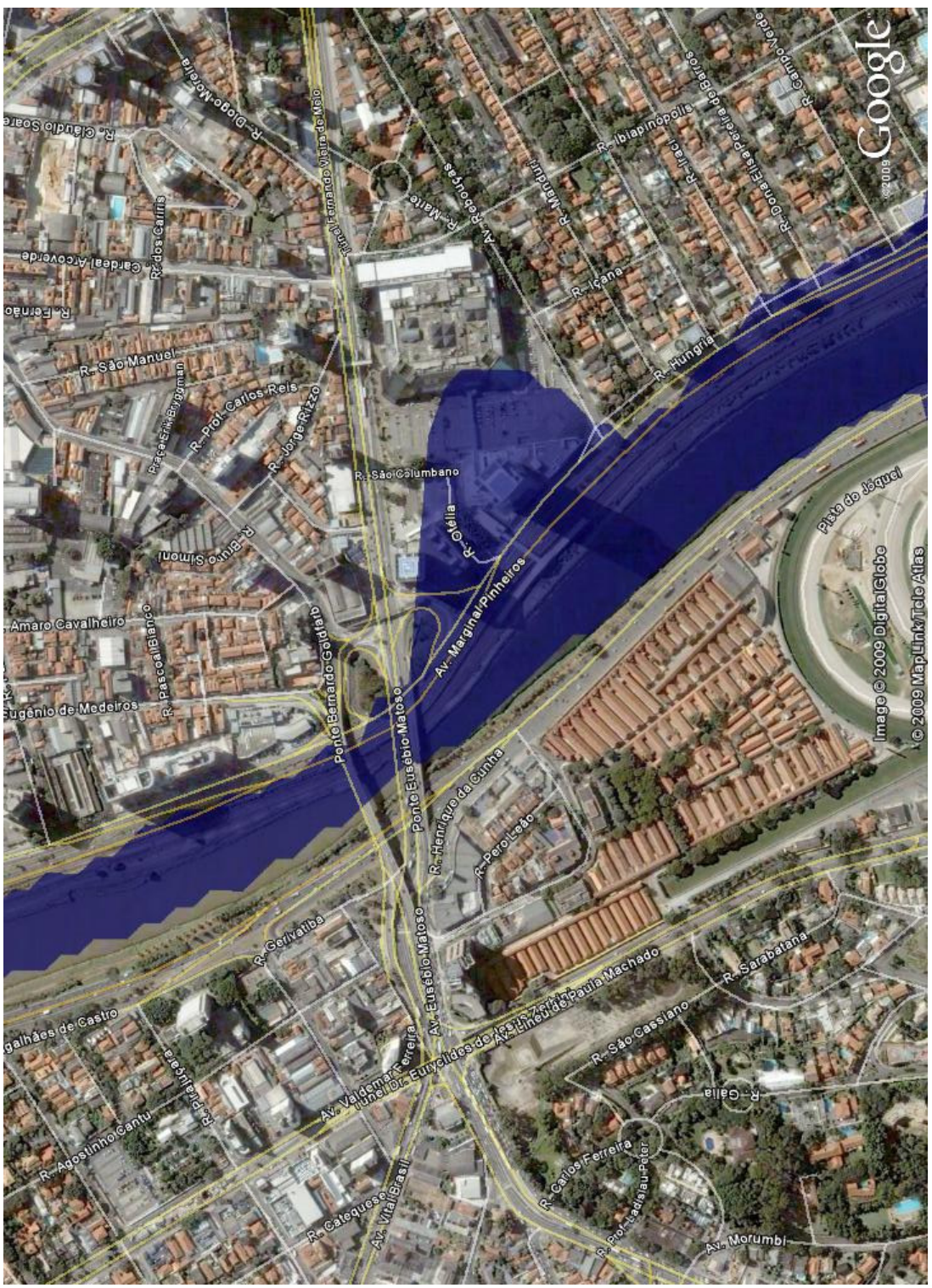

Figura 4.99: Ponte da Av. Eusébio Matoso - Área Potencialmente Inundada causada pelo Rompimento da Barragem Guarapiranga no cenário 22 


\section{$5 \quad$ CONCLUSÕES E RECOMENDAÇÕES}

As barragens são estruturas compostas de elementos projetados, construídos e operados de acordo com critérios de segurança que visam, entre outros aspectos, garantir o atendimento de suas finalidades precípuas, como criação de desníveis, a retenção e o armazenamento dos volumes, e o escoamento das cheias afluentes. Estes critérios seguem diretivas institucionais e tecnológicas, consolidadas a partir da experiência reunida em sucessos e fracassos de muitos empreendimentos similares. Diversos fatores, entretanto, podem levar a situações onde tanto os critérios da segurança estrutural como da hidrológica podem ser insuficientes, ocasionando acidentes que resultam na ruptura destas estruturas. Estas situações, documentadas historicamente na literatura específica, levaram ao surgimento de toda uma área de estudo, relacionada à gestão da segurança de barragens.

A pesquisa levada a termo neste trabalho documenta que, através de diferentes iniciativas, a sociedade em geral, os órgãos fiscalizadores e as instituições de pesquisa têm recomendado a inclusão, no arcabouço da tecnologia ligada ao tratamento do tema 'barragens', a avaliação e a gestão dos impactos potenciais causados por rupturas parciais ou totais destas estruturas. Essas ações permitem a consideração, ainda antes da tomada de decisão final sobre a construção da mesma,de medidas que possam eliminar ou atenuar danos, através de ações estruturais ou institucionais, resultando em classificações de risco mais baixas para o empreendimento. Pela importância do assunto, conclui-se que o tema é de interesse não apenas das autoridades governamentais e daquelas de apoio à segurança física e sanitária das pessoas, mas também do empreendedor e do investidor no empreendimento.

Diversas recomendações e dispositivos consultados permitiram concluir que a elaboração dos planos de ação deve seguir passos que permitam a avaliação dos impactos e o estabelecimento de rotinas executivas, ainda antes da construção. Estes planos devem conter a notificação e fluxo de informações entre os encarregados das medidas executivas, além de outros dados como a quantificação das áreas, infraestruturas e pessoas atingidas, tempo de antecipação e exposição, procedimentos de evacuação seguros, locais de atendimento médico e alojamento temporário. A concretização destes planos exige o emprego de ferramentas e outros instrumentos 
de engenharia, cuja apresentação e discussão compõem o objetivo perseguido neste trabalho.

Os mecanismos clássicos de ruptura de estruturas de barramentos foram apresentados, considerando desde as falhas instantâneas de estruturas rígidas como as barragens de concreto e também as falhas graduais, nas quais a estrutura é progressivamente destruída pela ação da água, nos processos originados pela erosão interna dos maciços de material granular ou pelo galgamento e o escoamento por sobre os paramentos e taludes das barragens de terra e enrocamento. $O$ conhecimento e a aplicação destes processos permite a avaliação da denominada onda efluente do rompimento. Neste sentido foram apresentadas formulações existentes para a estimativa das dimensões e velocidades de evolução das brechas que permitem a descarga do volume armazenado nos reservatórios.

O tratamento da questão da propagação desta onda de cheia ao longo do vale a jusante pode ser feito a partir do emprego de modelos matemáticos de simulação do escoamento hidrodinâmico unidimensional, tendo sido apresentadas algumas técnicas usualmente empregadas, e que são disponíveis no meio técnico através de softwares internacionais como o FLDWAV e o DAMBRK e nacionais, como o Cliv Plus.

O levantamento e a análise de alguns instrumentos de gestão elaborados para barragens importantes no Brasil e América do Sul, como o feito para a Barragem de Cerros Colorados, Dona Francisca e Peti, permitiram a prospecção e consolidação de métodos para execução destes estudos, suas fases de desenvolvimento e a tipificação dos resultados que podem ser obtidos.

A aplicação destas técnicas foi feita tomando-se como base um estudo de caso real, que é a Barragem do Guarapiranga, situada na cidade de São Paulo e que já esteve, no passado, exposta a uma situação de solicitação hidrológica extrema. Para este caso, foram analisados os mecanismos para uma ruptura hipotética da barragem de terra em função de uma solicitação hidrológica extrema, cuja probabilidade de ocorrência é remota, e para as quais foram avaliados o comportamento dos diferentes fatores intervenientes, destacando-se as alturas e larguras máximas da brecha, sua forma de evolução (linear ou não linear) e ainda a velocidade de evolução, concluindo-se que, destes fatores, a largura e a velocidade de evolução são os preponderantes. Com relação às rupturas ocasionais por falhas estruturais, o 
parâmetro avaliado foi o volume do reservatório, considerando que estes acidentes, embora mais freqüentes para a situação do reservatório cheio ao final do período úmido, tem a possibilidade de serem detectados previamente facilitando a tomada de medidas para o esvaziamento e a atenuação dos impactos. Desta forma, foram avaliadas situações paramétricas considerando o reservatório 40\%, 70\% e 100\% ocupados, o que permitiu concluir que estes acidentes, embora liberando menores volumes de água para jusante, podem gerar ondas efluentes de magnitude igual ou superior a algumas situações consideradas para overtopping.

A simulação da cheia efluente permitiu verificar a importância da representação fidedigna do sistema de rios e canais, especialmente com relação às condições de controle internas e nas extremidades, além da representação do armazenamento que ocorre na própria calha. No caso estudado, o sistema composto pelo Canal Guarapiranga, Rio Pinheiros e Rio Tietê engloba, além das confluências entre eles, três estruturas de controle, sendo duas ativas no processo de controle da propagação da cheia. Desta forma, conclui-se que a escolha do modelo é fundamental para a obtenção de resultados significativos na avaliação dos impactos.

Os resultados do modelo permitiram a elaboração dos mapas de áreas potencialmente inundáveis, conforme preconizado em diversas recomendações pesquisadas. Para tal os perfis de linha d'água foram transformados em superfície de inundação e com o auxilio de aplicativos de CAD e SIG, sobrepostos modelos digitais de terreno e a imagens de satélite detalhadas para identificação de pontos notáveis para o planejamento de ações preventivas e emergenciais. No caso especifico estudado verificou-se o comprometimento de importantes corredores de trafego rodoviário, metroviário e ferroviário, vias de acesso a áreas inundadas, além de extensas regiões ocupadas por vias de trafego local e edificações diversas. Desta forma, foi possível mapear não apenas os locais atingidos como o tempo de exposição dos mesmos.

A interpretação dos resultados permitiu ainda o levantamento de condicionantes para ações emergenciais, como a necessidade da preservação dos acessos a algumas pontes que cruzam a área inundável, de forma a permitir o acesso a estruturas importantes como centro hospitalares e centrais de abastecimento, bem como a necessidade de proteção do sistema ferroviário e metroviário no local, de forma a reduzir o impacto sobre a mobilidade na cidade. 
Por fim, a proposição de diretivas para a elaboração de um plano de ações emergenciais para a Barragem do Guarapiranga ilustra a compilação das informações produzidas e a organização de um documento especifico para gestão dos impactos.

Embora a elaboração destes instrumentos ainda não seja uma exigência legal no Brasil, sua prática tende a se expandir rapidamente, impulsionada de um lado pela quantidade de obras já existentes e que se encontram em fase intermediária de sua vida útil, e de outro pelo crescente número de novos empreendimentos destinados a aproveitamentos de finalidades múltiplas, sendo que, em ambas as situações, a ocupação dos vales a jusante já está implantada ou tende a ser adensada.

Durante a elaboração deste trabalho detectou-se ainda a necessidade de aprofundamento das pesquisas em diversos aspectos, como forma de melhorar a análise e a precisão dos estudos. Com relação aos modelos de ruptura, conclui-se que seria recomendável o aperfeiçoamento dos estudos ligados simulação dos modos de ruptura e estimativa das cheias efluentes, através de estudos de retro-análise de casos de rupturas documentadas e de estudos envolvendo modelação matemática e física, sendo estes últimos especialmente recomendados.

Com relação às ferramentas para simulação das cheias efluentes, os modelos disponíveis apresentam diversas restrições de estabilidade numérica em função de mudanças de regime no escoamento. A integração destes modelos com as ferramentas de CAD e SIG é fundamental para que os resultados possam ser utilizados pelos diversos intervenientes no processo, inclusive leigos.

Finalmente, o desenvolvimento e a consolidação das técnicas de previsão e avaliação de impactos gerados por rupturas de barragens poderão ser mais rapidamente aperfeiçoados quando este conceito passar a fazer parte dos requisitos de projeto e licenciamento destas obras, através das exigências legais. 
Agudo, C. M. (2009). http://www.camaraagudo.rs.gov.br/. Retrieved Janeiro 12, 2009, from Câmara Municipal de Agudo: http://www.camaraagudo.rs.gov.br/

ALTO TIETÉ, C. D. (2002, Julho). Plano da Bacia do Alto Tietê. Plano da Bacia do Alto Tietê . São Paulo.

AMAZÔNIA, D. d. http://www.diariodaamazonia.com.br/. Retrieved Fevereiro 22, 2008, from Diário da Amazônia: http://www.diariodaamazonia.com.br/

Argentina, D.-E. Plan de Acción Durante Emergencia - Hidroelectrica Cerros Colorados.

BALBI, D. A. (2008). Metodologias Para A Elaboração De Planos De Ações Emergenciais Para Inundações Induzidas Por Barragens. Estudo De Caso: Barragem De Peti - Mg. Dissertação apresentada ao Programa de Pós-graduação em Saneamento, Meio Ambiente e Recursos Hídricos da Universidade Federal de Minas Gerais, como requisito, 354. Belo Horizonte, MG.

BEGNUDELLI, L., \& SANDERS, B. (2007, Novembro). Simulation of the St. Francis Dam-Break Flood. Journal of Engeneers Mechanics , pp. 1200-1212.

BRASIL, M. d. IBGE. Retrieved dezembro 2008, from Instituto Brasileiro de Geografia e Estatistica - IBGE: http://www.ibge.gov.br/

CBDB. (2001). Comitê Brasileiro de Barragens. Retrieved Março 03, 2008, from Comitê Brasileiro de Barragens: http://www.cbdb.org.br

CBGB, C. B. (1999). Guia Básico de Segurança de Barragens. São Paulo.

CERMINARO, S., MARTINS, J. R., RAMOS, C. L., \& PINTO, D. P. (2008). Modelo de Previsão de Áreas Inundáveis no Rio Paraná, entre a UHE Porto Primavera e o Porto São José. Il Simpósio de Recursos Hídricos do Sul-Sudeste - ABRH . Rio de Janeiro, RJ.

COLLISCHONN, W. (1997). Análise do Rompimento da Barragem de Enerstina. Dissertação de Mestrado , 213. Porto Alegre, Rio Grande do Sul, Brasil. 
COLLISCHONN, W., \& TUCCI, C. (1997, Jul/Dez). Análise do Rompimento Hipotético da Barragem de Ernestina. pp. 191-206.

DER. (2008). DER - Departamento de Estradas de Rodagem do Estado de São Paulo. São Paulo.

DNOCS. Departamento Nacional de Obras Contra Secas. Retrieved maio 7, 2008, from DNOCS: http://www.dnocs.gov.br/

DUKE-Energy, A. (2008). Plan de Acción Durante Emergencia - Hidroeletrica Cerros Colorados S.A.

ELETROBRÁS. (2003). ELETROBRÁS. Retrieved Novembro 12, 2007, from http://www.eletrobras.com/elb/main.asp: http://www.eletrobras.com/elb/main.asp

ELETROBRÁS. (1999). http://www.eletrobras.org.br. Retrieved Março 26, 2008, from ELETROBRÁS.

EMAE. (2001). EMAE. Retrieved Março 2005, from Empresa Metropolitana de Águas e Energia S/A: http://www.emae.com.br/

FCTH. (2006). Plano de Contingência para as Barragens Pertencentes ao Sistemas Cantareira, Guarapirange e Alto Tietê. São Paulo, SP, Brasil.

FEMA. (2004, Abril). Federal Guidelines for Dam Safety. Federal Emergency Management Agency- U. S. Departament of Homeland Security, 50. USA.

FEMA, U. D.-F. (2004). Emergency Action Planning for Dam Owners - Federal Guidelines for Dam Safety. USA.

FEMA, U. D.-F. (2004). Federal Guidelines for Dam Safetty. USA.

FERC, F. E. (1998, Novembro). Emergency Action Plans - EAP. Emergency Action Plans. Estados Unidos.

FRANCO, C. S. (2008). Segurança de Barragens - Aspectos Regulatórios. Dissertação apresentada ao programa de Pós-Graduação em Engenharia do Meio Ambiente da Universidade Federal de Goiás como parte dos requisitos para obtenção do título de mestre em Engenharia do Meio Ambiente. Goiania, GO, Brasil.

FREAD, D. L., \& LEWIS, J. M. (1998, Novembro). NWS FLDWAV Model. Theoretical Description \& User Documentation - National Weather Service NOAA. 
FREAD, D. (1977). The Development and Testing of a Dam-Break Flood Forecasting Model. Proc. of Dam-Break Flood Modeling Workshop, 164-197. Washington, D.C.

FROEHLICH, D. C. (1995, Jan/Fev). Peak Outflow From Breached Embankment Dam. Journal of Water Resources Planning and Management, pp. 90-97.

FUNCATE. (2003). Relatório de Descrição dos Produtos de Sensoriamento Remoto" contrato IG 003/2003 - Instituto Geologico. São Paulo.

GEHRING, J. (1987). Aspectos Atuais na Avaliação da Segurança de Barragens em Operação. Dissertação de Mestrado apresentada a EPUSP . São Paulo.

GOOGLE, E. (2009).

ICOLD.. International Comission On Large Dam. Retrieved Março 15, 2008, from ICOLD: http://www.icold-cigb.net

ICOLD, I. C. (2005). Emergency Action Plan Guidelines. USA.

LEAL, J. G., FERREIRA, R. M., \& CARDOSO, A. H. (2006, Janeiro). Dam Break Wave-Front Celerity. Journal of Hydraulic Engineering , pp. 69-76.

LIGHT, S. d. (1978). Barragem do Guarapiranga - Obras de Complementação, Relatório Como Construído. São Paulo.

Longarone, C. d. http://www.vajont.net/. Retrieved Dezembro 10, 2007, from Disastro di Vajont - Diga del Vajont: http://www.vajont.net/

MACDONALD, T. C., \& LANGRIDGE-MONOPOLIS, J. (1984). Breaching Characteristics of Dam Failure. Journal of Hydraulic Division, pp. 567-586.

MARTINS, J. R. (2003). Hidrodinâmica das Macro-rugosidades de Fundo em Canais. Tese (Doutorado) Escola Politécnica da Universidade de São Paulo. São Paulo, SP.

MARTINS, J. R., \& FADIGA JR., F. M. (1989). Rompimento de Barragens. Cálculo Adimensional da Propagação da Enchente Efluente. 13º Congresso Latino Americano de Hidráulica - AIRH , 561-573. Foz do Iguaçu.

MENESCAL, R., \& MIRANDA, A. N. (1997). Plano de Ações Emergenciais para Barragnes - Um Modelo de Plano de Ações Emergenciais Para Açudes Estaduais. XII Seminário Nacional de Recursos Hídricos , 155-163. Vitória, ES.

Ministério da Integração Nacional; Secretaria de Infra-Estrutura Hídrica. (2002). Manual de Segurança - Inspeção de Barragens. Brasilia - DF. 
MOHAPATRA, P. K., \& CHAUDHRY, M. H. (2004, Fevereiro). Numerical Solution of Boussinesq Equations to Simulate Dam-Break Flows. Journal of Hydraulic Division , pp. 156-159.

PONCE, V. M., \& TSIVOGLOU, A. J. (1981, Julho). Modeling Gradual Dam Breaches. Journal of Hydraulic Engineering , 107, 829-838. New York.

Project, T. D. http://www.tetondam.org/. Retrieved Março 15, 2008, from Teton Dam Project: http://www.tetondam.org/

SCHINTTER, N. (1994). A History of Dams - The Useful Pyramids. Rotterdam: A.A.Balkema.

SINGH, V. P., \& SCARLATOS, P. D. (1988, Janeiro). Analysis of Gradual Earth-Dam Failure. Journal of Hydraulic Engineering , 114 , 21-42. New York.

Tietê, A. (2005). http://www.aestiete.com.br/. Retrieved Fevereiro 22, 2008, from AES Tietê: http://www.aestiete.com.br/

UEMURA, S., \& MARTINS, J. (2007, Novembro). Rompimernto de Barragens: Estudo de Caso da Barragem Guarapiranga em São Paulo. XVII Simpósio Brasileiro de Recursos Hídricos . São Paulo, SP, Brasil: ABRH.

WU, W., \& WANG, S. S. (2007, Janeiro). One-Dimensional Modeling of Dam-break Flow. Journal of Hydraulic Division, pp. 48-58.

ZOPPOU, C., \& ROBERTS, S. (2003, Janeiro). Expicit Schemes for Dam-Break Simulations. Journal of Hydraulic Division, pp. 11-34. 


\section{APÊNDICES}


Quadro 1: Histórico de Barragens Rompidas. (Adaptado de ICOLD, 1995)

\begin{tabular}{|c|c|c|c|c|c|}
\hline & Nome da Barragem & Tipo da Barragem & $\begin{array}{l}\text { Tipo de } \\
\text { Ruptura }\end{array}$ & $\begin{array}{l}\text { Ano da } \\
\text { Ruptura }\end{array}$ & $\begin{array}{c}\text { Ano de } \\
\text { Construção }\end{array}$ \\
\hline 1 & Ahrura & Terra & & 1954 & 1954 \\
\hline 2 & Apishapa & Areia Fina & & 1933 & 1920 \\
\hline 3 & Bagaudo & Terra e Enrocamento & & 1988 & 1970 \\
\hline 4 & Baldwin Hills & Terra & & 1963 & 1951 \\
\hline 5 & Banqiao & Terra & Estrutura & 1975 & 1956 \\
\hline 6 & Belci & Terra & & 1991 & 1963 \\
\hline 7 & Bilberry & Terra & Estrutura & 1852 & 1845 \\
\hline 8 & Bile Desna & Terra & Materiais & 1916 & 1915 \\
\hline 9 & Blackbrook I & Terra & Estrutura & 1799 & 1797 \\
\hline 10 & Blackbrook II & Concreto por Gravidade & Estrutura & 1804 & 1801 \\
\hline 11 & Blyderivier & Terra & Estrutura & 1922 & 1924 \\
\hline 12 & Bolan & Terra & Estrutura & 1976 & 1958 \\
\hline 13 & Bouzey & Concreto por Gravidade & Estrutura & 1895 & 1880 \\
\hline 14 & Buffalo Creek & Resíduos de Carvão & & 1972 & 1972 \\
\hline 15 & Bullock Draw Dike & Terra & & 1971 & 1971 \\
\hline 16 & Castlewood & Parede de Alvenaria & & 1933 & 1890 \\
\hline 17 & Cheaha Creek & Terra & & 1970 & 1970 \\
\hline 18 & Chiatauni & & & 1968 & \\
\hline 19 & Chikahole & Concreto por Gravidade & & 1972 & 1966 \\
\hline 20 & Dale Dyke & Terra & Estrutura & 1864 & 1863 \\
\hline 21 & Davis Reservoir & Terra com face de Concreto & & 1914 & 1914 \\
\hline 22 & Del monte & & & 1976 & \\
\hline 23 & Dnatiwada & $\begin{array}{c}\text { Terra e Concreto por } \\
\text { Gravidade }\end{array}$ & Estrutura & 1973 & 1969 \\
\hline 24 & Dykstra & Enrocamento & Materiais & 1926 & \\
\hline 25 & Elandsdrift & Enrocamento & Estrutura & 1974 & 1975 \\
\hline
\end{tabular}




\begin{tabular}{|c|c|c|c|c|c|}
\hline & Nome da Barragem & Tipo da Barragem & $\begin{array}{l}\text { Tipo de } \\
\text { Ruptura }\end{array}$ & $\begin{array}{l}\text { Ano da } \\
\text { Ruptura }\end{array}$ & $\begin{array}{c}\text { Ano de } \\
\text { Construção }\end{array}$ \\
\hline 26 & Elwa River & Concreto por Gravidade & Fundação & 1912 & 1912 \\
\hline 27 & Embalse Aramos & Terra & Fundação & 1984 & 1979 \\
\hline 28 & Embalse Lo Ovalle & Terra & Estrutura & 1985 & 1932 \\
\hline 29 & Enery & Terra & Estrutura & 1966 & 1850 \\
\hline 30 & English & Enrocamento & Fundação & 1883 & 1878 \\
\hline 31 & English Water Supply & Terra & Fundação & 1965 & 1965 \\
\hline 32 & Euclides da Cunha & Terra & & 1977 & 1958 \\
\hline 33 & Frankfurt & Terra & & 1977 & 1975 \\
\hline 34 & Fred Burr & Terra & Estrutura & 1948 & 1947 \\
\hline 35 & French landing & Terra & & 1925 & 1925 \\
\hline 36 & Frenchman Creek & Terra & & 1952 & 1952 \\
\hline 37 & Gallinas & Concreto por Gravidade & & 1957 & 1910 \\
\hline 38 & Ghattara & Terra & & 1977 & 1972 \\
\hline 39 & Goose Creek & Terra & & 1916 & 1903 \\
\hline 40 & Graham Lake & Terra & Estrutura & 1923 & 1922 \\
\hline 41 & Greenlick & Terra e Enrocamento & Estrutura & 1904 & 1901 \\
\hline 42 & Groose Creek & Enrocamento & Fundação & 1900 & \\
\hline 43 & Hans Strijdon Coffer & Terra & Fundação & 1977 & 1980 \\
\hline 44 & Hatchtown & Terra & Estrutura & 1914 & 1908 \\
\hline 45 & Hauser lake I & Concreto por Gravidade & Fundação & 1908 & 1906 \\
\hline 46 & Hauser Lake II & Concreto por Gravidade & & 1969 & 1911 \\
\hline 47 & Hebron I & Terra & Fundação & 1914 & 1913 \\
\hline 48 & Hebron II & Terra & & 1942 & 1913 \\
\hline 49 & Hell Hole & Enrocamento & & 1964 & 1966 \\
\hline 50 & Horse Creek & Terra & Fundação & 1914 & 1912 \\
\hline 51 & Hyogiri & Terra & & 1961 & 1940 \\
\hline 52 & Idbar & Concreto em Arco & Fundação & 1960 & 1959 \\
\hline
\end{tabular}




\begin{tabular}{|c|c|c|c|c|c|}
\hline & Nome da Barragem & Tipo da Barragem & $\begin{array}{l}\text { Tipo de } \\
\text { Ruptura }\end{array}$ & $\begin{array}{l}\text { Ano da } \\
\text { Ruptura }\end{array}$ & $\begin{array}{c}\text { Ano de } \\
\text { Construção }\end{array}$ \\
\hline 53 & Jennings Creek 16 & Terra & Estrutura & 1964 & 1960 \\
\hline 54 & Jennings Creek 3 & Enrocamento & Fundação & 1963 & 1962 \\
\hline 55 & Johnston City & Terra & & 1984 & 1921 \\
\hline 56 & Johnstown & $\begin{array}{c}\text { Terra com face de } \\
\text { Enrocamento }\end{array}$ & & 1889 & 1853 \\
\hline 57 & Jumbo & Enrocamento & Fundação & 1910 & 1905 \\
\hline 58 & Kantale & Terra & & 1986 & 1869 \\
\hline 59 & Kelly Barnes & Terra & & 1977 & 1948 \\
\hline 60 & Killington & Terra & Estrutura & 1839 & 1820 \\
\hline 61 & La Laguna & Terra & Estrutura & 1969 & 1912 \\
\hline 62 & Lake Barcroft & Terra & Estrutura & 1972 & 1913 \\
\hline 63 & lake Francis I & Terra & Estrutura & 1899 & 1899 \\
\hline 64 & Lake Francis II & Terra & & 1935 & 1901 \\
\hline 65 & Lake Hemet & Terra & & 1927 & 1923 \\
\hline 66 & Laurel Run & Terra & & 1977 & \\
\hline 67 & Leeuw Gamka & Terra & Estrutura & 1928 & 1920 \\
\hline 68 & Leguaseca (Fonsagrada) & Concreto Arco Múltiplo & Estrutura & 1987 & 1958 \\
\hline 69 & Little Deer Creek & Terra & & 1963 & 1962 \\
\hline 70 & Lliu-Lliu & Terra & Estrutura & 1985 & 1934 \\
\hline 71 & Log Falls & & & 1923 & \\
\hline 72 & Lower Otay & Terra & & 1916 & 1897 \\
\hline 73 & Lower Two Medicine & Terra & & 1964 & 1913 \\
\hline 74 & Lyman & Terra & & 1915 & 1913 \\
\hline 75 & Lynde Brook & Terra & & 1876 & 1870 \\
\hline 76 & Mafeteng & Terra & & 1988 & 1988 \\
\hline 77 & Malpasset & Concreto em Arco & Fundação & 1959 & 1954 \\
\hline 78 & Meihua & Concreto em Arco & Estrutura & 1981 & 1981 \\
\hline
\end{tabular}




\begin{tabular}{|c|c|c|c|c|c|}
\hline & Nome da Barragem & Tipo da Barragem & $\begin{array}{l}\text { Tipo de } \\
\text { Ruptura }\end{array}$ & $\begin{array}{l}\text { Ano da } \\
\text { Ruptura }\end{array}$ & $\begin{array}{c}\text { Ano de } \\
\text { Construção }\end{array}$ \\
\hline 79 & Melville & Terra & & 1909 & 1907 \\
\hline 80 & Mena & Terra & Estrutura & 1888 & 1885 \\
\hline 81 & Molteno & Terra & & 1882 & 1881 \\
\hline 82 & Nizhne Svirskaya & Terra & & 1935 & 1934 \\
\hline 83 & Noppikoski & Terra & Estrutura & 1985 & 1966 \\
\hline 84 & North Branch Tributary & Terra & & 1977 & \\
\hline 85 & Odiel & Enrocamento & & 1968 & 1970 \\
\hline 86 & Oros & Terra & & 1960 & 1960 \\
\hline 87 & Otto Run & Terra & & 1977 & \\
\hline 88 & Ovcar Bajna & Terra & & 1965 & 1952 \\
\hline 89 & Puentes & Concreto por Gravidade & Estrutura & 1802 & 1791 \\
\hline 90 & Rhodesworth & Terra & & 1852 & 1855 \\
\hline 91 & Rito Manzanares & Terra & & 1975 & \\
\hline 92 & Ruahihi & Enrocamento & Fundação & 1981 & 1981 \\
\hline 93 & Sales Oliveira & Terra & & 1977 & 1966 \\
\hline 94 & Sandy Run & Terra & & 1977 & \\
\hline 95 & Sargazonskaya & Terra & & 1987 & 1980 \\
\hline 96 & Schaeffer & Terra & & 1921 & \\
\hline 97 & Scott Falls & $\begin{array}{c}\text { Terra e Concreto por } \\
\text { Gravidade }\end{array}$ & & 1923 & 1921 \\
\hline 98 & Sheep Creek & Terra & & 1970 & 1969 \\
\hline 99 & Shimanthan & Terra & Estrutura & 1975 & 1952 \\
\hline 100 & Sinker Creek & Terra & & 1943 & 1910 \\
\hline 101 & Smartt Sindicate & Terra & Estrutura & 1961 & 1912 \\
\hline 102 & South Fork Tributary & Terra & & 1977 & \\
\hline 103 & Spitskop & Terra & & 1988 & 1974 \\
\hline 104 & Spring lake & Terra & & 1889 & 1887 \\
\hline
\end{tabular}




\begin{tabular}{|c|c|c|c|c|}
\hline Nome da Barragem & Tipo da Barragem & $\begin{array}{l}\text { Tipo de } \\
\text { Ruptura }\end{array}$ & $\begin{array}{l}\text { Ano da } \\
\text { Ruptura }\end{array}$ & $\begin{array}{c}\text { Ano de } \\
\text { Construção }\end{array}$ \\
\hline 105 Stockton Creek & Enrocamento & & 1950 & 1923 \\
\hline 106 Sweetwater & Terra & & 1916 & 1911 \\
\hline 107 Swift & Terra e Enrocamento & & 1964 & 1914 \\
\hline 108 Teton & Terra e Enrocamento & $\begin{array}{c}\text { Fundação/Estr } \\
\text { utura }\end{array}$ & 1976 & 1976 \\
\hline 109 Toreson & Terra & & 1953 & 1898 \\
\hline 110 Torside & Terra & & 1854 & 1855 \\
\hline 111 Tous & Enrocamento & Estrutura & 1982 & \\
\hline 112 Utica & Terra & & 1902 & 1873 \\
\hline 113 Van Norman Lake & Enrocamento & & 1971 & 1921 \\
\hline 114 Vaughn Creek & Concreto em Arco & & 1926 & 1926 \\
\hline 115 Veja de Tera & & & 1959 & 1956 \\
\hline 116 Wagner Creek & Terra & & 1938 & 1918 \\
\hline 117 Walnut Grove & Enrocamento & & 1890 & 1888 \\
\hline 118 Walter Bouldin & Terra & Estrutura & 1975 & 1967 \\
\hline 119 Wesley E. Seale & Terra & & 1965 & 1958 \\
\hline 120 Wheatland $N^{\circ} 1$ & Terra & & 1969 & 1893 \\
\hline 121 Whiteqater Brook Upper & Terra & & 1972 & 1949 \\
\hline 122 Winston & Terra & Overtopping & 1912 & 1904 \\
\hline 123 Wisconsin Dells & Enrocamento & & 1911 & 1909 \\
\hline 124 Xonxa & Terra e Enrocamento & Estrutura & 1972 & 1974 \\
\hline 125 Xuriguera & Concreto por Gravidade & Fundação & 1944 & 1902 \\
\hline
\end{tabular}


Seções Transversais do Canal Guarapiranga e Rio Pinheiros

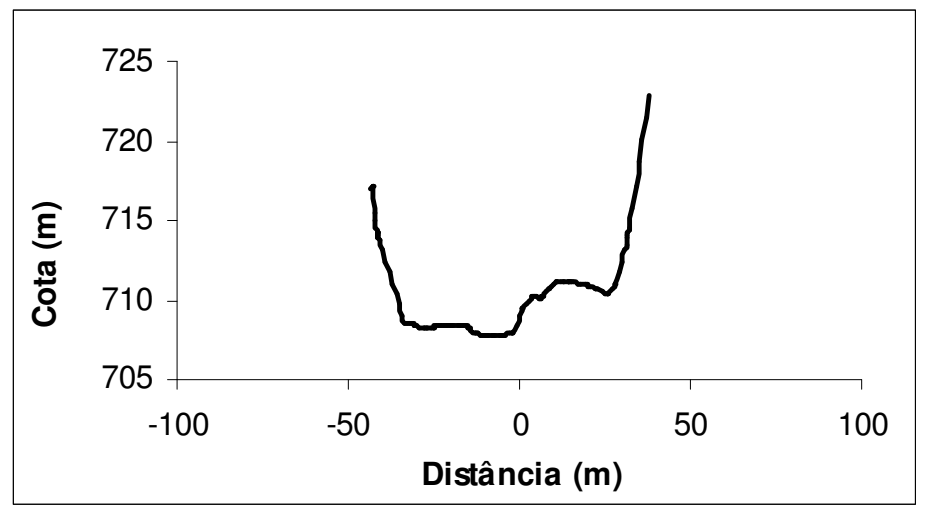

Fig. 1: Seção batimétrica Pl15_480

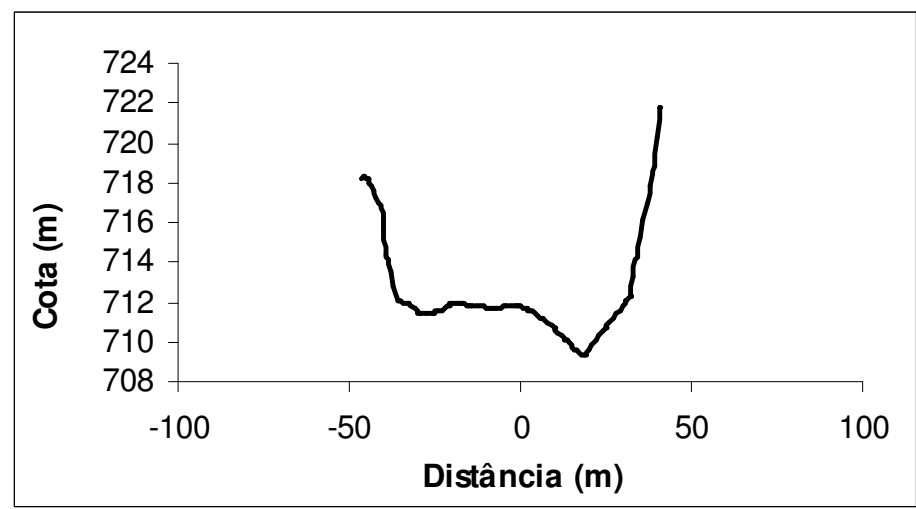

Fig. 2: Seção batimétrica PI15_500

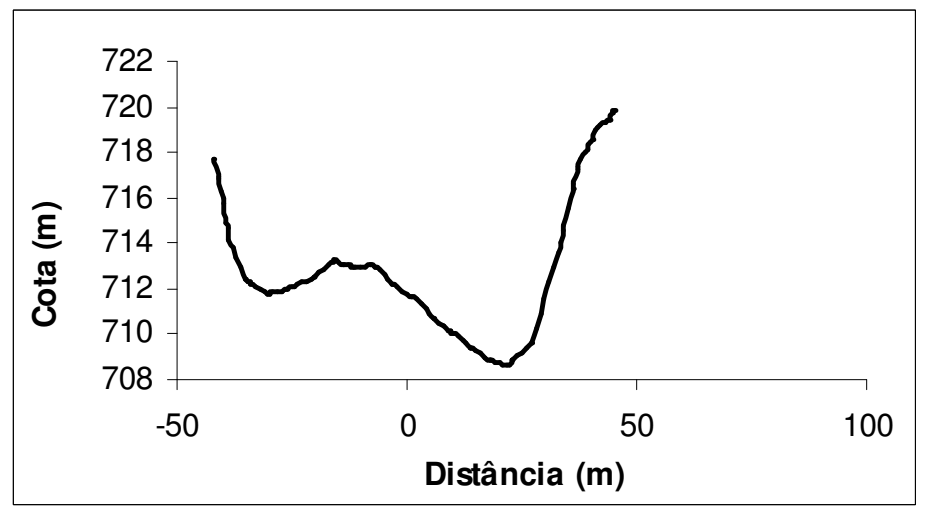

Fig. 3: Seção batimétrica PI15_700 


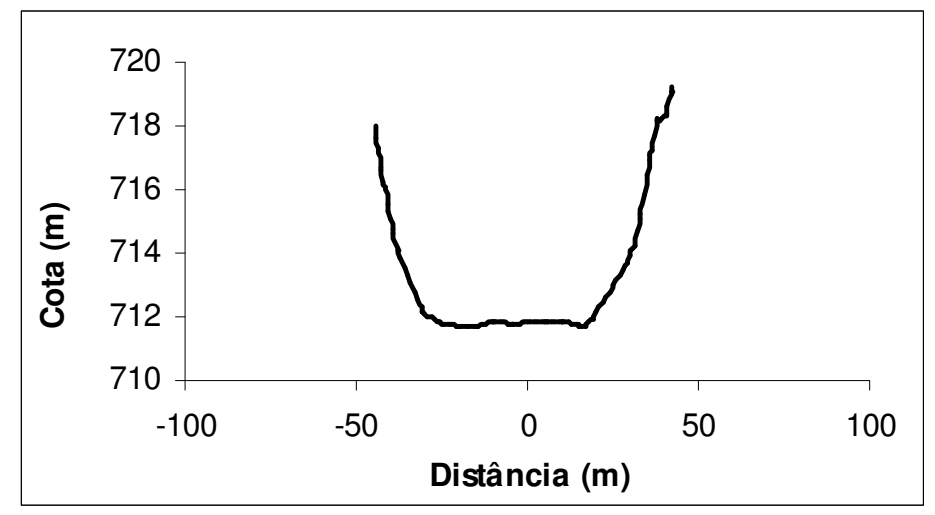

Fig. 4: Seção batimétrica PI15_900

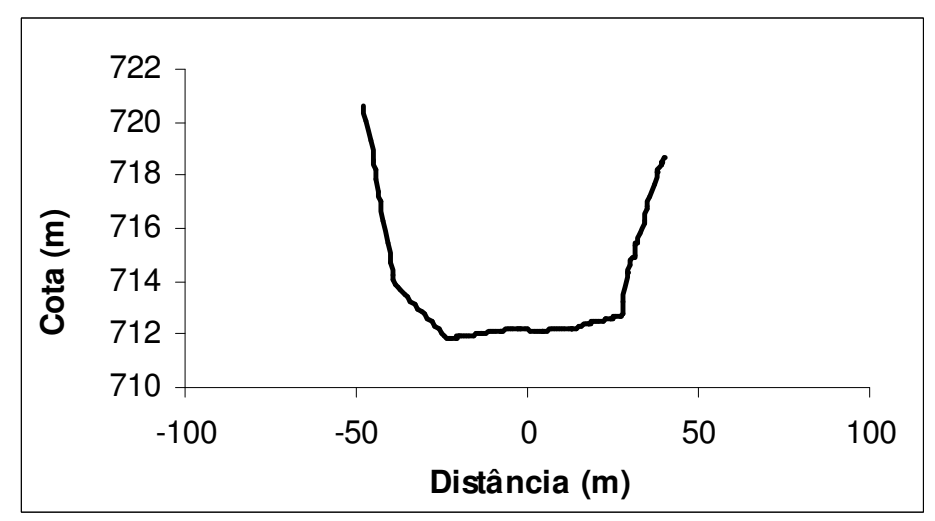

Fig. 5: Seção batimétrica Pl16_100

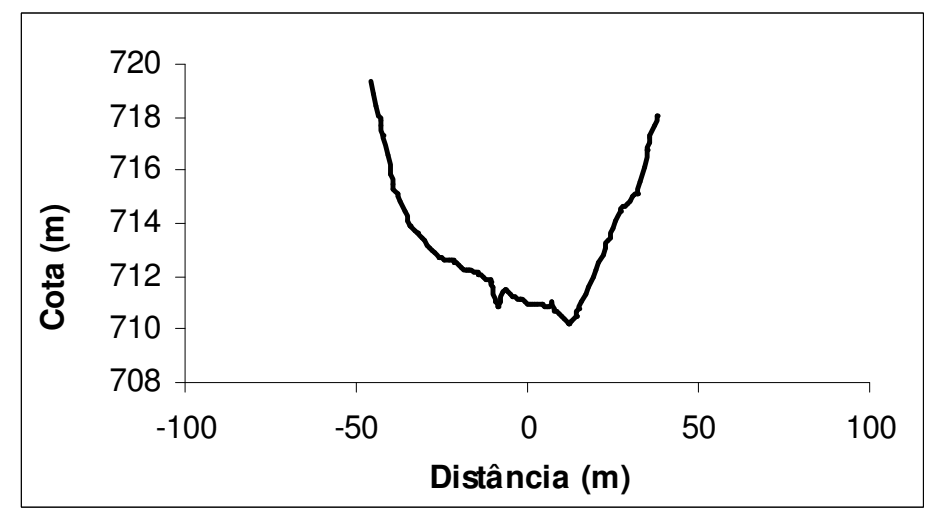

Fig. 6: Seção batimétrica PI16_300 


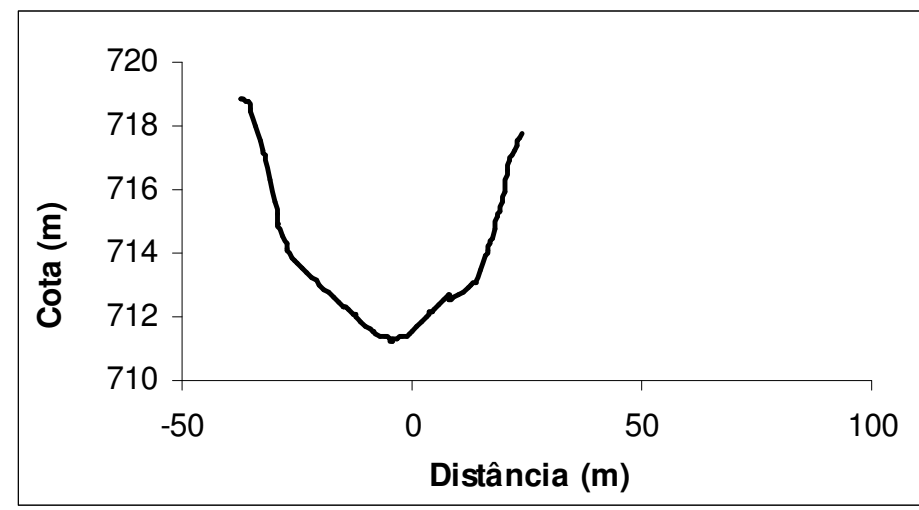

Fig. 7: Seção batimétrica Pl16_500

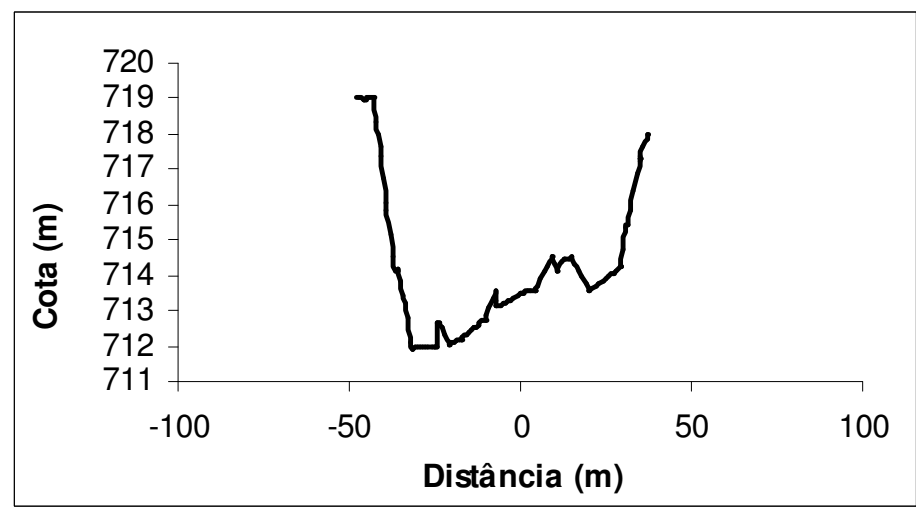

Fig. 8: Seção batimétrica Pl16_700

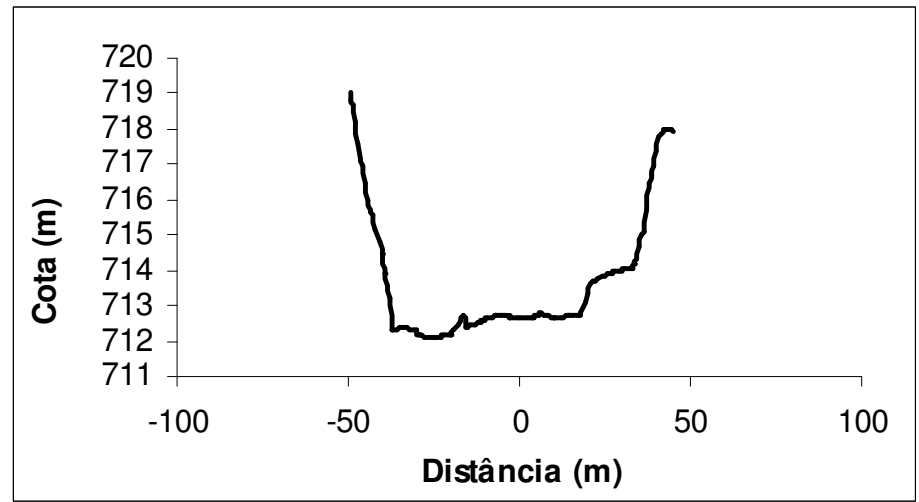

Fig. 9: Seção batimétrica Pl16_900 


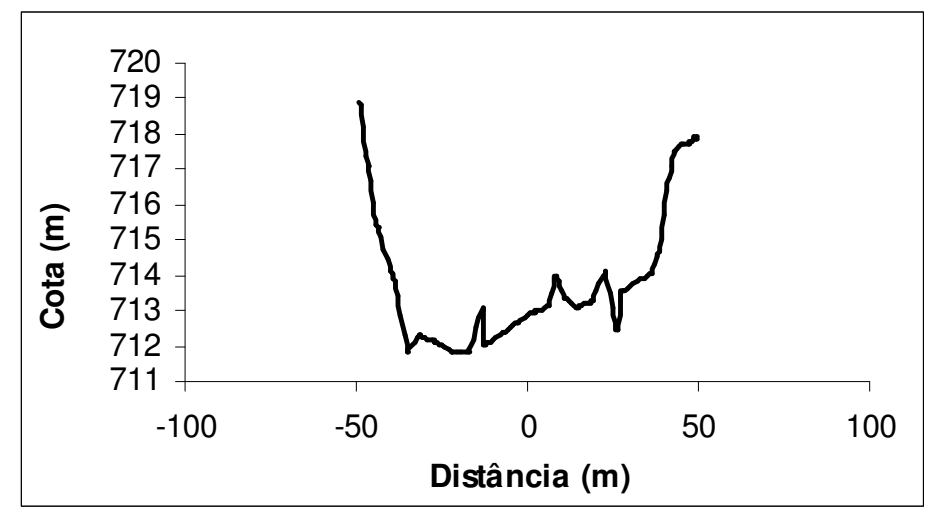

Fig. 10: Seção batimétrica PI17_100

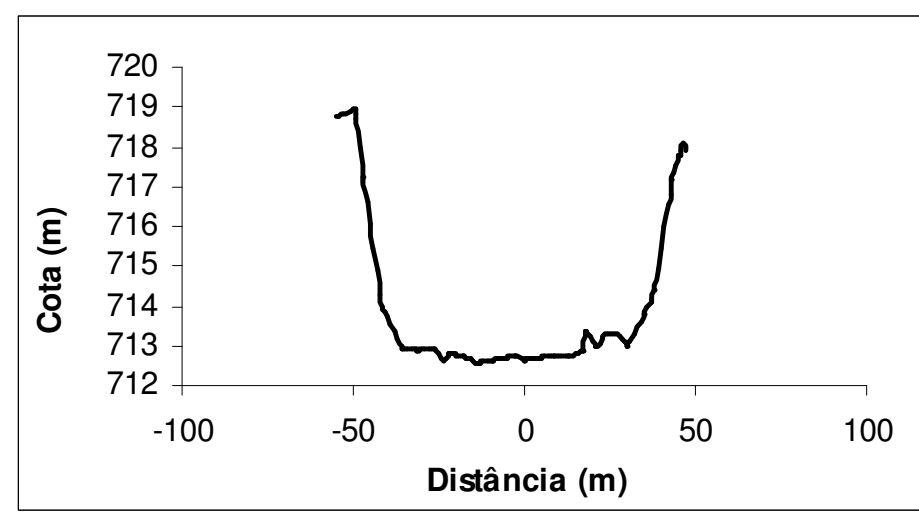

Fig. 11: Seção batimétrica PI17_300

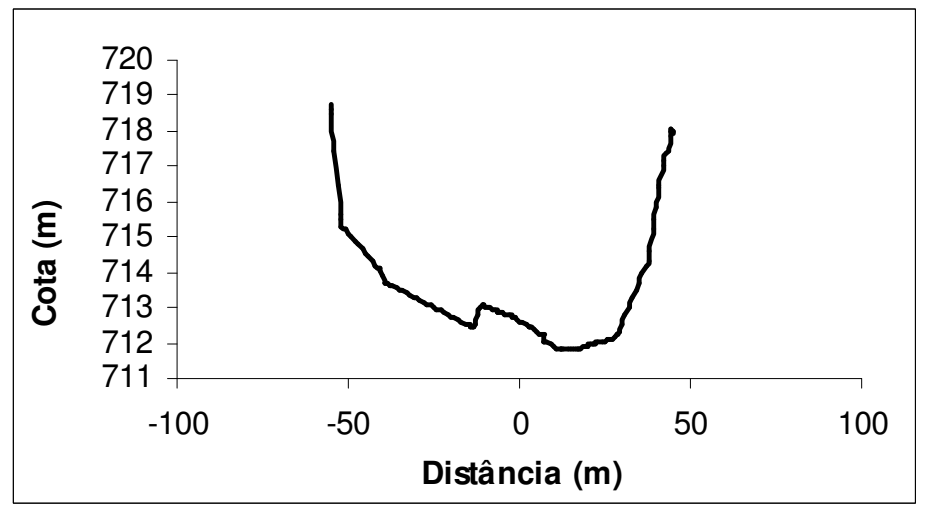

Fig. 12: Seção batimétrica PI17_500 


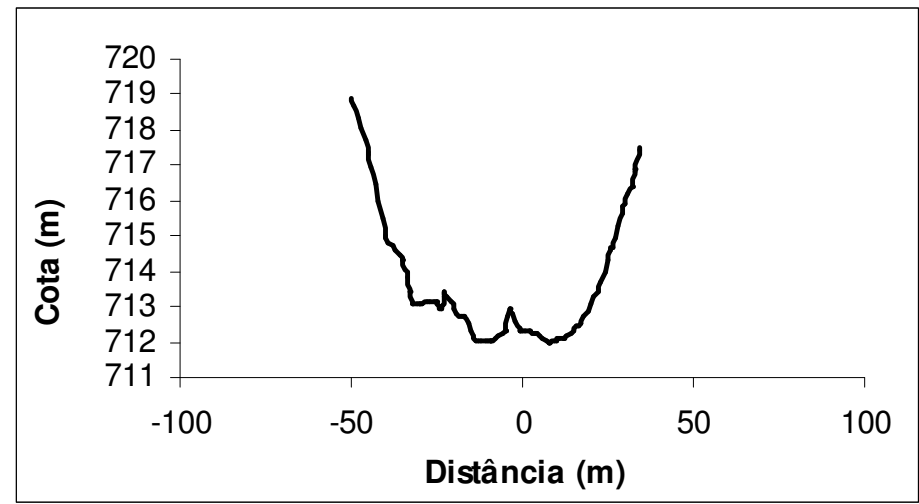

Fig. 13: Seção batimétrica PI18_100

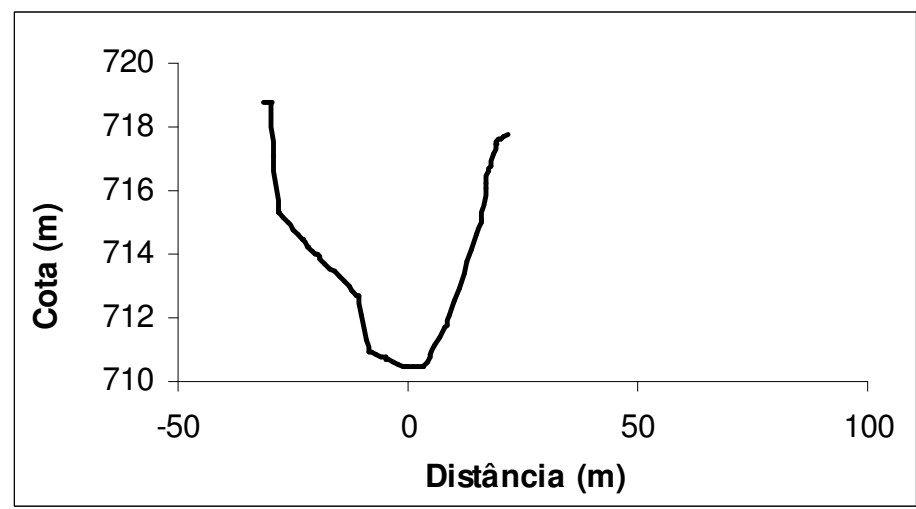

Fig. 14: Seção batimétrica PI18_300

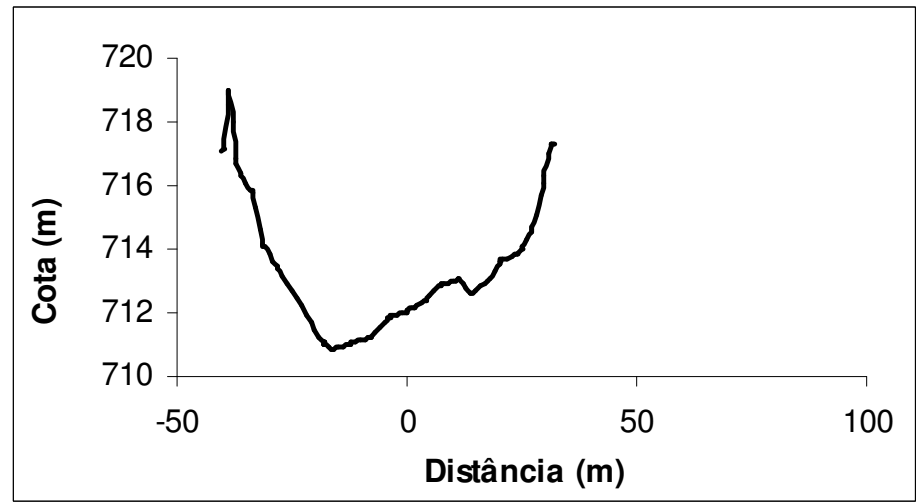

Fig. 15: Seção batimétrica PI18_500 


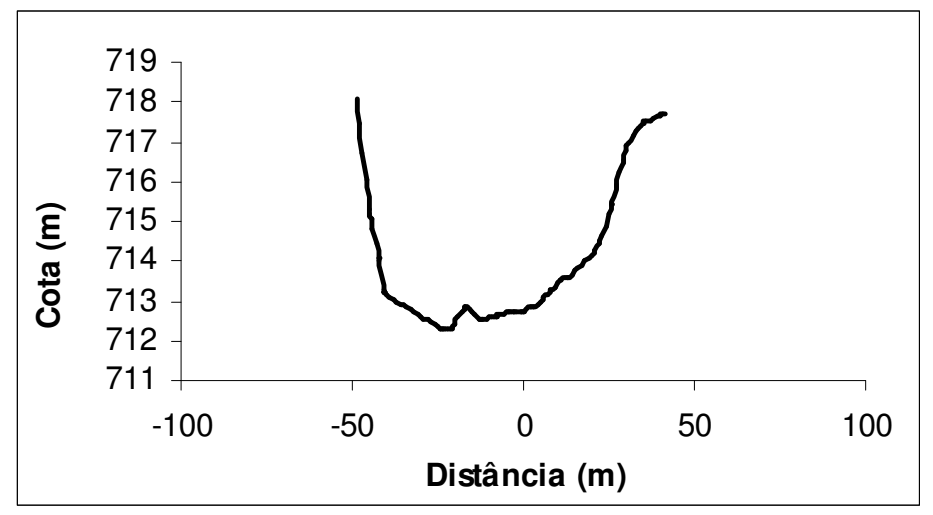

Fig. 16: Seção batimétrica PI18_700

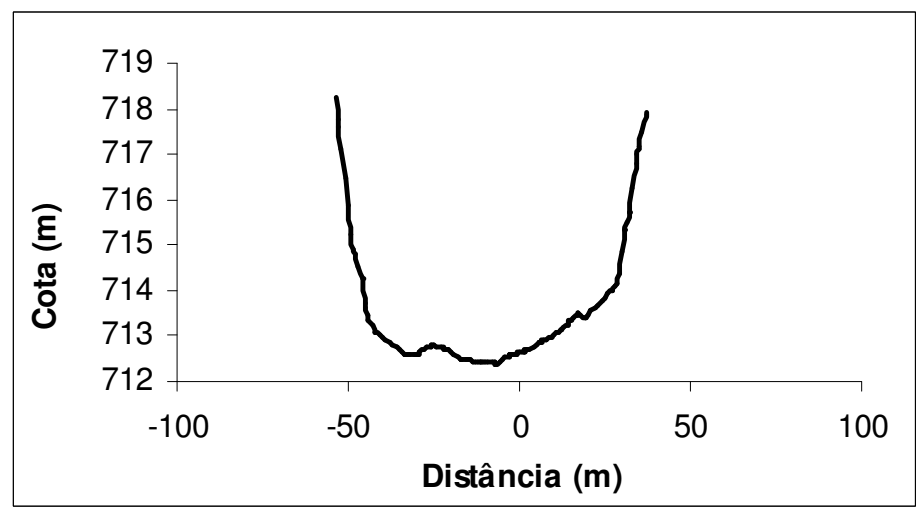

Fig. 17: Seção batimétrica PI18_900

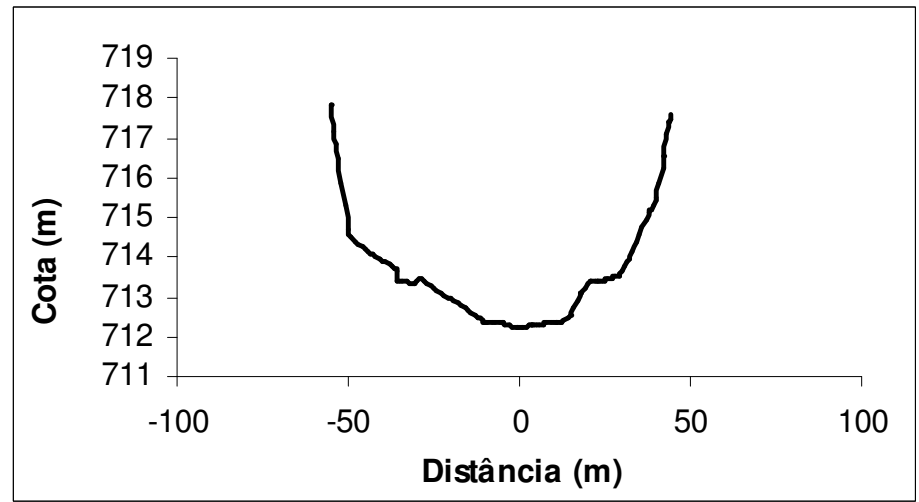

Fig. 18: Seção batimétrica PI19_100 


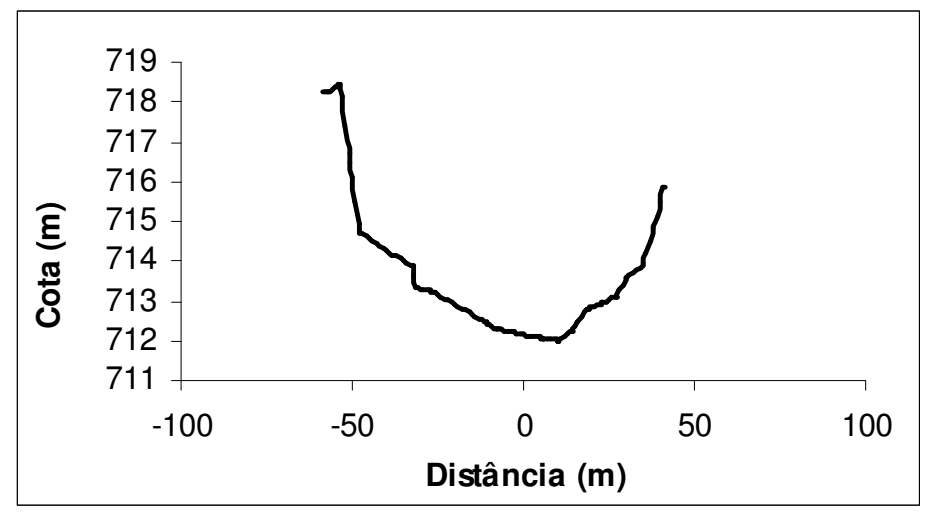

Fig. 19: Seção batimétrica PI19_300

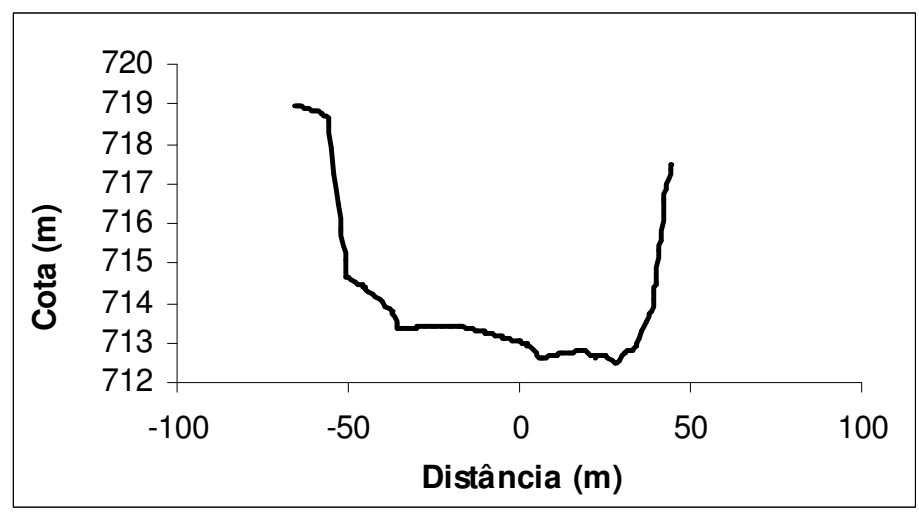

Fig. 20: Seção batimétrica PI19_500

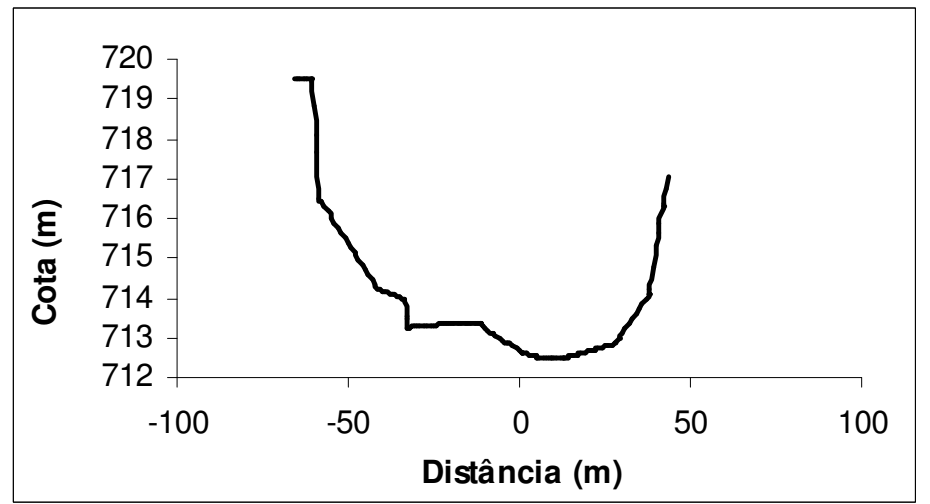

Fig. 21: Seção batimétrica PI19_700 


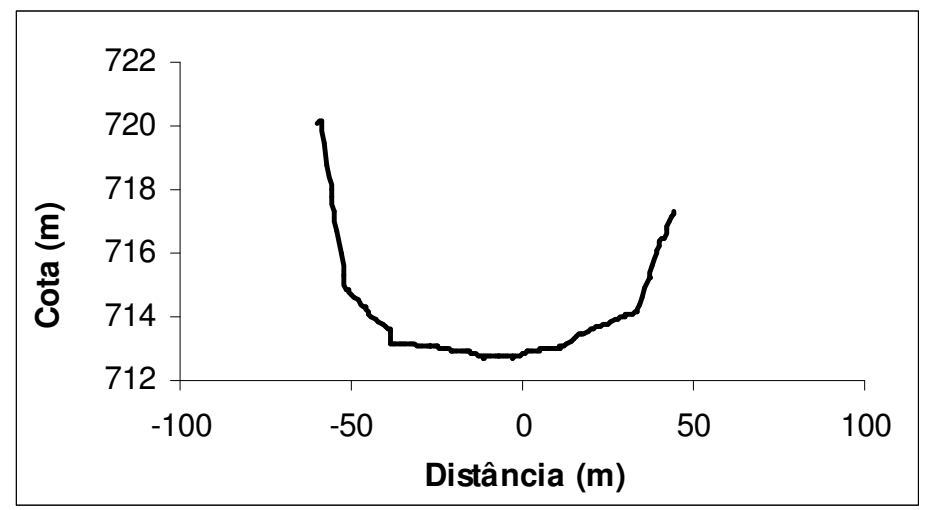

Fig. 22: Seção batimétrica PI19_900

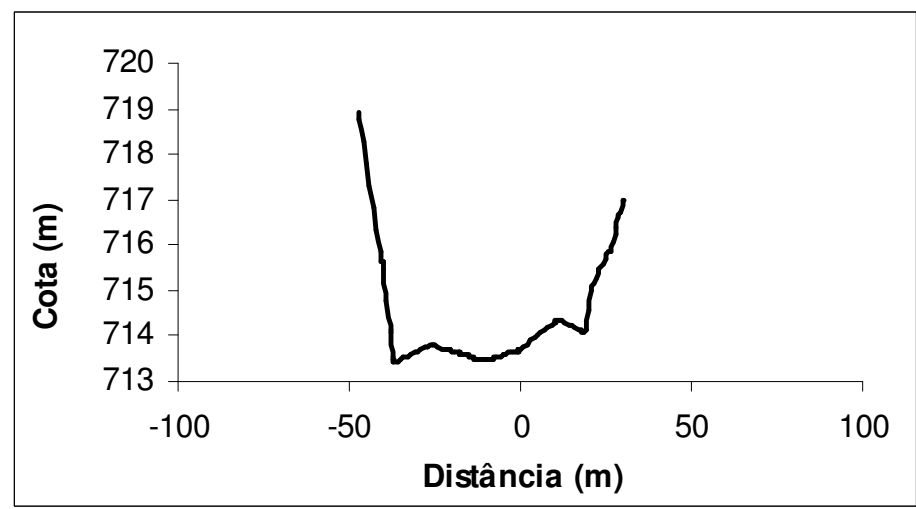

Fig. 23: Seção batimétrica PI20_100

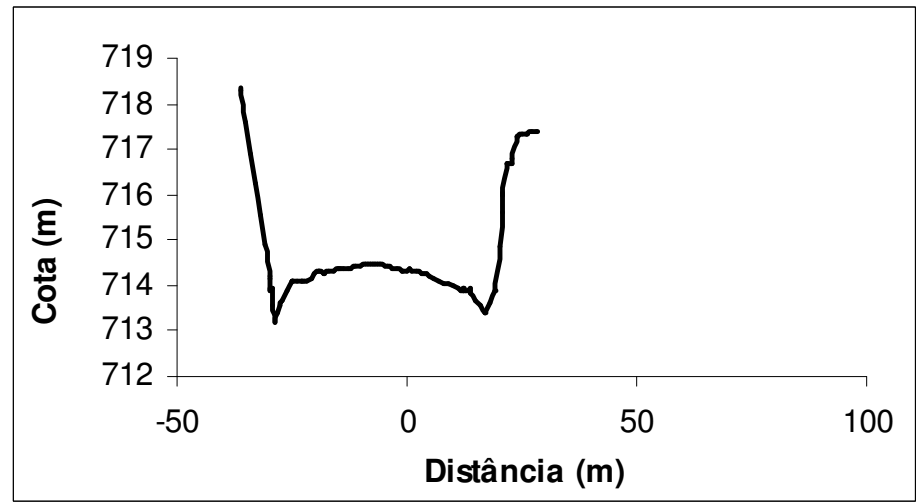

Fig. 24: Seção batimétrica PI20_300 


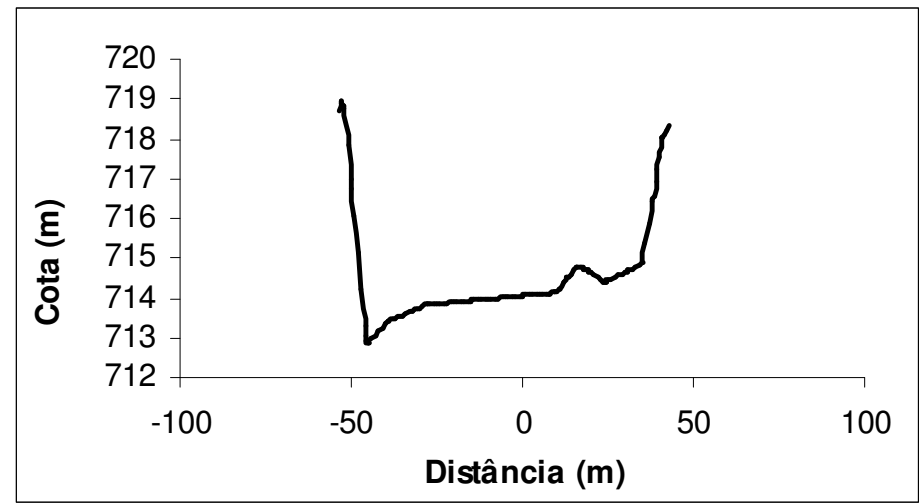

Fig. 25: Seção batimétrica PI20_500

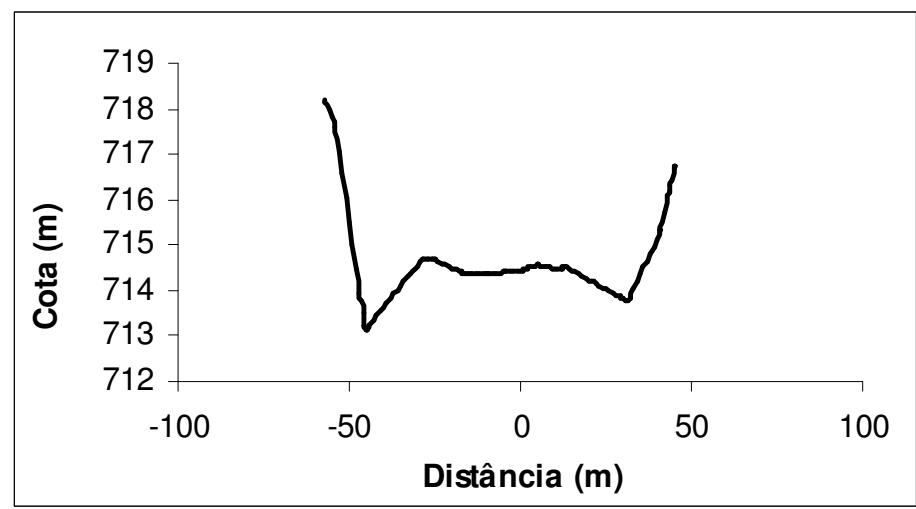

Fig. 26: Seção batimétrica PI20_700

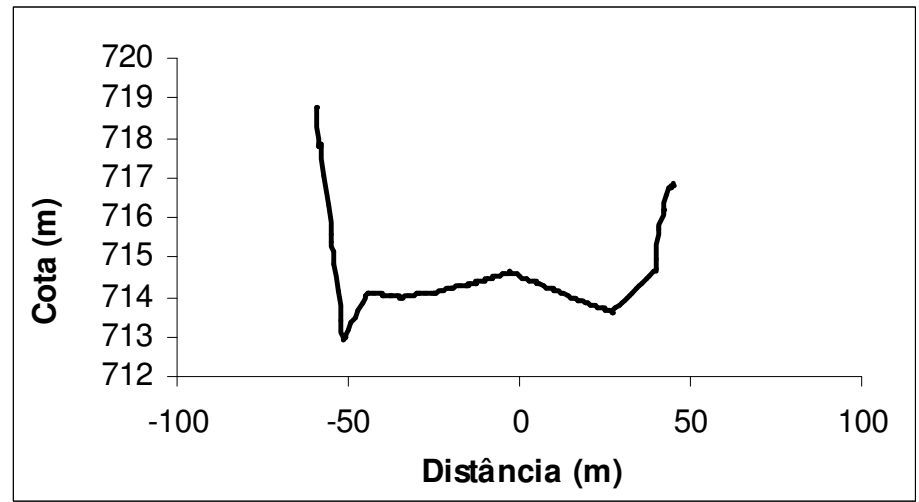

Fig. 27: Seção batimétrica PI20_900 


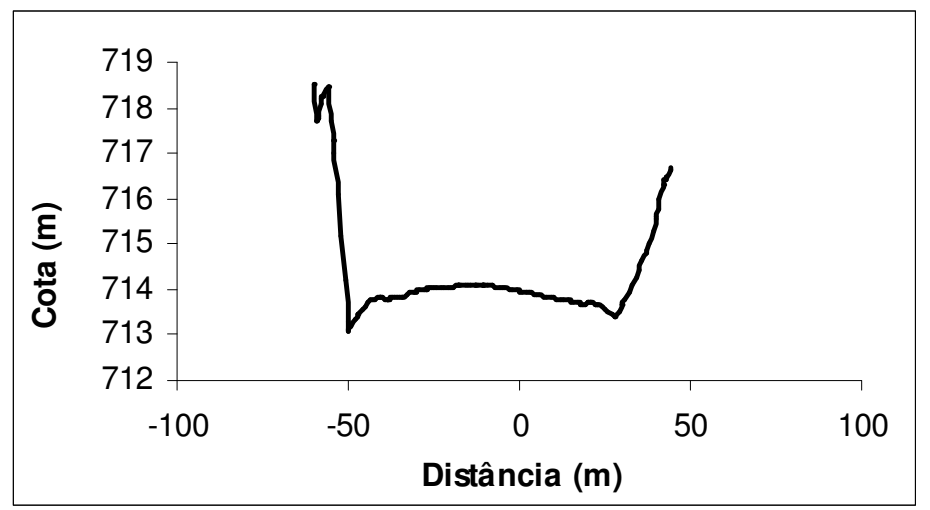

Fig. 28: Seção batimétrica PI21_100

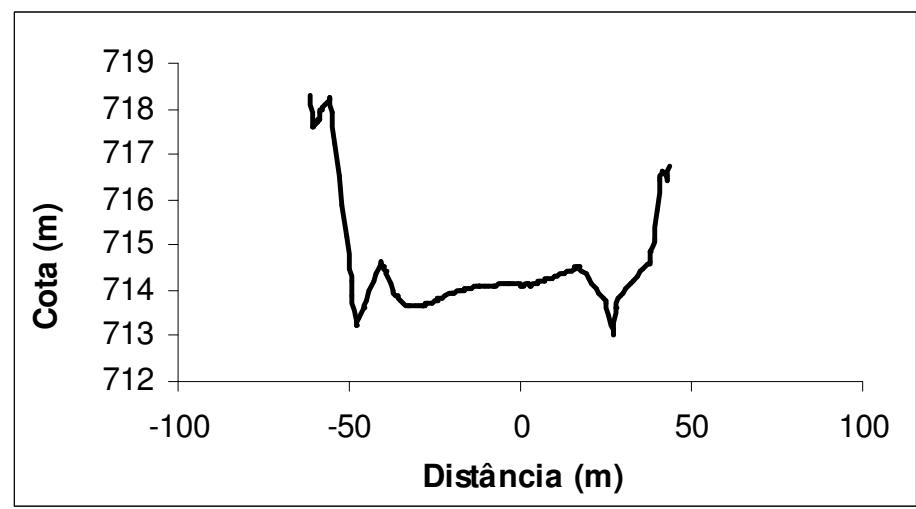

Fig. 29: Seção batimétrica PI21_300

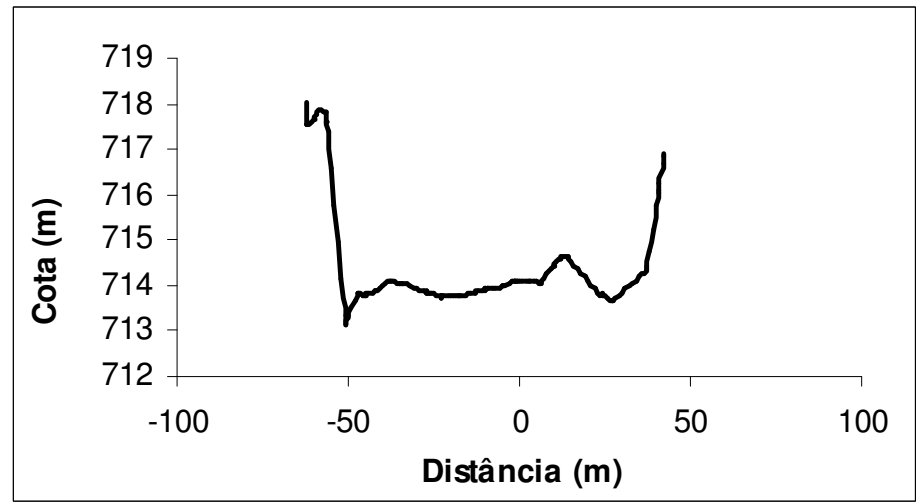

Fig. 30: Seção batimétrica PI21_500 


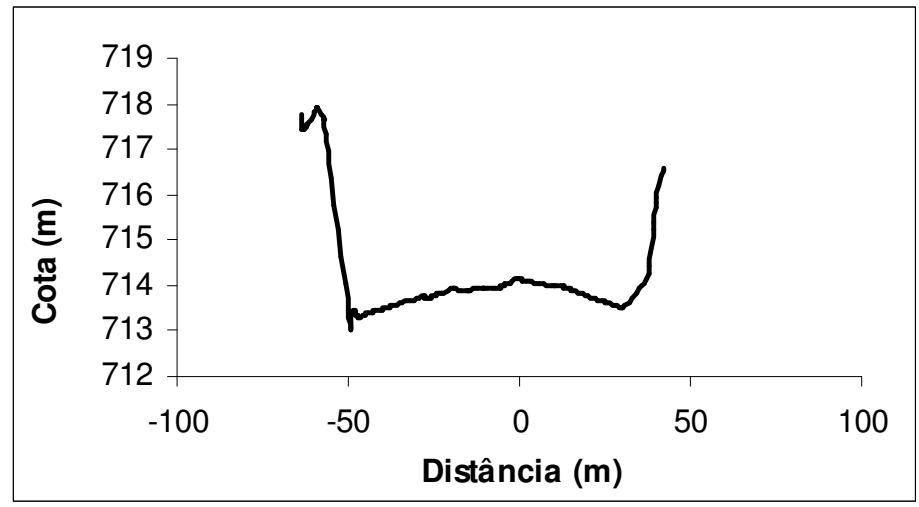

Fig. 31: Seção batimétrica PI21_700

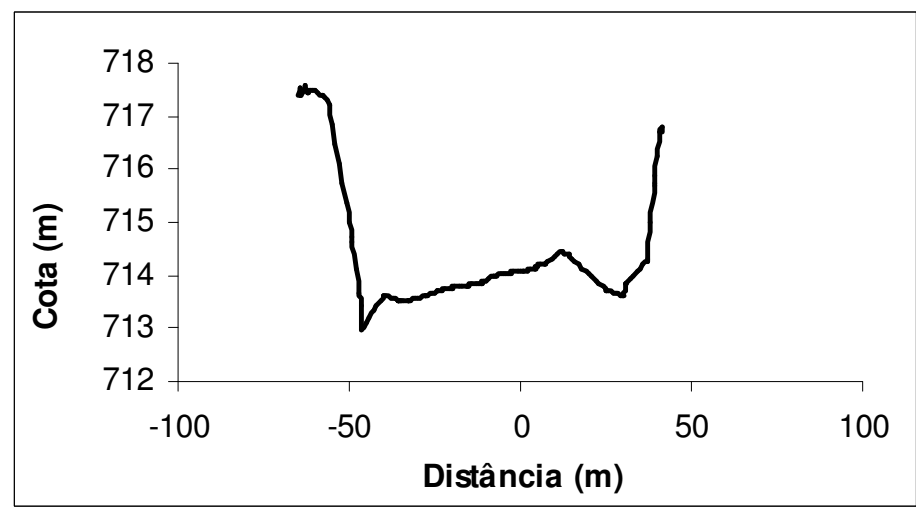

Fig. 32: Seção batimétrica PI21_900

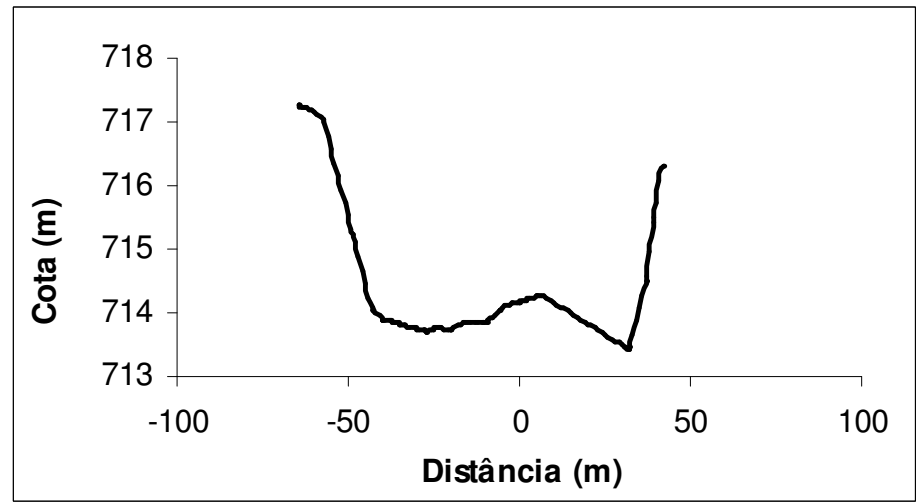

Fig. 33: Seção batimétrica PI22_100 


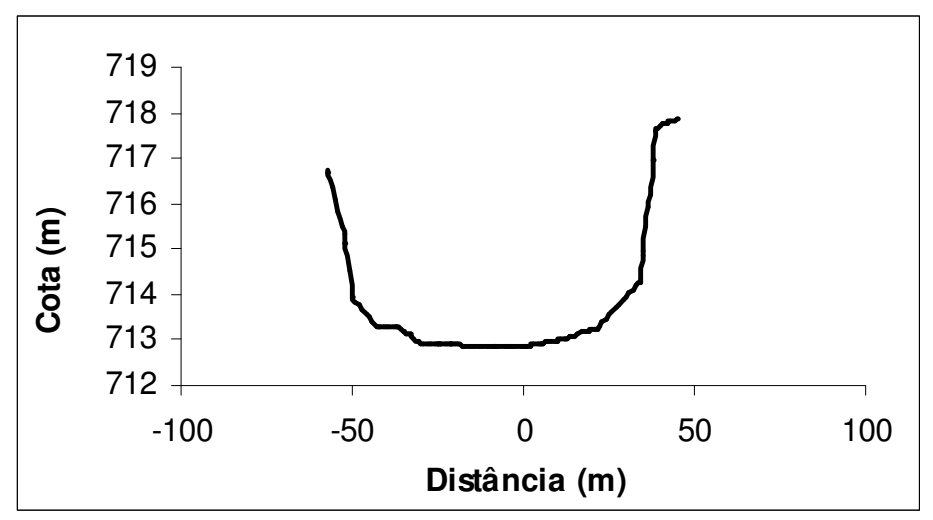

Fig. 34: Seção batimétrica PI22_300

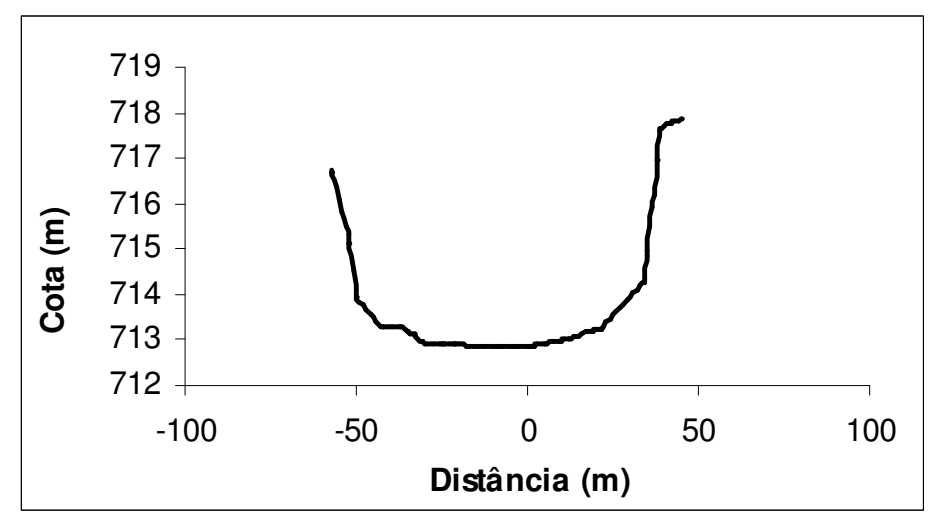

Fig. 35: Seção batimétrica PI22_500

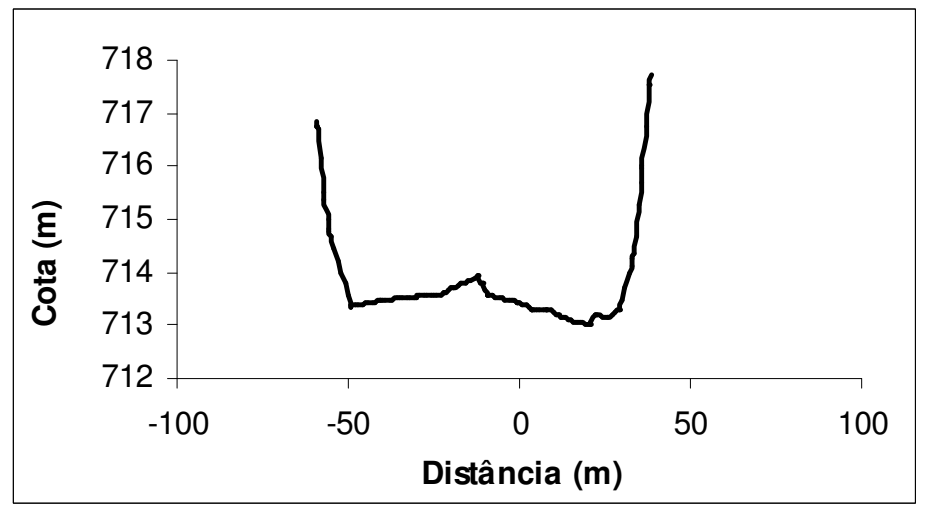

Fig. 36: Seção batimétrica PI22_700 


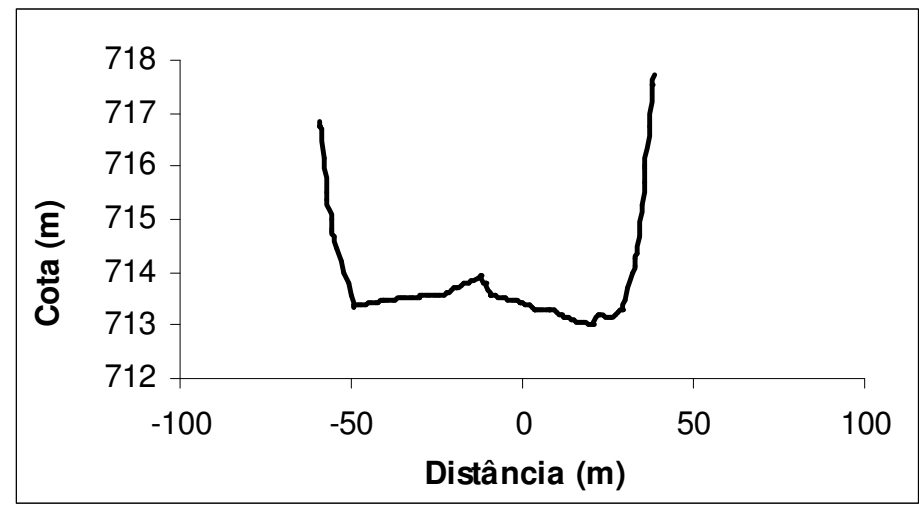

Fig. 37: Seção batimétrica PI22_900

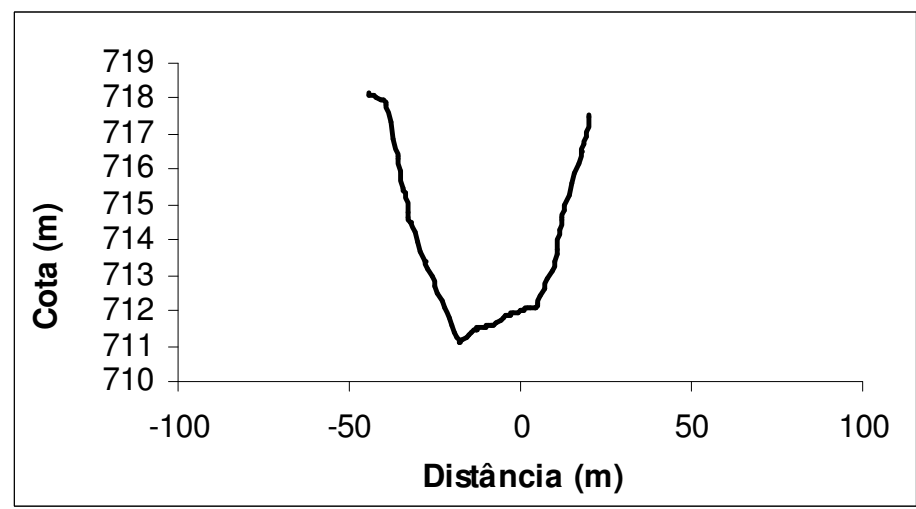

Fig. 38: Seção batimétrica PI23_100

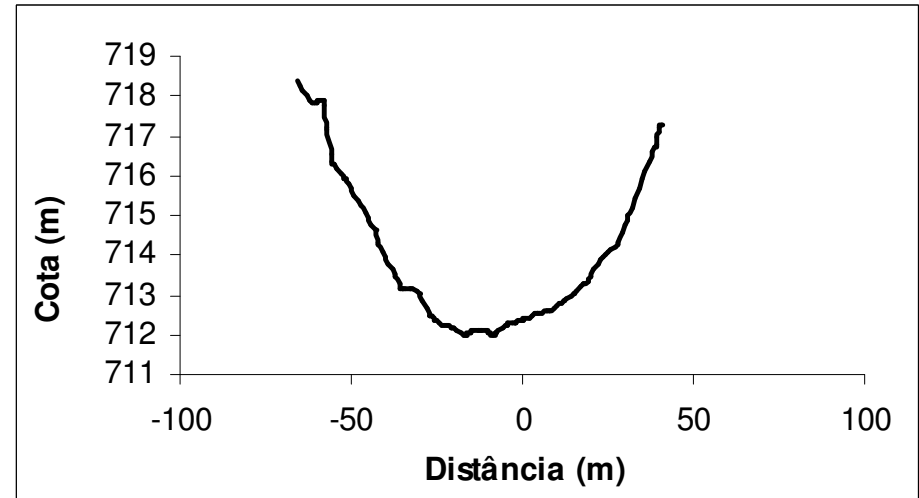

Fig. 39: Seção batimétrica PI23_300 


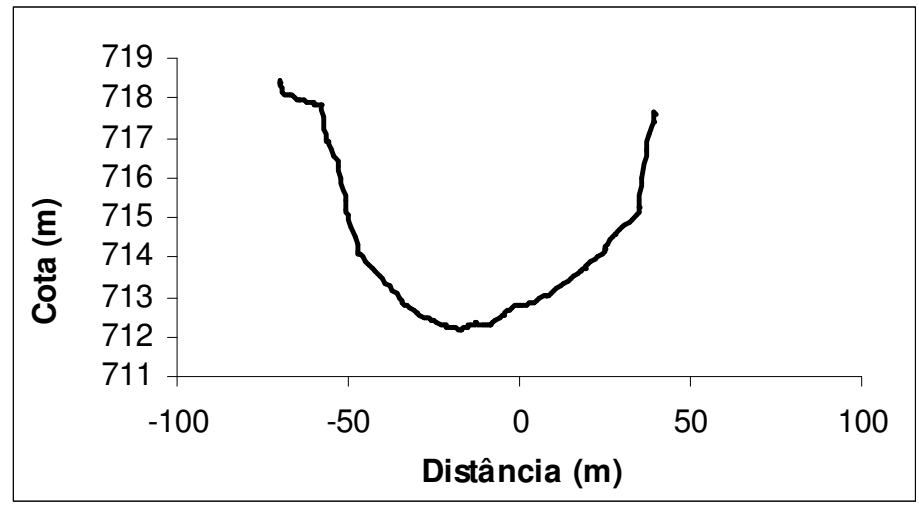

Fig. 40: Seção batimétrica PI23_500

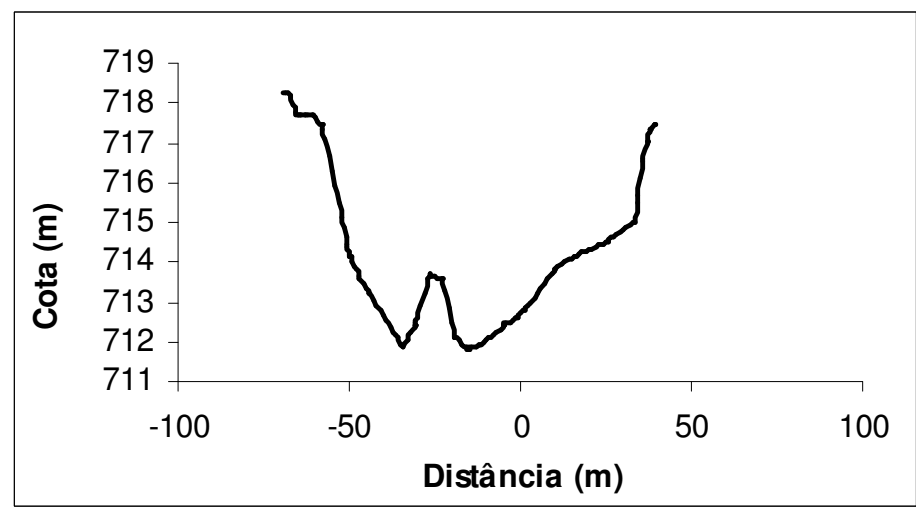

Fig. 41: Seção batimétrica PI23_700

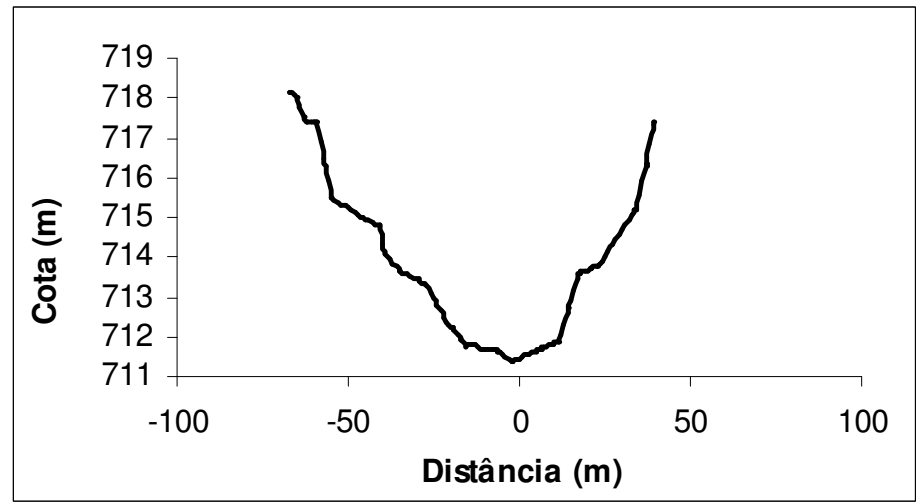

Fig. 42: Seção batimétrica PI23_900 


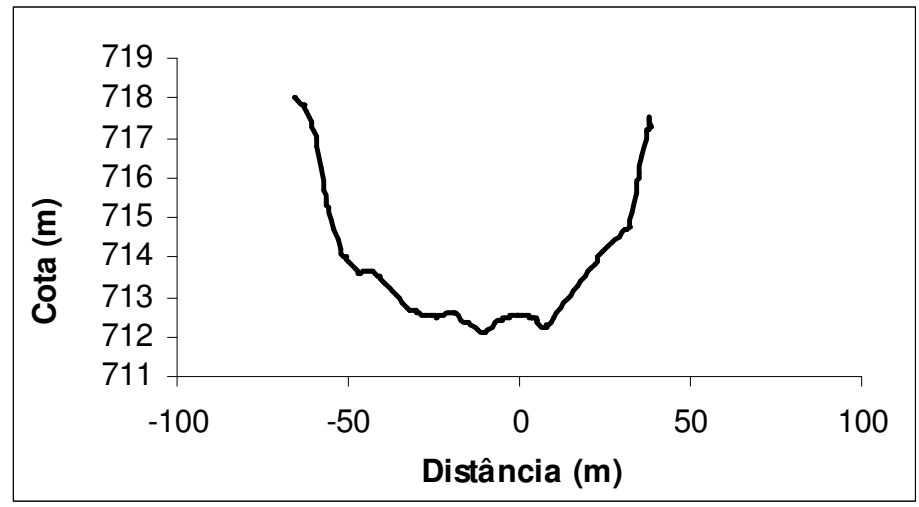

Fig. 43: Seção batimétrica PI24_100

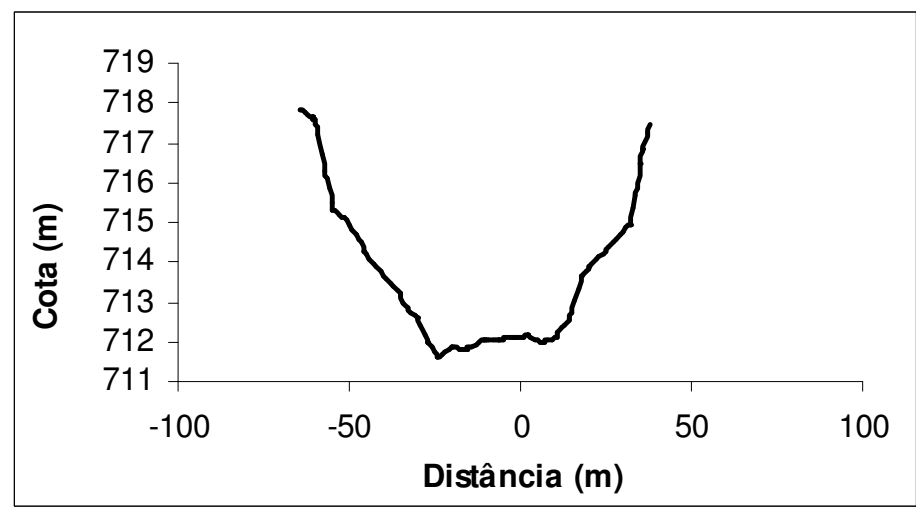

Fig. 44: Seção batimétrica PI24_300

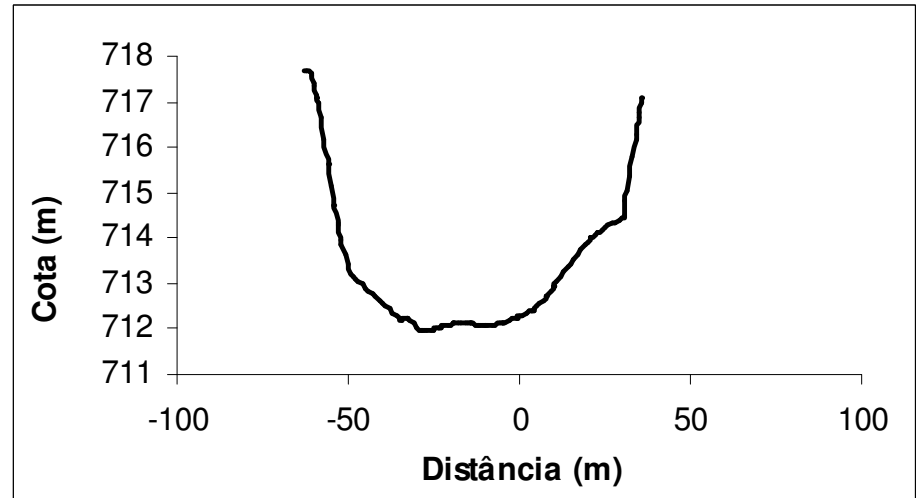

Fig. 45: Seção batimétrica PI24_500 


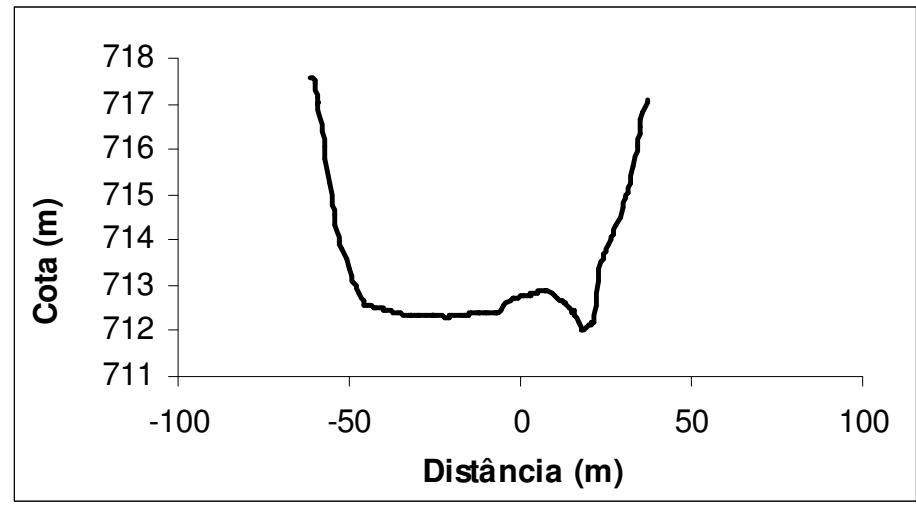

Fig. 46: Seção batimétrica PI24_700

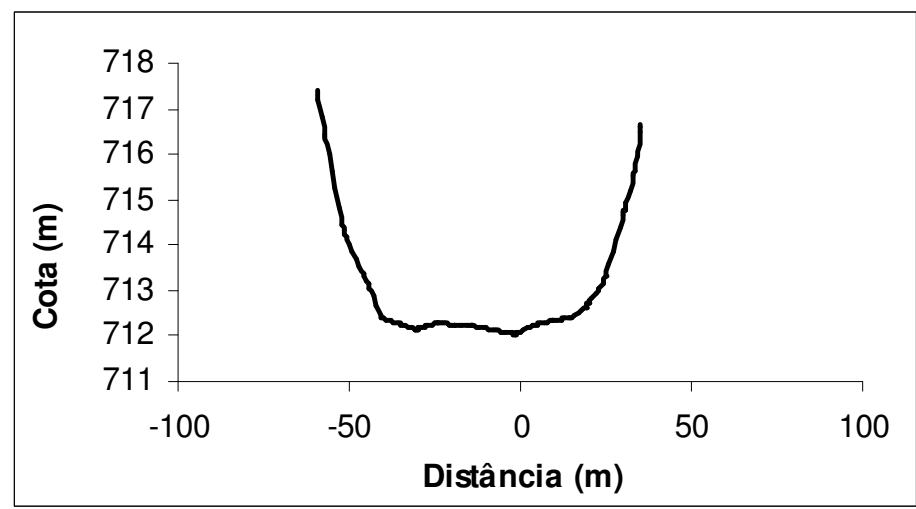

Fig. 47: Seção batimétrica PI24_900

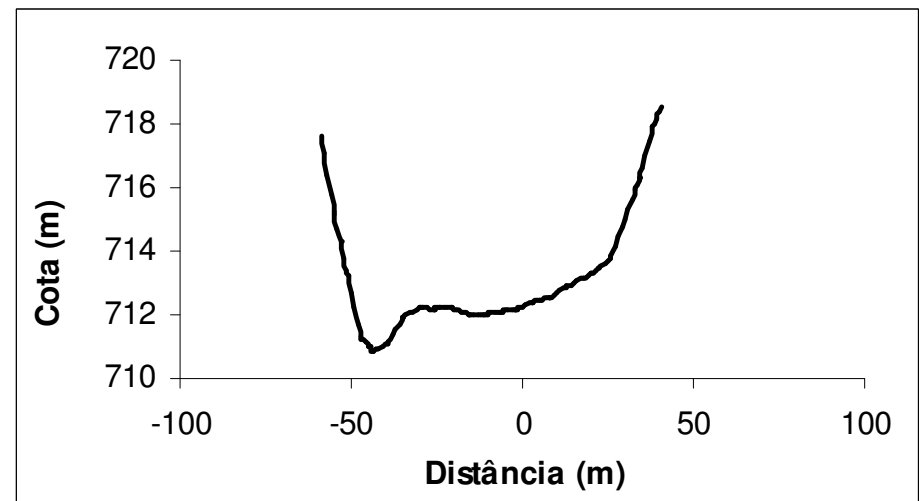

Fig. 48: Seção batimétrica PI25_100 


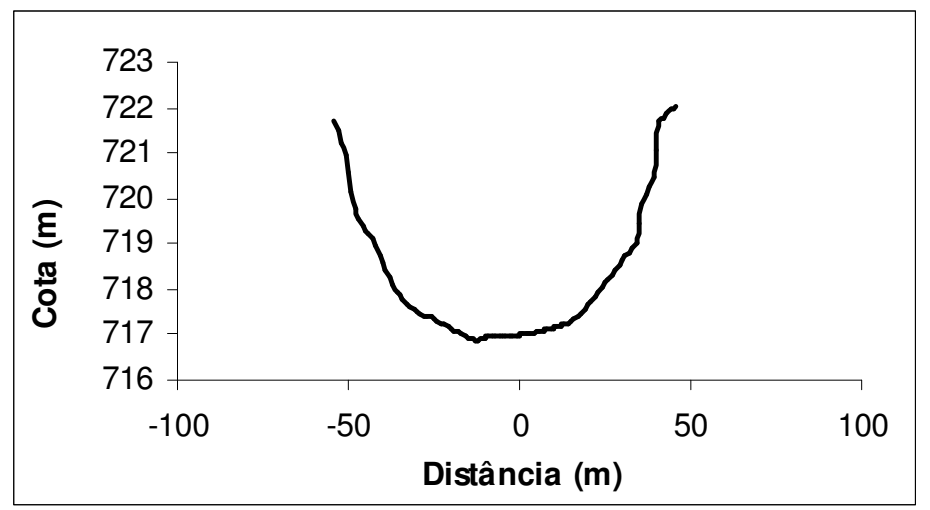

Fig. 49: Seção batimétrica PS07_300

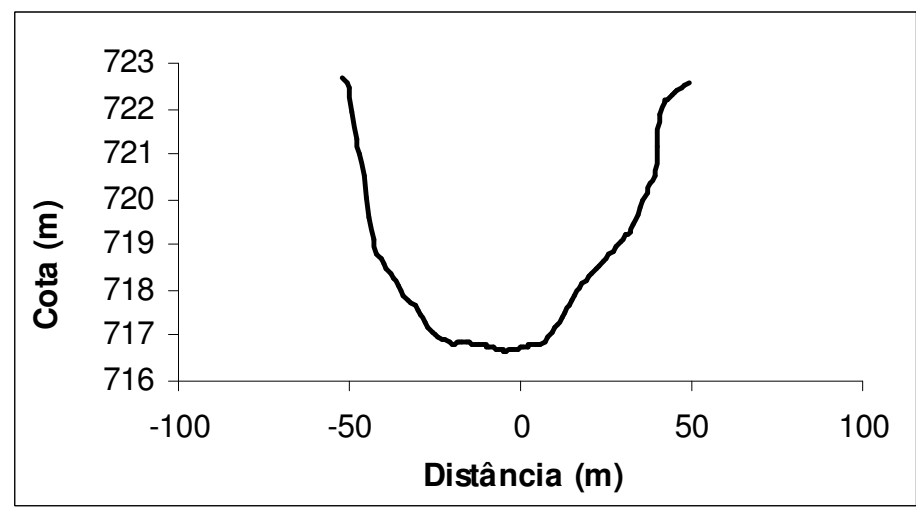

Fig. 50: Seção batimétrica PS07_500

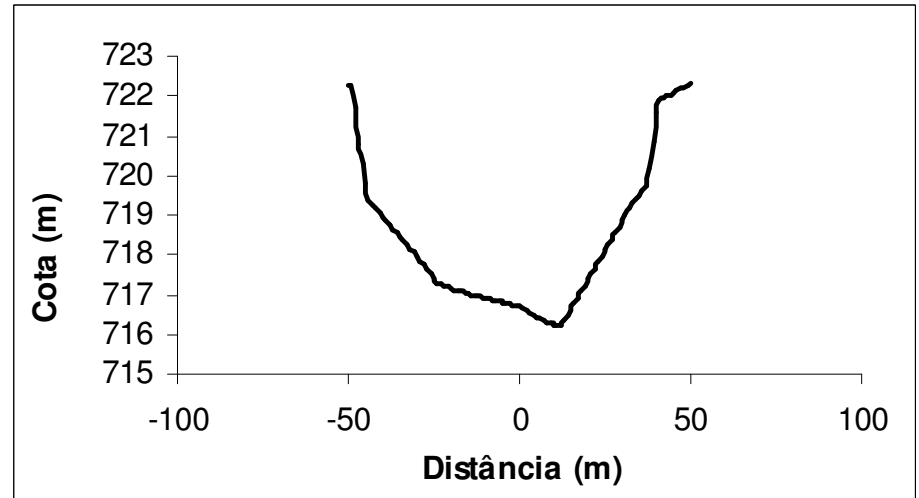

Fig. 51: Seção batimétrica PS07_700 


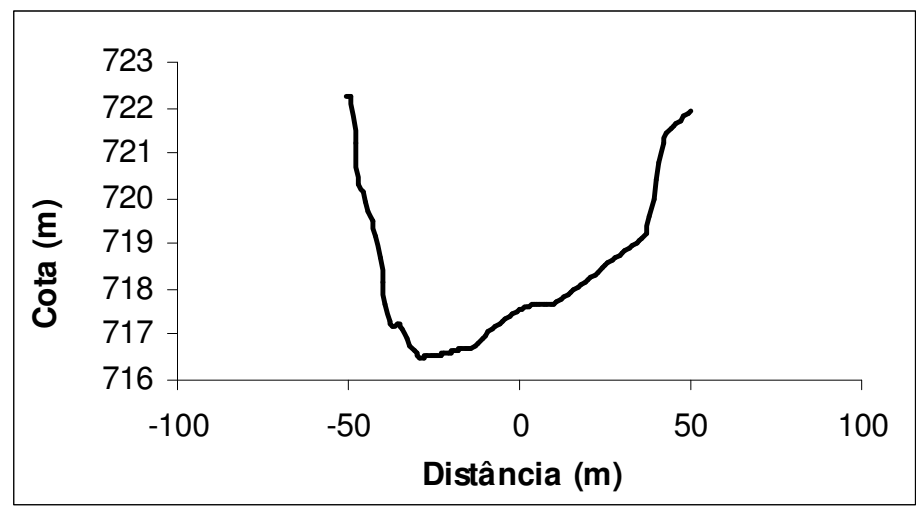

Fig. 52: Seção batimétrica PS07_900

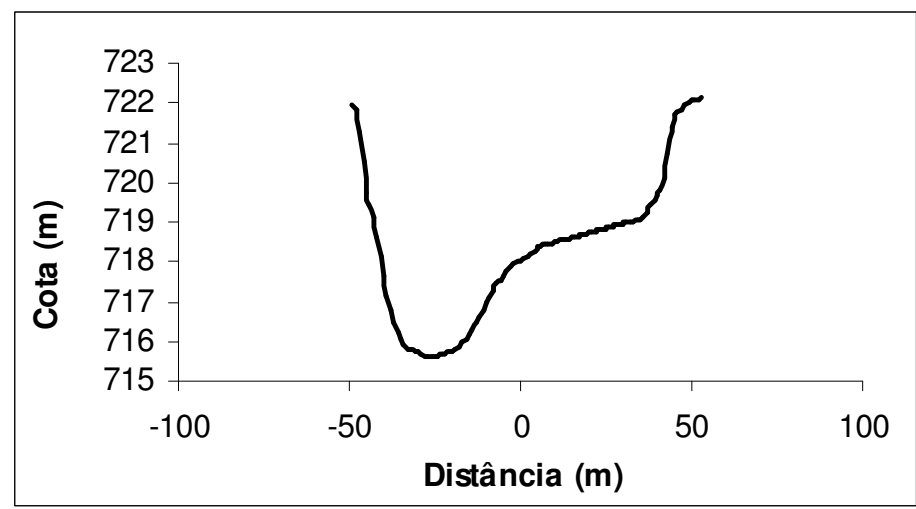

Fig. 53: Seção batimétrica PS08_100

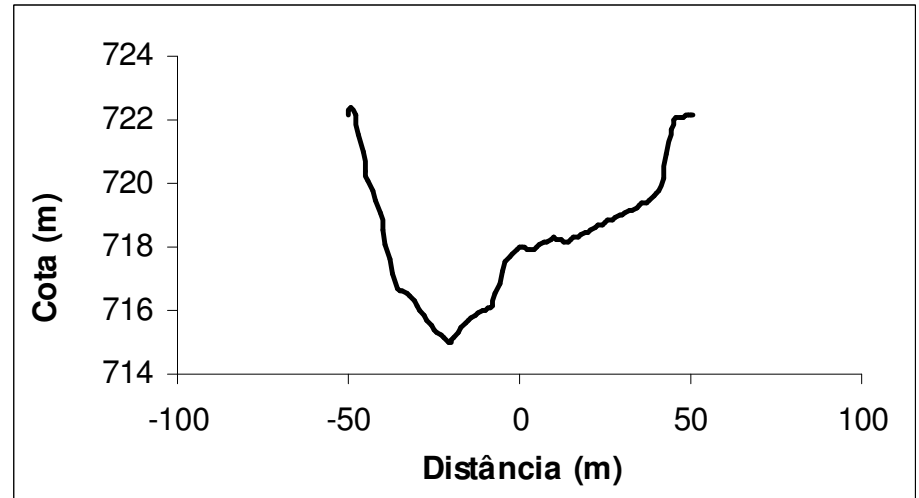

Fig. 54: Seção batimétrica PS08_300 


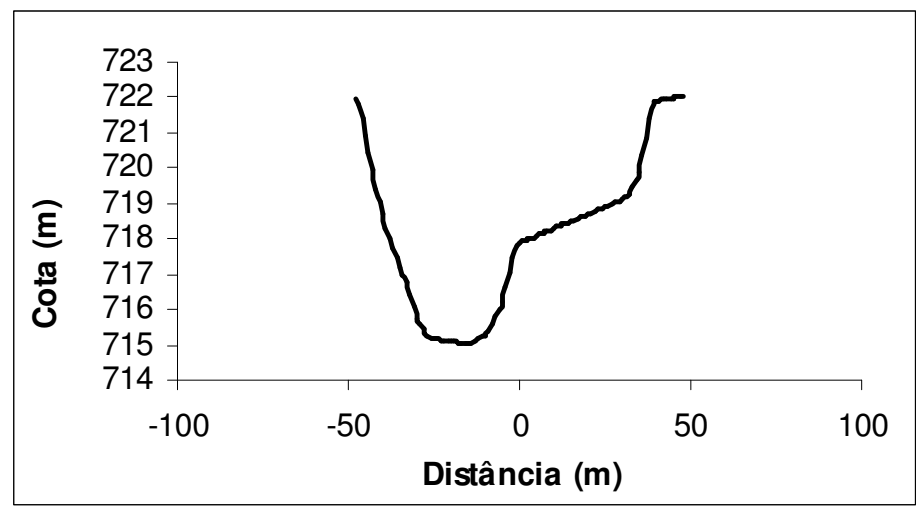

Fig. 55: Seção batimétrica PS08_500

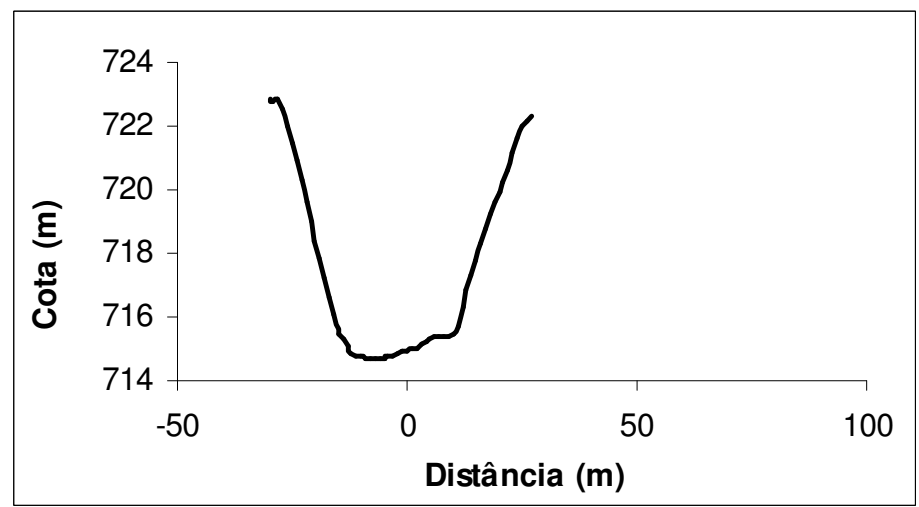

Fig. 56: Seção batimétrica PS08_700

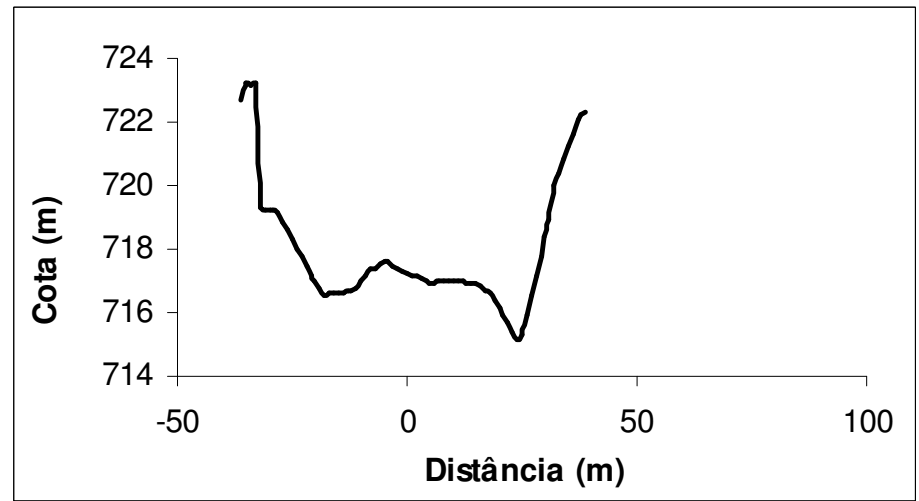

Fig. 57: Seção batimétrica PS08_900 


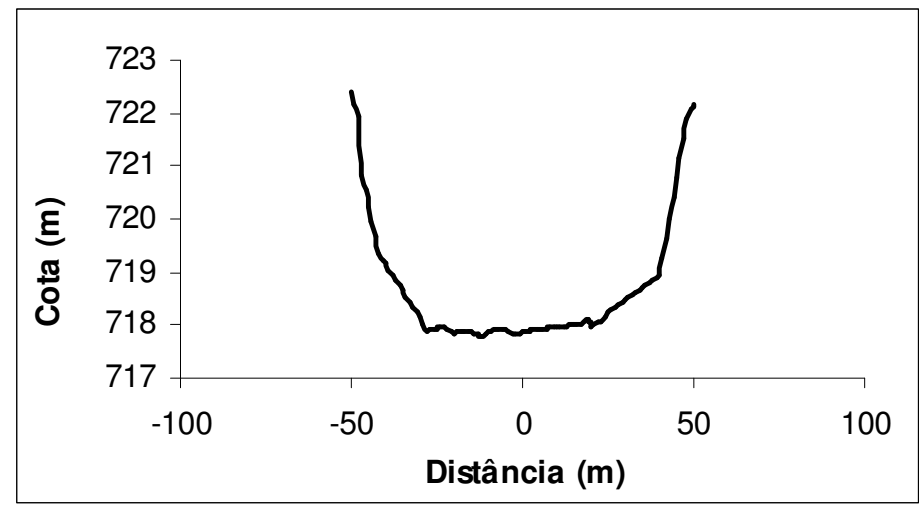

Fig. 58: Seção batimétrica PS09_100

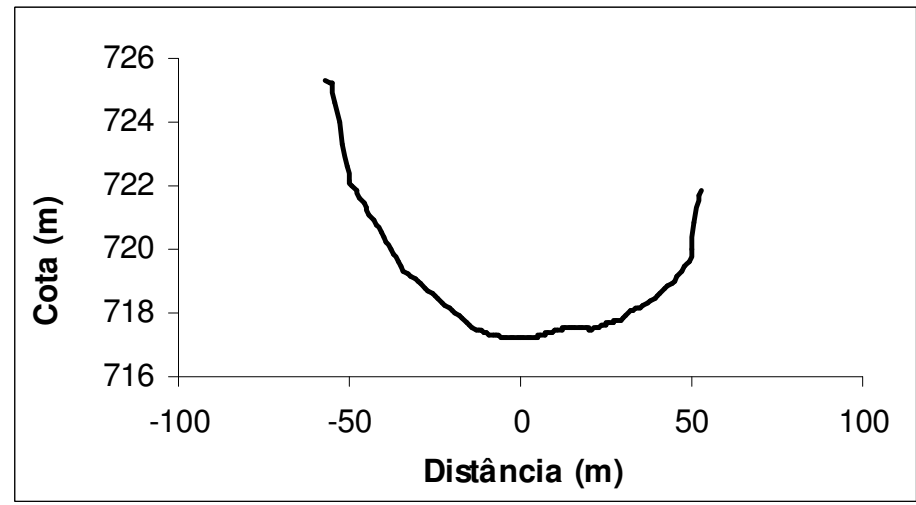

Fig. 59: Seção batimétrica PS09_300

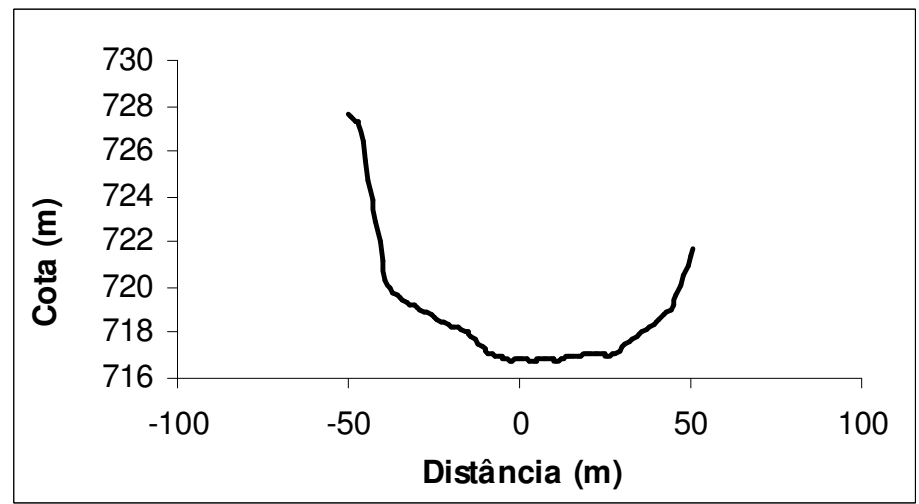

Fig. 60: Seção batimétrica PS09_500 


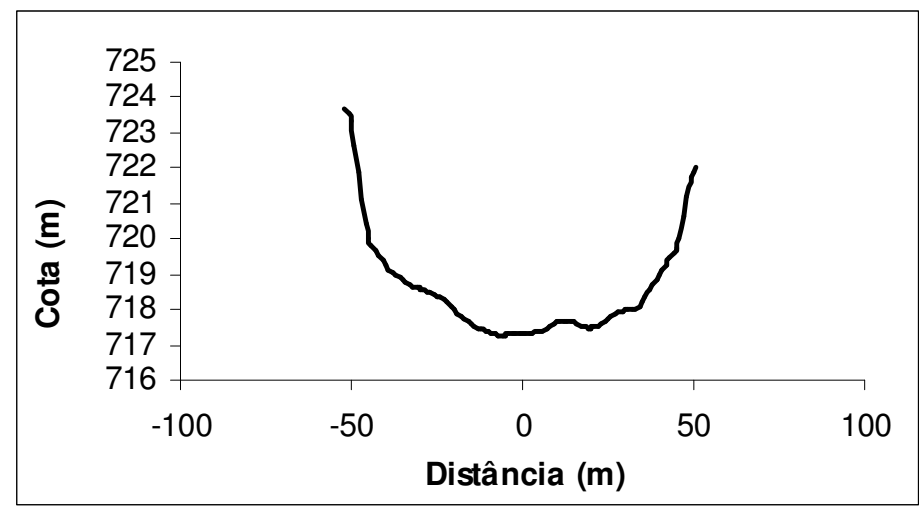

Fig. 61: Seção batimétrica PS09_700

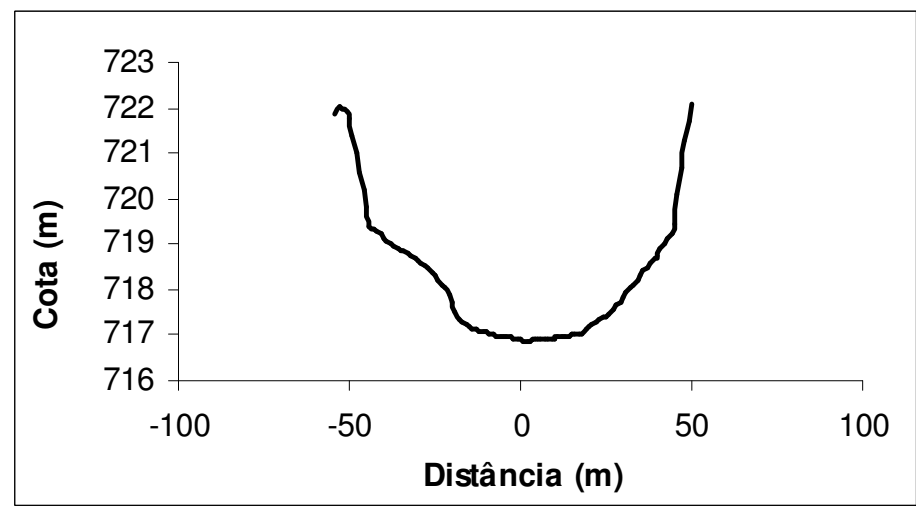

Fig. 62: Seção batimétrica PS09_900

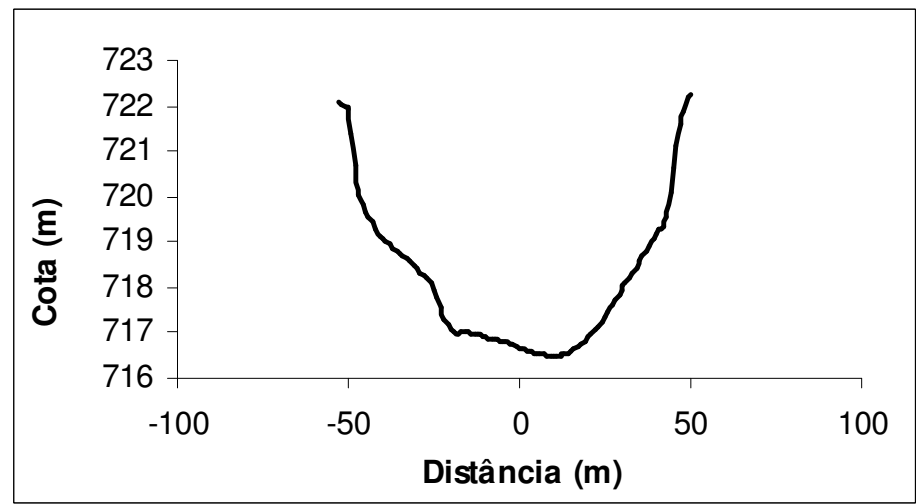

Fig. 63: Seção batimétrica PS10_100 


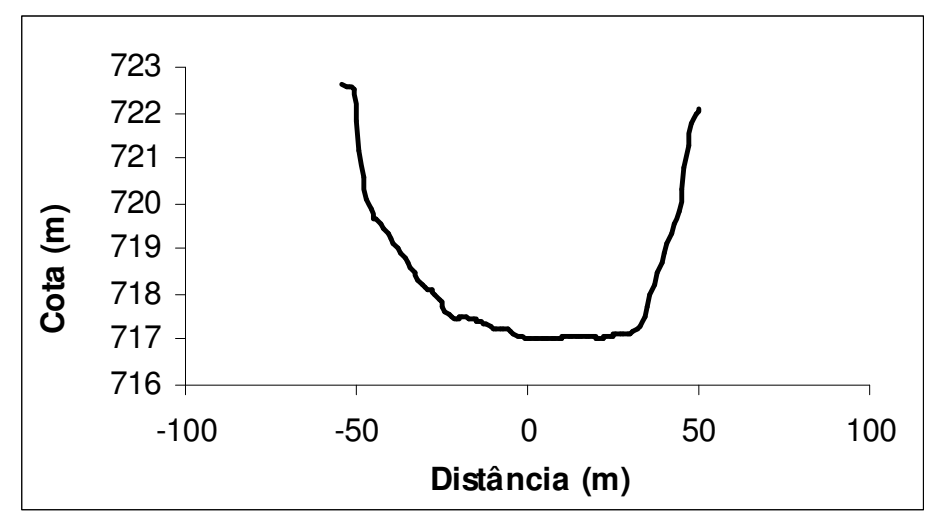

Fig. 64: Seção batimétrica PS10_300

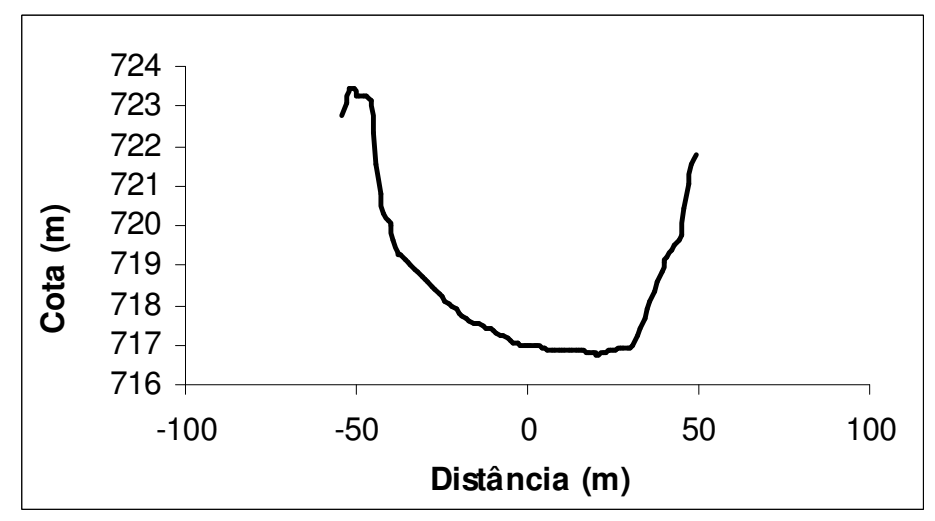

Fig. 65: seção batimétrica PS10_500

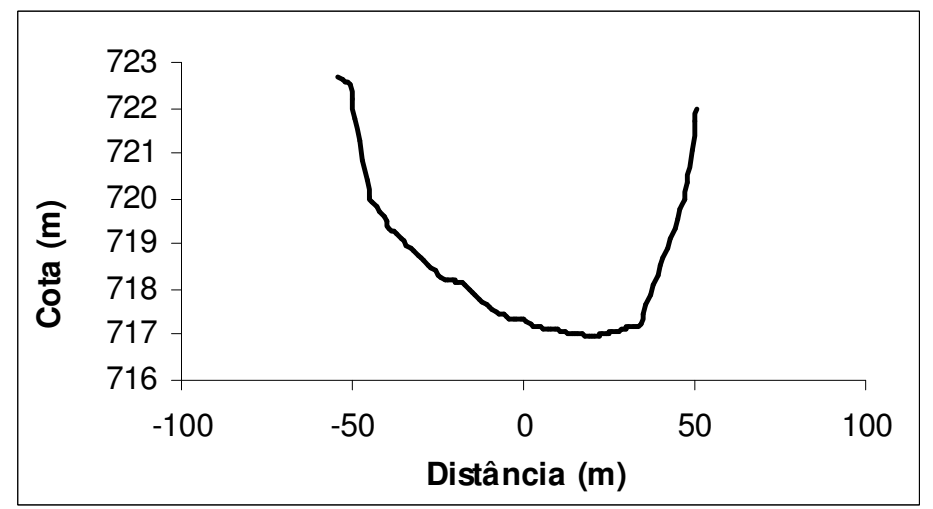

Fig. 66: Seção batimétrica PS10_700 


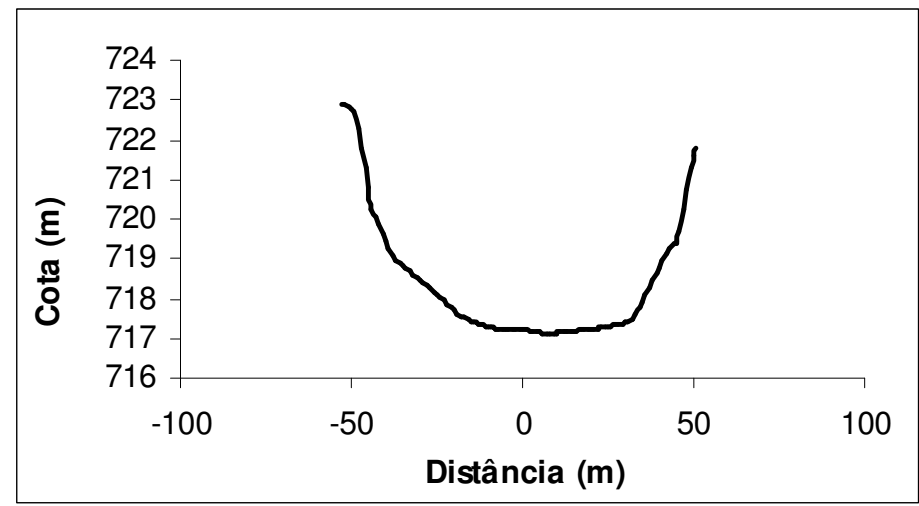

Fig. 67: Seção batimétrica PS10_900

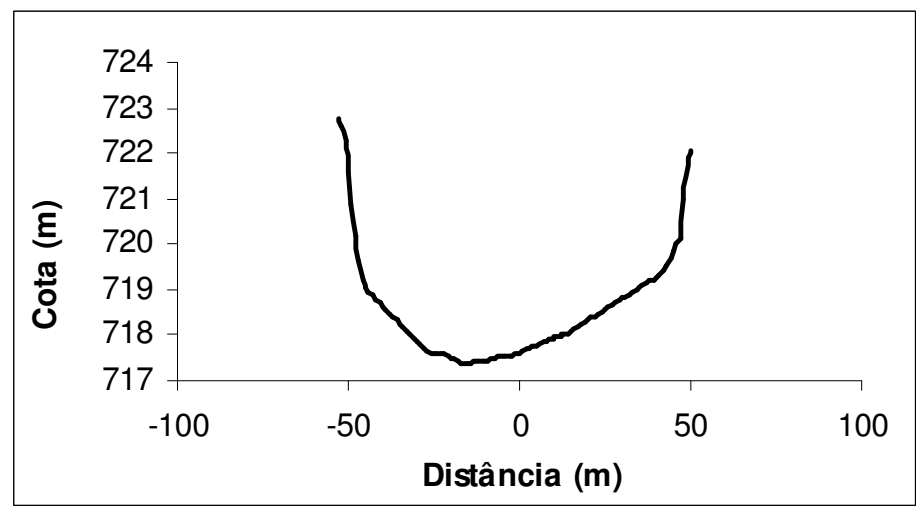

Fig. 68: Seção batimétrica PS11_100

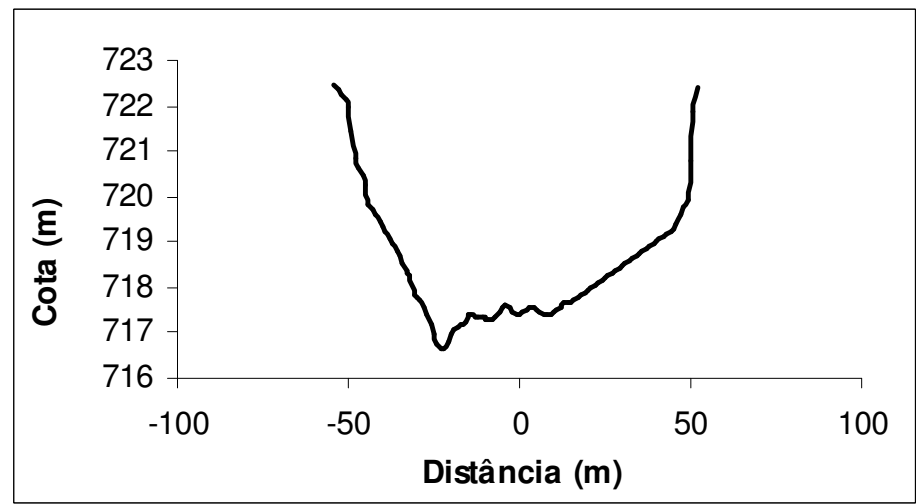

Fig. 69: seção batimétrica PS11_300 


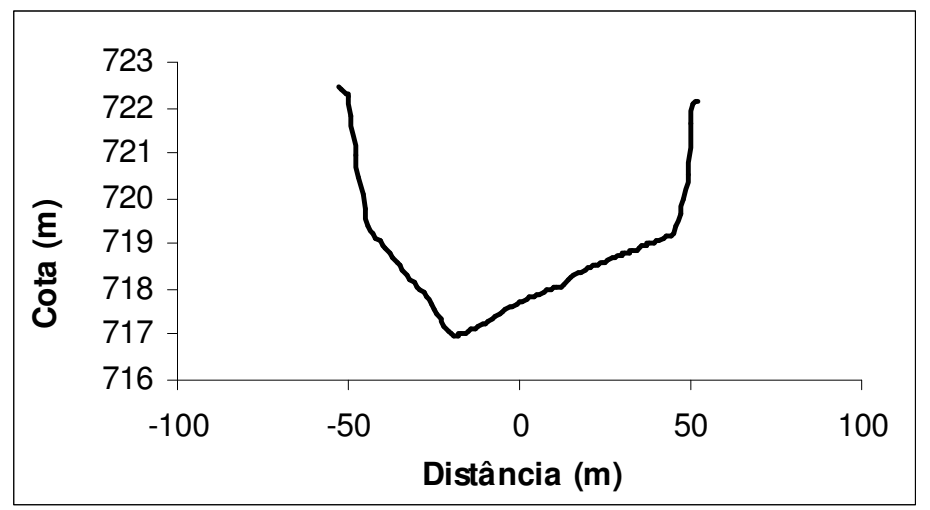

Fig. 70: Seção batimétrica PS11_500

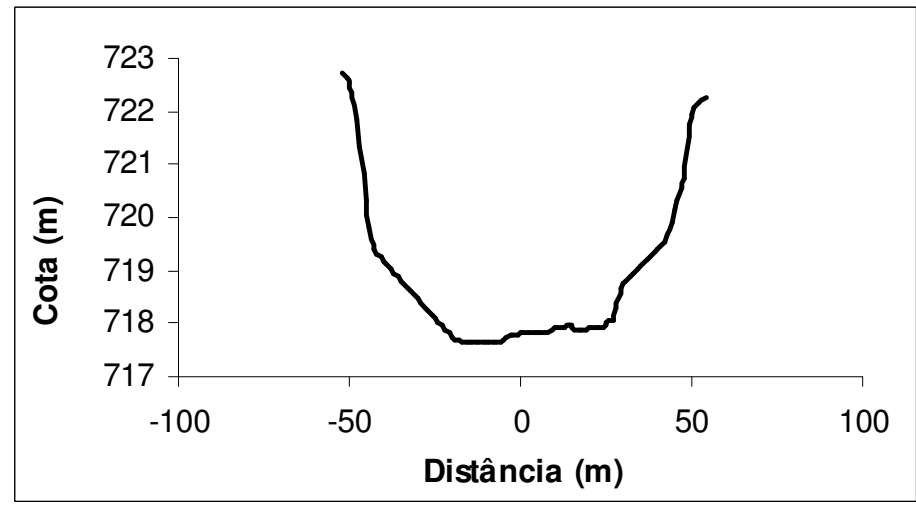

Fig. 71: seção batimétrica PS11_700

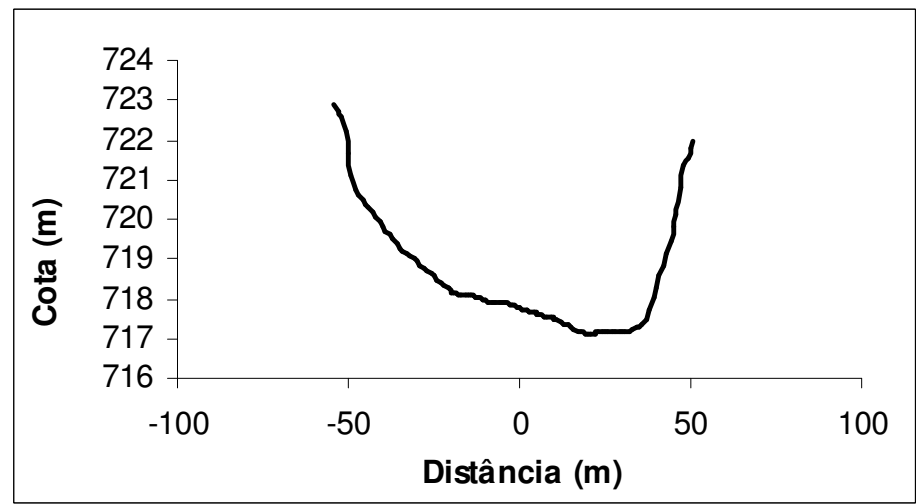

Fig. 72: Seção batimétrica PS11_900 


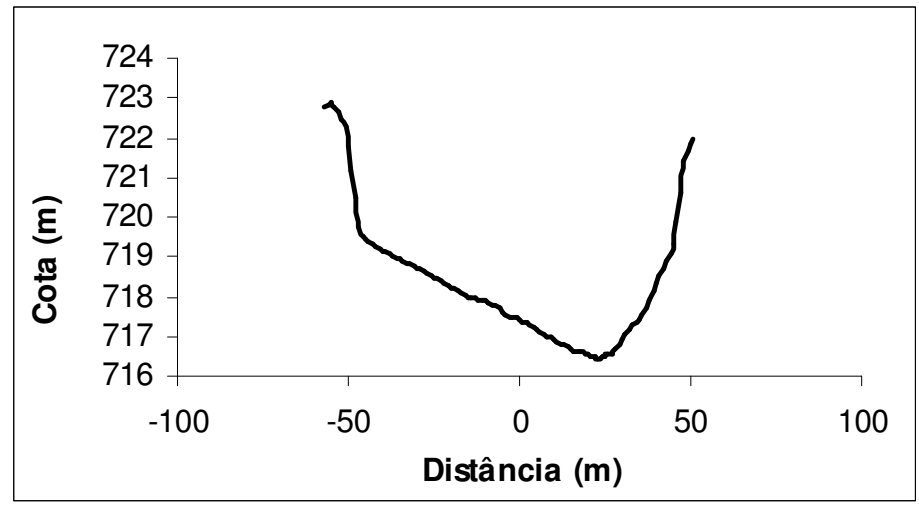

Fig. 73: Seção batimétrica PS12_100

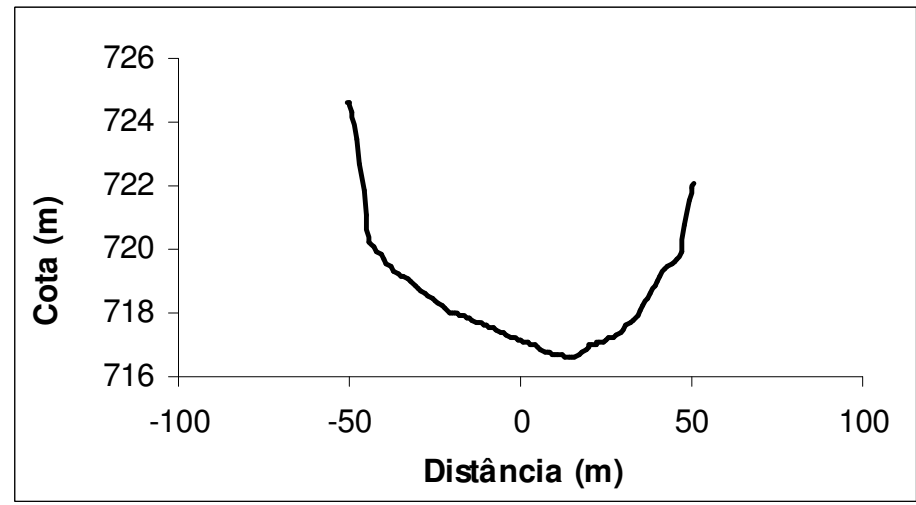

Fig. 74: Seção batimétrica PS12_300

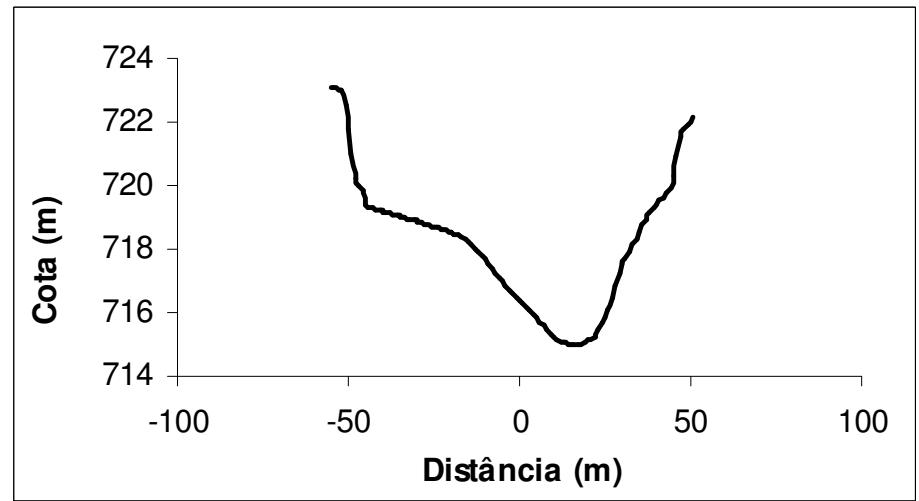

Fig. 75: Seção batimétrica PS12_500 


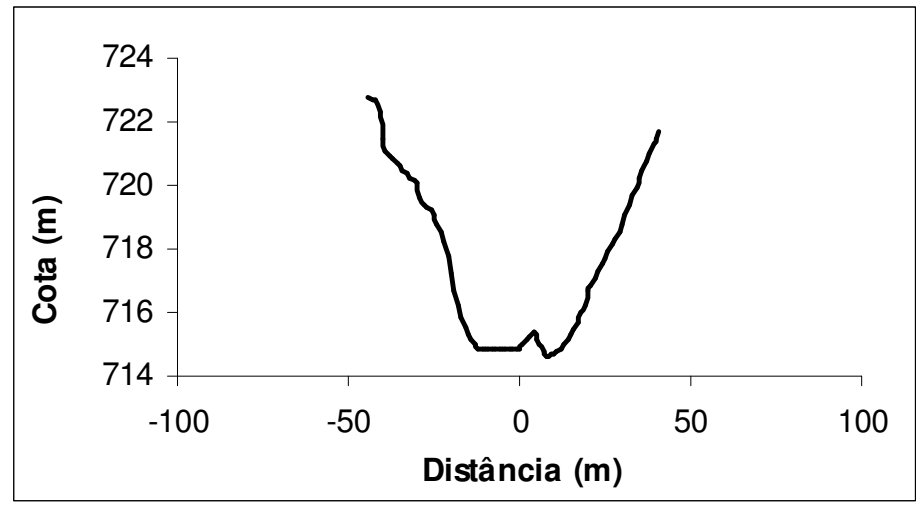

Fig. 76: Seção batimétrica PS12_700

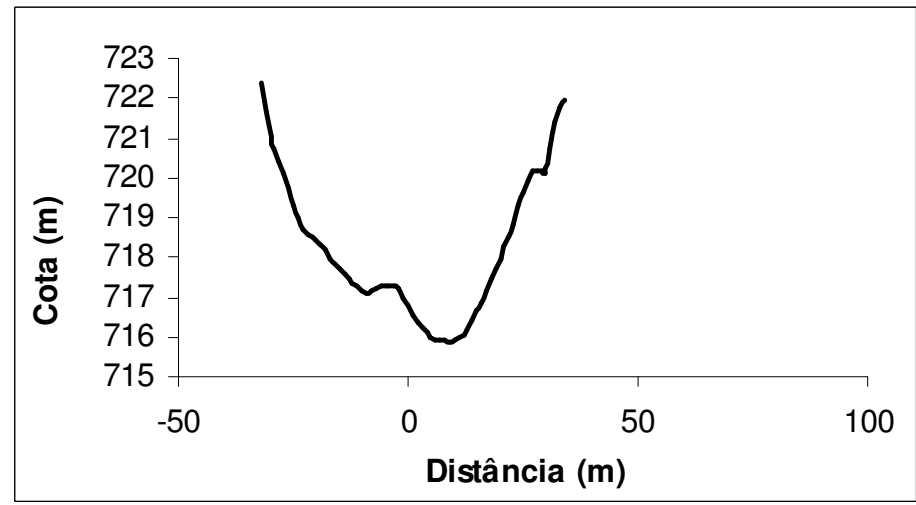

Fig. 77: Seção batimétrica PS12_900

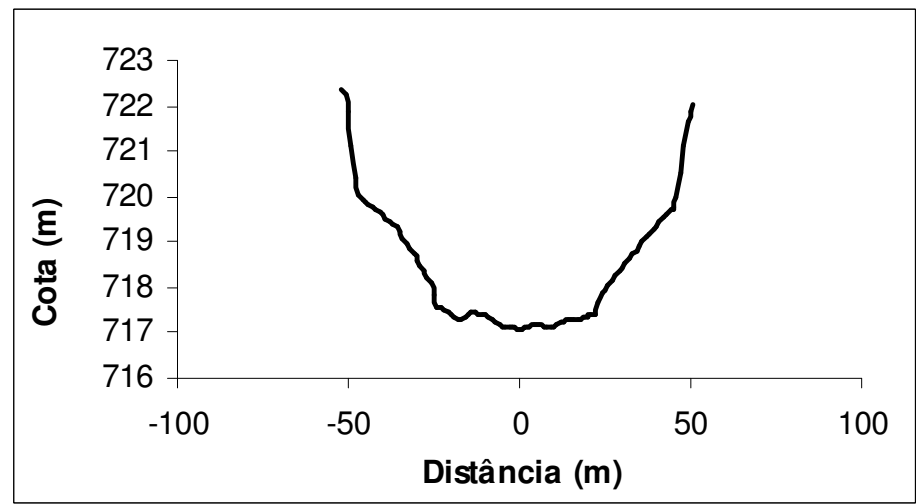

Fig. 78: Seção batimétrica PS13_100 


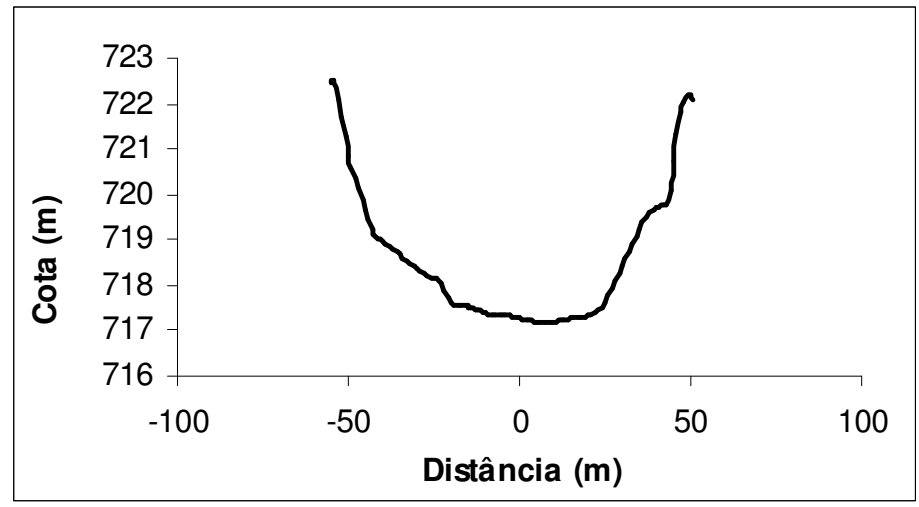

Fig. 79: Seção batimétrica PS13_300

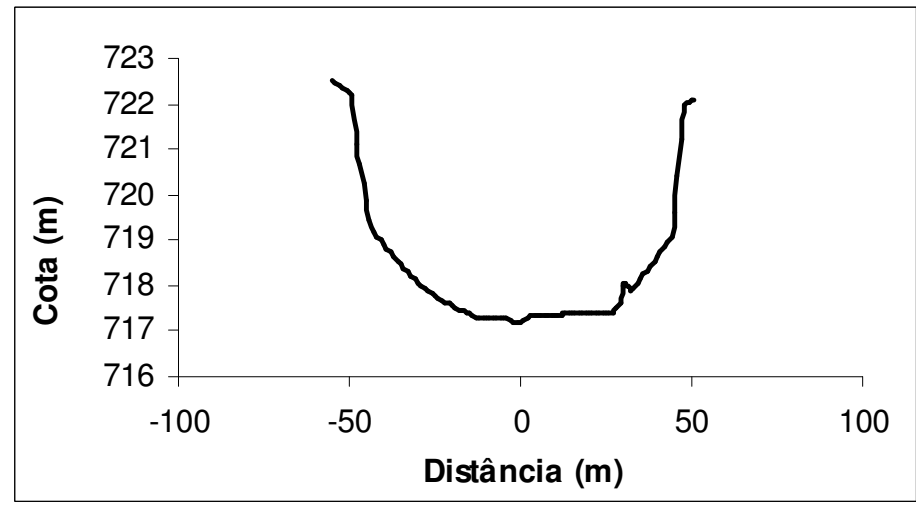

Fig. 80: Seção batimétrica PS13_500

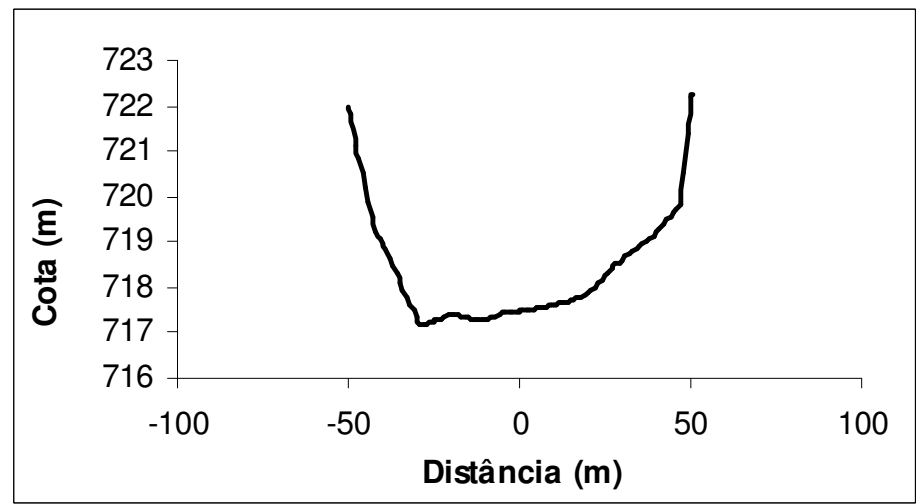

Fig. 81: Seção batimétrica PS13_700 


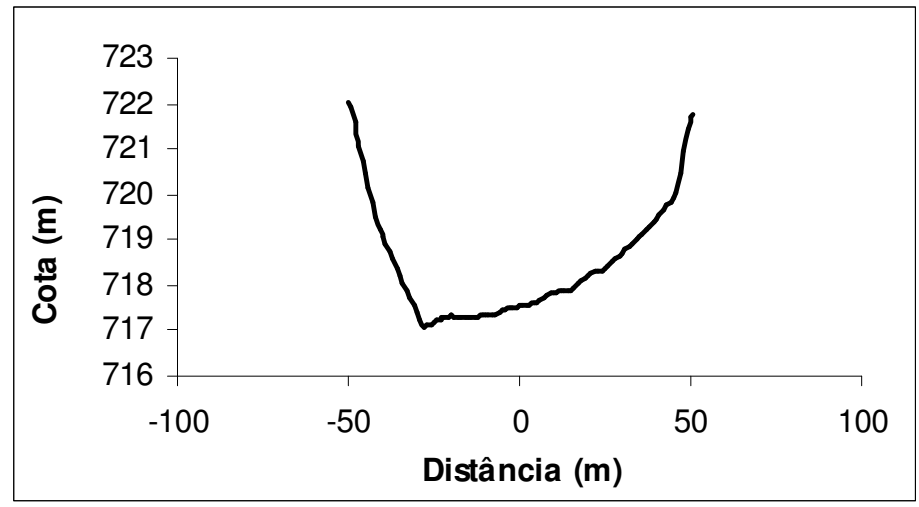

Fig. 82: Seção batimétrica PS13_900

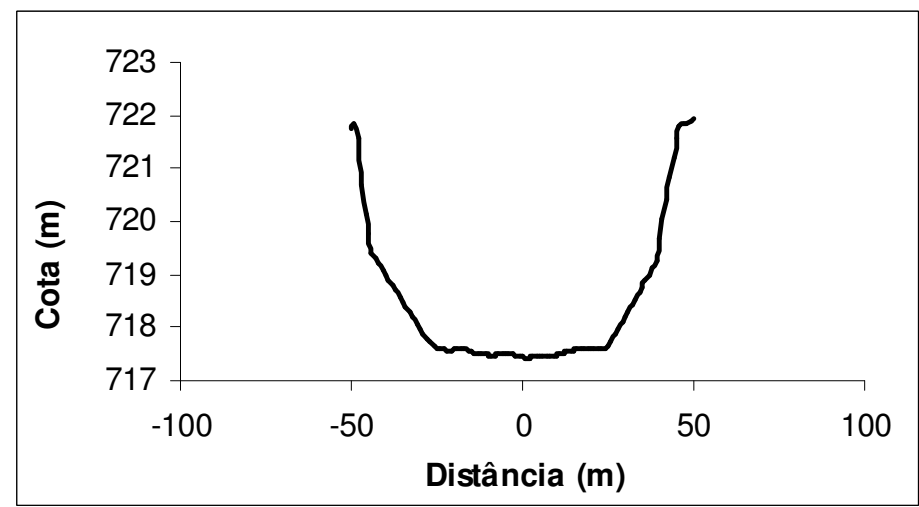

Fig. 83: Seção batimétrica PS14_100

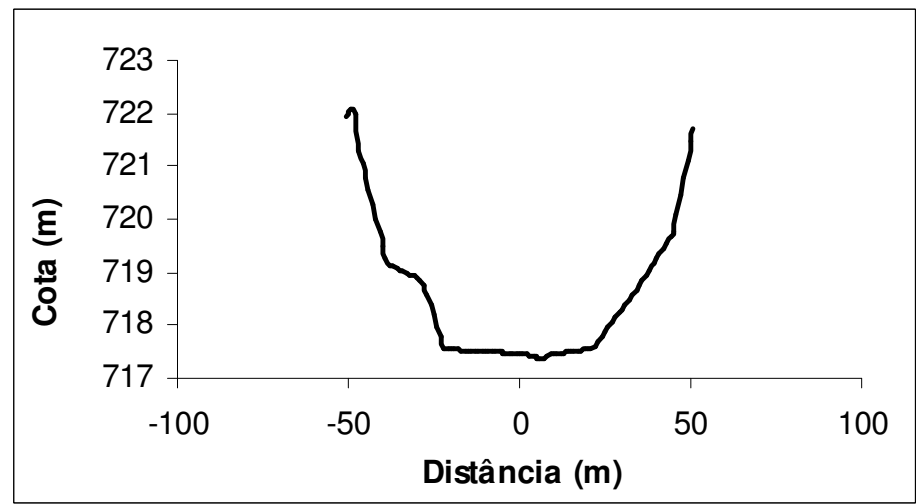

Fig. 84: Seção batimétrica PS14_300 


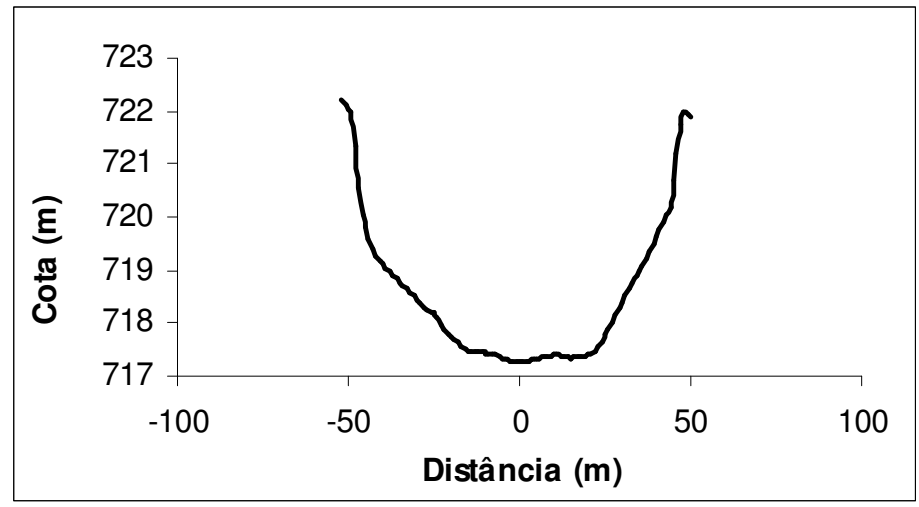

Fig. 85: Seção batimétrica PS14_500

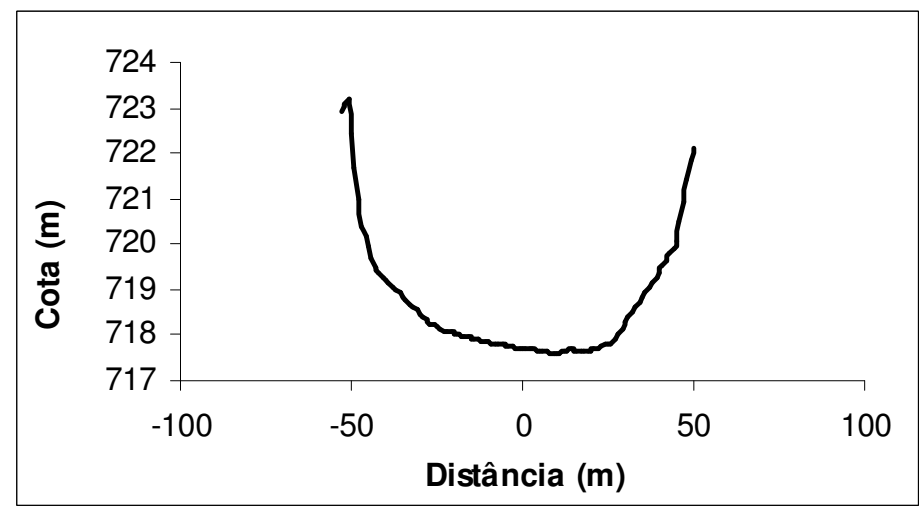

Fig. 86: Seção batimétrica PS14_700

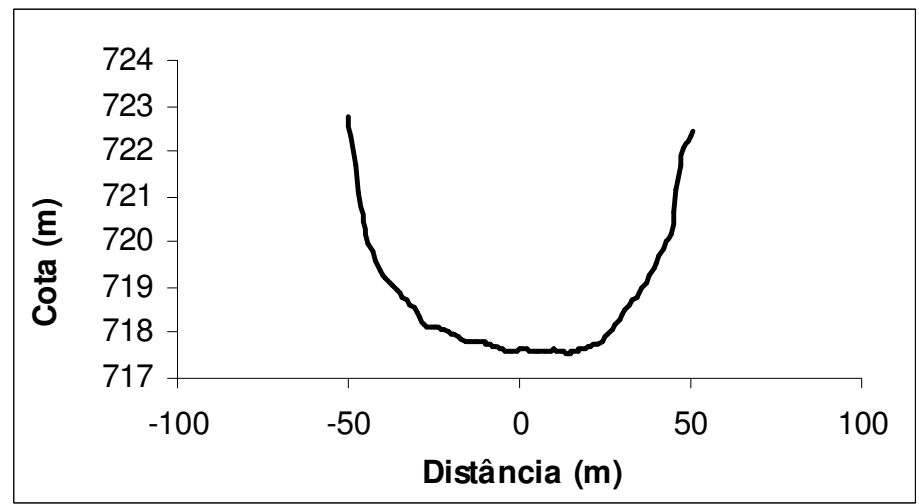

Fig. 87: Seção batimétrica PS14_900 


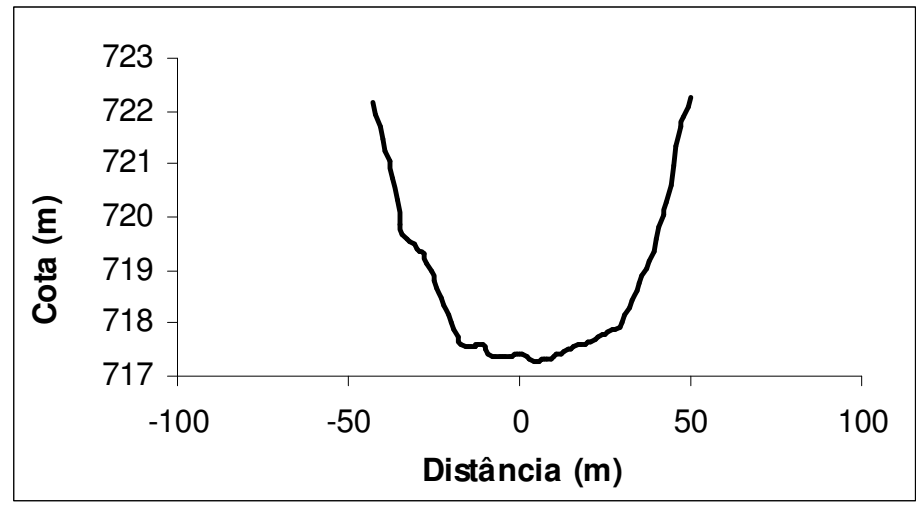

Fig. 88: Seção batimétrica PS15_100

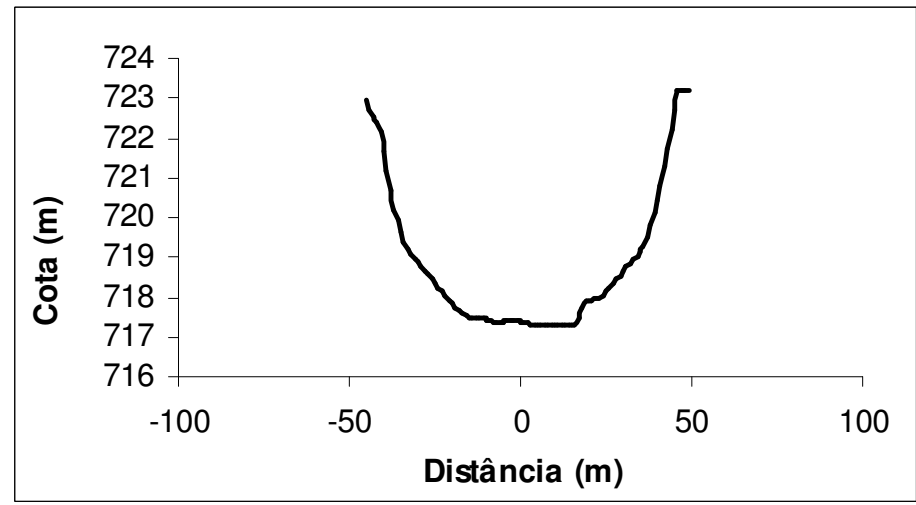

Fig. 89: Seção batimétrica PS15_300

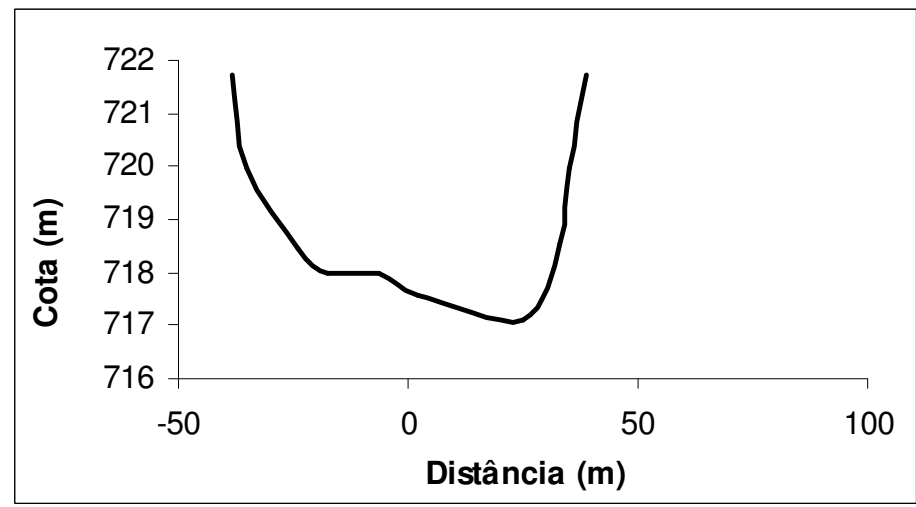

Fig. 90: Seção batimétrica GU00_250 


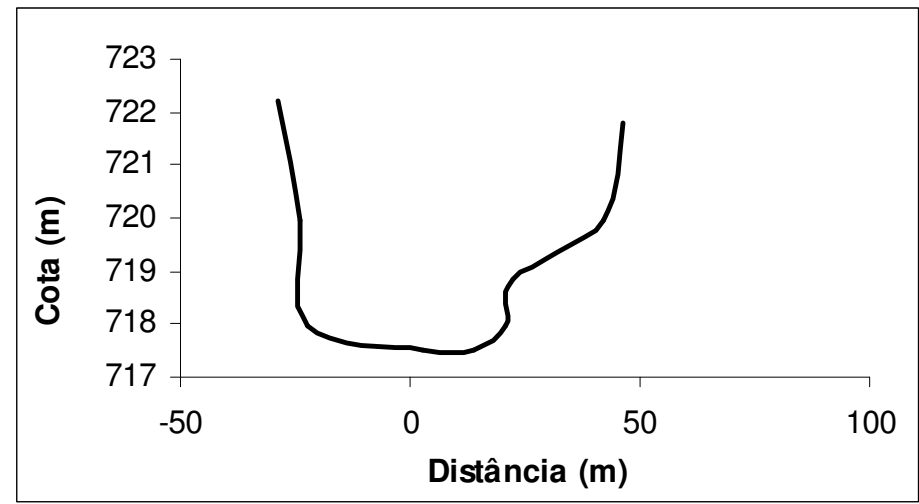

Fig. 91: Seção batimétrica GU00_300

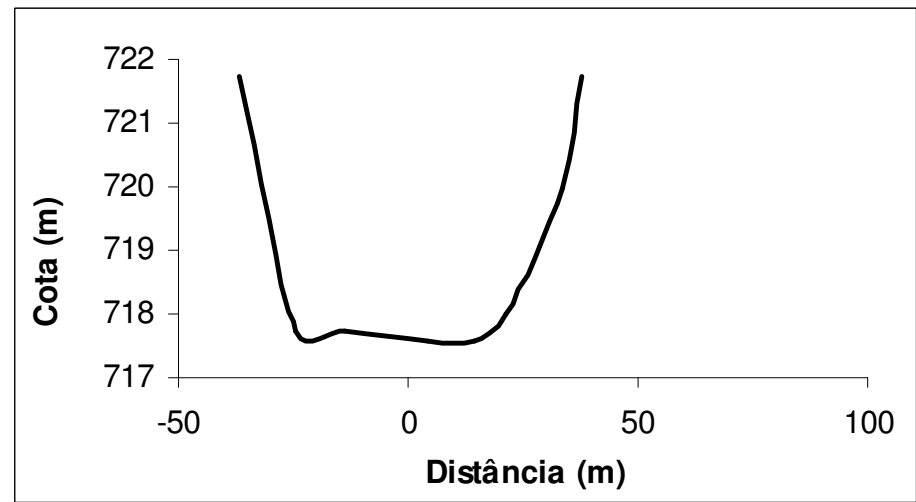

Fig. 92: Seção batimétrica GU00_350

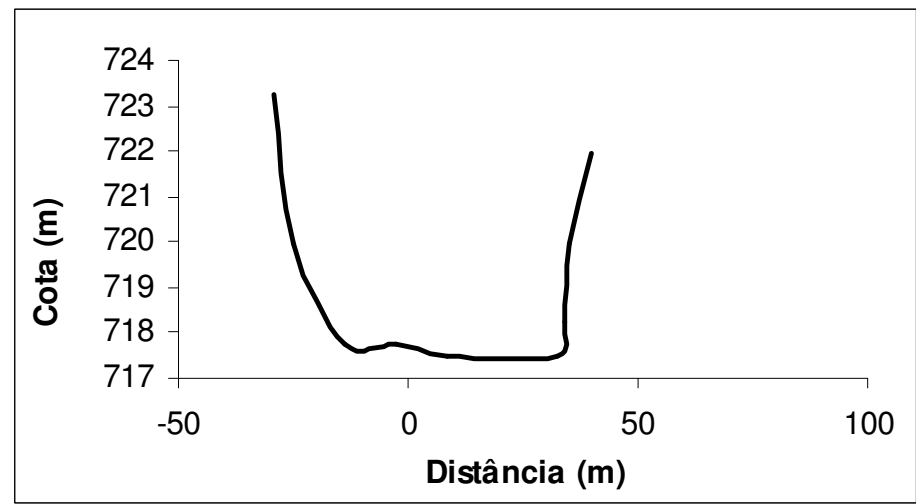

Fig. 93: Seção batimétrica GU00_400 


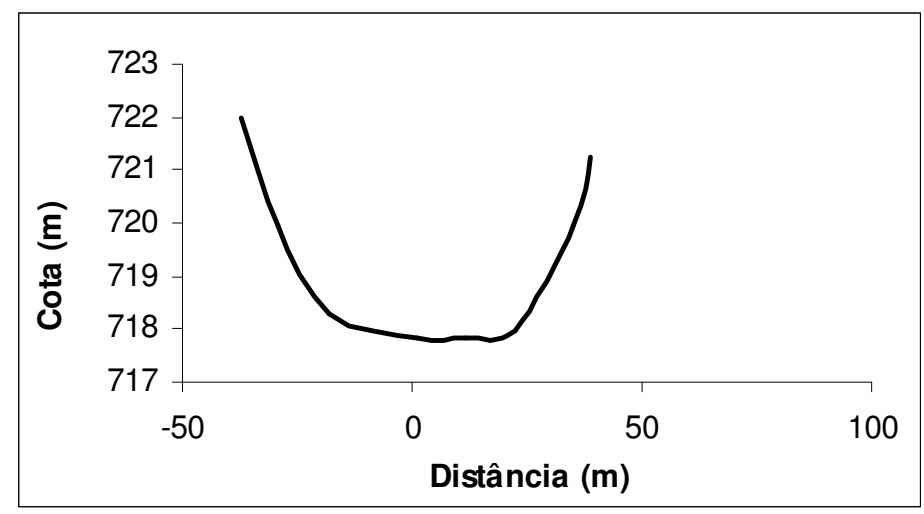

Fig. 94: Seção batimétrica GU00_450

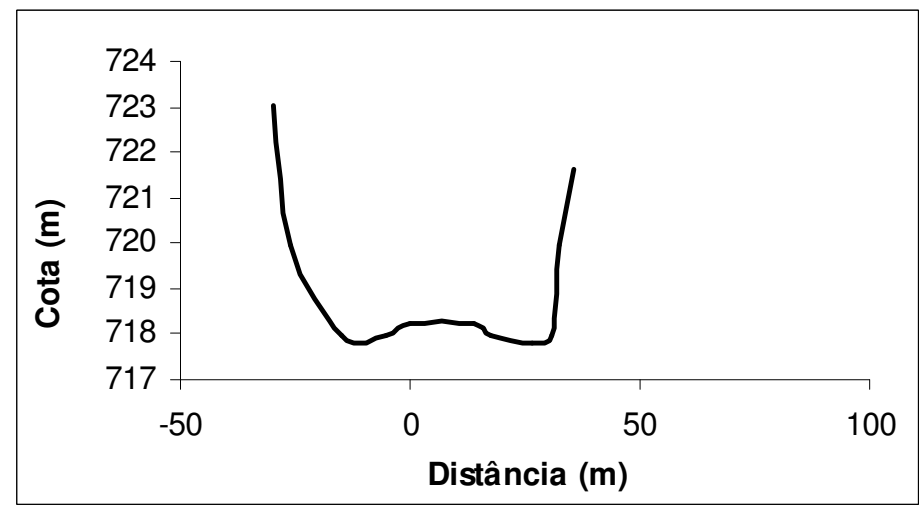

Fig. 95: Seção batimétrica GU00_500

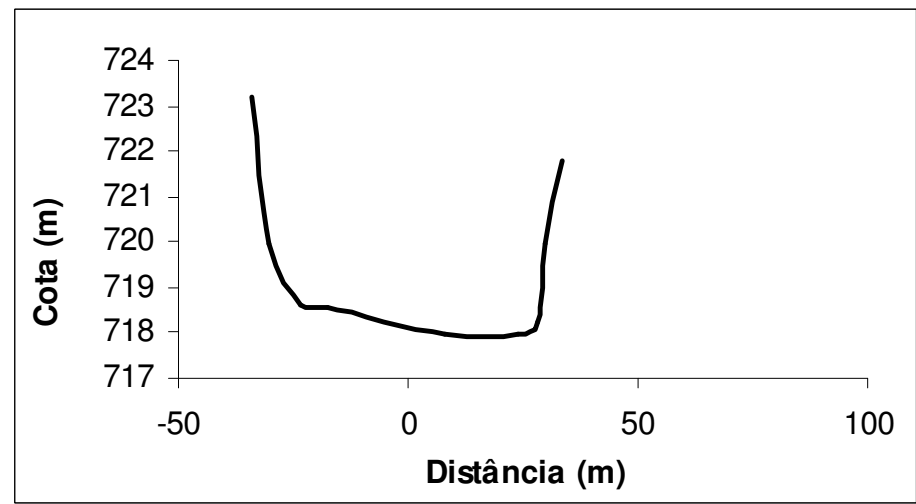

Fig. 96: Seção batimétrica GU00_550 


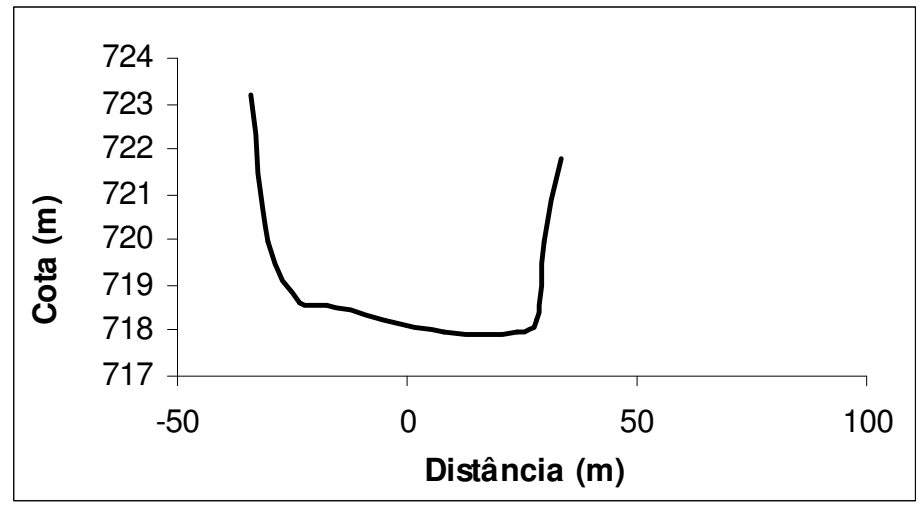

Fig. 97: Seção batimétrica GU00_600

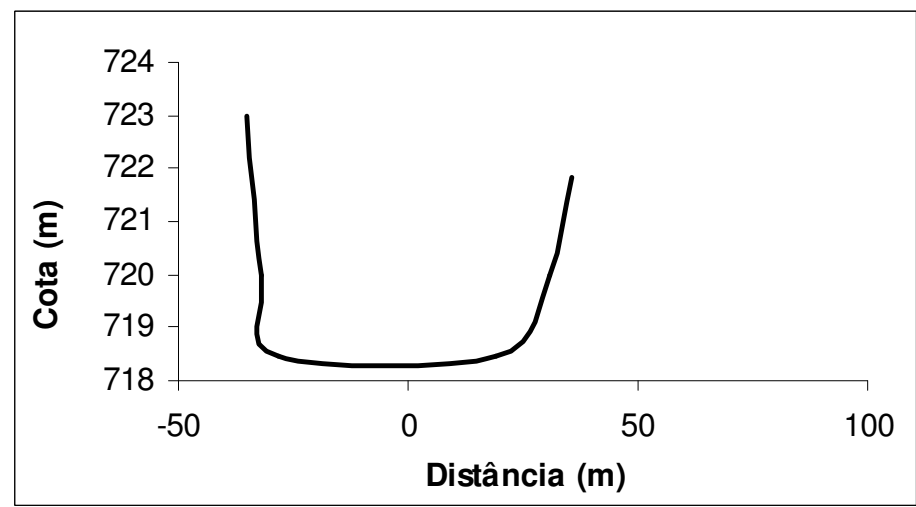

Fig. 98: Seção batimétrica GU00_650

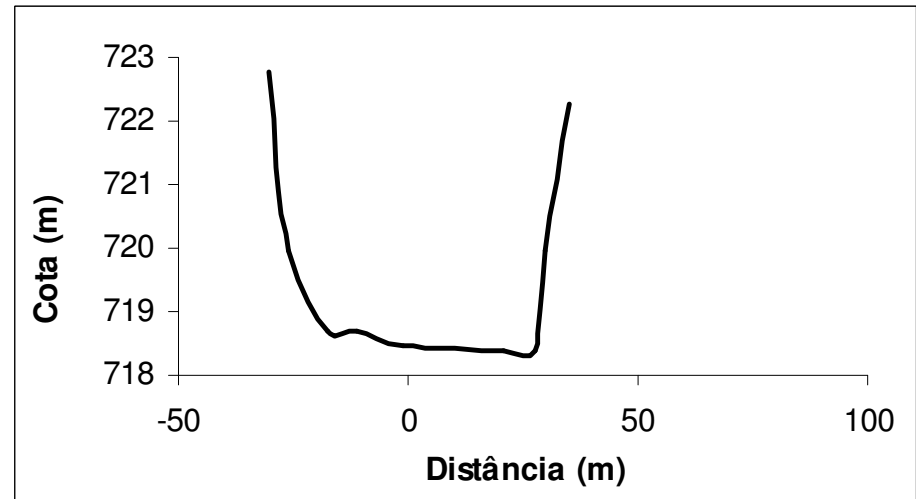

Fig. 99: Seção batimétrica GU00_700 


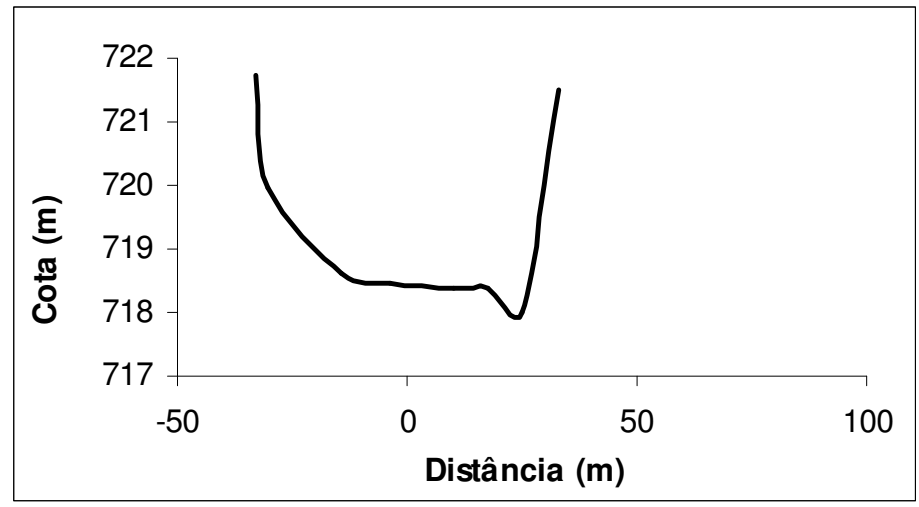

Fig. 100: Seção batimétrica GU00_750

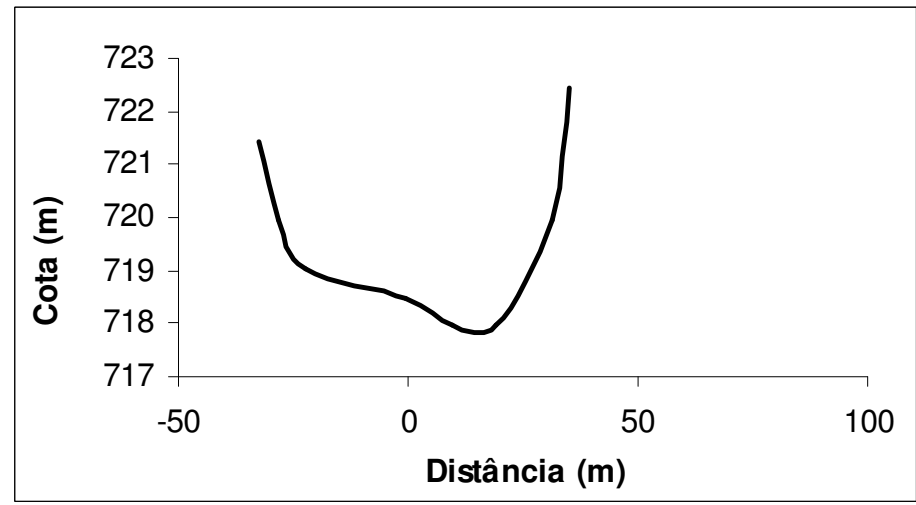

Fig. 101: Seção batimétrica GU00_800

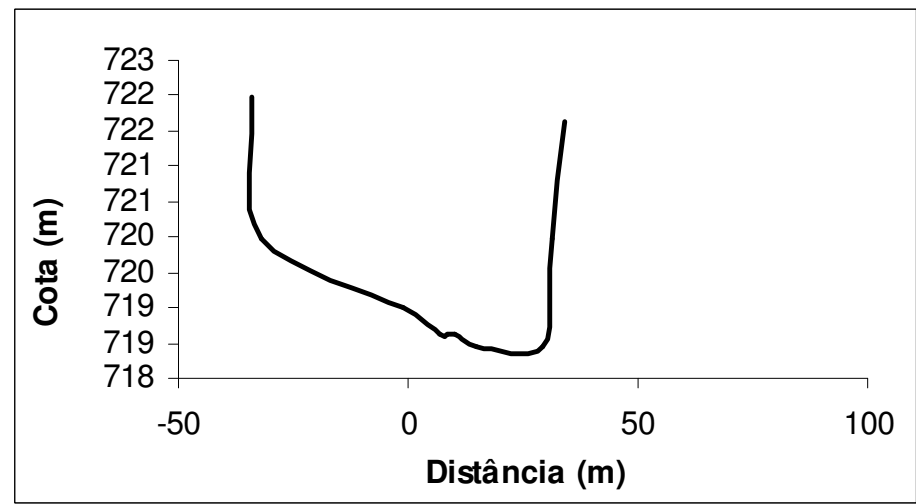

Fig. 102: Seção batimétrica GU00_850 


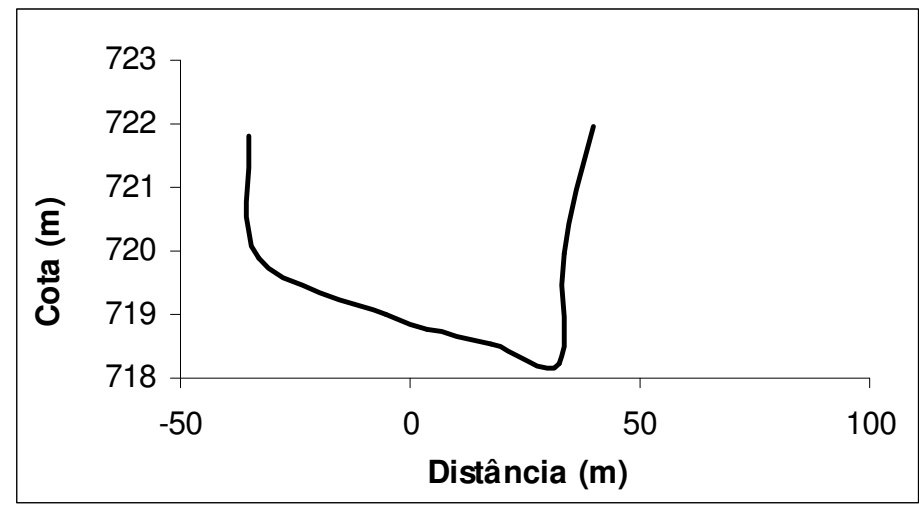

Fig. 103: Seção batimétrica GU00_900

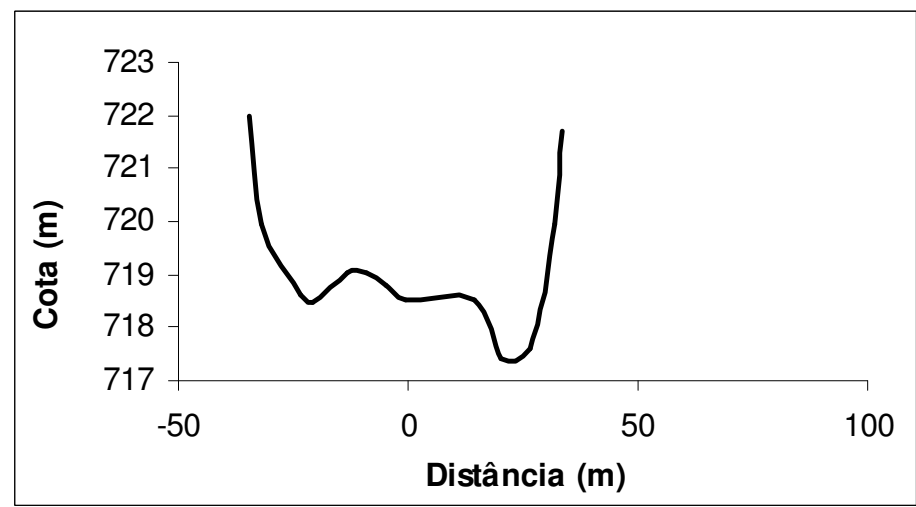

Fig. 104: Seção batimétrica GU00_950

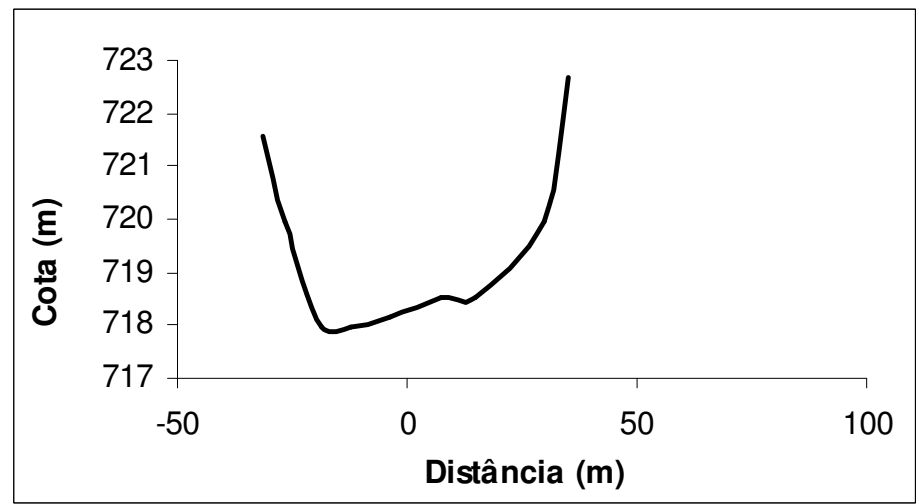

Fig. 105: Seção batimétrica GU01_000 


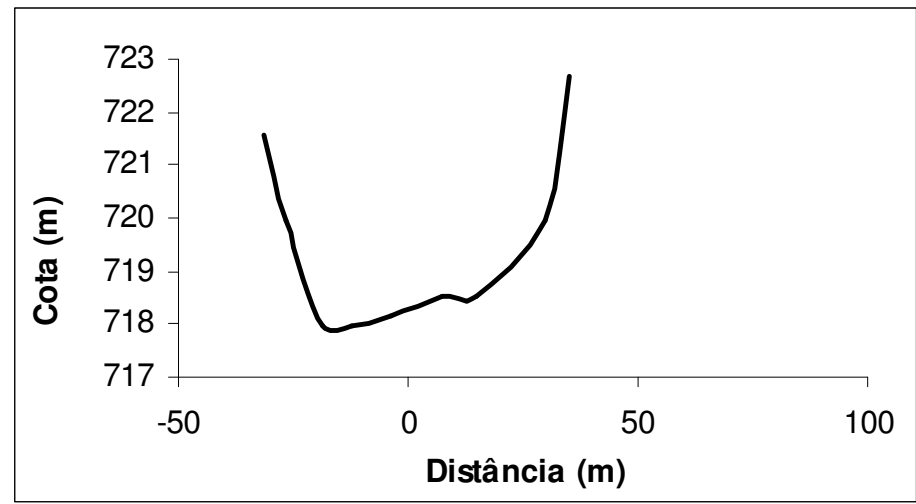

Fig. 106: Seção batimétrica GU01_050

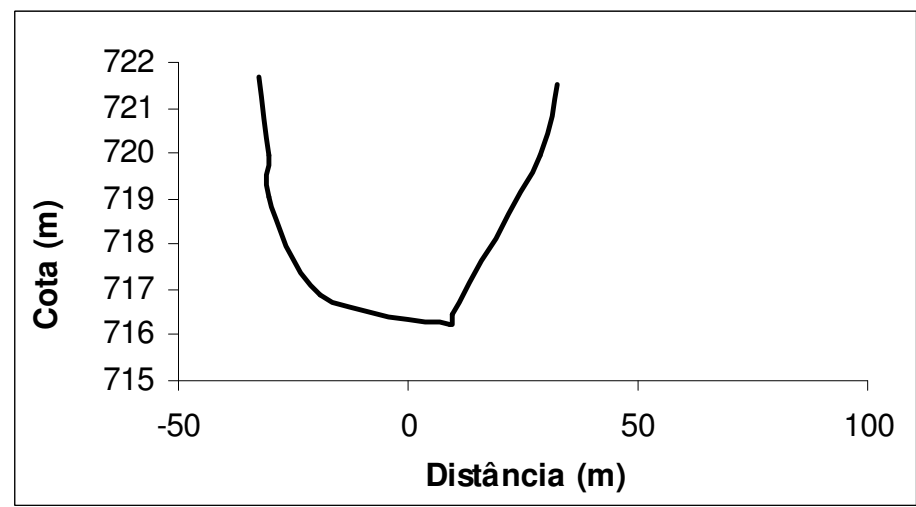

Fig. 107: Seção batimétrica GU01_150

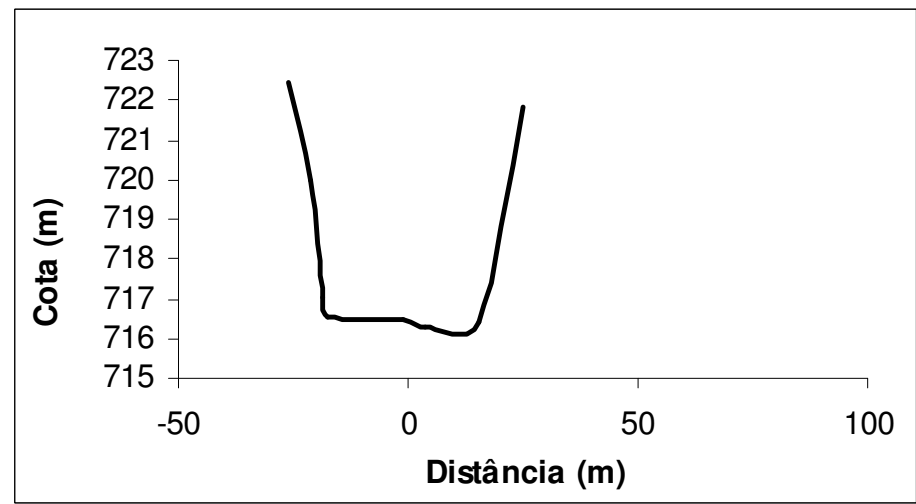

Fig. 108: Seção batimétrica GU01_250 


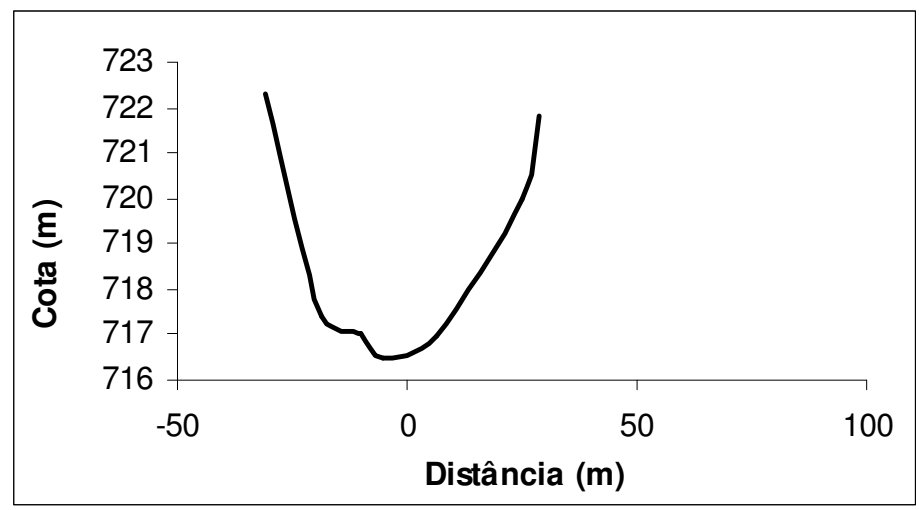

Fig. 109: Seção batimétrica GU01_350

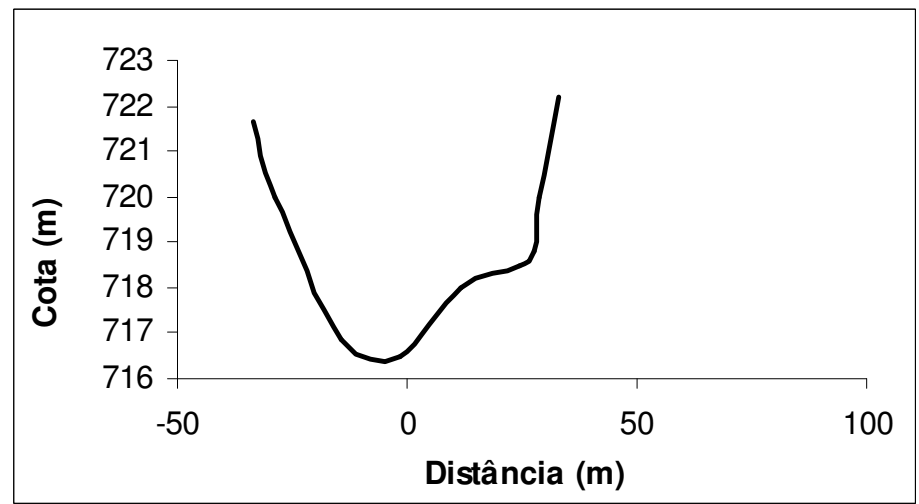

Fig. 110: Seção batimétrica GU01_450 